\title{
AN EAST COAST WINTER STORM PRECIPITATION CLIMATOLOGY
}

\author{
A Thesis \\ Presented to the Faculty of the Graduate School \\ of Cornell University \\ In Partial Fulfillment of the Requirements for the Degree of \\ Master of Science
}

by

Nicholas John Frankoski

May 2009 
(C) 2009 Nicholas John Frankoski 


\begin{abstract}
East Coast Winter Storms (ECWS) can have tremendous impacts throughout the eastern regions of the United States. Forecasting influences from these storms, particularly long range and due to seasonal variations, is extremely challenging. Using a previously compiled climatology of ECWS events, an ECWS precipitation climatology is developed for the eastern United States from 1951-1952 to 2005-2006, using an automated procedure. This climatology consists of the percentage of snowfall and precipitation from ECWS, on average per snow year. The exclusion of non-ECWS snowfall and precipitation during ECWS events is accomplished by utilizing a precipitation gradient line, a pressure gradient line, and the presence of a non-ECWS, if applicable. The issue of excluding lake effect snow (LES) is also addressed. This same climatology is developed for rapidly deepening ECWS, termed "bombs" by previous studies. A sensitivity analysis of the ECWS precipitation climatology is investigated considering the following scenarios during an event: the absence of any process for identifying ECWS snowfall or precipitation, the absence of any process for classifying LES, and a comparison of two methods for classification of LES. The ECWS precipitation climatology is then analyzed for relationships to ENSO phases and ECWS frequency, by snow year, and for the presence of time dependent trends.
\end{abstract}

The climatology reveals the highest percentages of snowfall from ECWS, on average per snow year, are located in a swath from southeastern Mississippi to northeastern Georgia, with percentages typically ranging from 65 to $80 \%$. While the highest percentages of precipitation from ECWS, on average per snow year, are located along the east coast from the Delaware and Maryland border, northward to Maine, with percentages generally from 20 to $25 \%$. No time dependent trends are evident for the amount of precipitation or snowfall from ECWS, nor are they evident 
for the percentage of precipitation or snowfall from ECWS. In northern New England and along the urban corridor of the Northeast, including the cities of Washington DC, Baltimore, Philadelphia, New York and Boston, El Niño years signal above average precipitation and snowfall amounts from ECWS, in addition to above average percentage of precipitation and snowfall from ECWS. While in portions of the Appalachian Mountains and the Southeast, La Niña years signal a below average percentage of precipitation from ECWS. Finally, high (low) ECWS occurrence snow years, or active (inactive) seasons, signal above (below) average ECWS precipitation amounts and percentage of precipitation from ECWS. Specifically, for the large metropolitan centers of the Northeast, high ECWS occurrence snow years, or active seasons, signal above average ECWS precipitation and snowfall amounts, above average total precipitation and snowfall amounts, and above average percentage of precipitation and snowfall from ECWS. In contrast, low ECWS occurrence snow years, or inactive seasons, signal below average ECWS precipitation and snowfall amounts, below average total precipitation amounts, and below average percentage of precipitation from ECWS. 


\section{BIOGRAPHICAL SKETCH}

Nicholas J. Frankoski was born in Johnson City, NY and grew up in Newark Valley, NY with his parents Nancy and Edward and siblings Sarah, Benjamin and Jeremy. Nicholas completed his undergraduate studies at the University of Delaware, graduating in May 2003, Magna Cum Laude, with an Honors Bachelor of Science in Business Administration, with a major in Finance and minors in Management Information Systems and Economics. Nicholas spent three semesters at the University of Delaware, beginning in February 2006, in the Department of Geography before attending Cornell University starting in August 2007. Nicholas will be getting married in July 2009 to his lovely fiancée and best friend of almost ten years, Larisa Cherewko. In his free time, Nicholas is an avid distance runner. 


\section{ACKNOWLEDGMENTS}

There are many people who I would like to express gratitude to, for without them completion of this work would not have been possible. This work was supported by NSF Grant ATM-0531817. Partial support from NOAA Grant NA05OAR4311122 as part of the Transition of Research Applications to Climate Services (TRACS) program and NOAA Contract EA133E-02-CN-0033 is also acknowledged. For my advisor, Arthur T. DeGaetano, I am grateful for his help, ideas, feedback, programming knowledge and encouragement. In the Department of Applied Economics and Management at Cornell University, I would like to thank my minor advisor, Antonio Miguel R. Bento. In the Department of Earth and Atmospheric Sciences at Cornell University, I would like to thank Brian Belcher for helping me answer countless questions regarding programming and formatting, undergraduate students Dean Fogarasi and Leon Nguyen, as well as Laura Joseph, Bill Noon, and Keith Eggleston for providing help and code for the programs that made this work possible. From the University of Delaware, and the Department of Geography, I would like to thank Daniel J. Leathers for helping to develop my interest in winter weather, and for feedback on this work. I would like to thank my family for their tremendous support and encouragement. For my fiancée and soon to be wife, Larisa and her family, thank you also for the tremendous support and encouragement. A special thanks goes to Larisa for listening to my frustrations when things were not going as well as planned. Most importantly, I would like to thank God and my Lord and Savior Jesus Christ for giving me the strength and knowledge to complete this work. 


\section{TABLE OF CONTENTS}

Biographical Sketch...............................................................ii

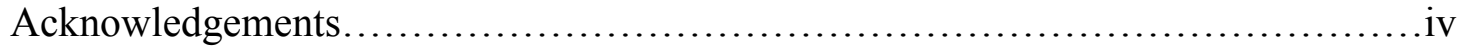

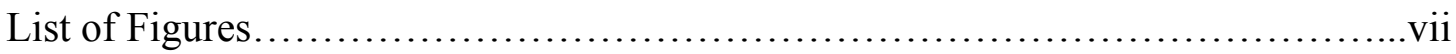

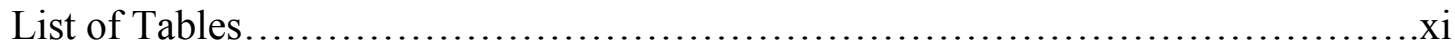

Chapter 1: Introduction...........................................................

1.1 Overview of East Coast Winter Storms...................................

1.2 Previous Research.........................................................

Chapter 2: Study Objectives.................................................. 8

2.1 Development of the ECWS Precipitation Climatology......................8

2.2 Evaluation of the ECWS Precipitation Climatology.......................11

Chapter 3: Data and Methods................................................. 14

3.1 Identifying East Coast Winter Storms................................ 14

3.2 Identifying Bombs................................................. 18

3.3 Gathering Data.............................................................

3.4 Interpolation to an Evenly Spaced Grid...............................25

3.5 Determining ECWS Snowfall and Precipitation: Overview...............27

3.6 Precipitation Gradient Line - General Case for Selecting Potential

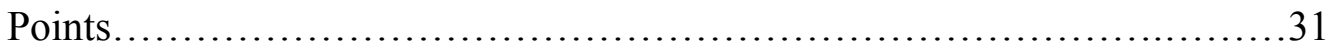

3.6.1 Potential Gradient Direction Lists and Identification of Local Minima ............................................................

3.6.2 Selection of One Gradient Point for each Potential Gradient Direction List................................................... 36

3.7 Precipitation Gradient Line - Special Cases for Selecting Potential

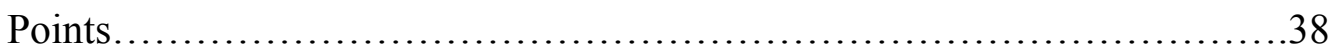


3.8 Precipitation Gradient Line - Final Selection of Points and

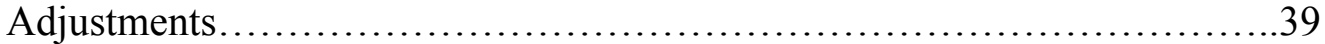

3.8.1 Special Cases for Final Selection............................39

3.8.2 General Cases for Final Selection........................43

3.8.3 Adjustments to the Precipitation Gradient Line.................43

3.9 Identification of Additional Storms (non-ECWS) ......................49

3.10 Pressure Gradient Line.........................................52

3.11 Classification of LES.......................................... 55

3.12 Classifying ECWS Snowfall and Precipitation - Decision Process.......58

3.13 Classifying ECWS Snowfall and Precipitation - Examples............63

3.14 Generation of ECWS and Bombs Percentages Climatology............81

Chapter 4: Results and Statistics......................................... 83

4.1 General Climatology.........................................83

4.2 Study Period Seasonal Average Percentages for ECWS and Bombs......85

4.3 Study Period Seasonal Average Totals for ECWS and Bombs............91

4.4 Study Period Overall Percentages for ECWS and Bombs...............95

4.5 Sensitivity Analysis for ECWS and Bombs........................98

4.6 ECWS and LES Manual Analysis................................. 106

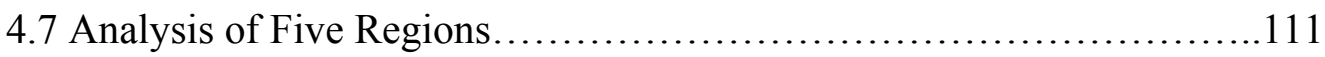

Chapter 5: Conclusions................................................ 126

5.1 General Summary............................................ 126

5.2 Key Findings.................................................... 127

5.3 Potential Further Research................................... 130

Appendix A: Results of Manual ECWS and LES Analysis..................... 132

Appendix B: Regions Analysis Snowfall and Precipitation Summaries............ 135

References................................................................ 145 


\section{LIST OF FIGURES}

Figure 1.1: Hirsch et al. (2001) ECWS boundaries..............................6

Figure 2.1: Idealized ECWS example.......................................9

Figure 3.1: States included in the study region.............................. 19

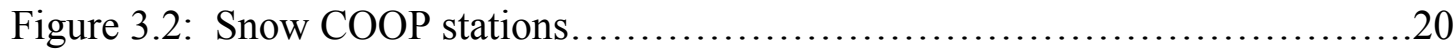

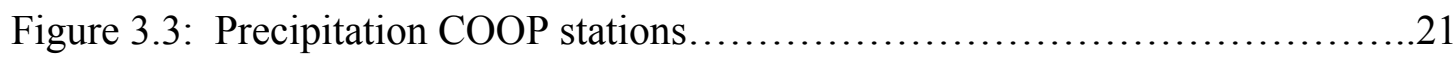

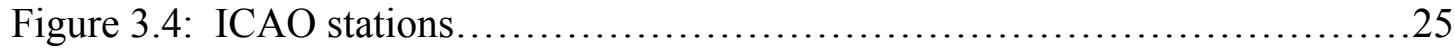

Figure 3.5: Hypothetical ECWS and COOP station reporting days................29

Figure 3.6: Generation of PGD lists from far north and far south storm positions....32

Figure 3.7: Generation of PGD lists from storm positions......................33

Figure 3.8: Key boundaries used throughout the study region...................... 35

Figure 3.9: Hypothetical PGD lists and selection of gradient points................ 37

Figure 3.10: Depiction of Northeast Value too Far scenario......................41

Figure 3.11: Depiction of South Zero Start scenario...........................42

Figure 3.12: Example of Mountain Adjustment where Stop Mountain Adjustment

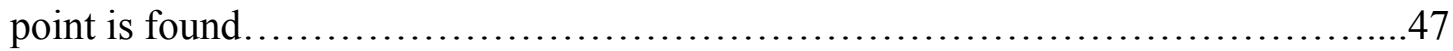

Figure 3.13: Example of Mountain Adjustment where Stop Mountain Adjustment

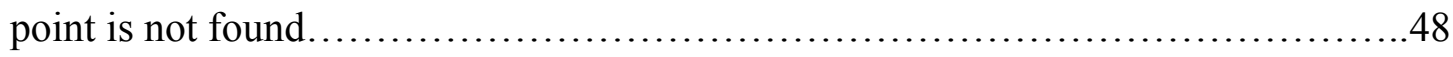

Figure 3.14: LES belts.............................................50

Figure 3.15: ECWS precipitation and snowfall decision process................59

Figure 3.16: Depiction of the Zero Swath Evaluation..........................62

Figure 3.17: ECWS case study example from 2 November $1970 \ldots \ldots \ldots \ldots \ldots \ldots \ldots 6$

Figure 3.18: ECWS case study example from 29 February $1952 \ldots \ldots \ldots \ldots \ldots \ldots . \ldots 6$

Figure 3.19: ECWS case study example from 18 November $1962 \ldots \ldots \ldots \ldots \ldots \ldots . \ldots 6$

Figure 3.20: ECWS case study example from 3 April $1952 \ldots \ldots \ldots \ldots \ldots \ldots \ldots . \ldots 6$

Figure 3.21: ECWS case study example from 7 April $1982 \ldots \ldots \ldots \ldots \ldots \ldots \ldots \ldots . \ldots 1$ 
Figure 3.22: ECWS case study example from 9 January $1996 \ldots \ldots \ldots \ldots \ldots \ldots \ldots . \ldots 72$

Figure 3.23: ECWS case study example from 12 March 1993...................74

Figure 3.24: ECWS case study example from 29 March $1992 \ldots \ldots \ldots \ldots \ldots \ldots \ldots . . . \ldots 76$

Figure 3.25: ECWS case study example from 2 November $1957 \ldots \ldots \ldots \ldots \ldots \ldots \ldots 77$

Figure 3.26: ECWS case study example from 7 February $1978 \ldots \ldots \ldots \ldots \ldots \ldots . . \ldots 78$

Figure 3.27: ECWS case study example from 25 January $1988 \ldots \ldots \ldots \ldots \ldots \ldots . \ldots . \ldots . \ldots$

Figure 4.1: ECWS occurrences by snow year............................. 83

Figure 4.2: Bomb occurrences by snow year............................... 84

Figure 4.3: The percentage of snowfall from ECWS per snow year.................86

Figure 4.4: The percentage of snowfall from ECWS for November...............87

Figure 4.5: The percentage of precipitation from ECWS per snow year.............88

Figure 4.6: The percentage of precipitation from ECWS for November............89

Figure 4.7: The percentage of snowfall from bombs per snow year................90

Figure 4.8: The average amount of snowfall from ECWS per snow year............92

Figure 4.9: The average amount of precipitation from ECWS per snow year........93

Figure 4.10: The average amount of snowfall from bombs per snow year...........94

Figure 4.11: The average amount of precipitation from bombs per snow year........95

Figure 4.12: Study period overall percentage of snowfall from ECWS.............96

Figure 4.13: Study period overall percentage of precipitation from ECWS.........97

Figure 4.14: Study period overall percentage of snowfall from bombs.............98

Figure 4.15: Sensitivity Analysis showing differences in ECWS snowfall percentages

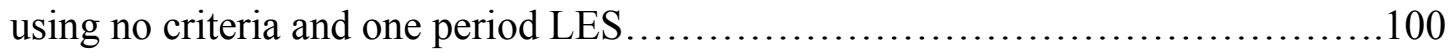

Figure 4.16: Sensitivity Analysis showing differences in ECWS precipitation percentages using no criteria and one period LES ............................ 101 Figure 4.17: Sensitivity Analysis showing differences in ECWS snowfall percentages assuming no LES scenario........................................... 102 
Figure 4.18: Sensitivity Analysis showing differences in ECWS precipitation percentages assuming no LES scenario. 103

Figure 4.19: Sensitivity Analysis showing differences in ECWS snowfall percentages using half versus one period LES criterion...................................... 104 Figure 4.20: Sensitivity Analysis showing differences in ECWS precipitation percentages using half versus one period LES criterion..............................105

Figure 4.21: Summary and comparison of manual and automated percentages......109

Figure 4.22: Five regions used in analysis....................................112

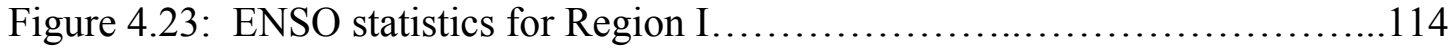

Figure 4.24: ENSO statistics for Region II.....................................115

Figure 4.25: ENSO statistics for Region III...................................115

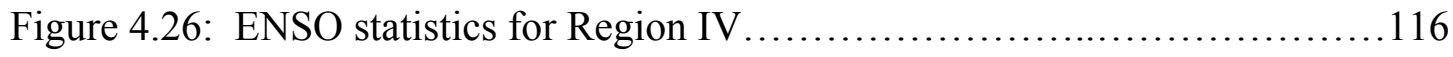

Figure 4.27: ENSO statistics for Region V V...................................116

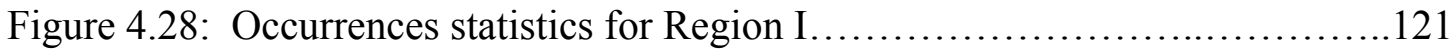

Figure 4.29: Occurrences statistics for Region II...............................121

Figure 4.30: Occurrences statistics for Region III............................122

Figure 4.31: Occurrences statistics for Region IV .............................122

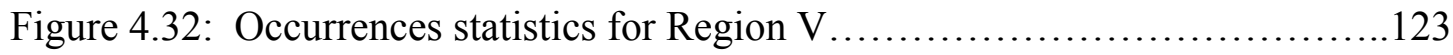

Figure A.1: Manual ECWS and LES analysis for Syracuse, NY ..................132

Figure A.2: Manual ECWS and LES analysis for Rochester, NY ..................133

Figure A.3: Manual ECWS and LES analysis for Buffalo, NY ....................134

Figure B.1: Region I ECWS snowfall percentages and amounts by snow year......135

Figure B.2: Region II ECWS snowfall percentages and amounts by snow year......136

Figure B.3: Region III ECWS snowfall percentages and amounts by snow year.....137

Figure B.4: Region IV ECWS snowfall percentages and amounts by snow year...138

Figure B.5: Region V ECWS snowfall percentages and amounts by snow year.....139 
Figure B.6: Region I ECWS precipitation percentages and amounts by snow

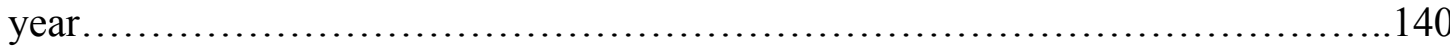

Figure B.7: Region II ECWS precipitation percentages and amounts by snow

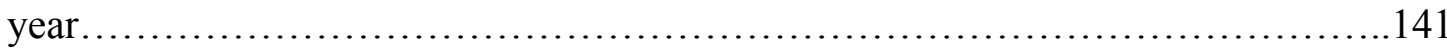

Figure B.8: Region III ECWS precipitation percentages and amounts by snow

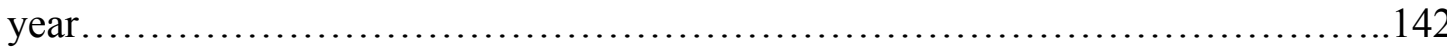

Figure B.9: Region IV ECWS precipitation percentages and amounts by snow year. 143

Figure B.10: Region V ECWS precipitation percentages and amounts by snow year. 


\section{LIST OF TABLES}

Table 3.1: Daily precipitation values exceeding $508 \mathrm{~mm}$ (20 in) considered valid after

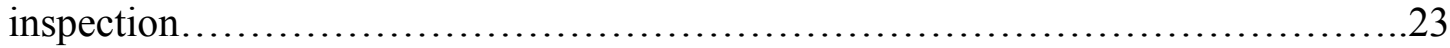

Table 3.2: Typical reporting time periods for COOP stations......................28

Table 3.3: Binned interpolated precipitation values..............................34

Table 3.4: Order of preference for selection of a gradient point in a PGD list..........39

Table 3.5: Binned interpolated SLP values......................................54

Table 3.6: Wind direction criteria for determining LES..........................57

Table 4.1: Summary of manual LES analysis amounts............................108

Table 4.2: Classification of ECWS seasonal activity...............................119 


\section{CHAPTER 1}

\section{INTRODUCTION}

\subsection{Overview of East Coast Winter Storms}

The occurrence of coastal winter storms, commonly referred to as Nor'easters, throughout the eastern regions of the United States can have tremendous impacts on the people, infrastructures and economies of these areas. Heavy snowfall, frigid temperatures, high winds, poor visibility, coastal flooding, significant ice accumulations, heavy rains and severe thunderstorms are some of the potential hazardous components of these storms. This study will use the terminology from Hirsch et al. (2001) in referring to these storms as East Coast Winter Storms (ECWS).

The American Meteorological Society’s Glossary of Meteorology defines a northeast storm as a cyclone along the east coast of North America that may occur throughout the year, but is most common and most intense between September and April (Glickman, 2000). Furthermore, the Glossary states that northeast storms typically develop between $30^{\circ}-40^{\circ} \mathrm{N}$ and within 100 miles east or west of the coastline, moving north to northeast and achieving maximum intensity in the vicinity of New England and the Canadian Maritime Provinces (Glickman, 2000).

A great deal of attention has been devoted to studying ECWS, particularly on understanding synoptic and mesoscale influences, improving forecasting, defining characteristic storm types and developing climatologies. Given the densely populated east coast of the United States, and the associated human and economic impacts of ECWS, continuing to assemble knowledge on ECWS is vital. The east coast of the United States is an intriguing environment for the development of these storms. Various geographic features of the region, including the Atlantic Ocean, Gulf of Mexico, Gulf Stream, Great Lakes and Appalachian Mountains and their associated 
effects on the wind and the thermodynamics of the atmosphere, enable frequent development of ECWS (Maglaras et al., 1995; Reitan, 1974; Colucci, 1976; Sanders and Gyakum, 1980; Roebber, 1984). More specifically, the interaction of short waves, or disturbances in the upper levels of the atmosphere, with the baroclinic zone, or zone of sharply contrasting temperatures, resulting from the distinct thermal contrast between the Gulf Stream and surrounding land, provides a key environment for cyclogenesis (Maglaras et al., 1995).

While tropical cyclones justifiably receive a great deal of attention, this paper will not focus on tropical cyclones along the east coast of the United States. Davis et al. (1993) note tropical cyclone damage is generally limited to a relatively narrow region of coastline near the location of landfall. In contrast, coastal storms with extratropical characteristics (ECWS) can produce widespread damage across large regions of the east coast of the United States (Davis et al., 1993; Mather et al., 1967). Consequently, coastal geologists and geomorphologists usually view coastal storms as large wind producers causing waves and associated coastal changes (Davis et al., 1993). Similarly, with tropical cyclones the core of strongest winds may be confined near the eye and where the center of the storm makes landfall, while with ECWS heavy snow bands can often cover hundreds of kilometers (Maglaras et al., 1995; Kocin and Uccellini, 1990).

Despite the width of these heavy snow bands, forecasting specific locations of these bands poses challenges to operational meteorologists. Variations in the positions of these heavy snow bands and rain/snow lines, particularly in heavily populated areas, by as little as 30-50 km can affect millions of people (Maglaras et al., 1995). As such, forecasting ECWS, particularly mesoscale elements, is extraordinarily difficult. Furthermore, cyclogenesis can occur off shore, where there is generally a lack of realtime observations and data over the Atlantic Ocean (Maglaras et al., 1995). Secondary 
cyclogenesis is a common component to ECWS, and predicting the onset and location of secondary cyclogenesis is difficult for operational meteorologists (Maglaras et al., 1995).

Occasionally, rapidly intensifying ECWS will occur. Commonplace in the literature, these types of storms are referred to as "bombs". Sanders and Gyakum (1980) note that Tor Bergeron is presumed to have characterized these rapidly intensifying or deepening cyclones as those in which the central sea level pressure (SLP) falls at a rate of at least $1 \mathrm{mb} \mathrm{h}^{-1}$ for a $24 \mathrm{~h}$ period. This study will employ this criterion for classifying an ECWS as a bomb.

\subsection{Previous Research}

A great deal of previous research has been devoted to studying coastal winter storms. Numerous classification schemes for ECWS have been developed with some authors focusing on identifying synoptic characteristics of cyclogenesis, and others focusing on storm intensity and impacts. Miller (1946) identified two types of cyclogensis, Type A and Type B, along the Atlantic coast of the United States. Type A storms were those forming along a cold front traversing through the east coast, while Type B storms were associated with secondary development along the midAtlantic coast, southeast of a low in the vicinity of the Great Lakes (Miller, 1946; Davis et al., 1993). Mather et al. (1964) identified eight classifications of storms that impact the east coast of the United States, ranging from hurricanes and tropical storms to strong cold fronts associated with squall lines. Gurka et al. (1995) documented different patterns of cyclogenesis, which included: “Classical” Miller cyclogenesis (Type A and Type B), “Zipper” lows, Late season 500-mb cutoff lows, and Cold-air cyclogenesis. Using wave heights to identify storms, and as a means of measuring a storm's “power”, Davis et al. (1993) developed a classification scheme for

extratropical storms in the northwestern Atlantic Ocean. Zielinski (2002) developed a 
real-time classification method, rating storms from a category 1 (least severe) to a category 5 (most severe). With a focus on the urban corridor of the northeast United States, Kocin and Uccellini (2004) constructed an impact scale termed the Northeast snowfall impact scale (NESIS). This scale considers the amount of snowfall from a storm and how this snowfall is distributed over a given population density, as opposed to looking solely at meteorological factors of a storm, such as wind speeds or SLP (Kocin and Uccellini, 2004).

In addition to classification schemes for ECWS, much work has been completed on understanding the physical processes behind these storms. Two significant projects mentioned by Hirsch et al. (2001), were the Genesis of Atlantic Lows Experiment (GALE) in 1986 (Dirks et al., 1988) and the Experiment on Rapidly Intensifying Cyclones over the Atlantic (ERICA) in 1989 (Hadlock and Kreitzberg 1988), both of which were focused on studying processes linked to cyclogenesis. However, most relevant to the work in this paper is previous research on spatial and temporal climatologies of ECWS.

As Hirsch et al. (2001) point out, one of the first climatologies completed was by Reitan (1974), who looked at frequencies of cyclones and cyclogensis, and identified mean cyclone tracks. Reitan (1974) identified an enhanced area of cyclogenesis off of the southeast coast of the United States during the month of January (Hirsch et al., 2001). Other important climatologies were completed by Colucci (1976), showing an area of maximum winter cyclone frequency parallel to the east coast of the United States from North Carolina to Maine, and by Zishka and Smith (1980), who found for the month of January a maximum area of cyclogenesis off of the New Jersey coast (Hirsch et al., 2001). More generally, Davis et al. (1993) note that a number of cyclone and anticyclone climatologies have been constructed using grids and counting storm occurrences in these grids. These climatologies listed 
by Davis et al. (1993), some of which have been previously mentioned, include: Hosler and Gamage (1956), Klein (1957, 1958), Reitan (1974, 1979), and Zishka and Smith (1980). In terms of bombs, Sanders and Gyakum (1980) found that they occur over a large range of sea surface temperatures from $0^{\circ}$ to $23^{\circ} \mathrm{C}$, but that bombs tend to occur in and around the most intense sea surface temperature gradients, which are strongest in the Atlantic Ocean at longitudes west of $40^{\circ} \mathrm{W}$, and between latitudes $35^{\circ}$ and $50^{\circ} \mathrm{N}$. In addition, the maximum sea surface temperature gradients found in the western Atlantic Ocean are nearly twice as large as those found in the western Pacific Ocean and therefore the tendency is for the more explosive or rapidly deepening bombs to occur in the Atlantic basin (Sanders and Gyakum, 1980). Based on this, clearly one would expect a subset of ECWS to be classified as bombs.

In terms of temporal climatologies of ECWS, Hirsch et al. (2001) note that few studies have been devoted to the time-dependent aspects of ECWS over the last few decades. However, Hirsch et al. (2001) also note that many previous studies on the climatology of ECWS have used a grid box approach to count storms or inferred occurrence based on waves and wind or damage reports. The original Hirsch et al. (2001) ECWS climatology, used as the starting point for this study, was developed using the NCEP-NCAR reanalysis dataset for the years 1948, and 1951-1997 (Kalnay et al., 1996). The original climatology was constructed using an automated routine to identify storms based on SLP as well as $u$ and $v$ component wind data, from a $2.5^{\circ}$ latitude by $2.5^{\circ}$ longitude grid (Hirsch et al., 2001). Data were available four times daily (0000, 0600, 1200, and 1800 UTC), and as such during an ECWS storm event, storm coordinates were assigned to the nearest grid point at each of these times (Hirsch et al., 2001). 
Using a synthesis of previous research, Hirsch et al. (2001) developed four criteria for defining a storm as an ECWS. The storm or area of low pressure must:

1) Have a closed circulation, defined as having at least $80 \%$ of 32 adjacent pressure values (grid points) be at least $4 \mathrm{hPa}$ greater than the minimum pressure, with these 32 adjacent grid points consisting of a square centered on the low pressure.

2) Be along the east coast of the United States, more specifically within the quadrilateral bounded at $45^{\circ} \mathrm{N}$ by $65^{\circ}$ and $70^{\circ} \mathrm{W}$ and at $30^{\circ} \mathrm{N}$ by $75^{\circ}$ and $85^{\circ} \mathrm{W}$ (Figure 1.1)

3) In general, show movement from the south-southwest to the north-northeast

4) During at least one $6 \mathrm{~h}$ period, have winds greater than $10.3 \mathrm{~ms}^{-1}(20 \mathrm{kt})$.

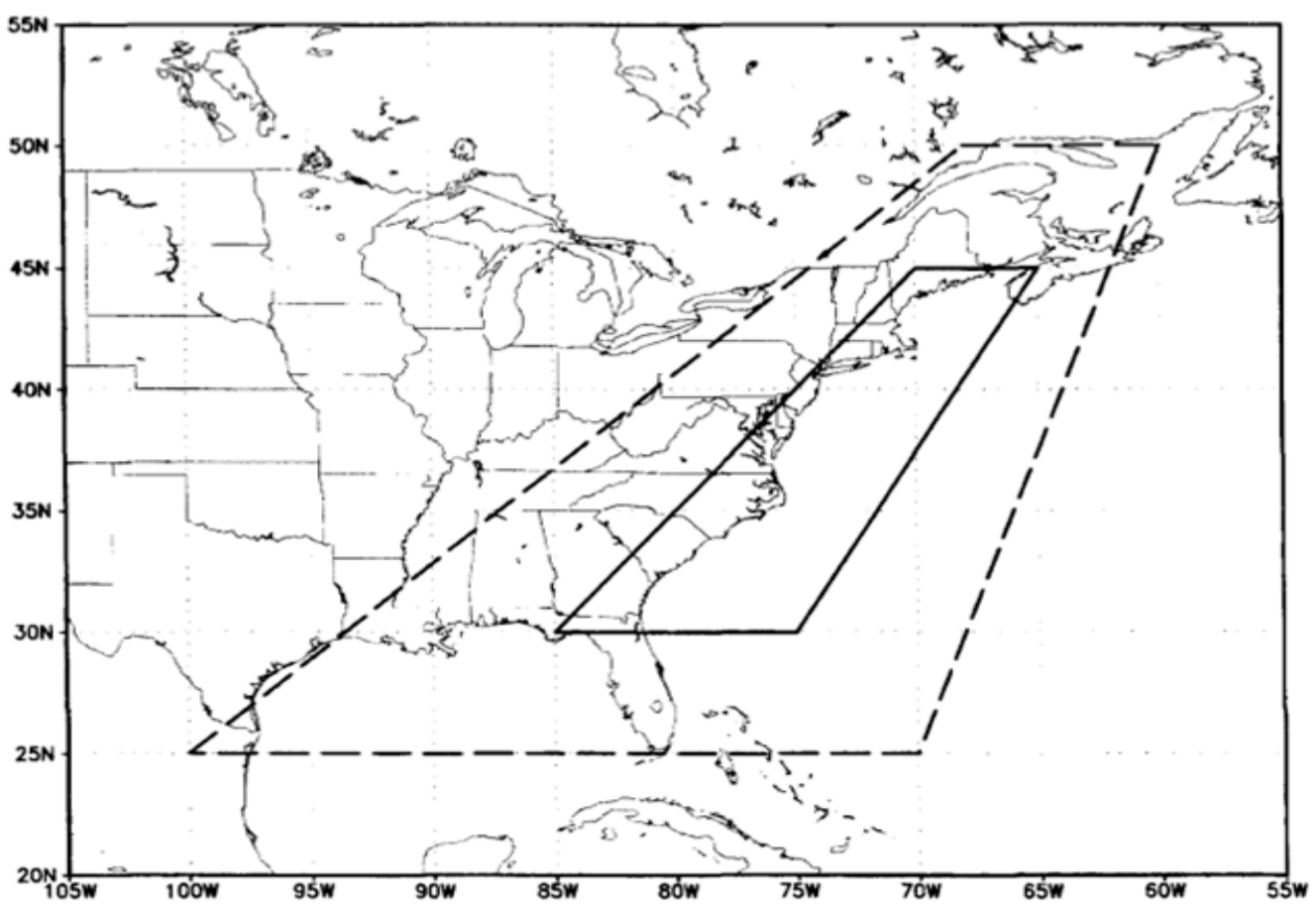

Figure 1.1: From Hirsch et al. (2001), the dashed lines indicate the boundaries used to identify areas of low pressure and the solid lines indicate areas of potential ECWS.

Hirsch et al. (2001) used the larger (dashed line) polygon in Figure 1.1 to identify the grid point with the lowest pressure, which was then tracked in terms of movement. If the lowest pressure entered the smaller (solid line) polygon in Figure 
1.1, the area of low pressure was checked against the criteria outlined previously, such as having a closed circulation, general movement and wind speeds (Hirsch et al., 2001). Storms meeting these criteria were classified as ECWS and their corresponding start and end dates and associated times were retained to develop the climatology (Hirsch et al., 2001). 


\section{CHAPTER 2}

\section{STUDY OBJECTIVES}

\subsection{Development of the ECWS Precipitation Climatology}

The primary objective of this study is to determine the percentage of snowfall and precipitation that is a direct result of ECWS. The objective is not to establish a climatology of ECWS events and occurrences, nor is the objective to generate a new definition for an ECWS. The main focus is to determine for a given location, on average per year, what percentage of total snowfall and total precipitation is the direct result of ECWS. These percentages are important when assessing seasonal impacts of ECWS, especially considering the frequency of ECWS expected. For example, if seasonal ECWS activity can be forecasted (e.g. DeGaetano et al., 2002), then an ECWS-specific climatology may provide a means of anticipating the tangible impacts of a season with above or below normal ECWS activity. In addition, how climate change may impact ECWS activity, and how this relates to the percentages, is also an important consideration.

When constructing the precipitation climatology, during an ECWS event the inclusion of snowfall resulting from Lake Effect Snow (LES) and snowfall and precipitation resulting from surrounding extratropical cyclones, not meeting the ECWS definition, will be minimized. These surrounding extratropical cyclones will hereinafter be referred to as "additional storms". Such additional storms may be "Alberta Clipper" systems, cyclones traversing the Ohio Valley in the wake of the ECWS, or any additional extratropical cyclone impacting the study region during an ECWS event. For example, refer to the idealized surface weather map in Figure 2.1. In this situation, assume the low pressure area off the New England coast is an ECWS with associated precipitation across portions of New England, becoming more 
scattered moving southward into the mid-Atlantic. The precipitation downwind of Lakes Erie and Ontario may be LES.

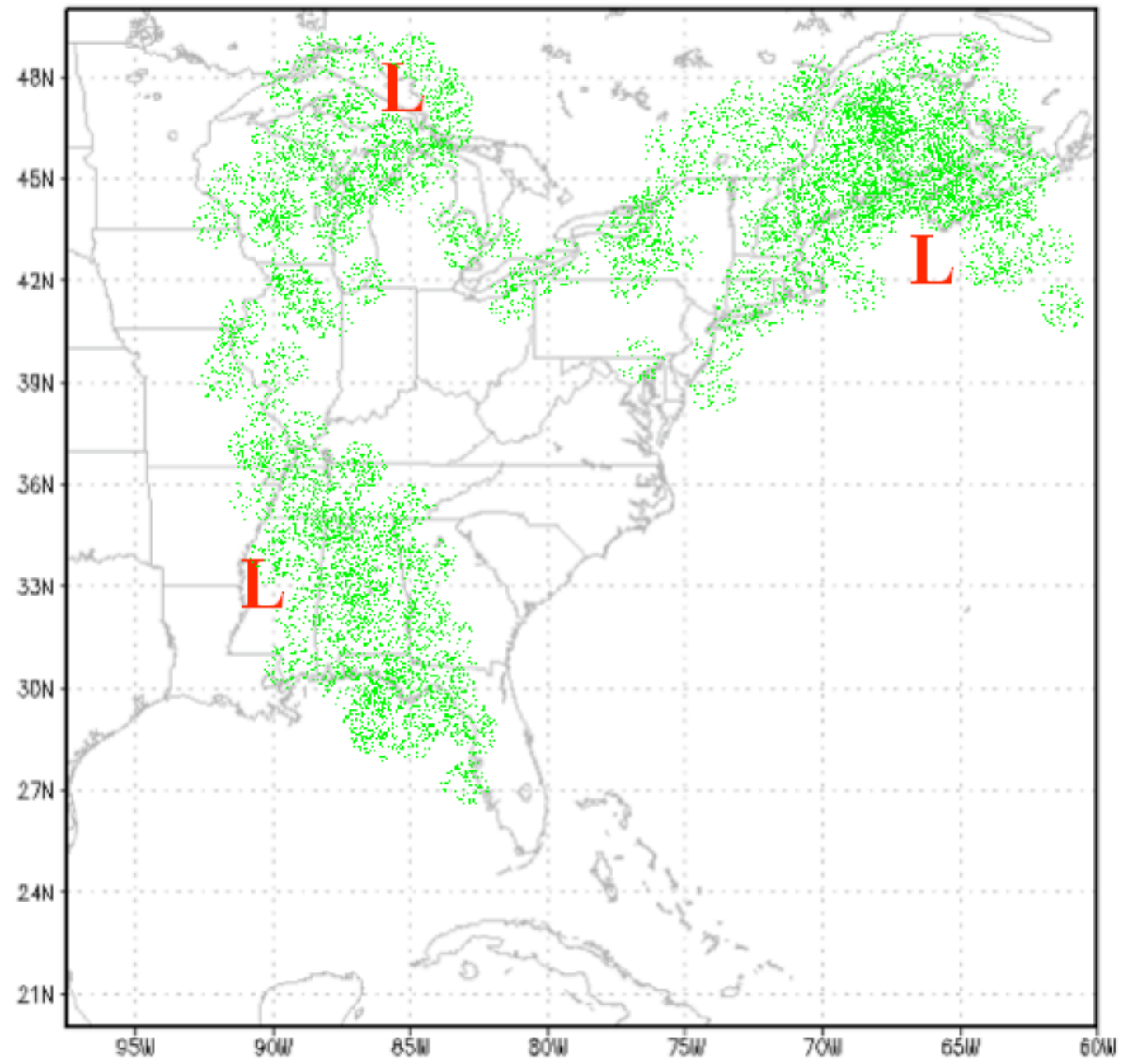

Figure 2.1: Idealized surface weather map depicting a hypothetical ECWS east of the New England coast, and two additional storms, one on Lake Superior and the other in western Mississippi. Associated precipitation with these storms is shaded in green.

In this idealized example, there are two additional storms, one on Lake Superior and the other in western Mississippi. Precipitation areas associated with such additional storms will be excluded from the climatology to the extent possible. In the idealized situation in Figure 2.1, if precipitation from all of the stations within the study region is assumed to be from the ECWS, this method would erroneously include precipitation in the climatology in states like Mississippi or Alabama. Clearly in 
Figure 2.1 ECWS precipitation is not occurring everywhere, particularly for the states of Alabama and Mississippi or Wisconsin. Therefore, this study will develop an automated procedure, which considers each day of an ECWS event, such as the day depicted in Figure 2.1, and determines whether or not the precipitation received by a station is directly from the ECWS.

This study does not attempt to directly identify areas of non-ECWS precipitation associated with upper level disturbances in the atmosphere, such as short wave troughs and areas of upper level divergence, nor does it try to directly identify areas of cyclonic vorticity or cyclonic vorticity advection responsible for non-ECWS precipitation. Furthermore, this study does not directly identify mesoscale aspects of non-ECWS precipitation, such as frontogenesis, frontal boundaries or coastal fronts. However, it is likely that these sources of precipitation are identified by the decision criteria used by the automated procedure, and therefore their inclusion in the climatology is limited. LES is the one mesoscale exception, and an attempt is made at directly quantifying the impacts of LES.

Due to the limitations of available snowfall and precipitation data, the determination of ECWS precipitation or snowfall for a given location will occur at the daily level. Consequently, for a specific location, the allocation of some of the daily precipitation total to ECWS precipitation, and the remainder to precipitation from an additional storm or LES, does not occur.

For each location, the percentage of snowfall and precipitation from ECWS will be calculated for each year and month in the study period. Then long-term annual and monthly averages of this value will be computed. In addition, overall percentages are computed reflecting the proportion of long-term precipitation that is associated with ECWS at each station. These percentages will be considered for the entire eastern region of the United States or roughly the eastern third of the country. 
These same percentages will be calculated for the subset of ECWS classified as bombs based on the criterion put forth in Sanders and Gyakum (1980). As such, these bombs will have the same start and end dates as the corresponding ECWS.

\subsection{Evaluation of the ECWS Precipitation Climatology}

The secondary objective of this study is to evaluate the climatology developed, and this will occur initially with a manual analysis, with two discussions. The first will involve a discussion of the ECWS precipitation and snowfall identification method, using specific examples from ECWS in the climatology. The strengths and weaknesses of the ECWS precipitation and snowfall identification method will be considered in Chapter 3. The second discussion will involve looking at three locations near Lake Erie and Lake Ontario, and using archived radar images, determining whether snowfall at these locations was from an additional storm, an ECWS, LES or some combination of ECWS and LES snowfall. For this portion of the analysis, four separate snow years will be considered, and based on this manual classification, percentages will be computed. This will serve as an approximate check against the percentages computed in the final results in this climatology by the automated procedure. In general, for locations within the LES belts, snowfall received during an ECWS may be greatly reduced if it were not for the effects of the Great Lakes. Snowfall at these locations during an ECWS may be directly from the ECWS, from the ECWS but enhanced by the Great Lakes, or strictly LES. Therefore, this manual analysis of three stations will provide some insight to these situations. Discussion of this analysis will occur in Chapter 4.

The remainder of evaluating the precipitation climatology will occur in four parts. First, will be a sensitivity analysis of the climatology. There are three scenarios in the sensitivity analysis both for snowfall and for precipitation. The first scenario considers what the climatology will look like if precipitation and snowfall from 
additional storms, outlined in Chapter 3, are included. In other words, what will the climatology look like if for every day of an ECWS event, if a station included in this study was receiving precipitation or snowfall, it was assumed to be the direct result of the ECWS storm regardless of anything else occurring synoptically. The second scenario will deal with LES. If LES had been ignored and no effort was made to exclude LES, how would the climatology differ from the actual results around the Great Lakes. The third scenario will consider a different criterion for identifying LES, and will be explained further in Chapter 3. Essentially, how do the ECWS percentages look around the Great Lakes when different criteria are applied for identifying and excluding LES from the climatology.

The second component in evaluating the developed climatology, will be to consider five separate regions throughout the study area, and to look at the average of all of the annual percentages and amounts in these regions to identify any time dependent trends in the percentage of snowfall and precipitation from ECWS and the amount of snowfall and precipitation from ECWS, during the study period. The third component is, for these same five regions, an analysis of the averages for each snow year in terms of how they relate to the El Niño Southern Oscillation (ENSO). Fourth, also using the five regions, ECWS occurrences by snow year and their relationship to overall snowfall and precipitation amounts, ECWS snowfall and precipitation amounts and ECWS percentages, will be investigated. These four components will be covered in Chapter 4.

From a practical sense, underlying all of the objectives in this study will be how these results may then be applied to long range forecasting techniques. For example, DeGaetano et al. (2002) find that active ECWS years during the December, January and February months, are linked with warmer than normal sea surface temperatures (SST) in the Gulf of Mexico during the previous winter. Regarding 
storm activity during the entire winter season (October to April), DeGaetano et al. (2002) find SST off the southeast coast of the United States during the preceding summer is the best predictor. These findings, and other previous research relating ENSO phases to ECWS activity or precipitation (DeGaetano et al., 2002; Hirsch et al., 2001; Noel and Changnon, 1998; and Janowiak and Bell, 1999), are relevant to the results of this study because relationships can be constructed between seasonal ECWS activity and relative percentages and amounts of ECWS precipitation expected at a given location. Furthermore, how climate change influences ECWS activity, has important implications for seasonal forecasting of ECWS and the associated tangible impacts. 


\section{CHAPTER 3}

\section{DATA AND METHODS}

\subsection{Identifying East Coast Winter Storms}

The climatology of ECWS complied by Hirsch et al. (2001) was used as a starting point for developing the climatology of storms used in this study. The time period considered is the snow year 1951-1952 through the snow year 2005-2006. A snow year is defined as beginning 1 August and ending 31 July. All annual (seasonal) averages and totals are based on this definition. The Hirsch et al. (2001) climatology will be referred to as original storms. In an effort to improve this climatology and to achieve more optimal results in this study, original storms were edited using an automated procedure, with these newly edited storms being referred to as preliminary adjusted storms. From this point, the climatology of preliminary adjusted storms was further edited, with these storms being referred to as improved storms and the accompanying Improved ECWS Climatology used in this study.

The first step in editing the original storms was to evaluate data for each ECWS event. Yearly data from the Hirsch et al. (2001) study were obtained, which contained $6 \mathrm{~h}$ data at $0000,0600,1200$, and $1800 \mathrm{UTC}$ on a $2.5^{\circ}$ by $2.5^{\circ}$ resolution grid. Since an ECWS must occur between the months of October through April, consistent with the original climatology, the months from May through September were omitted from this $6 \mathrm{~h}$ data in each year (Hirsch et. al, 2001). In a few cases, days of data were missing during the months of October through April. The assumption was made that no ECWS were occurring during these missing days and the instances of missing days during the months of October through April were minimal. Data available for each $6 \mathrm{~h}$ storm period included the storm coordinates in latitude and longitude on the $2.5^{\circ}$ grid, SLP, and whether or not the storm was closed as defined by 
Hirsch et al. (2001). For $6 \mathrm{~h}$ time periods when an ECWS event was not occurring, the same information was available, except the coordinates represented the location of minimum SLP anywhere in the domain as defined by Hirsch et al. (2001).

The first step, using the original storms' start and end dates and times, was to move the actual start of the storm back twelve hours and to expand the actual end of the storm forward twelve hours. Hirsch et al. (2001) sought to count the occurrences of ECWS events, not necessarily to look at each storm event, and associated precursors to storms and storm remnants. To identify precipitation or snowfall from an ECWS, these storm precursors and remnants were considered. Therefore, this time adjustment was an attempt to capture precipitation that was impacting areas just prior to the storm meeting ECWS criteria and just after failing to meet ECWS criteria, as defined by Hirsch et al. (2001). For example, a storm departing the northeast United States at its actual end date and time as defined by Hirsch et al. (2001) may still be causing precipitation for some additional time period across New England. These twelve-hour extensions were an effort to capture such an instance. However, start dates and times of storms were not moved back prior to 1 October 0000 UTC and end dates of storms were not extended beyond 30 April 1800 UTC. This was an issue applicable to seven storms.

Once the storm lifetimes were extended, the $6 \mathrm{~h}$ time periods for each storm were considered, mainly focusing on the movement of the storm. The main purpose of focusing on movement was to ensure these extended time periods and coordinates were associated with the original ECWS, and not a minimum SLP identified elsewhere in the domain. The movement for each storm was broken up into two cases, movement with the twelve hour period prior to the original storm start (period one), and movement from original storm start through twelve hours after the original storm end (period two). During period one, only future movement of the storm was 
considered and during period two only previous movement was considered. For a time period to be classified as "good" movement, two basic criteria were required. The storm had to be moving in a general north or northeast direction and the storm could not be moving too quickly. If either of these conditions were not met, the assumption was made that a different storm was present.

For the distance criterion, a storm moving $600 \mathrm{~km}$ or less in a $6 \mathrm{~h}$ time period was considered "good" movement. This distance may seem unreasonable, but given the $2.5^{\circ}$ grid spacing, choosing a smaller distance unnecessarily divided one ECWS into two separate ECWS in some cases. This movement criterion differs slightly from Hirsch et al. (2001), in that their distance of movement was based on five grid units, representing the maximum distance a storm could travel in a $12 \mathrm{~h}$ period. This maximum distance is greater than $600 \mathrm{~km}$. In terms of movement direction, for Hirsch et al. (2001), average positions were calculated using time periods 12 and $6 \mathrm{~h}$ prior to, and 12 and $6 \mathrm{~h}$ after, the period being considered. For this current study's movement direction criterion, a storm was allowed to move southward for one time period. Two or more consecutive southward moves resulted in "bad" movement. Once "bad" movement was detected, the original ECWS in question was given a new actual end date and time and was now considered an adjusted ECWS. The remaining time periods of the original ECWS were considered to determine if a new start date should be assigned to a new adjusted storm. Again, the same movement criteria were applied. Due to this process, there were instances of original ECWS storms being divided into two or more new adjusted ECWS. Occasionally during this editing process, it was necessary to estimate coordinate and pressure information for a $6 \mathrm{~h}$ period. This primarily resulted when, during an individual storm period, the automated procedure identified the lowest SLP outside the ECWS region, such as in the upper Great Lakes. In situations like this, a simple averaging technique was 
applied, by averaging the two surrounding $6 \mathrm{~h}$ time period pressures, and assuming a linear storm track between available coordinates. The majority of storms requiring this filling were further edited manually.

Once this climatology of adjusted storms was developed, further manual editing was performed. An undergraduate student in the Department of Earth and Atmospheric Sciences at Cornell University, Dean Fogarasi, performed this editing of the adjusted climatology using the yearly data and the 6-Hourly National Centers for Environmental Prediction (NCEP) / National Center for Atmospheric Research (NCAR) Reanalysis Data Composites from the Earth System Research Laboratory (ESRL, 2008). Fogarasi made the following adjustments. He removed erroneous beginning time periods, which were the result of the expanded start times, from 4 storms. These time periods were erroneous because they corresponded with storm coordinates not associated with the ECWS, which were not identified by the automated editing procedure. He analyzed twelve storms, which had long tracks or large "jumps" to the west, and edited them accordingly. These "jumps" were found by testing for $6 \mathrm{~h}$ movement of at least $5^{\circ}$ west or $12 \mathrm{~h}$ movement of greater than $5^{\circ}$ west. Two of these twelve storms were deleted from the climatology and the remaining ten were either divided into two separate storms or the time period with incorrect coordinates resulting in the "jump" was corrected. He also considered storms, which had fewer than two time periods within the inner box as identified by Hirsch et al. (2001) in Figure 1.1. There were 80 ECWS meeting this criterion, and of these, 57 were removed from the climatology, with remaining storms manually adjusted. For these remaining storms, time periods were either corrected or the storm was combined with an existing ECWS. He also considered all ECWS containing time periods that were estimated or filled in by the automated editing procedure. For the majority of these storms, the time period filled in was either corrected by reverting to the original 
coordinates from the yearly data or by using the 6-Hourly NCEP/NCAR Reanalysis Data Composites (ESRL, 2008). In most of these cases, where the filled in time period was corrected, it was corrected by reverting to the original coordinates from the yearly data. In other words, the previous automated editing erroneously classified coordinates as incorrect. Finally, Fogarasi considered ECWS only defined by one or two coordinate positions, spanning $6 \mathrm{~h}$ or less. When applicable, a time period or more was added to the storm. Otherwise, the storm was removed from the climatology. This process leaves all storms in the climatology with at least three coordinate positions, not necessarily different, meaning all ECWS events were at the minimum, twelve-hour events. With this editing of the original Hirsch et al. (2001) climatology complete, this Improved ECWS Climatology was used for this study.

\subsection{Identifying Bombs}

The climatology of bombs is a subset of ECWS. To identify an ECWS as a bomb, the criterion from Sanders and Gyakum (1980), developed by Tor Bergeron, was adopted. To be classified as a bomb, the ECWS must have a central SLP that deepens at a rate of at least $1 \mathrm{mb} \mathrm{h}^{-1}$ for a $24 \mathrm{~h}$ period (Sanders and Gyakum, 1980). However, while Sanders and Gyakum (1980) make adjustments to the deepening rate based on the latitude of the cyclone, no such adjustments were made here. Therefore, because of this lack of adjustment and due to the $2.5^{\circ} \times 2.5^{\circ}$ resolution of the data, true bomb occurrences are likely underestimated by this study. In fact, using this definition on this grid resolution, it is likely that only the "strongest" bombs are captured. A finer grid resolution would be desirable, but this would result in fewer years of data available. The desire was to keep the bomb climatology the same length in years as the ECWS climatology. 


\subsection{Gathering Data}

In all, 30 states, including the District of Columbia, were used for gathering data. Refer to Figure 3.1 for a map of the states included in the study.

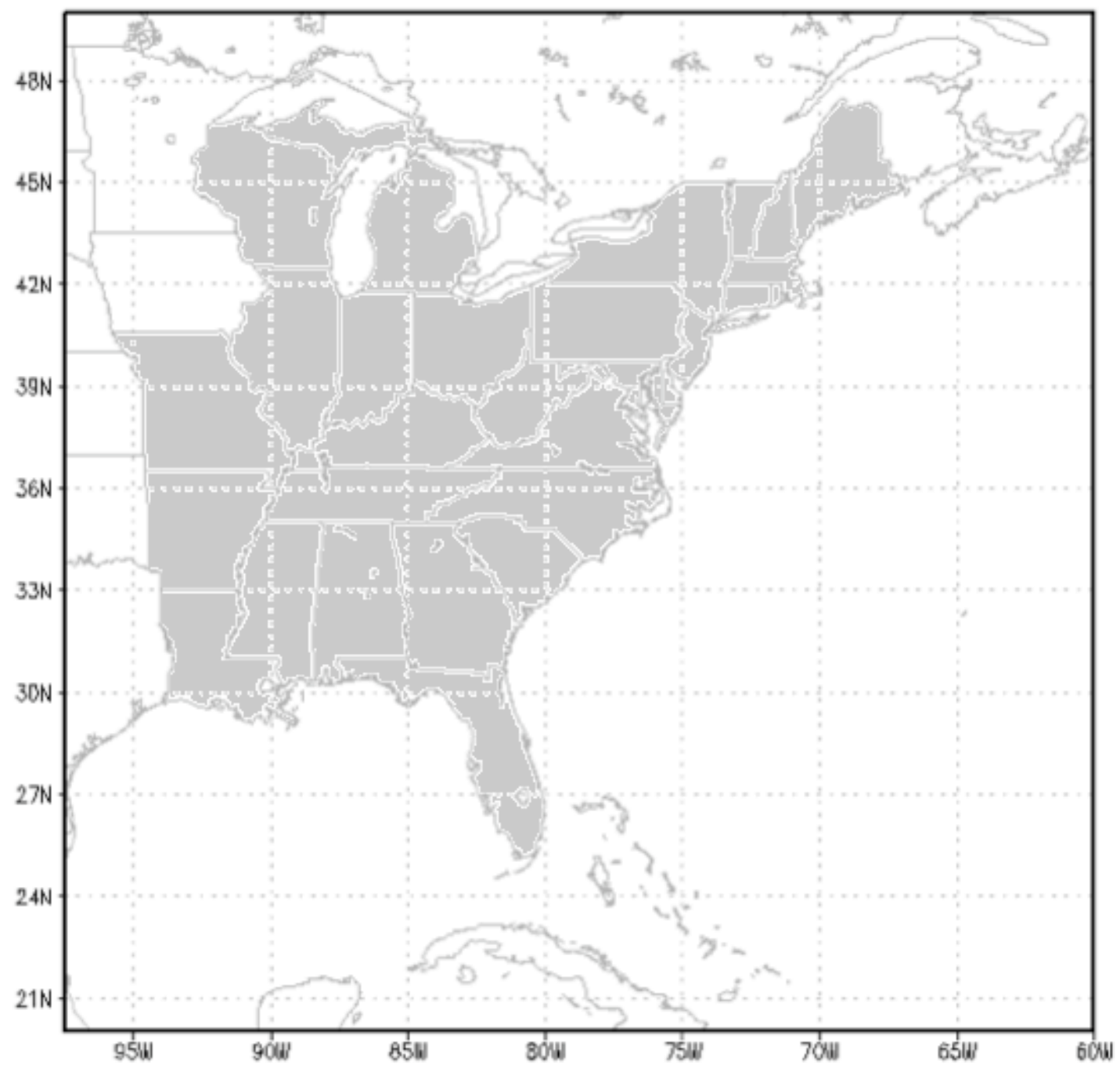

Figure 3.1: States included in this study (shaded).

The National Weather Service's Cooperative Observer Network, more commonly known as COOP stations, were utilized to gather daily precipitation, snowfall, and minimum temperature data for the period of study. Prior to gathering data from these COOP stations, basic criteria were applied to see if the station had an acceptable level of data. Regardless of the data type being collected from the station, 
if the station ceased operations prior to 1 January 1975 or began operations after 1 January 1990, the COOP station was disregarded. From this point, the COOP stations used were broken down into precipitation COOP stations or COOP stations recording daily precipitation, and snow COOP stations or COOP stations recording daily snowfall. For a map of the snow COOP stations and precipitation COOP stations included in this study, refer to Figures 3.2 and 3.3, respectively.

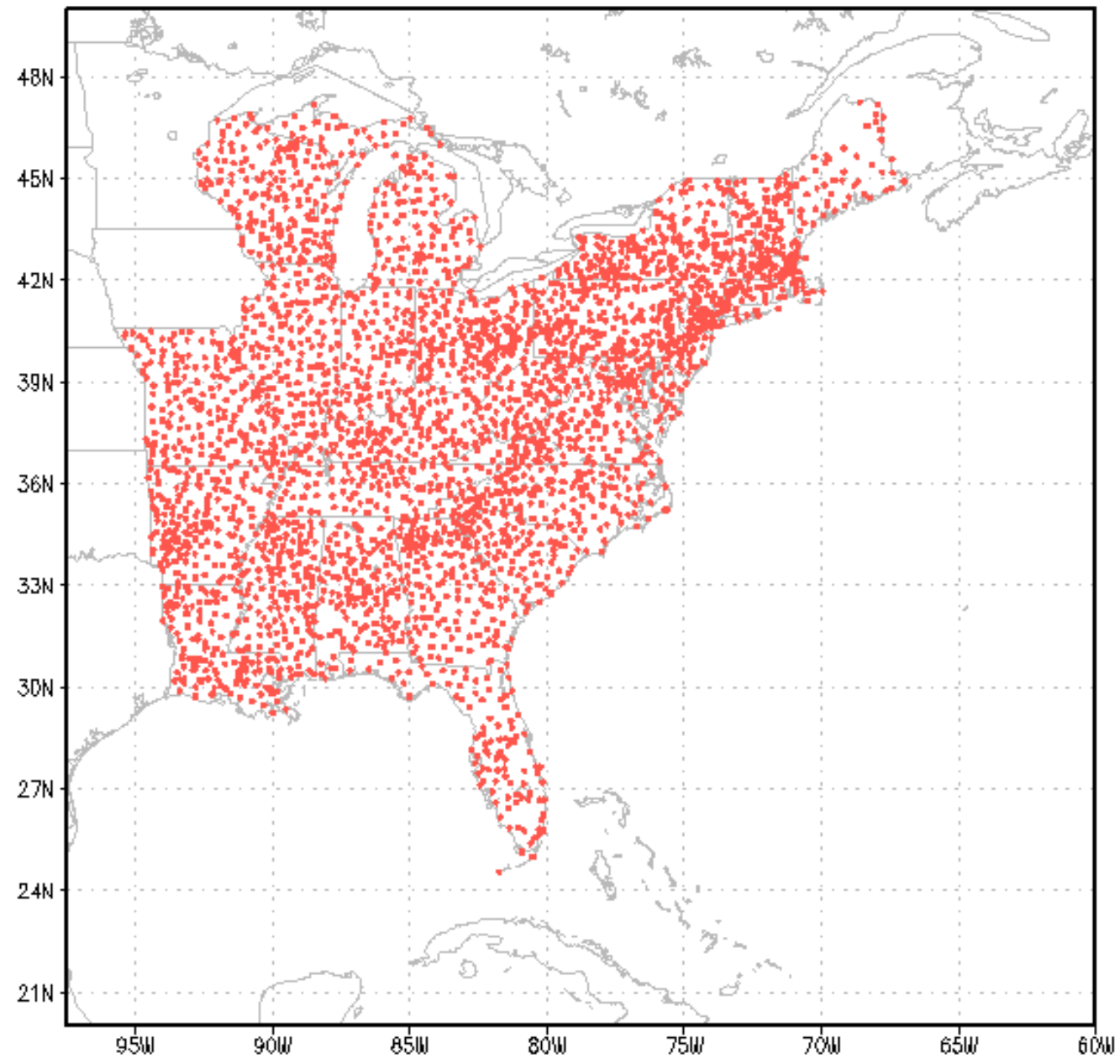

Figure 3.2: Snow COOP Stations, where each station is represented by a red dot.

Both Figures 3.2 and 3.3 reveal sufficient spatial coverage for both daily precipitation and snowfall, particularly along the urban corridor of the Northeast, as well as along the Appalachian Mountains. Hereinafter, the urban corridor will be 
defined similarly to Kocin and Uccellini (2004) as "from southern Virginia to New England". For both daily precipitation and snowfall, the most sparse area of coverage is northern Maine, and to some extent, the Florida peninsula. The number of snow COOP stations used was 3,191, and the number of precipitation COOP stations used was 3,308 . For each data type, the station was required to collect a minimum of 25 years of data. In addition, for each data type, the station was required to have $50 \%$ or less of the data missing for the entire data collection period. If either of these criteria failed to be met, the COOP station was disregarded.

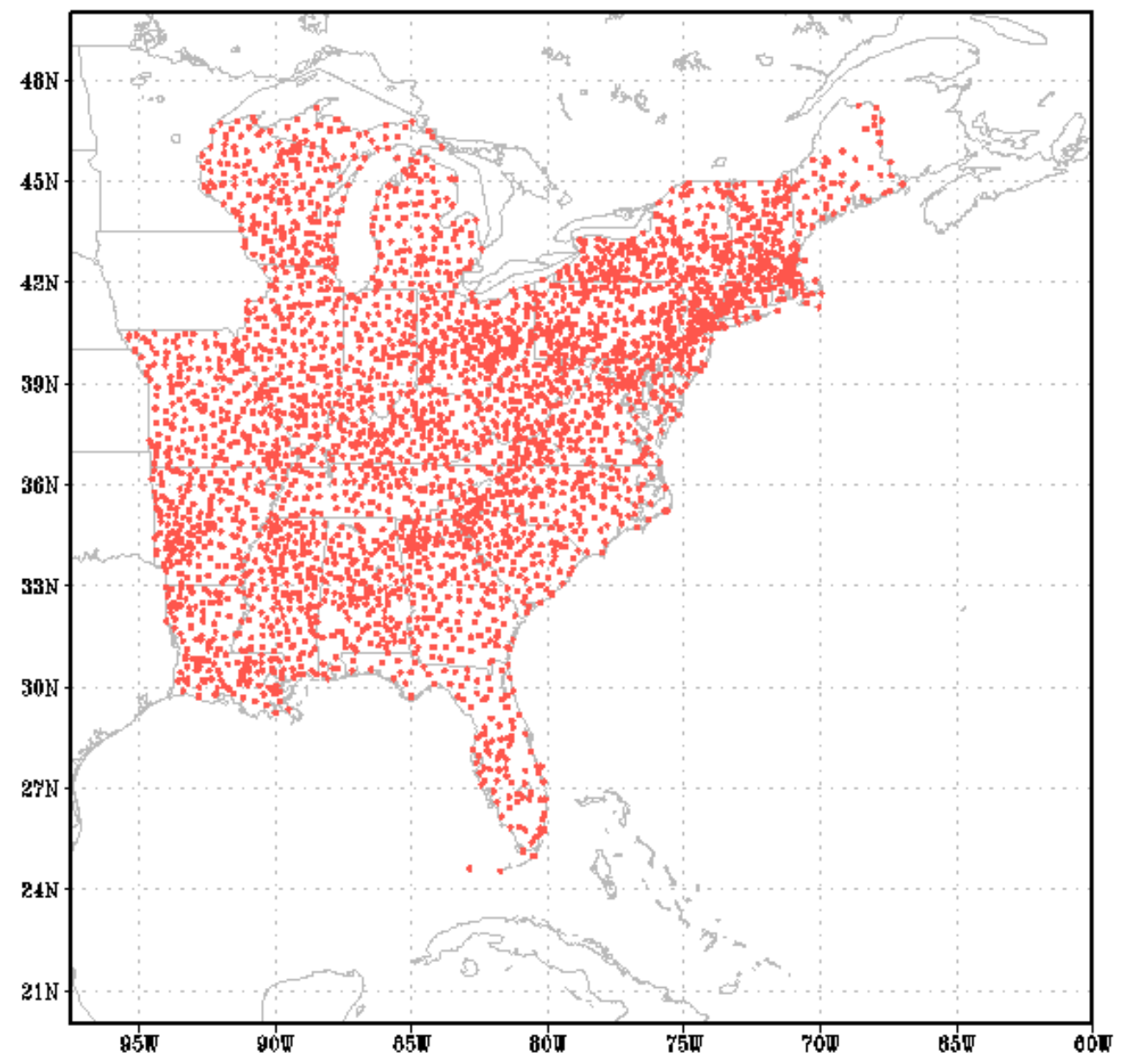

Figure 3.3: Precipitation COOP Stations, where each station is represented by a red dot.

Once the COOP stations meeting the above criteria had been established for precipitation and snow, the further handling of missing data was addressed. In regards 
to snowfall, if the daily snowfall for a particular day at a station was missing, the snowfall was considered to be $0.0 \mathrm{~cm}$ if either of the following criteria were met: if the daily precipitation recorded the same day at the same station was $0.0 \mathrm{~cm}$ or if the minimum temperature the same day at the same station was greater than $4.4^{\circ} \mathrm{C}\left(40^{\circ}\right.$ F). If these criteria were not met, the snowfall amount was then in fact considered missing. Checking each non-missing snowfall amount against the same criteria also filtered out erroneously recorded snowfall of any significance. If daily snowfall was recorded for a station, and the daily precipitation recorded for the same station on the same day was $0.0 \mathrm{~mm}$ (where a trace amount was not equal to $0.0 \mathrm{~mm}$ in this check) or if the minimum temperature for the same station on the same day was greater than $4.4^{\circ} \mathrm{C}\left(40^{\circ} \mathrm{F}\right)$, the daily snowfall was considered to be $0.0 \mathrm{~cm}$. No such adjustments were made to daily precipitation values. However, maximum threshold criteria were established for both daily snowfall and daily precipitation to filter out erroneous values. After imposing the above criteria on daily snowfall amounts, if any daily snowfall amount exceeded $127 \mathrm{~cm}$ (50 in), these amounts were flagged for further inspection. No such instances occurred. This snow threshold may seem arbitrary and high, however, there are two points to consider. One, since LES belts are included in the study, the effort was made not to exclude any unusually high daily snowfall amounts due to LES. Two, prior to applying the previously mentioned criteria, there were daily snowfall amounts greater than the snow threshold. Visual inspection showed these amounts were clearly erroneous, and after application of the previously mentioned minimum temperature and precipitation criteria, they were corrected, and therefore no longer flagged. Thus, it is felt the majority of erroneous daily snowfall values should be accounted for prior to the application of the snow threshold.

If any daily precipitation amount exceeded $508 \mathrm{~mm}$ (20 in), it was flagged for further inspection. There were twenty of these instances. For these COOP stations, 
archived daily surface maps were consulted using the National Oceanic Atmospheric Administration (NOAA) Central Library U.S. Daily Weather Maps Project (Daily Weather Maps, 2008). If the daily surface maps did not reveal a tropical system impacting the station and/or did not reveal an area of comparable $24 \mathrm{~h}$ precipitation amounts in the surrounding areas, then the value for that COOP station was considered erroneous and therefore missing. These erroneous values occurred in seventeen of the twenty instances. If however, a tropical system was impacting the area, either directly, in the vicinity or by its remnants, and surrounding $24 \mathrm{~h}$ precipitation was consistent with the COOP station being considered, the amount flagged was considered a legitimate value and included in the climatology. These three cases were also approximately verified using information from the National Weather Service and State Climatologists Offices available on-line at no cost. The three cases where a daily precipitation value at a COOP station exceeded the precipitation threshold and was determined to be a valid precipitation value are illustrated in Table 3.1.

Table 3.1: Daily precipitation totals exceeding $508 \mathrm{~mm}$ (20 in) that were considered valid after manual inspection.

\begin{tabular}{|l|l|l|l|l|}
\hline Station Name & COOP ID & Date & $\begin{array}{l}\text { 24 h Precipitation } \\
\text { Amount }(\mathrm{mm})\end{array}$ & $\begin{array}{l}\text { Synoptic } \\
\text { Explanation }\end{array}$ \\
\hline $\begin{array}{l}\text { Dauphin Island } \\
\text { \#2 (AL) }\end{array}$ & 012172 & 20 July 1997 & 609.35 (23.99 in) & $\begin{array}{l}\text { Tropical Storm } \\
\text { Danny }\end{array}$ \\
\hline $\begin{array}{l}\text { Key West } \\
\text { International } \\
\text { Airport (FL) }\end{array}$ & 084570 & $\begin{array}{l}11 \text { November } \\
1980\end{array}$ & $\begin{array}{l}577.85 \mathrm{~mm}(22.75 \\
\text { in) }\end{array}$ & $\begin{array}{l}\text { Hurricane } \\
\text { Jeanne }\end{array}$ \\
\hline $\begin{array}{l}\text { Americus } \\
\text { (GA) }\end{array}$ & 090253 & 6 July 1994 & $\begin{array}{l}535.94 \mathrm{~mm}(21.10 \\
\text { in) }\end{array}$ & $\begin{array}{l}\text { Tropical Storm } \\
\text { Alberto }\end{array}$ \\
\hline
\end{tabular}

Since monthly and annual precipitation and snowfall totals are important to this study, the number of missing days per month was addressed. After accounting for erroneous values, if the number of missing days in a month exceeded two, the entire month was considered missing. This number is arbitrary, but the effort was to keep this number conservative and to minimize the amount of precipitation or snowfall that 
could have occurred and therefore not been counted on these missing days, while at the same time not classifying an entire month as missing because one day had been missed. Ideally, for any station with missing daily precipitation or daily snowfall data, archived weather maps should be consulted to assess whether or not precipitation or snowfall could have occurred on that day in an appreciable amount. However, given the scope of this study, such a task was not feasible. Similarly, if the number of missing months in a year exceeded three, then the entire year was considered missing.

In addition to gathering daily snowfall and daily precipitation data, wind direction and SLP were obtained. During an ECWS event, International Civil Aviation Organization (ICAO) stations were used to obtain wind direction and SLP data on an hourly basis. An ECWS event was defined by the number of calendar days in terms of local time. All of the ECWS in the Improved Climatology have start and end dates and times in UTC. Since all of the locations within the study area have a GMT offset of five or six hours, if a storm start time was 0000 UTC, the local calendar day start date of the storm was the UTC start date minus one day. If a storm start time was 0600,1200 or $1800 \mathrm{UTC}$, the local calendar day start date of the storm was the UTC start date. Similarly for the end date, if the storm end time was 0000 UTC, the local calendar day end date of the storm was the UTC end date minus one day. If a storm end time was 0600,1200 or 1800 UTC, the local calendar day end date of the storm was the UTC end date. Based on these dates for an ECWS event, hourly data were collected from ICAO stations within the study region. In all, 123 ICAO stations were used to gather hourly data. For a map of the ICAO stations used, refer to Figure 3.4. The spatial coverage of ICAO stations appears sparse, but spatial coverage of these stations is uniform throughout the study area. Moreover, the spatial coverage is consistent with the $2.5^{\circ}$ resolution used to generate the original ECWS climatology. To be considered a "good" station, the ICAO station had to be in operation starting in 
1970 or before. The amount of missing data was not considered since the station data would later be interpolated to an evenly spaced grid.

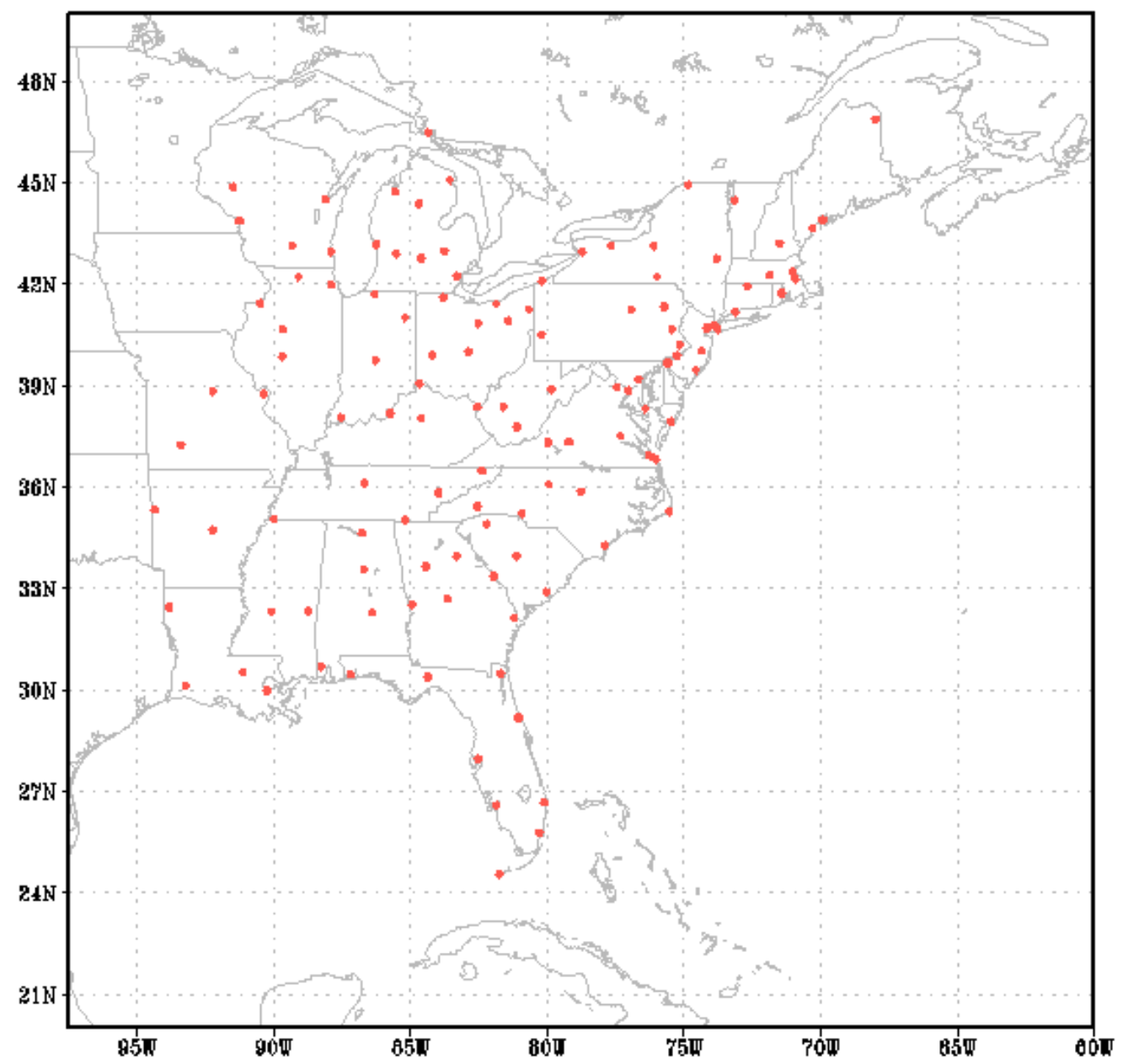

Figure 3.4: ICAO Stations, where each station is represented by a red dot.

\subsection{Interpolation to an Evenly Spaced Grid}

Prior to determining whether or not precipitation or snowfall was a direct result of an ECWS, snowfall and precipitation COOP data for each local calendar day of the ECWS event were interpolated to an evenly spaced grid. In addition, for each $6 \mathrm{~h}$ UTC period of an ECWS event, SLP was interpolated to the same evenly spaced grid. These interpolated grid values were key in making determinations as to what was snowfall or precipitation directly from the ECWS. The study domain used in the interpolation covers the area from $97.5^{\circ} \mathrm{W}$ to $60.0^{\circ} \mathrm{W}$, bounded on the south by $20.0^{\circ} \mathrm{N}$ and 
bounded on the north by $50.0^{\circ} \mathrm{N}$. The resolution used for this grid was $0.5^{\circ}$ and was chosen to be a fine enough grid resolution to assess the source of the precipitation and also so the grid based on the $2.5^{\circ}$ resolution used to identify the storms in the original ECWS climatology would be a subset of the finer grid. Therefore, original storm positions could remain on the same grid point.

Due to missing data at some stations, the number of stations used during each day of the interpolation varied. The method of interpolation used was Inverse Distance Squared Weighting. This interpolation technique was chosen because in using a comparable grid resolution, DeGaetano and Belcher (2007) found Inverse Distance Weighting exhibited superior performance in comparison to other methods, such as multiquadric interpolation (Nuss and Titley, 1994). The Inverse Distance Squared Weighting equation used is as follows:

$$
\begin{gathered}
E_{g}=\frac{\sum_{i=1}^{n} \frac{v_{i}}{d_{i}^{2}}}{\sum_{i=1}^{n} \frac{1}{d_{i}^{2}}} \\
\text { where: } d_{i}=\sqrt{\left(y_{g}-y_{i}\right)^{2}+\left(x_{g}-x_{i}\right)^{2}}
\end{gathered}
$$

In equation (1), $E_{g}$ represents the estimated value of grid point " $g$ ", $v_{i}$ is the data value of the $i^{\text {th }}$ nearby station, and $n$ is the number of nearby stations. In equation (2), $y_{g}$ represents the grid point latitude, $y_{i}$ is the latitude of the $i^{\text {th }}$ nearby station, $x_{g}$ is the grid point longitude, and $x_{i}$ is the longitude of the $i^{\text {th }}$ nearby station. All stations within a $2.0^{\circ}$ radius of the grid point being interpolated were used in calculating the interpolated value. Since the study area spans two time zones, regarding hourly data from ICAO stations for SLP interpolation, GMT offset times were noted to match the hourly data from the station to the correct $6 \mathrm{~h} \mathrm{UTC}$ period. There was one $6 \mathrm{~h}$ period 
of one ECWS where all hourly data was missing. For this instance, the previous hour and associated data were used.

\subsection{Determining ECWS Snowfall and Precipitation: Overview}

There are four main components in determining precipitation from an ECWS each day of an event: a precipitation gradient line, a pressure gradient line, whether or not an additional storm is present, and if applicable, the presence of LES. Using these components, relationships between precipitation maxima to each side of the precipitation gradient line were important as well. In developing these components, a total of thirty ECWS were considered in detail as case studies. These thirty storms were chosen at random, but with some reasoning behind their selection. The thirty storms consisted of a mix of short-lived ECWS, such as storms only lasting one day, and long-lived ECWS, such as storms lasting up to five days. The thirty storms also represented storms that were primarily rain events, storms that were classified as bombs, and historic storms identified by Kocin and Uccellini (1990). Also included in the case studies were the famous Superstorm of '93, the Blizzard of '96 and the President's Day Storm of 2003. In this case study approach, twenty of the thirty storms were analyzed individually, first by subjectively and qualitatively assessing the performance of the precipitation gradient line and the pressure gradient line. Some of the criteria used in constructing these lines were also developed and adjusted based on this analysis. Using knowledge of the size and characteristics of typical extratropical synoptic systems, the ECWS snowfall and precipitation decision criteria were developed. These twenty storms were then used to tune the criteria by comparing the results of applying criteria to a manual determination of the source of the precipitation and snowfall across the stations. These manual classifications of precipitation sources were facilitated by inspection of archived weather maps. Ten additional ECWS were evaluated using the final criteria as an independent assessment of the ECWS 
precipitation and snowfall decision process. A later sub-section in this chapter provides examples of some of these case studies and illustrates the decision process.

To develop the components used in the decision process it was first necessary to define an ECWS event in terms of COOP station reporting days, which will be termed storm days. Consider the hypothetical ECWS event in Figure 3.5, with a start time of 0000Z 8 Jan 2005, and an end time of 1800Z 10 Jan 2005. Based on Figure 3.5, station reports will be used from 7-10 January to determine ECWS precipitation and snowfall from this hypothetical event. While choosing a station report from 7 January will include as much as an additional $36 \mathrm{~h}$ of precipitation (e.g. from morning stations), such a selection was necessary because the hypothetical ECWS was actually occurring during the evening of 7 January, local time. Therefore, precipitation associated with the 7 January station report, needs to be assessed for possible inclusion in the climatology, particularly at midnight stations. Since COOP station data are reported based on local time, these four storm days will be used in determining ECWS precipitation and snowfall. Because a mix of COOP station reporting times comprise a typical $24 \mathrm{~h}$ day, and it is difficult to obtain the reporting times at a given station on a given day, stations with a mix of times were combined, resulting in a storm day being defined as longer than $24 \mathrm{~h}$. Table 3.2 represents typical reporting times for COOP stations.

Table 3.2: Typical reporting time periods for COOP stations, for the hypothetical day 7 Jan, assuming a UTC offset of minus $5 \mathrm{~h}$.

\begin{tabular}{|l|l|l|}
\hline \multicolumn{1}{|c|}{ Station Description } & \multicolumn{1}{c|}{ Start Time } & \multicolumn{1}{c|}{ End Time } \\
\hline Morning & 1200Z 6 Jan & 1200Z 7 Jan \\
\hline Evening & 0000Z 7 Jan & 0000Z 8 Jan \\
\hline Midnight & 0500Z 7 Jan & 0500Z 8 Jan \\
\hline
\end{tabular}




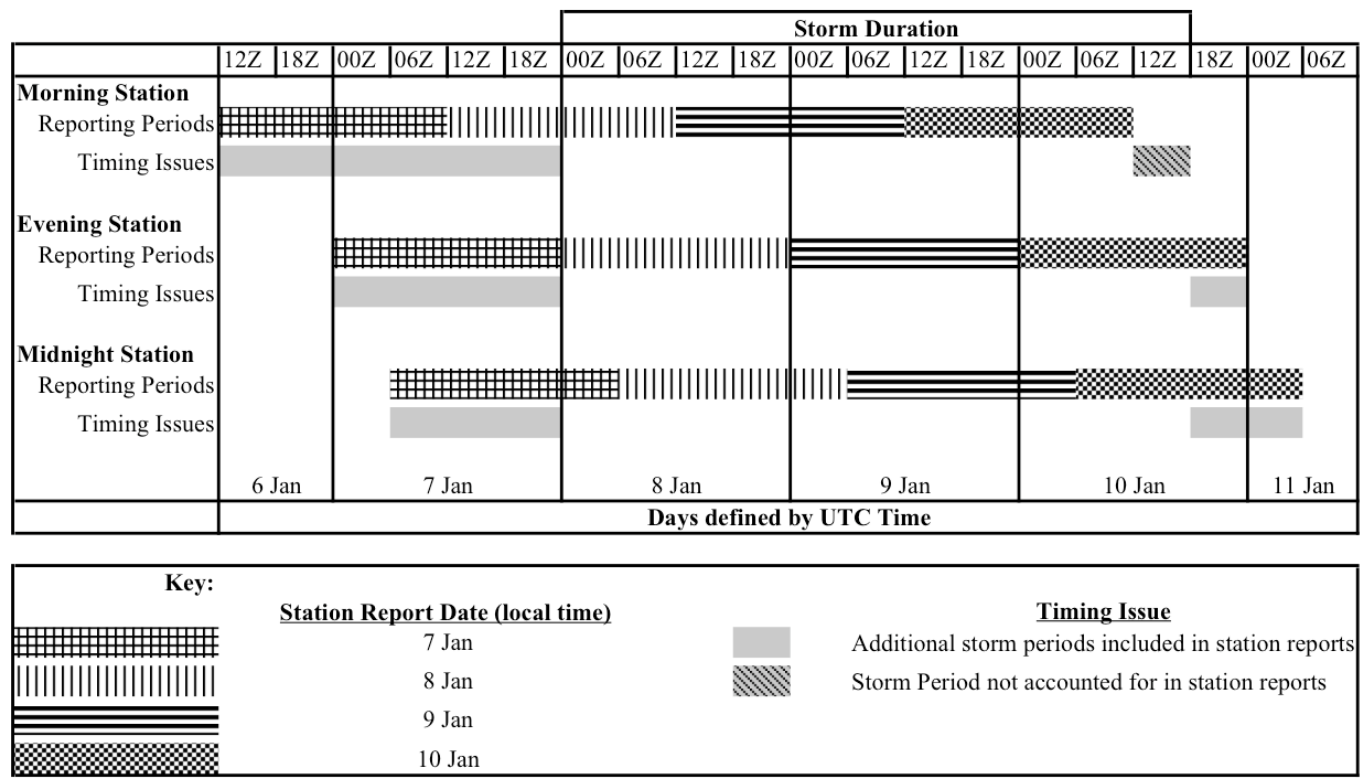

Figure 3.5: Hypothetical ECWS and an example of how COOP station reporting days are selected to define an ECWS event, and how this relates to station reporting times. Hypothetical start and end dates are 0000Z 8 Jan 2005 and 1800Z 10 Jan 2005, respectively.

Excluding the LES component of the ECWS decision process, the precipitation gradient line is necessary for development of the other components. The precipitation gradient line is determined for each storm day of an ECWS event, based on data interpolated from the stations. In contrast, the pressure gradient line is determined based on data interpolated from ICAO stations, for each $6 \mathrm{~h}$ period constituting a storm day. These pressure gradient lines will be combined to form one pressure gradient line for each day. Since a storm day needs to be defined longer than a typical $24 \mathrm{~h}$ day, and the time periods defining this day need to include the corresponding midnight station report, a storm day is defined as a $37 \mathrm{~h}$ period covering the following UTC (hourly observation) times: 0600Z, 1200Z, 1800Z, 0000Z, 0600Z, 1200Z, 1800Z. These hourly observation times also correspond to ECWS positions, and the purpose is to map these storm positions to each storm day. These storm positions are used in developing the starting points for constructing the precipitation gradient line, and are important in development of the pressure gradient line. For each ECWS 
event, the first storm day will begin with the start time of the storm, and all other days will begin at $0600 \mathrm{Z}$. In addition, each storm day will typically end at $1800 \mathrm{Z}$ on the following day, with the exception of the last day, or the last two days, of the event, which will end at the storm end time. Therefore, each storm day does not necessarily consist of the same number of storm positions. From the example in Figure 3.5, the storm day 7 January will be defined by the storm positions from 0000Z 8 January to $1800 \mathrm{Z} 8$ January. In contrast, the storm day 8 January will be defined from $0600 \mathrm{Z} 8$ January to $1800 \mathrm{Z} 9$ January. On occasion, due to the editing process of the original ECWS climatology, a $6 \mathrm{~h}$ UTC storm position may not correspond to a grid point. Therefore, these storm positions were assigned to the nearest grid point.

There are imperfections with this definition of storm days and how they define an ECWS event. These imperfections primarily result from the differing daily accumulation periods of the station reports. By design, the definition errs on the side of including too much precipitation or snowfall in the climatology. The inclusion of storm positions beyond the station reporting period may include "old" precipitation, such as that occurring from a separate feature, prior to the ECWS. Such precipitation could be excluded by subsequent analysis. However, it would be impossible to reintroduce precipitation that was erroneously excluded by too strict of a storm day definition.

One of the first steps in finding the gradient lines is to note the farthest north and farthest south storm position for each storm day. If two or more of these positions were found to be at the same latitude, the eastern most position was chosen. The rationale is that beginning at these positions, a precipitation gradient is sought northeast of the farthest north position and west of the farthest south position (e.g. region $\mathrm{A}$ and $\mathrm{C}$ in Figure 3.6). Choosing the farthest east position, when applicable, minimizes the automated procedure "missing" a precipitation gradient in these 
locations. Next is a discussion of the construction of the precipitation gradient line beginning with a general case, followed by an explanation of special cases, then concluding with a description of adjustments made to the line.

\subsection{Precipitation Gradient Line-General Case for Selecting Potential Points}

From the farthest north storm position for each day, a list of grid point coordinates was generated extending due north to the northern extent of the study domain. Similarly, from the southern most position a list of grid point coordinates was generated extending due south to the southern extent of the study domain. These grid coordinates were used to check for a precipitation gradient only in the westward looking direction. In addition, from only the far north storm position, a list of grid coordinates was generated due east to the eastern extent of the study domain. These coordinates were used to check for a precipitation gradient only in the northward looking direction. Figure 3.6 shows a hypothetical ECWS and how these lists of grid coordinates are generated.

Using the $6 \mathrm{~h}$ UTC storm positions for each storm day, a linear track was assumed between each position, and applicable grid points were assigned along this track. Therefore, every latitude in the study domain between the southern most and northern most storm position had either an assumed or actual storm position. Each of these points was used to check for a precipitation gradient in the southwestward, westward, northwestward, northward and northeastward looking directions. Figure 3.7 shows a hypothetical ECWS and how these directions were considered, for one particular point, as an example. Including the points extending due north and due south from the northern and southern most storm positions, respectively, each latitude in the study domain had at least one point to begin from when checking for a precipitation gradient each day. 


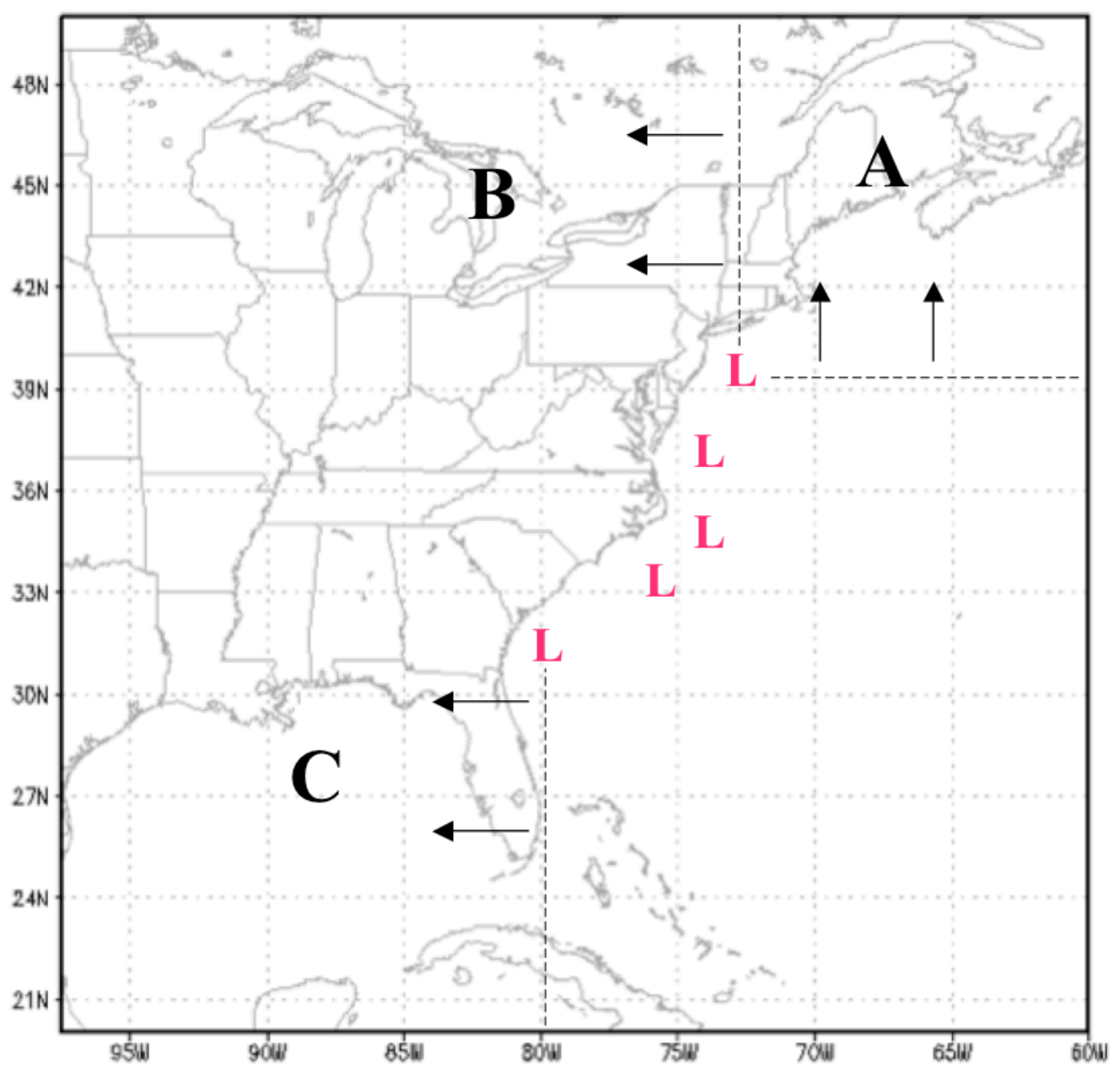

Figure 3.6: Hypothetical ECWS for a particular day, showing generation of coordinate lists (PGD lists) from far north and south positions. Regions referenced in text denoted by "A", "B", and "C". 


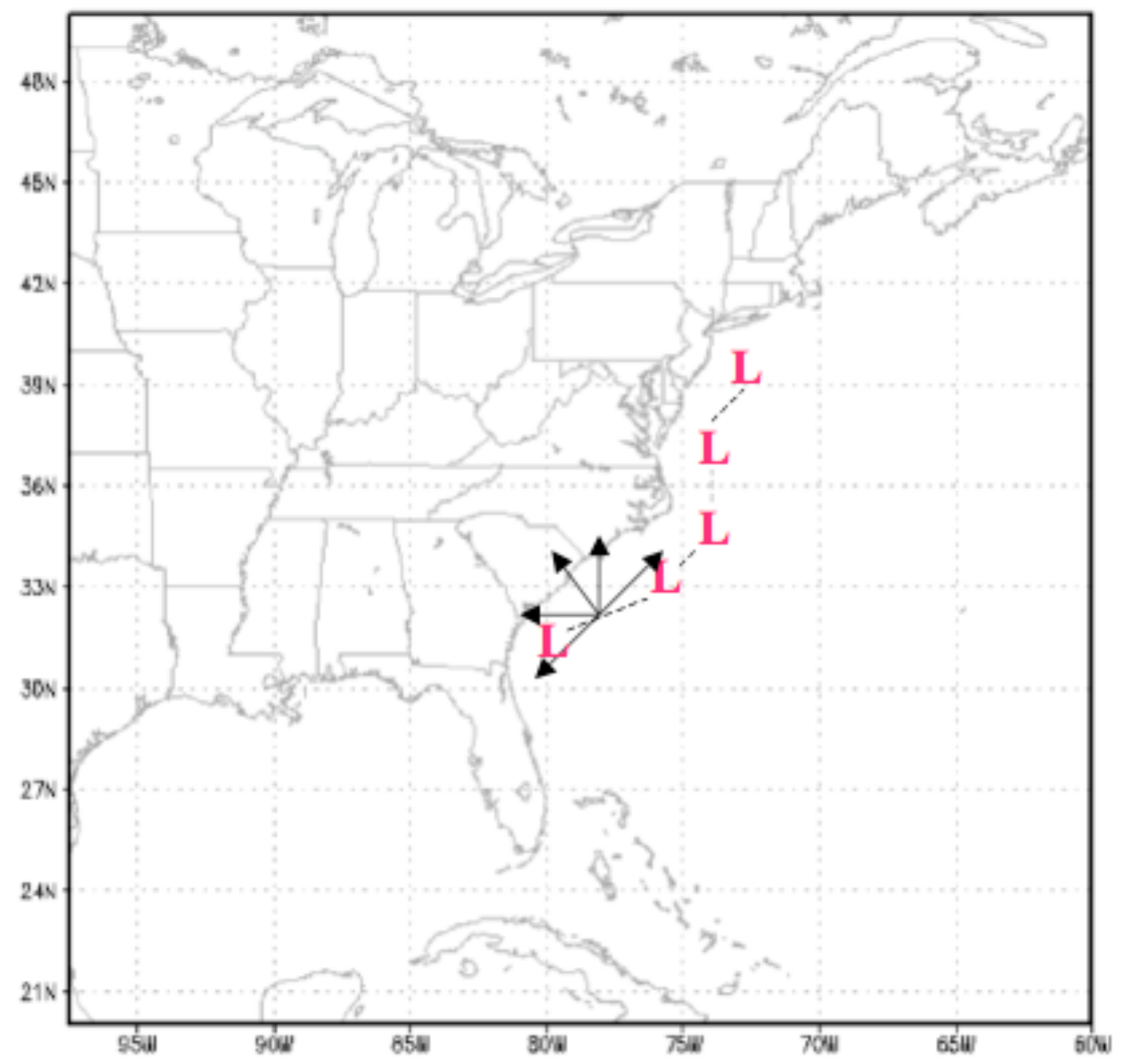

Figure 3.7: Hypothetical ECWS for a particular day, showing generation of coordinate lists (PGD lists) from actual and assumed storm positions.

\subsubsection{Potential Gradient Direction Lists and Identification of Local Minima}

For each of these beginning points, a list of precipitation values was generated from the interpolated values. This list will be termed potential gradient direction (PGD) list. For example, looking northward from a beginning point, a list of precipitation values was generated corresponding to the coordinates along that longitude. Similarly, looking northwestward from a beginning point, a list of precipitation values was generated from the interpolated values along a transect characterized by a $0.5^{\circ}$ increase in latitude and a $0.5^{\circ}$ decrease in longitude (i.e. 
diagonally across the interpolated grid). Each of these PGD lists is analyzed by an algorithm, which notes local precipitation minima. The coordinates of one local precipitation minimum are then selected from each list as a potential gradient point to be used in developing the precipitation gradient line. While the algorithm moves through the PGD list, precipitation values are rounded to three decimal places and assigned to one of thirteen bins. The details of this binning technique can be seen in Table 3.3.

Table 3.3: Binned precipitation ( $\mathrm{mm}$ ) values in algorithm determining precipitation gradient coordinates. Values in parentheses and italics are in inches (in).

\begin{tabular}{|c|c|c|c|c|c|}
\hline \multicolumn{2}{|c|}{$\begin{array}{l}\text { Initial Precipitation Value } \\
\text { Greater Than or Equal To }\end{array}$} & \multicolumn{2}{|c|}{$\begin{array}{c}\text { Initial Precipitation Value } \\
\text { Less Than }\end{array}$} & \multicolumn{2}{|c|}{$\begin{array}{c}\text { Binned Precipitation } \\
\text { Value }\end{array}$} \\
\hline- & & 0.25 & $(0.01)$ & 0.0 & $(0.0)$ \\
\hline 0.25 & $(0.01)$ & 1.91 & $(0.075)$ & 1.27 & $(0.05)$ \\
\hline 1.91 & $(0.075)$ & 3.18 & $(0.125)$ & 2.54 & $(0.1)$ \\
\hline 3.18 & $(0.125)$ & 6.35 & $(0.25)$ & 5.08 & $(0.2)$ \\
\hline 6.35 & $(0.25)$ & 19.05 & $(0.75)$ & 12.70 & $(0.5)$ \\
\hline 19.05 & $(0.75)$ & 31.75 & $(1.25)$ & 25.40 & $(1.0)$ \\
\hline 31.75 & $(1.25)$ & 44.50 & $(1.75)$ & 38.10 & (1.5) \\
\hline 44.45 & $(1.75)$ & 57.15 & $(2.25)$ & 50.80 & $(2.0)$ \\
\hline 57.15 & $(2.25)$ & 69.85 & $(2.75)$ & 63.50 & $(2.5)$ \\
\hline 69.85 & $(2.75)$ & 82.55 & $(3.25)$ & 76.20 & (3.0) \\
\hline 82.55 & (3.25) & 222.25 & $(8.75)$ & 152.40 & (6.0) \\
\hline 222.25 & $(8.75)$ & 387.35 & $(15.25)$ & 304.80 & (12.0) \\
\hline 387.35 & (15.25) & - & & 457.20 & (18.0) \\
\hline
\end{tabular}

Grid points outside of the study region boundary in Figure 3.8 were not considered. The algorithm notes the coordinates of the first non-missing precipitation 
value encountered in the PGD list and within the study region boundary. Along each PGD list all local precipitation minima were identified. These local minima may consist of one or more grid points. Precipitation values that decreased steadily then remained constant to the end of the study domain were noted, with the constant values considered a local minimum. The end grid point of the study domain was considered a local minimum when precipitation values decreased steadily before reaching the boundary.

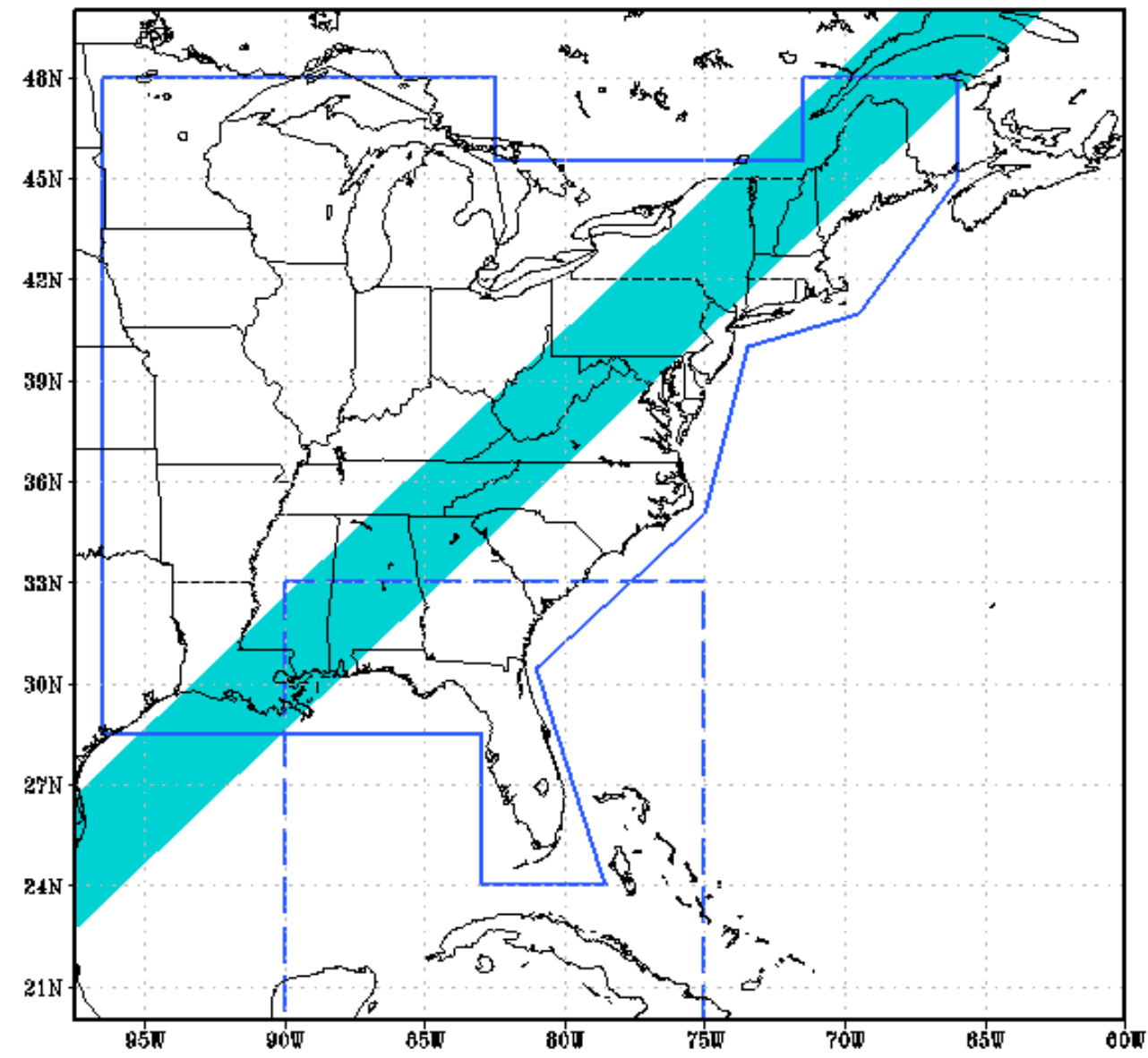

Figure 3.8: Key boundaries across study domain used in construction of precipitation gradient line. Boundaries of interpolated precipitation values used in calculation of precipitation gradient line or study region boundary (solid - blue), AMWE (left edge of shaded - light blue), Appalachian Mountains swath spanning entire domain (shaded - light blue), Florida Box (dashed - blue). 


\subsubsection{Selection of One Gradient Point for each Potential Gradient Direction List}

Ultimately, a single local minimum was chosen for each PGD list. The grid point corresponding to this single minimum is termed the gradient point. Each PGD list will thus have one point designated as a gradient point. To aid in this selection process, an approximation of the Appalachian Mountains was necessary, which is visible in Figure 3.8. This line, termed Appalachian Mountains West Extent (AMWE), extends from $\left(20.0^{\circ} \mathrm{N}, 106.0^{\circ} \mathrm{W}\right)$ to $\left(50.0^{\circ} \mathrm{N}, 68.0^{\circ} \mathrm{W}\right)$. This line also represents the approximate western edge of the outer most box in the original study by Hirsch et al. (2001). The coordinates were also chosen to not only represent the western extent of the Appalachian Mountains, but to also span the entire study domain.

Local minima greater than $2.54 \mathrm{~mm}(0.1 \mathrm{in})$ were ignored. When local minima existed to the east of the AMWE line, the minimum associated with the longest length, in terms of grid points, was selected. If more than one minimum is found to be the same length, the local minimum farthest east was chosen. If a local minimum did not exist to the east of the AMWE meeting the $2.54 \mathrm{~mm}(0.1 \mathrm{in})$ criterion, then the longest local minimum to the west of the AMWE line was selected. When more than one local minimum to the west of the AMWE line had the same length, the farthest east, but still west of the line was chosen. To this point, regardless of what side of the AMWE line is being considered, preference was not given to local minima with 0.0 mm values.

If the selected local minimum was associated with more than one grid point, the grid corresponding to the mid point of the minimum was ultimately retained as the gradient point. However, in cases where the string of minima crossed over the AMWE line, the grid point just to the east of the AMWE line was retained as the gradient point. In this situation, the Mountains are assumed to represent the gradient 
point for the PGD list in question. Of course if the selected local minimum only consists of one grid point, that point becomes the gradient point. Figure 3.9 shows examples of hypothetical PGD lists and how the gradient point is selected.

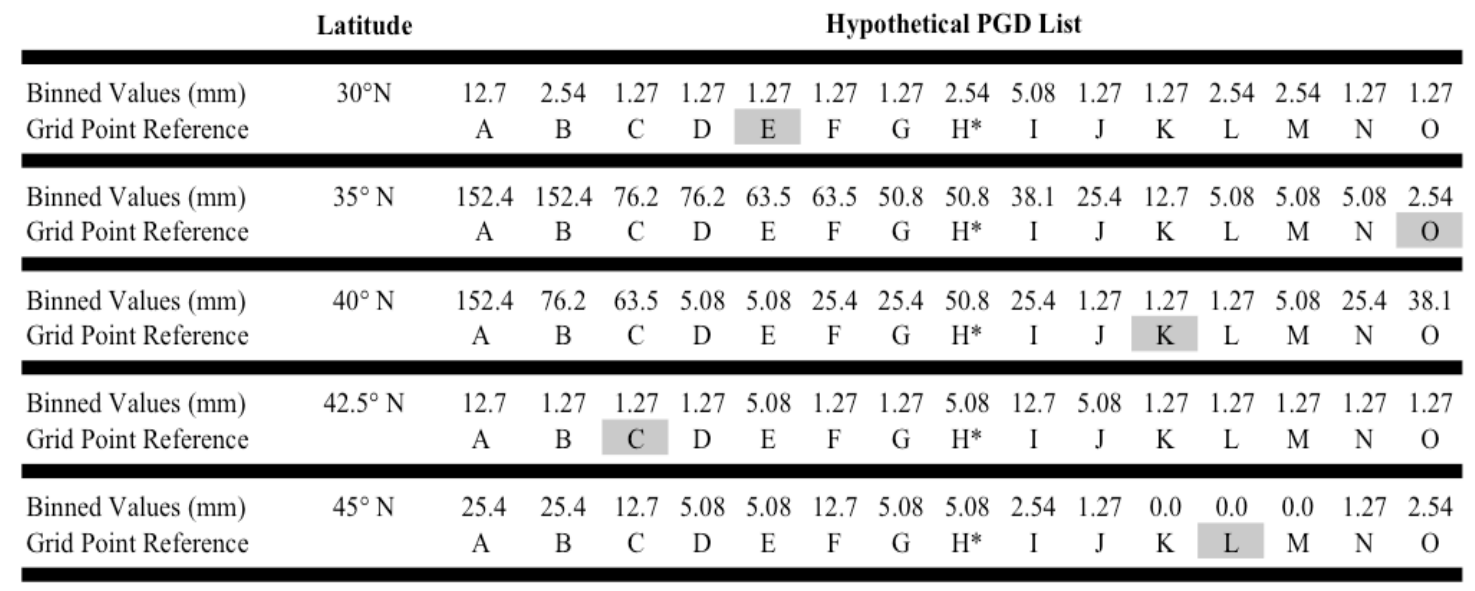

Figure 3.9: Hypothetical PGD Lists, with binned precipitation values (mm) and arbitrary grid point coordinates A-O. Latitudes are arbitrary, and are only for distinguishing between PGD Lists. The gradient point selected for the hypothetical PGD lists is shaded, and $\mathrm{H}^{*}$ indicates the position of the AMWE line.

From Figure 3.9, at latitude $30^{\circ} \mathrm{N}$, grid point " $\mathrm{E}$ " is selected as the gradient point, because this is the longest and only local minimum to the east of the AMWE line. At $35^{\circ} \mathrm{N}$, grid point " $\mathrm{O}$ " is selected because no other local minima exist, and when the end of the study domain is reached with steadily decreasing values, the last grid point becomes a local minimum. Latitudes $40^{\circ} \mathrm{N}$ and $45^{\circ} \mathrm{N}$ are similar in that no local minima to the east of the AMWE line exist meeting the $2.54 \mathrm{~mm}(0.1 \mathrm{in})$ criterion, so grid points "K" and "L", respectively, are chosen as the gradient points. Finally, at $42.5^{\circ} \mathrm{N}$, two local minima exist to the east of the AMWE line, and the longest minimum is selected, with grid point " $\mathrm{C}$ " becoming the gradient point.

Lastly, if all of these values in a PGD list are $2.54 \mathrm{~mm}(0.1 \mathrm{in})$ or less, then a second gradient point for that list is assigned to the grid point corresponding to the AMWE line. This instance is referred to as the Low East scenario. The reasoning is 
that while moving from the ECWS to the western extent of the Appalachian Mountains, if only "small" values of precipitation exist, there is no need to consider what is occurring beyond the Mountains and farther west.

Since multiple PGD lists are associated with each storm position, it is possible that more than one gradient point is indicated within each band of grid point latitudes. These must be culled such that only one gradient point exists within each latitude band in the study domain. This single point is referred to as the Precipitation Gradient Line (PGL) point. Prior to discussing this selection process, a number of exceptions or special cases need to be considered.

\subsection{Precipitation Gradient Line - Special Cases for Selecting Potential Points}

A special gradient point is indicated when a string of $0.0 \mathrm{~mm}$ values are encountered with length exceeding $400 \mathrm{~km}$ after a run of greater than $0.0 \mathrm{~mm}$ precipitation values. The coordinates of the first $0.0 \mathrm{~mm}$ value are included as a gradient point. The distance of $400 \mathrm{~km}$ was chosen as an arbitrary distance and by inspecting case studies of ECWS in the climatology. This scenario is referred to as the Middle Zero Scenario.

Another special case for tracking $0.0 \mathrm{~mm}$ values involves identifying large areas of precipitation away from and not associated with the ECWS. This situation is termed the Zero Swath Evaluation. This case is similar to the Middle Zero Scenario, and often redundant, but eventually incorporates multiple PGD lists in identifying large areas of no precipitation. As in the Middle Zero Scenario, the first area of no precipitation in a PGD list exceeding $400 \mathrm{~km}$ is noted. If one or more precipitation values greater than or equal to $2.54 \mathrm{~mm}(0.1 \mathrm{in})$ are found following this string of 0.0 $\mathrm{mm}$ values, the first grid point in the string of no precipitation, while moving away from the beginning point of the PGD list is indicated with a Zero Swath Flag. 
Finally, an additional scenario involves the identification of the first value exceeding $0.0 \mathrm{~mm}$ within PGD lists originating with beginning points along the storm track. Moving away from these beginning points, regardless of the direction being considered, if the first precipitation value exceeding $0.0 \mathrm{~mm}$ is greater than a distance of $1,000 \mathrm{~km}$, then a gradient point is assigned to the grid value of $0.0 \mathrm{~mm}$ that immediately precedes this occurrence. The objective of this case is to exclude precipitation occurring a large distance from the ECWS, regardless of direction. This situation will be referred to as First Value too Far. This distance of $1,000 \mathrm{~km}$ is arbitrary and was chosen based on case study analysis of ECWS in the climatology. Regarding the general and special cases discussed, for each PGD list the single gradient point is selected according to the order of preferences given in Table 3.4.

Table 3.4: By order of preference, the case involved in selecting a gradient point for each PGD list, and a description of how this point is selected.

\begin{tabular}{|l|l|l|}
\hline \multicolumn{1}{|c|}{ Order of Preference } & \multicolumn{1}{|c|}{ Case Involved } & \multicolumn{1}{c|}{ Description of Point Selected } \\
\hline First & First Value too Far & $\begin{array}{l}\text { The last grid value of 0.0 mm, } \\
\text { prior to the point signaling First } \\
\text { Value too Far }\end{array}$ \\
\hline Second & $\begin{array}{l}\text { All values in PGD list } \\
\text { are } 0.0 \mathrm{~mm}\end{array}$ & First non-missing grid value \\
\hline Third & Low East & $\begin{array}{l}\text { Last grid value east of the } \\
\text { AMWE line }\end{array}$ \\
\hline Fourth & Middle Zero & $\begin{array}{l}\text { This first grid value of } 0.0 \mathrm{~mm} \\
\text { unless a gradient point exists } \\
\text { closer to the beginning point of } \\
\text { the PGD list }\end{array}$ \\
\hline Fifth & General & $\begin{array}{l}\text { Based upon length and position } \\
\text { with respect to AMWE line }\end{array}$ \\
\hline
\end{tabular}

\subsection{Precipitation Gradient Line - Final Selection of Points and Adjustments}

\subsubsection{Special Cases for Final Selection}

Specifying the position of the PGL point involves decision rules concerning the gradient points as well as several special cases most of which involve precipitation values of $0.0 \mathrm{~mm}$. The first case involves PGD lists generated from the beginning 
points extended to the east of the farthest north position of the ECWS, and looking northward. Specifically, this corresponds to region "A" in the example in Figure 3.6. In this case, when the first precipitation value exceeding $0.0 \mathrm{~mm}$ is more than 1,200 $\mathrm{km}$ from the farthest north position of the ECWS, the grid with $0.0 \mathrm{~mm}$ precipitation just to the south is termed the Too Far Northeast point. It is possible for multiple Too Far Northeast points to occur in a day. Once all Too Far Northeast points have been found, if applicable, the point farthest east is noted. In the case of multiple points being located farthest east, the northern most is selected. The PGL extends from this selected point to the northern extent of the study domain. Figure 3.10 details this scenario.

The objective of this scenario, termed Northeast Value too Far, is to construct a PGL such that precipitation occurring a large distance to the northeast of an ECWS would not be included on the same side of the PGL as the ECWS. From Figure 3.10, precipitation occurring in New England is clearly not associated with the ECWS. With insufficient interpolated precipitation data moving northeast from most ECWS to northern Maine, due to the Atlantic Ocean, the 1,200 km distance criterion was adopted. This distance was also chosen after examination of individual ECWS on a case study basis. Furthermore, the distance was chosen to be great enough so as not to incorrectly exclude overrunning precipitation associated with the ECWS. In the hypothetical situation in Figure 3.10, four Northeast Value too Far points are identified. From the farthest east point, a PGL is extended north, regardless of any other existing gradient points at these latitudes. In an ideal situation, the remainder of the PGL would be constructed in red. 


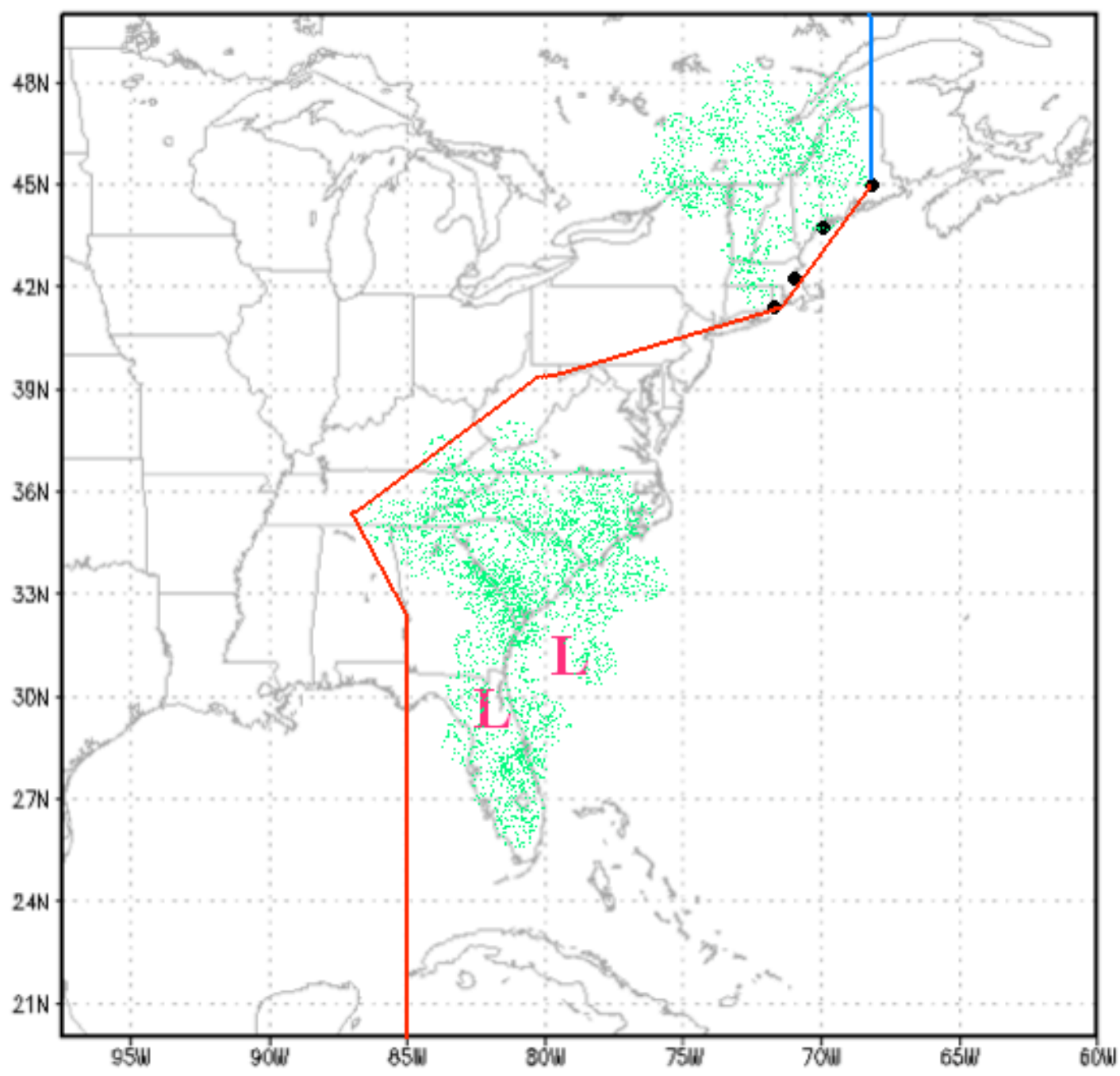

Figure 3.10: A hypothetical ECWS and example of the special case Northeast Value too Far. The ECWS is positioned in the Southeast, with associated precipitation in green. Precipitation from an additional storm is also shaded green in New England. Too Far Northeast points are in black, and the PGL points extended north from the selected Too Far Northeast point are in blue. The remainder of a hypothetical PGL is represented in red.

An analogous procedure is used for PGD lists generated from the beginning points extended south from the southern most ECWS position and the direction being considered is westward. Specifically, this corresponds to region " $\mathrm{C}$ " in the example in Figure 3.6. In this situation, if the string of $0.0 \mathrm{~mm}$ values moving away from the beginning point initially exceeds $400 \mathrm{~km}$, the coordinates of the first $0.0 \mathrm{~mm}$ value are 
termed a South Zero Point. Multiple South Zero Points can exist for a day. This distance of $400 \mathrm{~km}$ is arbitrary, but again was chosen based on case study analysis of the ECWS in the climatology. This situation, termed South Zero Start scenario, attempted to exclude precipitation to the south and west not associated with the ECWS. Figure 3.11 details the South Zero Start scenario.

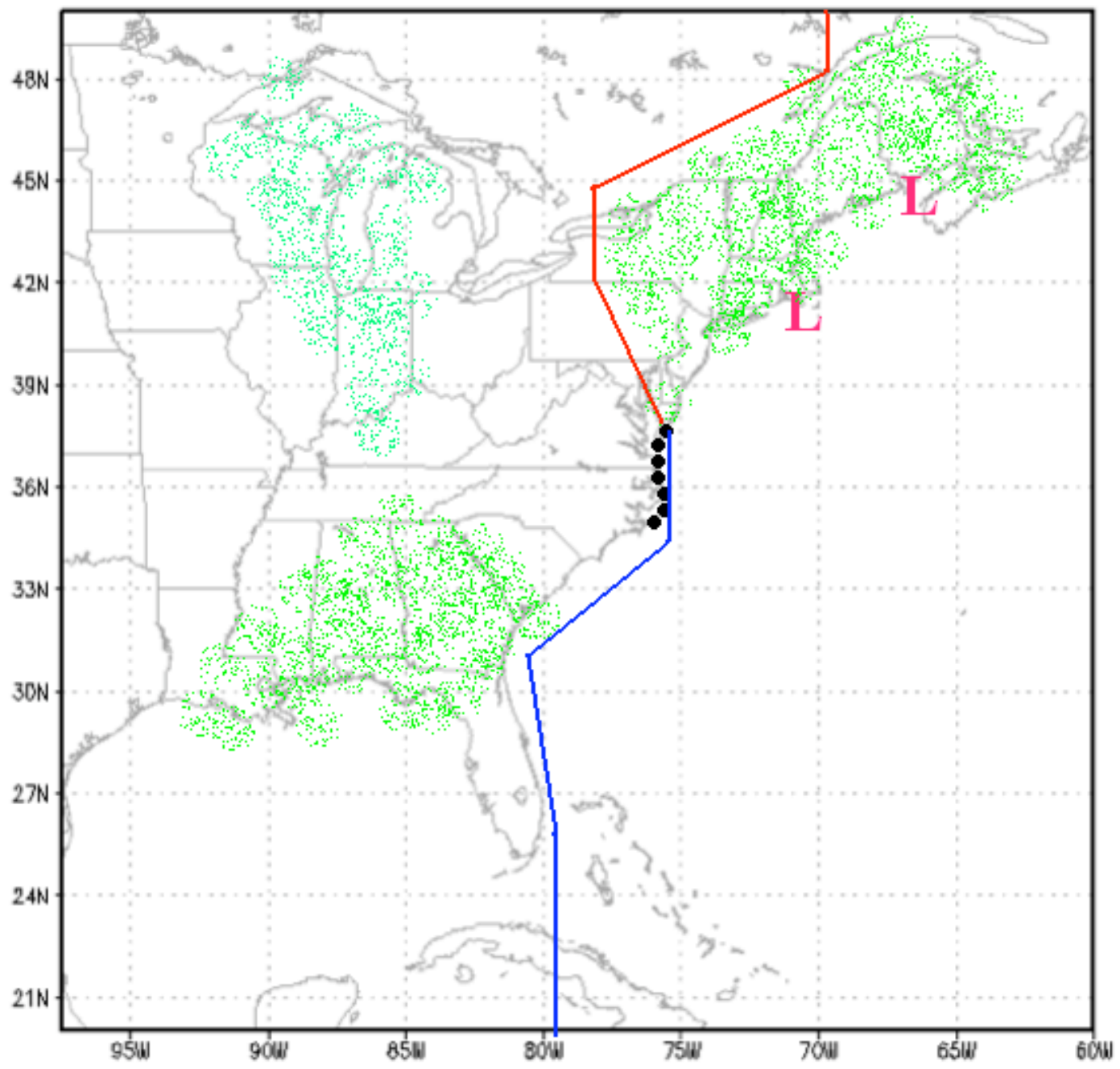

Figure 3.11: A hypothetical ECWS and example of the special case South Zero Start. The ECWS is positioned in New England, with associated precipitation in green. Precipitation from an additional storm(s) is also shaded green throughout the western Great Lakes and Southeast. South Zero points are in black, and the PGL points, extended south from the northern South Zero point, are in blue. Remainder of a hypothetical PGL is represented in red. 
In the hypothetical ECWS depicted in Figure 3.11, an ECWS is approaching the Canadian Maritime Provinces. Moving southward from the ECWS the algorithm encounters a large area of $0.0 \mathrm{~mm}$ values looking in the westward direction in the midAtlantic states, mainly Virginia and North Carolina. The objective is for no precipitation south of this region to be on the same side of the PGL as the ECWS. This is accomplished by considering latitudes south of the southern most storm position. If seven of these latitudes contain South Zero points, and the points occur consecutively, amounting to $3.5^{\circ}$ of latitude, then the PGL extends from the first South Zero point southward to the southern extent of the study domain.

\subsubsection{General Cases for Final Selection}

Since multiple gradient points may exist for a given latitude, conditions are set forth to choose one point for each latitude in constructing the PGL. These conditions are closely related to the storm positions for that day. For latitudes less than the farthest north position of the ECWS for that day, plus $2.5^{\circ}$, and for latitudes greater than the farthest south position of the ECWS for that day, minus $2.5^{\circ}$, the gradient point farthest west at each latitude is selected as the PGL point. The $2.5^{\circ}$ was chosen as a buffer to correspond to the resolution of the original research by Hirsch et al. (2001), which identified the ECWS positions. If the latitude is greater than or equal to the farthest north position of the ECWS, plus $2.5^{\circ}$, then the farthest east gradient point at these latitudes is selected as the PGL point. When the latitude is less than or equal to the farthest south position of the ECWS, minus $2.5^{\circ}$, then the farthest east gradient point is selected as the PGL point.

\subsubsection{Adjustments to the Precipitation Gradient Line}

After these selections of PGL points have been made, a few adjustments are made before the line is considered final. One adjustment is to account for precipitation occurring on the Florida peninsula, especially since frontal boundaries, 
which may traverse the peninsula during an ECWS event, are not directly identified. Referring to Figure 3.8, a box is outlined and termed the Florida Box. The box extends from $90.0^{\circ} \mathrm{W}$ to $75.0^{\circ} \mathrm{W}$, bounded on the north by $33.0^{\circ} \mathrm{N}$ and on the south by $20.0^{\circ} \mathrm{N}$. If any of the $6 \mathrm{~h}$ UTC storm positions for a day are located within or on the boundaries of the Florida Box, then any precipitation or snowfall during that day on the peninsula is assumed to be from the ECWS, and an adjustment to the PGL is needed. The objective of this adjustment is to ensure that if the ECWS passes through the Florida Box, then all of the precipitation from that day occurring on the Florida peninsula is included on the same side of the PGL as the ECWS. The Florida peninsula is defined as any point along and south of $28.5^{\circ} \mathrm{N}$. If the ECWS passes through the Florida Box, then from $28.5^{\circ} \mathrm{N}$ southward, points on the PGL are assigned a longitude to the west of the Florida peninsula.

The next adjustment is the application of a simple smoothing and filling technique to the PGL points. Each latitude should have one PGL point, but this may not always be the case to this point. In the unlikely case that a PGL point is absent in a section of the study domain, excluding the outer perimeters of the domain, a filling technique is used to estimate coordinates of the missing PGL point. This ensures there will be 61 precipitation gradient points, consistent with the number of $0.5^{\circ}$ latitude bands in the study domain. If PGL points exist at the northern or southern edge of the domain, the PGL is simply extended northward (or southward) along the longitude of the last available PGL point. Within the study domain, the PGL is estimated at latitudes with missing PGL points by a linear path between the adjacent existing points.

After this filling procedure, a smoothing technique is applied to the PGL points. Points at or above the northern most PGL point prior to filling in missing points, and points at or below the southern most PGL point prior to filling in missing 
points, are ignored for the purposes of smoothing. From there, all PGL points in between are considered for smoothing, moving from south to north. For a given PGL point, the technique considers the point just to the south and just to the north. If the given PGL point has a longitude less than or greater than both surrounding points, then smoothing is applied. To smooth the given PGL point, the latitude remains the same, but the new longitude becomes an average of the PGL points directly to the north and to the south. When considering the next PGL point, and whether or not to apply smoothing, the previously smoothed point becomes the PGL point to the south, and so on. If a given PGL point has a longitude equal to one of the points directly to the north or to the south, or the point has a longitude in between these points, then no smoothing is needed and the PGL point remains as is. At this point, the PGL consists of 61 points.

After smoothing, the next adjustment deals with the presence of the Appalachian Mountains. A swath is created by extending each point on the AMWE line by $5^{\circ}$ longitude moving east. This swath, termed Appalachian Mountains Swath, spans the entire study domain, and can be viewed in Figure 3.8. Such a swath creates an area to be used in adjusting the PGL for precipitation occurring in the vicinity of the Appalachian Mountains. The main objective of this adjustment is to assess whether or not the PGL failed to recognize any precipitation occurring in the vicinity of the Appalachian Mountains. Specifically, this adjustment attempts to identify precipitation occurring along the Appalachian Mountains in West Virginia, Virginia and North Carolina as precipitation from an ECWS.

Starting at $45.0^{\circ} \mathrm{N}$ or the farthest north ECWS position, whichever is less, a count of $0.0 \mathrm{~mm}$ precipitation values is made for each latitude band of the Appalachian Mountains Swath, moving from the north, to the southern extent of the Swath. These criteria were necessary because in determining whether an adjustment is 
needed, identifying areas of little or no precipitation, but not to the north of the storm or Mountains, was key. As for the $45.0^{\circ} \mathrm{N}$ criterion, it was felt if the storm were at or above that latitude, then the original PGL would perform an adequate job in identifying the gradient.

This procedure notes the coordinates of the grid point nearest to the AMWE line, within the first (northernmost) latitude band of the Swath having seven or more $0.0 \mathrm{~mm}$ precipitation values. This point is referred to as the Mountain Adjustment point. If all of the latitudes of the Appalachian Mountains Swath are searched and no Mountain Adjustment point exists, the assumption is that precipitation is occurring at some point in the Appalachian Mountains Swath at each latitude south of $45.0^{\circ} \mathrm{N}$ or the northernmost storm position, whichever is less. Given this band of precipitation occurring throughout the Appalachian Mountains Swath, the Mountain Adjustment point becomes $28.5^{\circ} \mathrm{N}, 95.0^{\circ} \mathrm{W}$. This coordinate is located southwest of the coast of southwestern Louisiana, and was chosen to include as much of the study domain to its north as possible in the adjustment process.

To see if an actual adjustment to the current PGL is needed, the proximity of the Mountain Adjustment point to the current gradient line is considered. If the Mountain Adjustment point is within a $1.0^{\circ}$ radius of the current PGL, then the PGL effectively identified precipitation in the vicinity of the Mountains because an area of no precipitation was found to be close to the current PGL. In this case, adjustment of the PGL is not necessary.

If the Mountain Adjustment point is greater than a $1.0^{\circ}$ radius from the current PGL, then it is possible that the PGL missed precipitation occurring in the vicinity of the Mountains. In this case, the PGL is adjusted. In Figures 3.12 and 3.13, for example, this may occur with an ECWS off the coast of New Jersey, with very little, if 
any, precipitation occurring along the coastal plain, but precipitation associated with the ECWS occurring in the mountains of West Virginia and western Maryland.

To adjust the PGL, the first point on the existing PGL to the west of the AMWE line, and north of the Mountain Adjustment point, is identified. This point is termed the Stop Mountain Adjustment point, for example in Figure 3.12. This point does not necessarily always exist, because all of the PGL points north of the Mountain Adjustment point may be to the east of the AMWE line, for example in Figure 3.13.

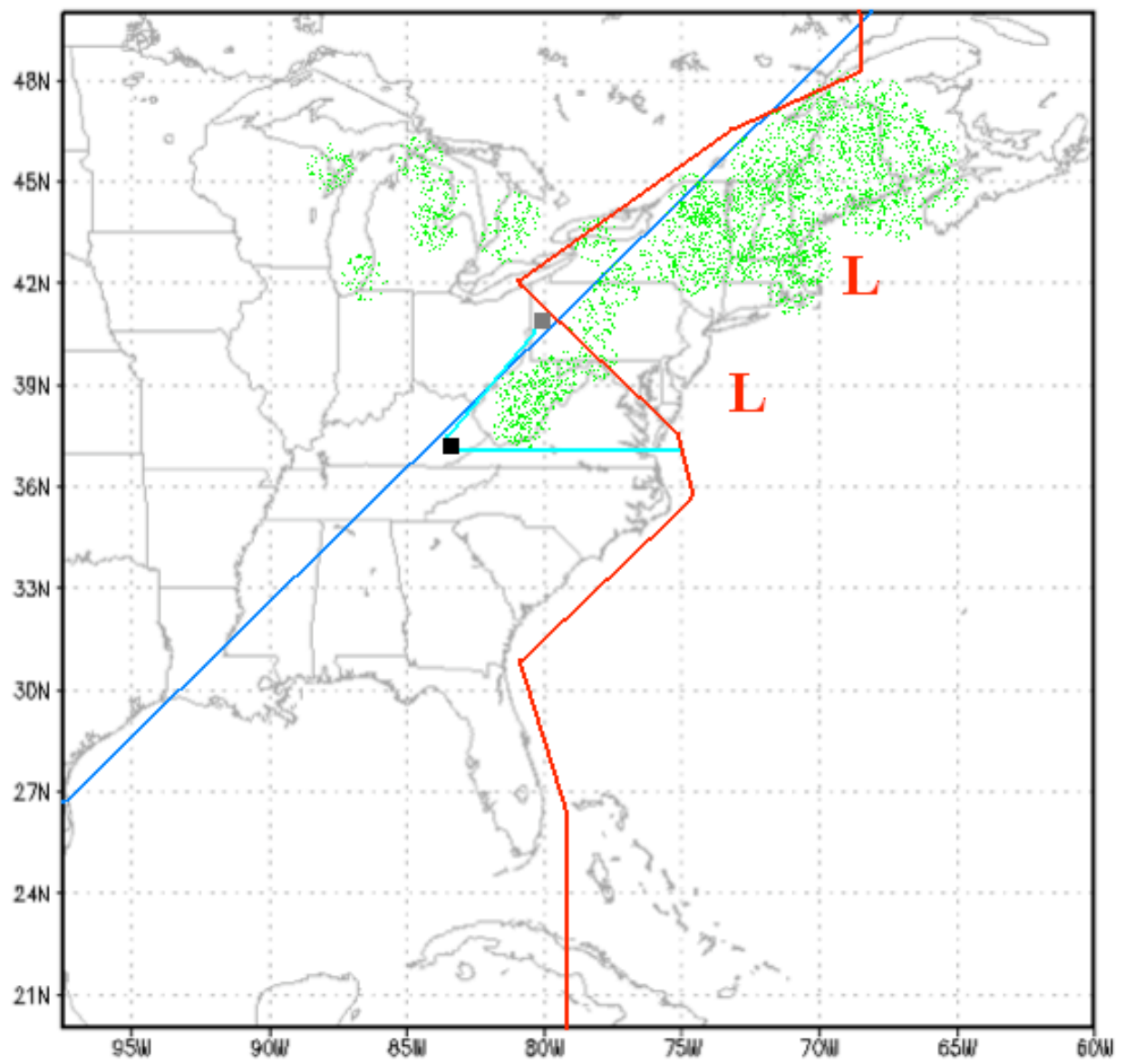

Figure 3.12: A hypothetical ECWS and idealized example of a scenario in which Mountain adjustment is needed, for the case where a Stop Mountain Adjustment point is found. The ECWS is approaching New England, with associated precipitation in green, and the AMWE line is in dark blue. The pre-adjustment precipitation gradient line is represented in red, with the Mountain Adjustment point in black, in eastern Kentucky. The Stop Mountain Adjustment point is in gray, in Western Pennsylvania, and associated adjustments to the precipitation gradient line are in light blue. 


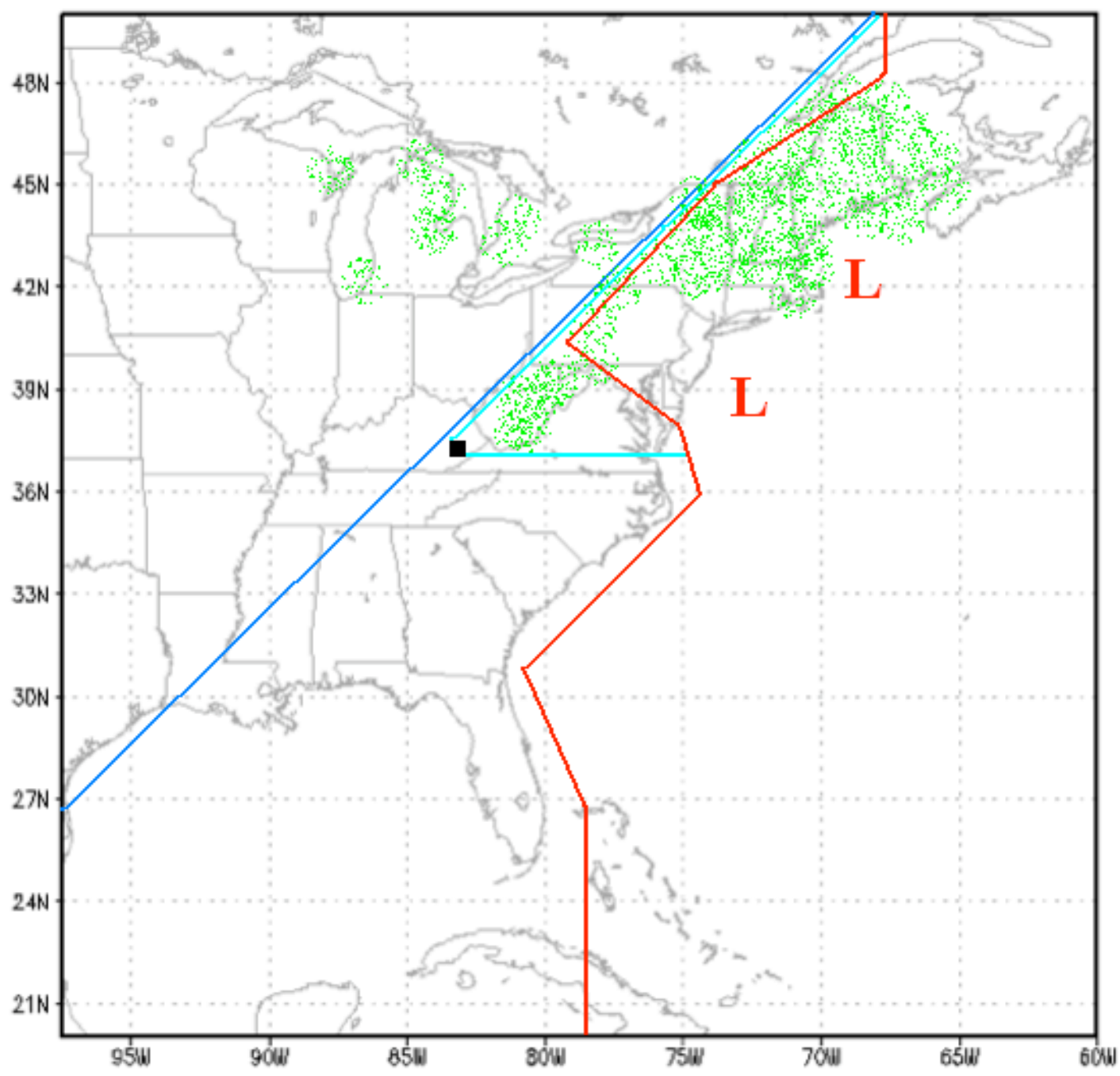

Figure 3.13: A hypothetical ECWS and idealized example of the Mountain Adjustment Needed scenario, for the case where a Stop Mountain Adjustment point is not found. The ECWS is approaching New England, with associated precipitation in green, and the AMWE line is in dark blue. The pre-adjustment precipitation gradient line is represented in red, with the Mountain Adjustment point in black, in eastern Kentucky. The adjustments to the precipitation gradient line are in light blue.

To make the actual adjustments to the PGL, all of the points south of the Mountain Adjustment point remain the same. The Mountain Adjustment point becomes a PGL point, replacing the old point on the PGL at that latitude. From the Mountain Adjustment point northward, the adjusted PGL follows the grid points closest to the AMWE line until it intersects the original PGL, at which point the 
original PGL remains unadjusted (e.g. Figure 3.12). If the adjusted PGL does not intersect the original, the adjusted PGL follows the AMWE line to the northern boundary of the study domain (e.g. Figure 3.13). These adjustments signal the occurrence of ECWS related precipitation within the Swath that the original PGL did not properly classify. This concludes the construction of the PGL for a storm day of an ECWS event. This PGL will be key in the ECWS precipitation and snowfall decision process and will be used to evaluate the presence of an additional storm and to develop the pressure gradient line.

\subsection{Identification of Additional Storms (non-ECWS)}

One of the components in determining ECWS precipitation and snowfall is assessing whether or not there is an additional storm(s) present during the ECWS event, and if so, on which days is the additional storm(s) impacting the study region. These additional storms can vary in classification and intensity from a vigorous southern plains storm formed in the lee of the Rocky Mountains, to a quick moving, light precipitation producing Alberta Clipper making its way across the Great Lakes. The intensity of any additional storm is not identified, nor does intensity factor into the decision process. If an additional storm is identified, a decision is made regarding areas impacted by the additional storm and areas not impacted. No distinction is made for COOP stations impacted for a portion of the day by the additional storm and impacted the remainder of the day by the ECWS. For each COOP station, if there was an additional storm present on a given day, the station either was or was not impacted for the entire day.

The first step in identifying the presence of an additional storm is to identify the maximum grid point interpolated precipitation value to the west of the PGL, and to identify the maximum grid point interpolated precipitation value to the east of the PGL. Grid points on the PGL were considered to be to the east of the PGL. If more 
than one maximum of the same precipitation value exists to either the east or the west of the PGL, all coordinates of these maxima were noted. The only criterion in finding these maxima was that the interpolated precipitation value had to be within the study region boundary and the value could not be in one of the four LES belts. Figure 3.14 shows the LES belts adopted from previous work by Norton and Bolsenga (1993) and Schmidlin (1993).

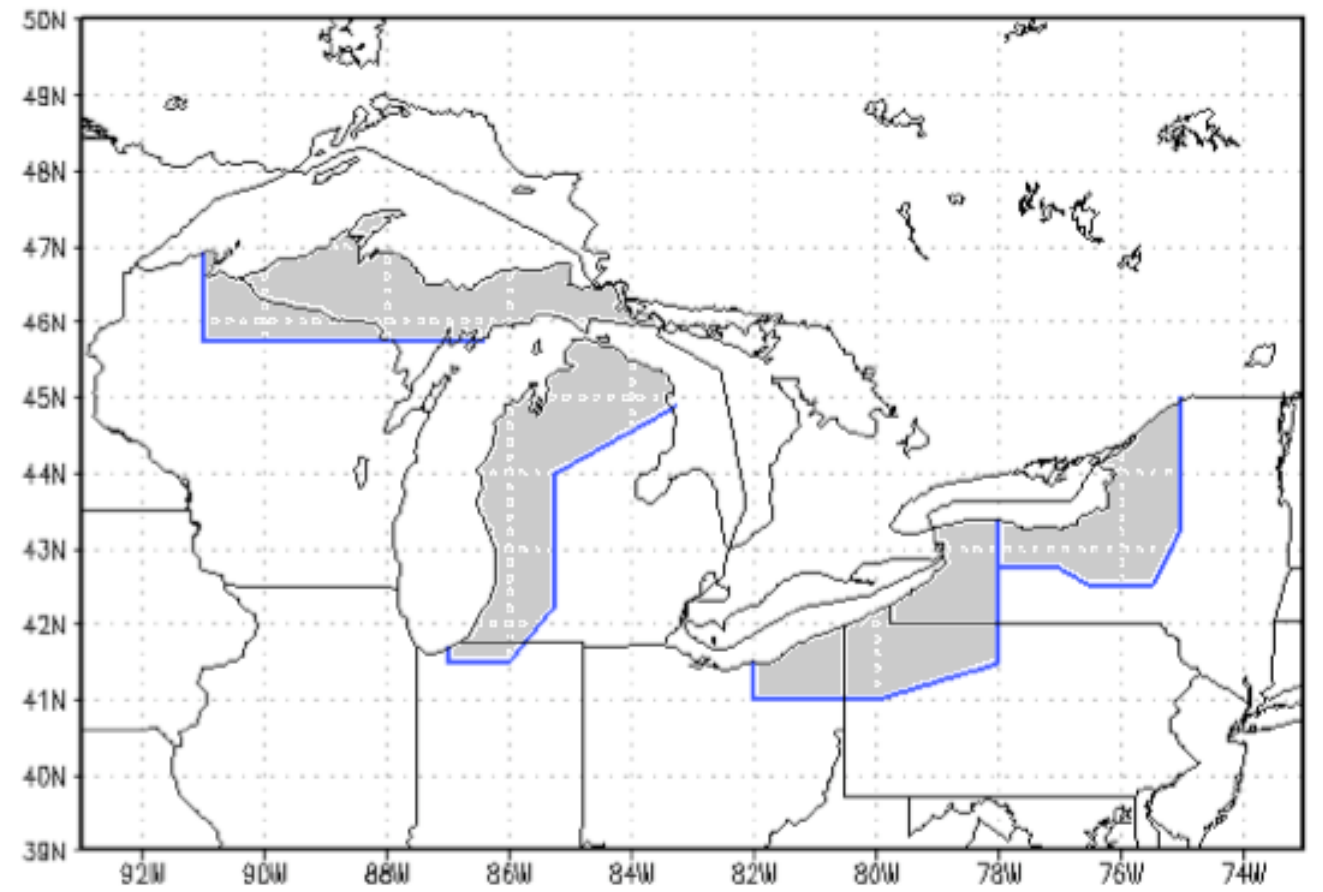

Figure 3.14: Lake Effect Snow Belts for the United States downwind of Lakes Superior, Michigan, Erie and Ontario. A Snow Belt downwind of Lake Huron was not necessary since Canadian stations were not included in this study.

The LES belts were primarily constructed from Norton and Bolsenga's Figure 2, “Average 1951-1980 Great Lakes seasonal snowfall” (1993), and from Schmidlin’s Figure 1, "The approximate area of the Lake Erie snowbelt (shaded) and mean annual snowfall (cm)" (1993), and these belts were constructed to include the majority of the areas downwind of the Great Lakes receiving 150-200 $\mathrm{cm}$ of snowfall or greater per season. The one exception to this rule was in the Adirondack Mountains, in New York, where the eastern edge of the Lake Ontario belt excludes an area of snowfall, to 
its east, which exceeds $400 \mathrm{~cm}$ per year (Norton and Bolsenga, 1993). It was felt this area of snowfall exceeding $400 \mathrm{~cm}$ per year east of the Lake Ontario belt was primarily the result of synoptic scale systems and topographic forcing associated with these synoptic scale systems, and not as much the result of LES. This contrasts with the neighboring Tug Hill plateau slightly to the west, which is highly influenced by LES, which is included in the belt. This boundary just described, which cuts through the area of snowfall exceeding $400 \mathrm{~cm}$ per year in upstate New York, runs approximately through Potsdam, NY to the south just to the east of Utica, NY.

The next step in identifying the presence of an additional storm was to locate the minimum pressure(s) to the west of the PGL. If more than one grid point was noted as the minimum pressure, each of these grid points were evaluated. Next the minimum pressure at this(these) grid point(s) is evaluated to determine if there is at least one closed isobar surrounding it. Regardless of if there were one, or more than one grid point to evaluate, the process is the same. The process used is similar to what Hirsch et al. (2001) use to identify a closed area of low pressure.

To determine if the minimum pressure is closed, the process begins by considering a square of grid points around the minimum pressure grid point. This square was $10.0^{\circ}$ by $10.0^{\circ}$, centered on the minimum pressure grid point. However, only points on this square within the study region boundary were considered, and thus not all squares necessarily contained the same number of grid points for analysis. If the number of grid points in the square that are at least $4 \mathrm{hPa}$ greater than the minimum pressure point, divided by the number of total non-missing grid points in the square, is 0.80 or greater, then a closed area of low pressure exists, and this low pressure is identified as an additional storm. Once the determination has been made as to whether or not an additional storm is present, the next step is to construct a pressure gradient line for each day of an ECWS event. 


\subsection{Pressure Gradient Line}

A useful tool in the decision process for ECWS snowfall and precipitation is the construction of a pressure gradient line to the west of the existing PGL. The pressure gradient line is used to signal where SLP begins to decrease while moving west of the PGL, and therefore west of the ECWS. The pressure gradient line represents maximums in SLP and attempts to identify areas of low pressure or areas where pressure is decreasing moving west of the PGL, which are not identified as an additional storm. These areas, which will be west of the pressure gradient line, may be troughs of low pressure, disorganized areas of low pressure, or low pressure associated with an additional storm too far from the study domain to be identified. Furthermore, the pressure gradient line is used as a supplemental tool in the decision process for ECWS precipitation and snowfall.

The first task in constructing the pressure gradient line is to generate lists of grid points and associated SLP values originating at each of the PGL points. These lists, termed potential sea level pressure gradient direction (PSGD) lists, are generated moving southwest, west, northwest and north, and in a similar manner to the PGD lists. These PSGD lists are generated for each $6 \mathrm{~h}$ UTC storm period defining each storm day of an ECWS event. From here, a three-part process occurs. First, potential pressure gradient points are identified for each PSGD list, where one or more points may be identified at each latitude for a $6 \mathrm{~h} \mathrm{UTC}$ storm period. Second, for each time period, at each latitude, the farthest east potential pressure gradient point is chosen. Third, using each of these points, and all of the $6 \mathrm{~h}$ UTC time periods defining that day, at each latitude, the farthest east potential pressure gradient point is chosen to build the pressure gradient line.

An automated routine finds one potential pressure gradient point for each

PSGD list. While the coordinates of points in the PSGD lists should remain the same 
for each $6 \mathrm{~h}$ UTC time period for each day, the SLP values will change for each time period. Within each PSGD list, potential pressure gradient points are identified by stepping through the SLP values moving away (westward) from the beginning point of the list. When considering each SLP value in the PSGD lists, binned pressures are used in a similar way to the precipitation values earlier. Table 3.5 details this binning process for SLP values.

Only grid points within the portion of the PSGD list to the west side of the PGL are evaluated. Even though all of the PSGD lists originate at the PGL, it is possible, particularly with a PSGD list moving north, for points within the PSGD list to be on the east side of the PGL at some point. Likewise, only grid points within the PSGD list to the west of the ECWS position are considered. This condition minimizes SLP decreases associated with the ECWS, being incorrectly identified for potential pressure gradient points.

As the routine moves through the PSGD list, the search is for grid points where SLP values are decreasing. If there are two consecutive decreases in SLP, then a potential pressure gradient point is noted. The only instance where the decreases in SLP do not need to be consecutive is when the SLP in between the decreases is constant. For example, if the following grid points and SLP values (hPa) were moved through, by the routine, $1012.0,1008.0,1008.0,1008.0,1004.0$, a potential pressure gradient point would be noted. However, if the following grid points and SLP values (hPa) were moved through, 1012.0, 1008.0, 1012.0, 1008.0, a potential pressure gradient point would not be noted. In this situation, while two decreases occurred in grid points within a close proximity, they were not consecutive and there was a pressure increase separating the decreases. In addition, the two consecutive decreases must not be separated by missing data, a value outside of the study region boundary, or a value to the east of the PGL. 
Table 3.5: Binned SLP values in automated routine determining pressure gradient coordinates. All values are in hectopascals (hPa).

\begin{tabular}{|c|c|c|}
\hline $\begin{array}{c}\text { Initial SLP Value Greater } \\
\text { Than or Equal To }\end{array}$ & $\begin{array}{c}\text { Initial SLP Value Less } \\
\text { Than } \\
\end{array}$ & Binned SLP Value \\
\hline- & 958.0 & 956.0 \\
\hline 958.0 & 962.0 & 960.0 \\
\hline 962.0 & 966.0 & 964.0 \\
\hline 966.0 & 970.0 & 968.0 \\
\hline 970.0 & 974.0 & 972.0 \\
\hline 974.0 & 978.0 & 976.0 \\
\hline 978.0 & 982.0 & 980.0 \\
\hline 982.0 & 986.0 & 984.0 \\
\hline 986.0 & 990.0 & 988.0 \\
\hline 990.0 & 994.0 & 992.0 \\
\hline 994.0 & 998.0 & 996.0 \\
\hline 998.0 & 1002.0 & 1000.0 \\
\hline 1002.0 & 1006.0 & 1004.0 \\
\hline 1006.0 & 1010.0 & 1008.0 \\
\hline 1010.0 & 1014.0 & 1012.0 \\
\hline 1014.0 & 1018.0 & 1016.0 \\
\hline 1018.0 & 1022.0 & 1020.0 \\
\hline 1022.0 & 1026.0 & 1024.0 \\
\hline 1026.0 & 1030.0 & 1028.0 \\
\hline 1030.0 & 1034.0 & 1032.0 \\
\hline 1034.0 & 1038.0 & 1036.0 \\
\hline 1038.0 & 1042.0 & 1040.0 \\
\hline 1042.0 & - & 1044.0 \\
\hline
\end{tabular}


The coordinates of the grid point of the first decrease are assigned to the potential pressure gradient point. For example, if the grid points or SLP values (hPa) were the following: $1000.0,996.0,992.0$, then the potential pressure gradient point would have the coordinates of the grid point containing the value of 996.0. For each PSGD list, the first instance of two consecutive SLP decreases is signaled as the potential pressure gradient point. If the entire PSGD list is evaluated, and there are no instances of two consecutive SLP decreases, then the potential pressure gradient point becomes the grid coordinates of the last non-missing SLP value within the study region boundary.

After all of the potential pressure gradient points are developed for a $6 \mathrm{~h} \mathrm{UTC}$ time period of a storm day, then for each latitude, one potential pressure gradient point is selected by taking the farthest east point. However, not all latitudes will necessarily have a potential pressure gradient point at first, due to missing data, for example. Next, all of the potential pressure gradient points for each $6 \mathrm{~h}$ UTC time period constituting a day of an ECWS event are considered, where the farthest east point is selected at each latitude to make up the pressure gradient line for that day. Once the coordinates of the pressure gradient line have been established, a simple smoothing and filling procedure is applied identical to the technique applied to the PGL. The filling procedure is needed because not all latitudes may have a pressure gradient point. Once this smoothing and filling technique is applied, the pressure gradient line is complete for that day and will consist of 61 coordinates, one for each latitude of the study domain. This pressure gradient line will be used as a supplemental component of the ECWS precipitation and snowfall decision making process.

\subsection{Classification of LES}

The LES belts depicted in Figure 3.14 were used to determine whether a COOP station was receiving LES during an ECWS and therefore, snowfall not from 
the ECWS. Only the snow COOP stations were considered when determining whether or not a station was receiving LES. If the coordinates of these snow COOP stations fell within one of these LES belts, the wind direction from the nearest ICAO station, during each $6 \mathrm{~h}$ UTC time period defining a day of an ECWS event, was considered to determine if LES was impacting the station for that day. Due to a storm day being defined as longer than $24 \mathrm{~h}$, LES favorable winds associated with a departing ECWS may prematurely signal the occurrence of LES. The possibility of Lake Effect Rain was not considered.

The reasoning behind this assumption deals with instability and the difference in temperature between the lake surface and the air, particularly at $850 \mathrm{hPa}$. In general, to have an environment conducive to LES, or what is termed "pure" LES, the temperature at $850 \mathrm{hPa}$ should be at least $13^{\circ} \mathrm{C}$ colder than the lake surface, which is basically the dry adiabatic lapse rate over this distance (Holroyd, 1971 and Niziol, 1987). Considering previous research by the National Weather Service (NWS) Forecast Office in Buffalo, NY for Lake Erie, the stable season is from roughly early March to late July where the air temperature is warmer than the lake surface (NWS Buffalo - Lake Effect Seasons, 2008). Another way to consider the stable season is to note that the difference between lake surface temperature and air temperature at 850 hPa may not be great enough to generate the instability associated with LES events (NWS Buffalo - Lake Effect Seasons, 2008). In contrast, from late July to early March, the lake surface temperature is generally warmer than the air temperature (NWS Buffalo - Lake Effect Seasons, 2008). This situation may result in lake effect precipitation when the lake is not frozen, particularly when the difference between lake surface temperature and air temperature at $850 \mathrm{hPa}$ is enough to promote instability and a steep lapse rate (NWS Buffalo - Lake Effect Seasons, 2008). LES is possible from mid to late October until the lake freezes, whereas Lake Effect Rain is 
possible from late July to mid to late October (NWS Buffalo - Lake Effect Seasons, 2008).

Based on this research, and based on the fact that ECWS in the climatology only occur from October through April, it was felt ignoring Lake Effect Rain altogether was a reasonable assumption, because most if any occurrences of Lake Effect Rain would occur in October. Beyond October, the assumption was made that lake surface temperatures would be too cool, relative to the warmer air temperatures needed for rain, thereby producing a stable, non-Lake Effect situation. Table 3.6 shows the wind directions for each LES belt where a COOP station was concluded to be influenced by LES if a nearby ICAO station had this wind direction. This table also shows the number of COOP stations in each LES belt.

Table 3.6: Wind direction criteria used when determining whether or not a COOP station within a LES belt was influenced by LES and the number of COOP stations within each LES belt.

\begin{tabular}{|l|l|l|l|}
\hline \multicolumn{1}{|c|}{ LES Belt } & \multicolumn{1}{|c|}{$\begin{array}{c}\text { Wind direction greater } \\
\text { than or equal to }\end{array}$} & $\begin{array}{c}\text { Wind direction less } \\
\text { than or equal to }\end{array}$ & $\begin{array}{c}\text { Number of COOP } \\
\text { stations within belt }\end{array}$ \\
\hline Superior & $292.5^{\circ}$ & $67.5^{\circ}$ & 51 \\
\hline Michigan & $270.0^{\circ}$ & $337.5^{\circ}$ & 53 \\
\hline Erie & $202.5^{\circ}$ & $337.5^{\circ}$ & 71 \\
\hline Ontario & $270.0^{\circ}$ & $337.5^{\circ}$ & 49 \\
\hline
\end{tabular}

There were 224 COOP stations within the four LES belts and there were two scenarios considered for determining whether or not LES was occurring. The first scenario is termed "one period". If the COOP station has a nearby ICAO station wind direction meeting LES criteria as described in Table 3.6 for at least one $6 \mathrm{~h} \mathrm{UTC}$ period defining that storm day, then LES was considered to be possible and therefore no ECWS snowfall or precipitation was included in the climatology for that station for that day. The second scenario is termed "half period". If the COOP station has a 
nearby ICAO station wind direction meeting LES criteria for more than half of the $6 \mathrm{~h}$ UTC periods defining that day, then LES was considered to be possible, and therefore at that station no ECWS snowfall or precipitation was included in the climatology for that day. The one exception in the "half period" scenario was for a day consisting of only two $6 \mathrm{~h}$ UTC periods. In this situation, if at least one period met LES criteria, LES was considered possible. Certainly these methods are not perfect. The classification of a mesoscale event such as LES, using low resolution spatial and temporal data, is an extremely difficult task. Ideally, a combination of radar, upper air data, including temperature, wind speeds and direction, lake surface temperatures, including ice cover, snow to liquid ratios, and the chemical composition of the melted liquid precipitation, would be needed to more accurately classify LES during an ECWS event.

\subsection{Classifying ECWS Snowfall and Precipitation - Decision Process}

To determine whether the snowfall or precipitation at a COOP station is from the ECWS or some other source, the precipitation gradient line, the possibility of an additional storm and its location, relationships between precipitation maxima, the pressure gradient line, and the LES belts are used. Figure 3.15 details this decision process. The strengths and weaknesses of this decision process, and its associated components, will be discussed in a later section of this chapter, including examples from some of the ECWS case studies. 


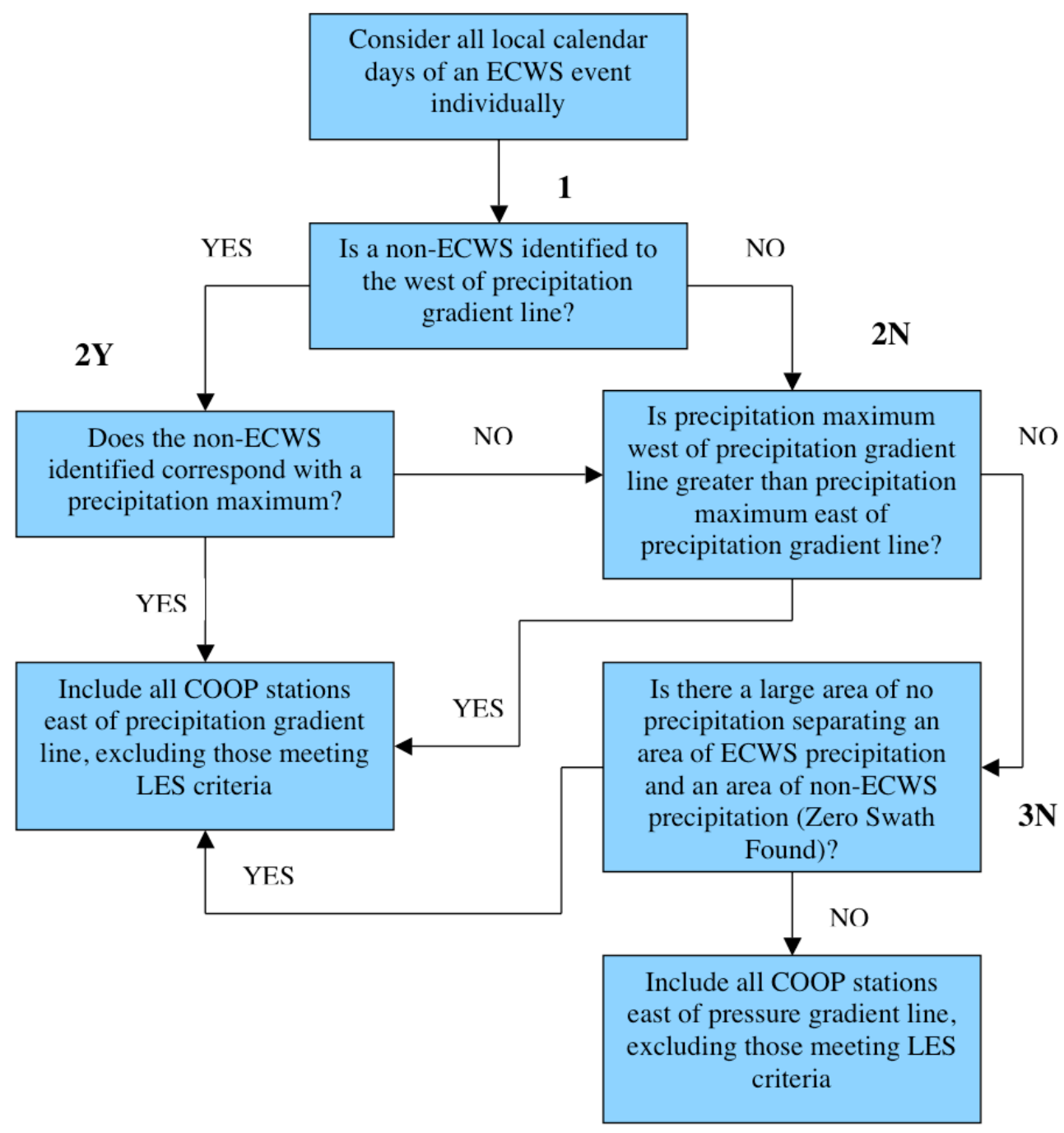

Figure 3.15: The decision process for determining ECWS snowfall and precipitation for each day of an ECWS event.

The first component addressed in the decision making process is whether an additional storm has been identified (e.g. Box 1 in Figure 3.15). For an additional storm to be considered present, the criteria need to be met in at least one $6 \mathrm{~h} \mathrm{UTC}$ period defining that day. If there is an additional storm present, the proximity of this storm to a precipitation maximum is established. Each day of an ECWS event, the precipitation maxima to the east and west of the PGL are noted. Multiple maxima may exist to each side of the line, so long as they are the same value. However, maxima within LES belts were not considered. The distance from the additional storm 
to the maximum or maxima west of the PGL is noted for each $6 \mathrm{~h} \mathrm{UTC}$ period that an additional storm is present. If during at least one of these $6 \mathrm{~h}$ UTC periods, the additional storm is within an $8.0^{\circ}$ radius of at least one of the precipitation maxima, then the additional storm corresponds with a precipitation maximum. When this is the case (e.g. answering "yes" to box $2 \mathrm{Y}$ in Figure 3.15), then the decision is to include all COOP stations not meeting LES criteria to the east of the PGL in the ECWS precipitation climatology for that day. For all of the decision process, COOP stations on the decision line used (PGL or pressure gradient line) were included. The $8.0^{\circ}$ radius was chosen based on the ECWS case studies and general knowledge of midlatitude extratropical storms, such as allowing for associated frontal boundaries. While the methods in this study do not directly identify frontal boundaries, they do allow for precipitation maxima along a boundary to be associated with an additional storm.

Referring to Figure 3.15, when the answer to box $2 \mathrm{Y}$ is "no" or when the answer to box 1 is "no", a comparison of the precipitation maxima on each side of the PGL is made. In the event the maxima on each side are equal, the west maximum is considered higher. As Figure 3.15 illustrates, if this west precipitation maximum is higher, than the decision is to include in the climatology all COOP stations not meeting LES criteria to the east of the PGL for that day (e.g. answering "yes" to box $2 \mathrm{~N})$. If however, the west precipitation maximum is lower, an additional step is considered (e.g. answering "no" to box 2N in Figure 3.15).

The basis of this additional step is a Zero Swath Evaluation. From the case studies of ECWS, it became apparent there might be situations where an additional storm was not identified, and the precipitation maximum to the east of the PGL was higher than the west. Prior to the development of the Zero Swath Evaluation, the process was to include all COOP stations to the east of the pressure gradient line in the 
climatology. However, considering the hypothetical ECWS in Figure 3.16, the precipitation along and to the west of the Mississippi River would be erroneously included in the climatology. Clearly in Figure 3.16 there are two distinct areas of precipitation, yet the assumption is an additional storm is not identified. Therefore, the Zero Swath Evaluation was implemented as an additional step attempting to identify these two distinct areas of precipitation and to preferentially use the PGL in the decision process.

From the hypothetical ECWS in Figure 3.16, which provides an example of the Zero Swath Evaluation, the storm is approaching New England with associated precipitation shaded in green. Assume the precipitation along and west of the Mississippi River is associated with an additional storm ejecting from the Rocky Mountains, and too far west of the study domain to be identified. Further assume the pressure gradient line in blue does not identify any decreases in SLP until west of the Mississippi River in some places. Because of the ECWS precipitation and snowfall decision process, this precipitation in Missouri and Arkansas may be erroneously included in the climatology without the Zero Swath Evaluation. The black dots in Figure 3.16 represent Zero Swath Flag coordinates. If enough of these coordinates exist, the algorithm signals an additional distinct area of precipitation, i.e. in Missouri and Arkansas, associated with an unidentified additional storm, and the ECWS precipitation and snowfall decision process then reflects this. Hereinafter, unidentified additional storms refer to non-ECWS storms the automated procedure did not identify. 


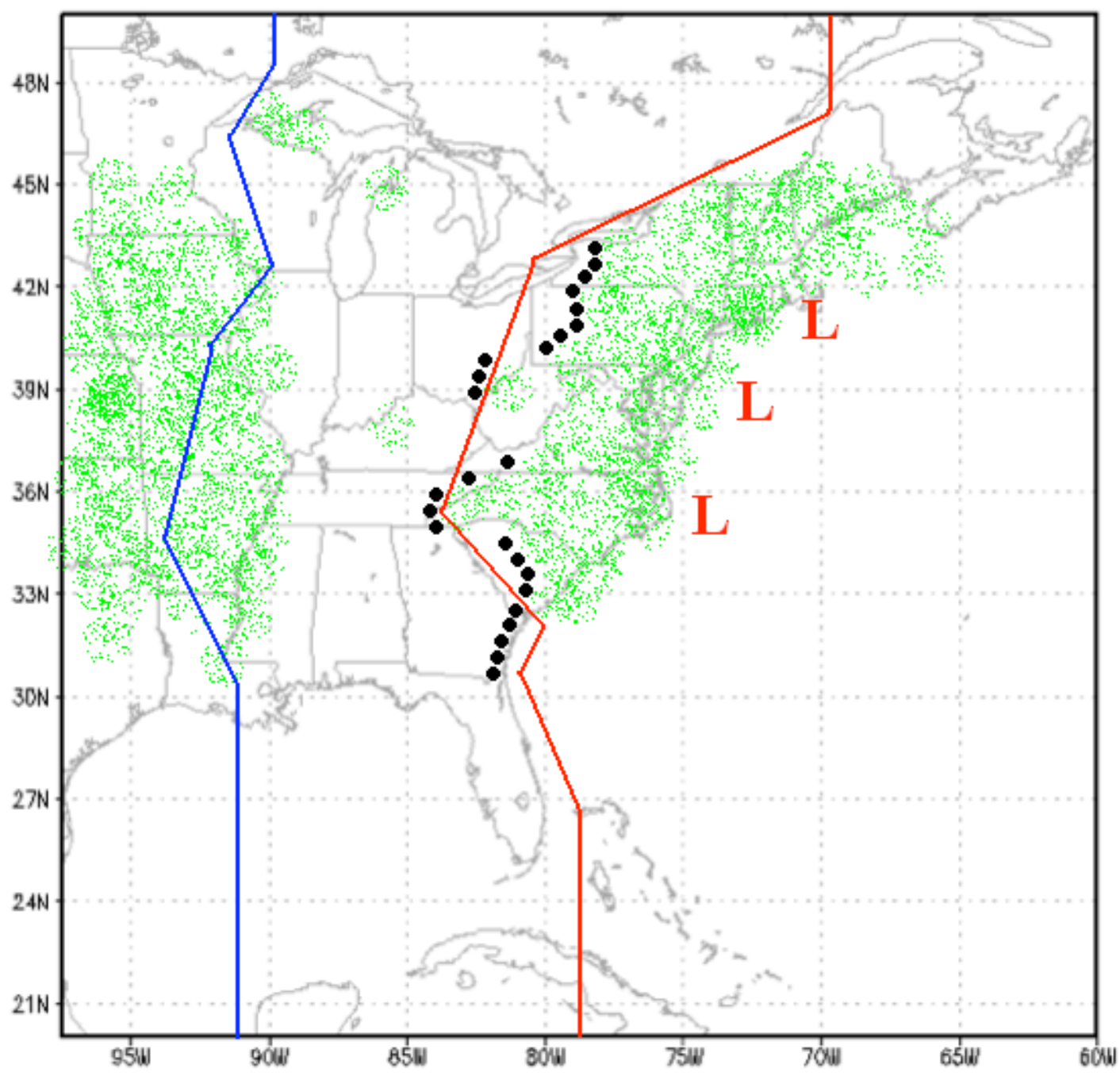

Figure 3.16: A hypothetical ECWS and idealized example of the special case, Zero Swath Evaluation. The ECWS is approaching New England, with associated precipitation in green. Precipitation from an unidentified additional storm west of the study domain is also shaded green along the Mississippi River and west. A hypothetical precipitation gradient line is represented in red, with a hypothetical pressure gradient line in blue. Zero Swath Flag coordinates are represented in black.

To signal whether this additional area of precipitation beyond the Zero Swath Flags should not be included as ECWS precipitation, the latitudes of the Zero Swath Flag coordinates are used. If $60 \%$ or more latitudes within an $8.0^{\circ}$ latitude band contain a Zero Swath Flag, then the algorithm denotes this day as Zero Swath Found. Using Figure 3.16 as an example, the algorithm may consider the latitudes from $30.0^{\circ}$ 
$\mathrm{N}$ to $38.0^{\circ} \mathrm{N}$. If $60 \%$ of the latitudes in this band contain a Zero Swath Flag, the Zero Swath Found criterion is met. Based on Figure 3.16, this is likely. The algorithm will also check all remaining $8.0^{\circ}$ latitude bands (i.e. $30.5^{\circ} \mathrm{N}$ to $38.5^{\circ} \mathrm{N}, 31.0^{\circ} \mathrm{N}$ to $39.0^{\circ} \mathrm{N}$, and so on). However, since each band is $8.0^{\circ}$, the farthest north starting latitude for performing this check is $42.0^{\circ} \mathrm{N}$, as the study domain only extends to $50.0^{\circ} \mathrm{N}$. This band of $8.0^{\circ}$ was chosen as a large enough area to assess the presence of an additional area of precipitation. The $60 \%$ was chosen to avoid identifying widely scattered areas of precipitation, and to identify more concentrated areas of additional storm precipitation. In addition, $8.0^{\circ}$ and $60 \%$ were chosen based on analysis of ECWS case studies.

Referring to Figure 3.15, when an additional storm has not been identified (e.g. "no" for box 1), and when the west precipitation maximum is less than the east maximum (e.g. "no" for box $2 \mathrm{~N}$ ), and the Zero Swath Found criteria are met in the Zero Swath Evaluation (e.g. "yes" for box $3 \mathrm{~N}$ ), then the decision is to include in the climatology all COOP stations not influenced by LES to the east of the PGL. However, in the same situation when Zero Swath Found criteria are not met (e.g. "no" for box $3 \mathrm{~N}$ in Figure 3.15), the decision is to include in the climatology any COOP station not influenced by LES to the east of the pressure gradient line. To determine the COOP stations included in the bomb climatology, the analysis is handled in the exact same way as just described for ECWS.

\subsection{Classifying ECWS Snowfall and Precipitation - Examples}

Following are examples from individual days of ECWS considered in the case studies and an explanation of the ECWS decision process and how this process applies to each example. Nine of the examples are from the first twenty case studies considered, and two examples are from the ten independent verifications. These examples were selected to show both the strengths and the weaknesses of the ECWS 
decision process applied in this study and to represent each of the seven decision scenarios.

The first four scenarios and corresponding examples deal with the situation in which an additional storm is identified by the algorithm to the west of the PGL. Scenario 1: An additional storm is identified to the west of the PGL and with a nearby corresponding maximum in precipitation. This scenario results in the selection of only COOP stations to the east of the PGL as those stations included in the climatology for that day. Figure 3.17 shows an example of this situation from a 1970 ECWS on 2 November. This example is from one of the storms selected for independent verification. Not depicted in the figure, the algorithm identifies two additional storms for this day, one near Minnesota and Wisconsin and the other in the Ohio Valley. These additional storms are primarily responsible for the majority of the precipitation across the study region. Precipitation directly from the ECWS appears to be confined primarily to the east coast. Since at least one of these additional storms corresponds with a precipitation maximum to the west of the PGL, the decision is to only include COOP stations to the east of the PGL in the climatology. In this example, this results in a reasonable decision because precipitation amounts in any questionable areas, such as in central Pennsylvania and northwestern Georgia, are very small. Overall, this example represents a good decision by the automated procedure. 


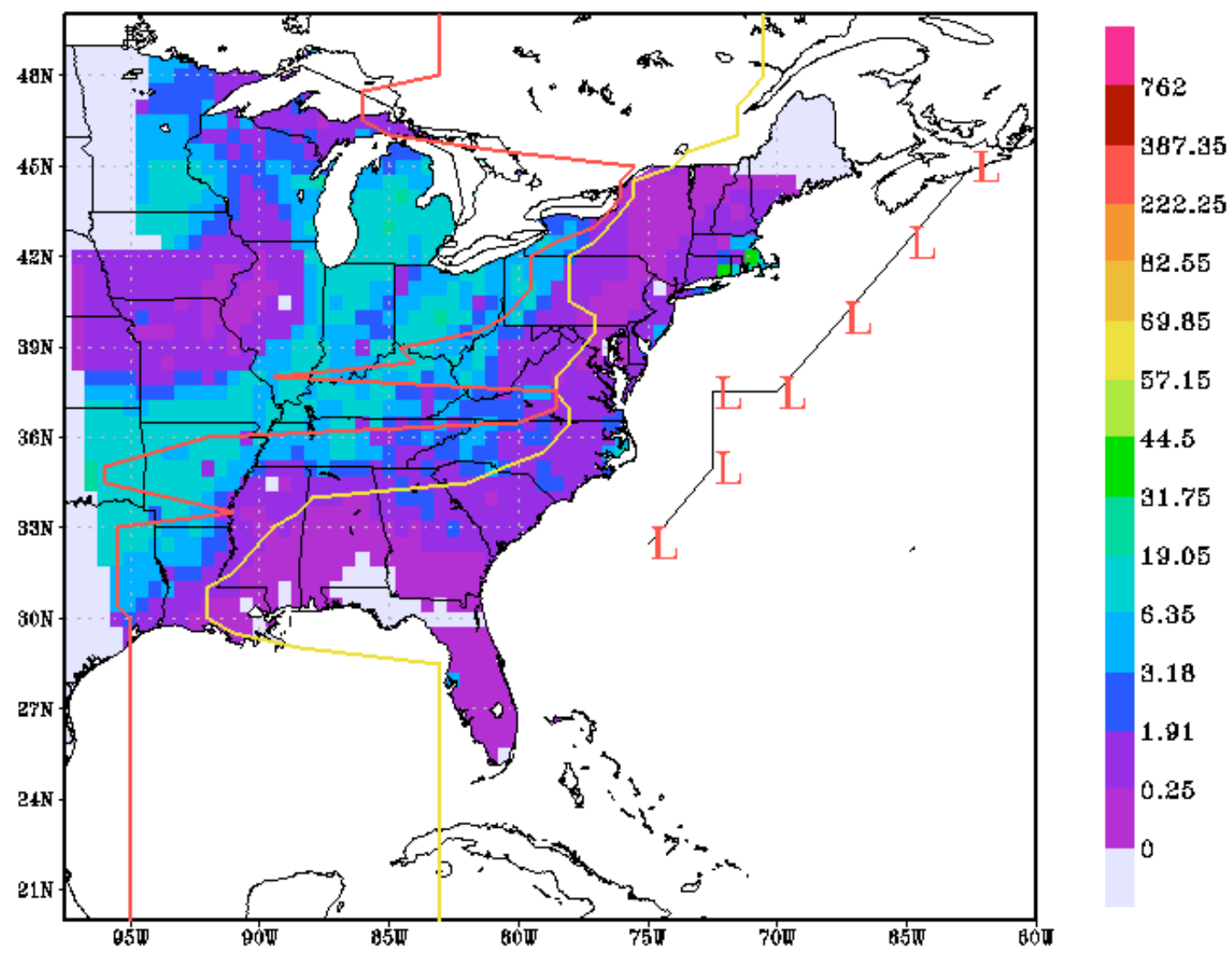

Figure 3.17: An ECWS from 2 November 1970 and an example from Scenario 1 in the ECWS precipitation decision process. The L denotes the ECWS track for the $6 \mathrm{~h}$ periods defining that storm day. The shaded regions represent $24 \mathrm{~h}$ precipitation $(\mathrm{mm})$ from the COOP stations interpolated to the evenly spaced $0.5^{\circ}$ resolution grid. The precipitation gradient line (yellow) and the pressure gradient line (red) are shown.

An example where the automated procedure does not perform as well for this situation, is from a 1952 ECWS on 29 February. This particular ECWS was longlived, lasting from 26 February to 1 March. While the algorithm performed reasonably for the entire duration of the event, 29 February is an example where too much non-ECWS precipitation was included in the climatology, particularly in central Pennsylvania and the Carolinas. Figure 3.18 shows this situation on 29 February. 


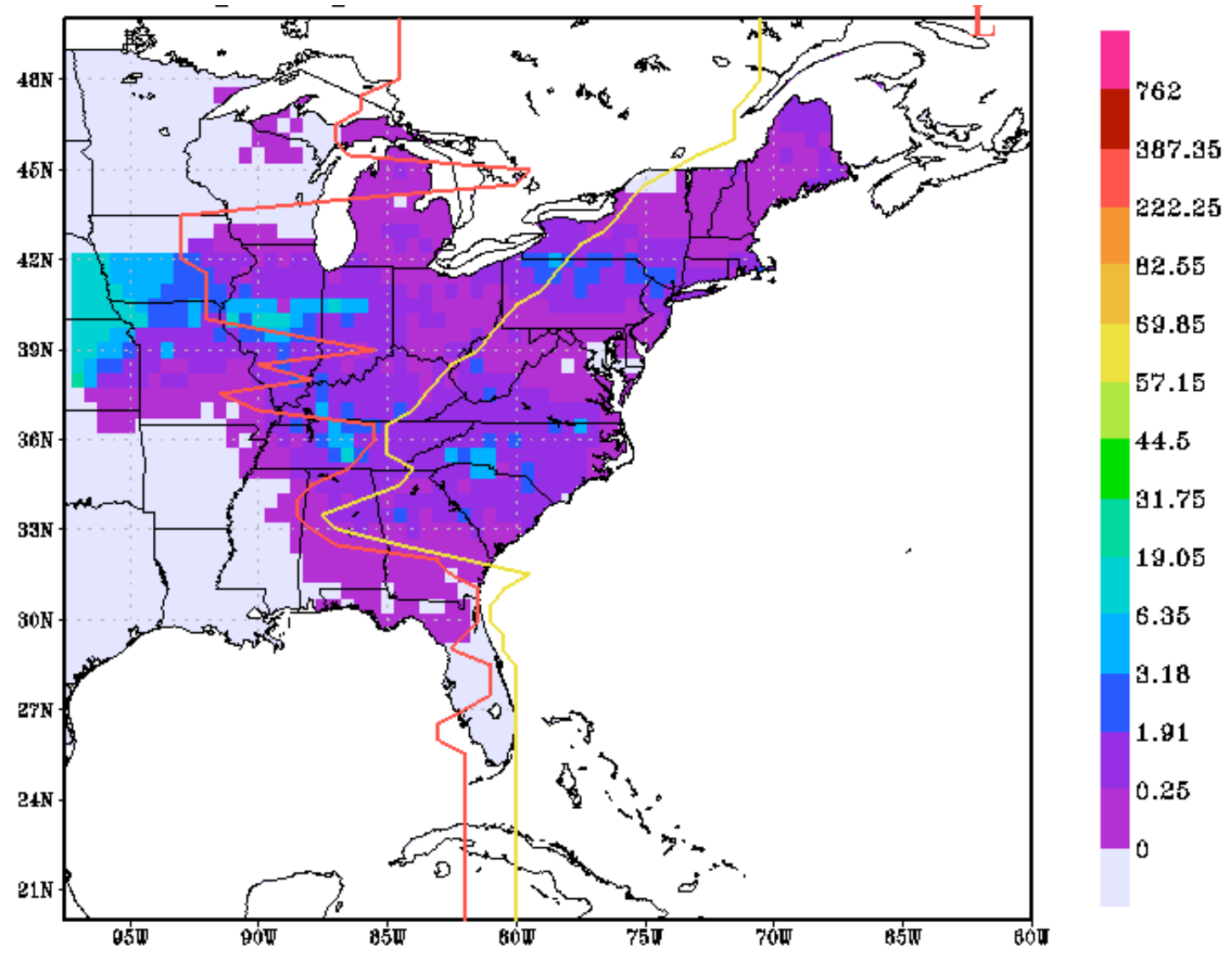

Figure 3.18: An ECWS from 29 February 1952 and an example of Scenario 1 in the ECWS precipitation decision process. Lines and shading information are the same as Figure 3.17.

On this day, as the ECWS is exiting the study area moving into the Canadian Maritimes, an additional storm is traversing almost due East through Maryland and into Delaware with an associated warm front extending east and a trailing cold front. The algorithm does not identify this feature as an additional storm because it is to the east of the PGL. Unfortunately, in this example, the PGL fails to identify the desired precipitation gradient. The only ECWS precipitation on this day is essentially confined to northern New England and Maine. This example illustrates a weakness of this automated procedure in that it has a difficult time identifying subtle precipitation gradients, particularly when an additional storm is in close proximity to the ECWS. Nonetheless, the decision for this example does exclude all of the precipitation west of the Appalachian Mountains. 
Scenario 2: An additional storm is identified to the west of the PGL, without a nearby corresponding maximum in precipitation, and the precipitation maximum to the west of the PGL is higher than the maximum to the east of the line. This scenario results in the selection of only COOP stations to the east of the PGL as those stations included in the climatology for that day. Figure 3.19 shows an example of this scenario from a 1962 ECWS on 18 November. This ECWS lasted from 18 to 19 November and originated in eastern Virginia downstream of a $500 \mathrm{hPa}$ trough located over the southern Central Plains. This example illustrates mediocre performance of the automated procedure and decision process. The difficulty arises with a trailing frontal boundary from the ECWS, and by early in the day local time on 18 November, a wave and additional area of low pressure develops in Alabama along this frontal boundary. Whether or not this additional area of low pressure is energy associated with the ECWS or is a separate entity and therefore an additional storm is a somewhat subjective decision. This additional low pressure tracks right along the trailing frontal boundary of the ECWS and in close proximity to the ECWS through 19 November. However, its track is too far east to be classified as an ECWS. Nonetheless, Figure 3.19 shows the two main areas of precipitation excluded from the ECWS precipitation climatology for this day are in northern Pennsylvania and central and western NY, as well as areas along the Mississippi River in Arkansas, Missouri and just to the east. The first area, in New York and Pennsylvania could be associated with a departing additional storm from the previous day. 


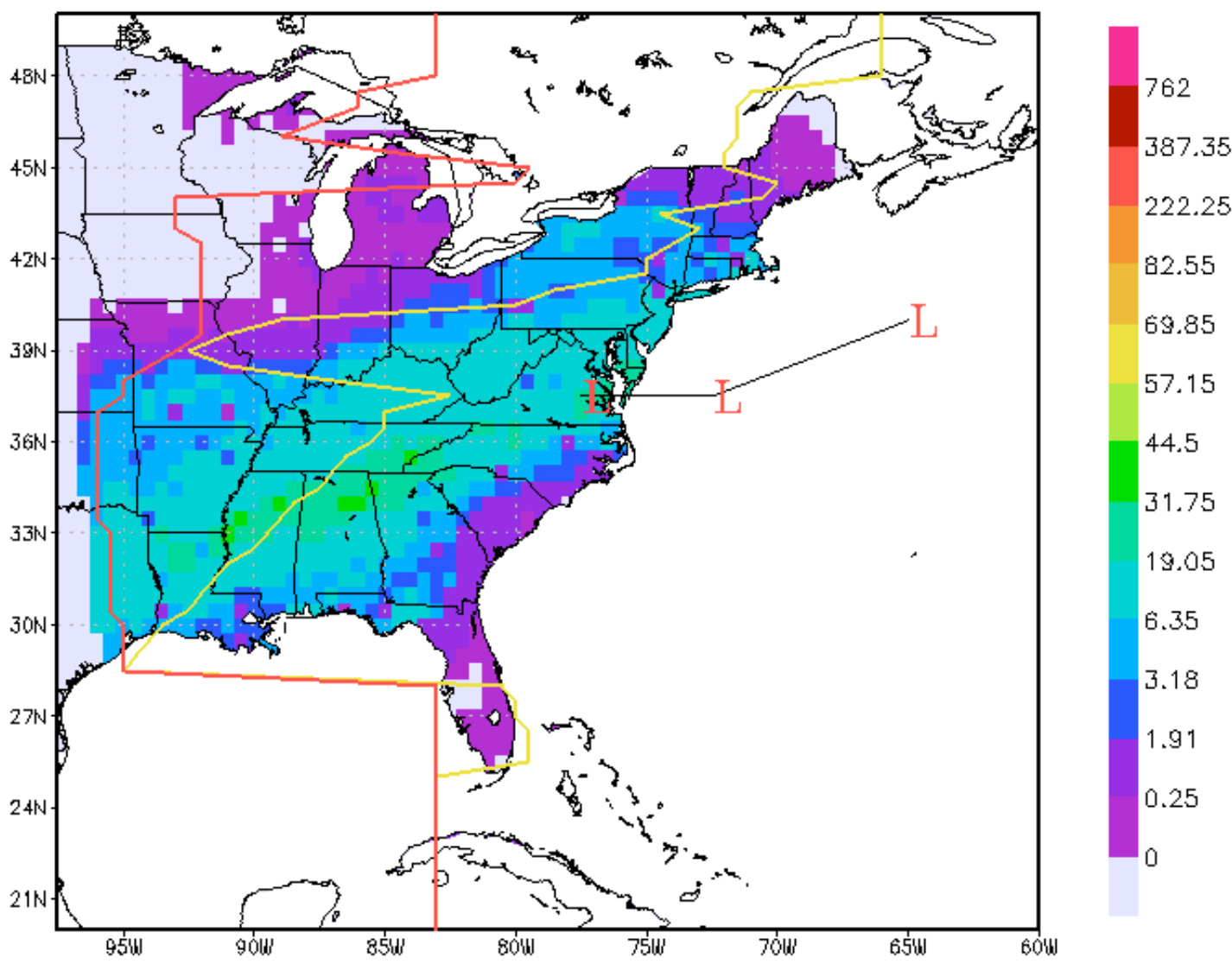

Figure 3.19: An ECWS from 18 November 1962 and an example of Scenario 2 in the ECWS precipitation decision process. Lines and shading information are the same as Figure 3.17.

This departing storm is not identified, likely because the storm either filled and/or was too far from the study domain by 18 November 1962 at 18Z, which was the beginning of the ECWS. So the exclusion of this precipitation in New York and Pennsylvania is satisfactory. The exclusion of the second area of precipitation near the Mississippi River is far more subjective. This precipitation is likely associated with the secondary cyclone developing along the trailing cold front associated with the ECWS. The PGL is placed through central Mississippi, depicted in Figure 3.19. Classification of this entire area of precipitation is subjective, so from that standpoint, the PGL and the decision process is satisfactory in this example.

Scenario 3: An additional storm is identified to the west of the PGL without a corresponding nearby maximum in precipitation. Furthermore, the maximum in 
precipitation to the west of the PGL is less than the maximum to the east of the line. However, there is a large swath of no precipitation identified, from the Zero Swath Evaluation (e.g. Zero Swath Found criteria are met). The decision in this scenario is to include only COOP stations to the east of the PGL in the climatology for that day. Figure 3.20 is an example of this scenario from a 3 April 1952 ECWS. This event lasted from 2 to 3 April, and snowfall was primarily confined to parts of the northern Appalachians, the Great Lakes and New England.

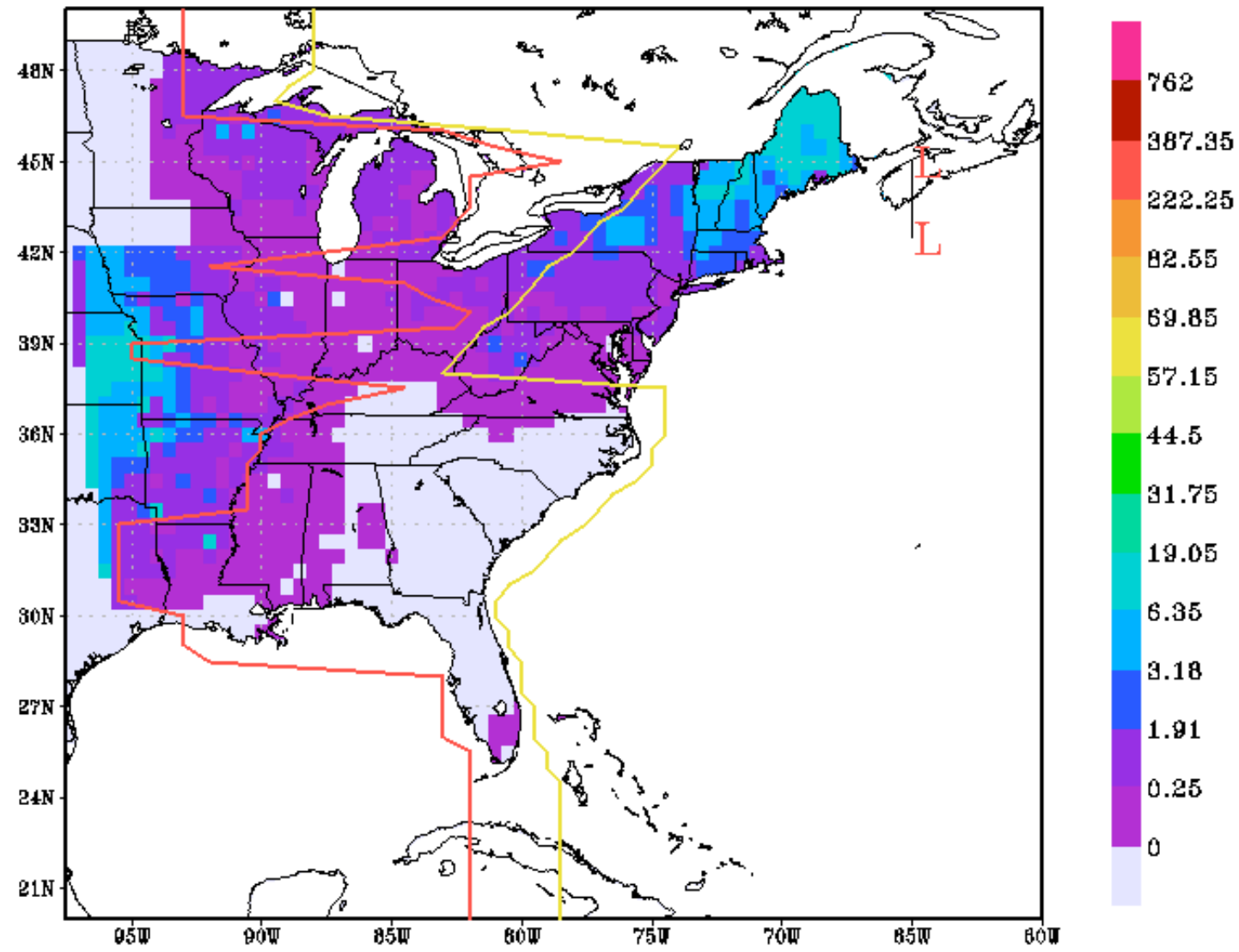

Figure 3.20: An ECWS from 3 April 1952 and an example of Scenario 3 in the ECWS precipitation decision process. Lines and shading information are the same as Figure 3.17.

On this day, an additional storm is identified, which is present over Lake Huron and Lake Superior. Not identified, because it is too far from the study domain is an approaching additional storm from New Mexico and western Texas. Although, the pressure gradient line does seem to signal some approaching decreases in SLP in 
Arkansas and Missouri possibly associated with this feature. Therefore, the area of precipitation to the west of the Mississippi River in Arkansas and Missouri is likely the result of this approaching additional storm. The precipitation across the majority of the Great Lakes is then likely associated with the identified additional storm. Therefore, the automated procedure performs well on this particular day, only including precipitation from the Appalachians Mountains in West Virginia and points north and east, as precipitation directly from the ECWS.

Scenario 4: The final scenario where an additional storm is identified to the west of the PGL. This additional storm is identified without a corresponding nearby precipitation maximum and the precipitation maximum to the west of the PGL is lower than the maximum to the east of the line. However, in this situation, a large area of no precipitation is not identified (e.g. Zero Swath Found criteria are not met). The decision for this scenario is to include only COOP stations to the east of the pressure gradient line in the ECWS precipitation climatology for that particular day. The first example of this scenario is from a 7 April 1982 ECWS, which lasted from 6 to 8 April. This storm was also selected and described in Kocin and Uccellini's (1990) book on snowstorms along the east coast from 1955 to 1985. Figure 3.21 depicts 7 April 1982 of this storm. An additional storm is identified around the Florida Keys, but based on the surface map and interpolated pressure map a closed area of low pressure is not indicated. Moving south through Florida, there does appear to be pressure decreases, and given the sparse amount of grid points associated with southern Florida, the algorithm may have incorrectly identified an additional storm. This represents a weakness of the automated procedure, in that additional storms are sometimes incorrectly identified when a limited amount of grid points are available surrounding the minimum SLP west of the PGL. 


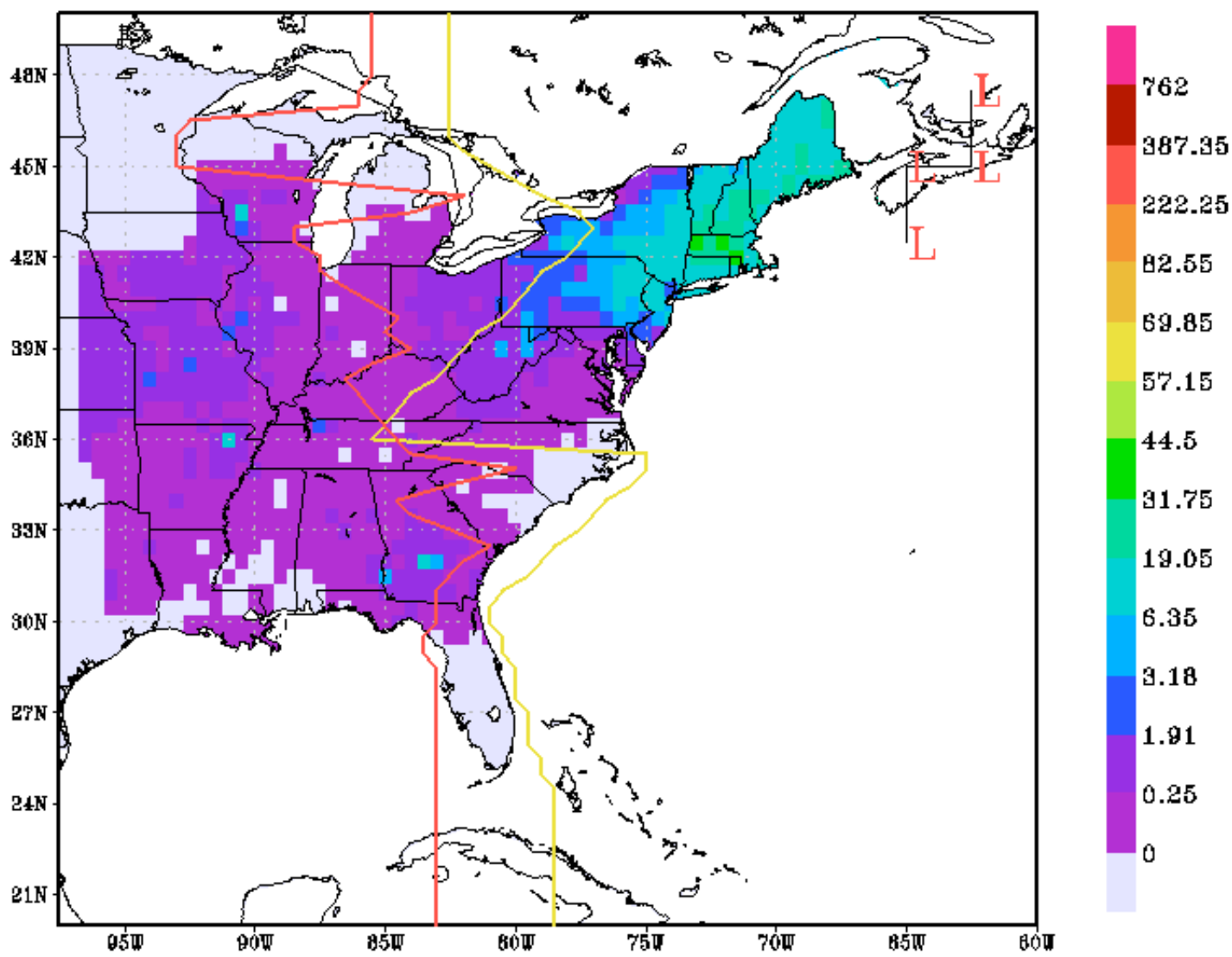

Figure 3.21: An ECWS from 7 April 1982 and an example of Scenario 4 in the ECWS precipitation decision process. Lines and shading information are the same as Figure 3.17.

Also on 7 April 1982, there is an approaching additional storm in Colorado with an associated warm front and trailing cold front. This storm is too far from the study domain to be identified, however, the pressure gradient line for this day does indicate some pressure decreases mainly from Lake Michigan southward, likely associated with this approaching cyclone. Therefore, the decision to select COOP stations to the east of the pressure gradient line as stations to be included in the precipitation climatology for this day, results in a suitable decision.

This would correctly include all of the precipitation from Ohio and West Virginia and points north and east. Furthermore, this would exclude precipitation along and west of the Mississippi River in Illinois and westward, which is likely associated with the cyclone in Colorado, possibly due to overrunning precipitation 
along the cyclone's associated warm front. The majority of the precipitation in Georgia would be excluded, with the exception of small areas along the coast. This area of precipitation could be associated with a trailing cold front from the ECWS.

A second example from scenario four, resulting in mediocre performance of the decision process is from a 9 January 1996 ECWS. This storm lasted from 7 to 9 January and is known as the "Blizzard of '96", resulting in tremendous snowfall across portions of the Northeast. Figure 3.22 depicts 9 January 1996 of this ECWS.

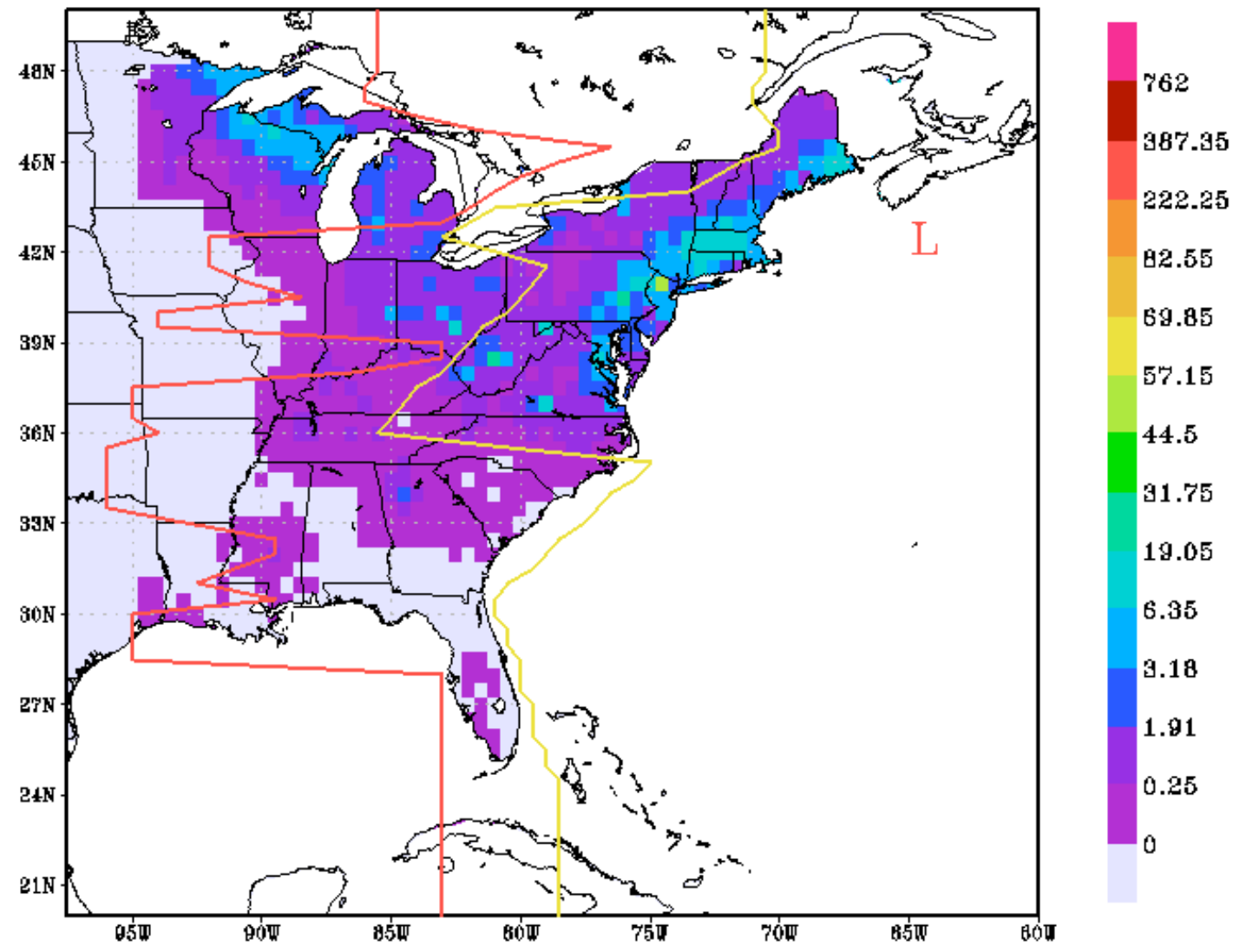

Figure 3.22: An ECWS from 9 January 1996 and an example of Scenario 4 in the ECWS precipitation decision process. Lines and shading information are the same as Figure 3.17.

An additional storm is identified to the north of New Hampshire, which is incorrect. This identification likely occurs because low pressure extending from the ECWS is just to the west of the PGL in northern New England. With limited grid points in this area due to the proximity to the Canadian border and missing 
interpolated data in northern Maine at the time period the additional storm was identified (not pictured here), the algorithm incorrectly identifies an additional storm here. However, there was an additional storm impacting the Great Lakes as a Clipper system to the north of Lake Huron. The algorithm likely missed identifying this Clipper due to the lack of grid points in this northern region of the study domain. However, in northern Michigan, the pressure gradient line does key in on this feature, signaling pressure decreases coupled with this Clipper system. With the decision for this day being the inclusion of COOP stations to the east of the pressure gradient line, the results are clearly imperfect. However, even though the pressure gradient line is erratic, and does erroneously include some precipitation in the Ohio Valley, the heaviest precipitation with the Clipper system in Northern Michigan, and Wisconsin, is excluded. This example results in one of the weaknesses of this automated decision procedure. When the algorithm fails to identify the correct additional storm, often a less than desirable decision results. A solution would be to include a larger study domain reaching well beyond the targeted area, when searching for additional storms impacting the region. Just how large this domain would be is somewhat subjective without additional extensive research.

The remaining three scenarios in the ECWS decision process involve circumstances where no additional storms are identified by the automated procedure. Scenario 5: An additional storm is not identified to the west of the PGL, but the precipitation maximum to the west of the PGL is higher than the maximum to the east of the line. The outcome is to include COOP stations to the east of the PGL in the precipitation climatology for that day.

The first example of this scenario is from the Superstorm of '93 on 12 March 1993. This historic storm lasted from 12 to 14 March and resulted in tremendous 
snowfall totals spanning a large portion of the eastern region of the United States.

Figure 3.23 details the components of the decision process for 12 March.

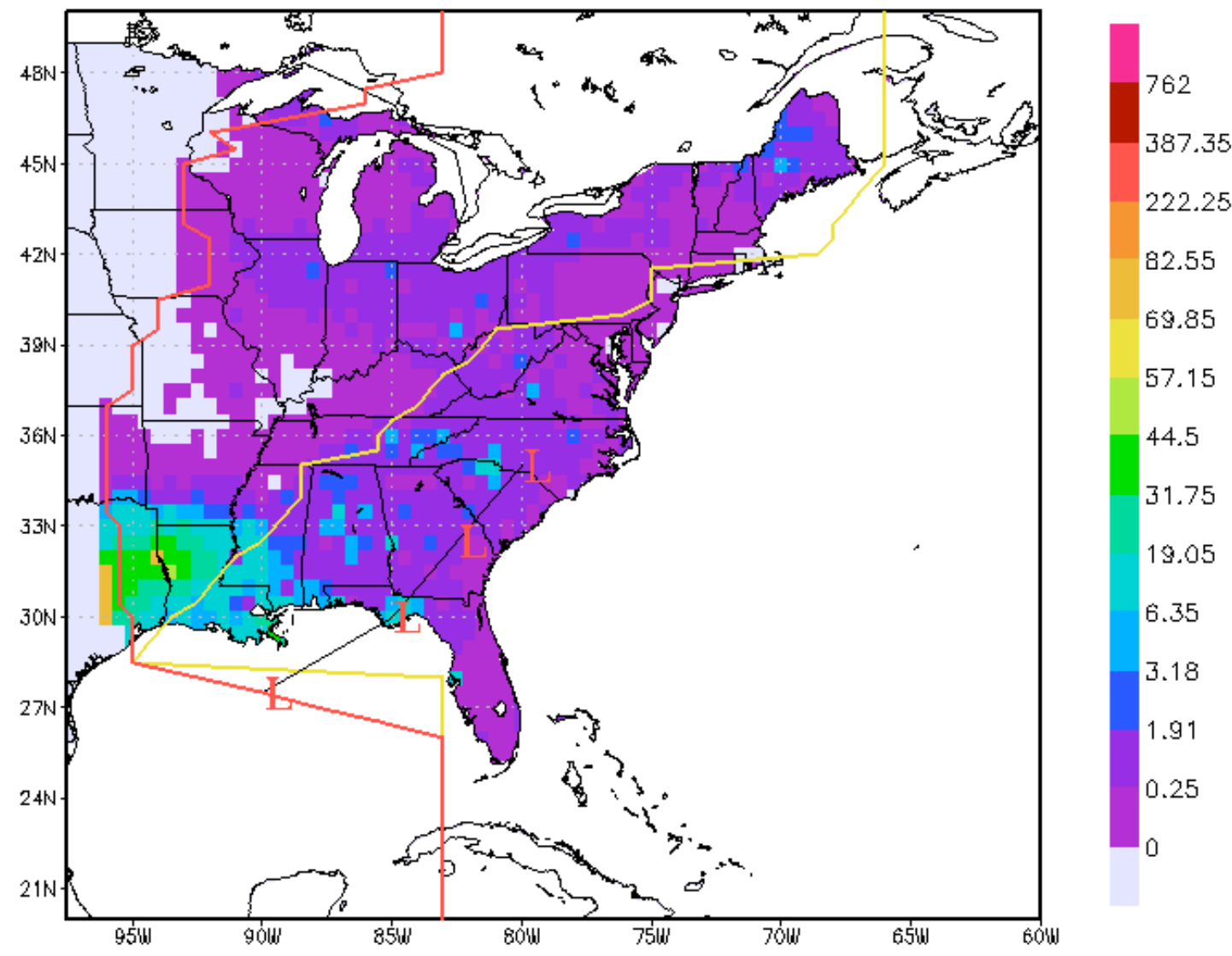

Figure 3.23: An ECWS from 12 March 1993 and an example of Scenario 5 in the ECWS precipitation decision process. Lines and shading information are the same as Figure 3.17.

The outcome for 12 March is satisfactory, with the only error occurring in northwestern Louisiana and southern Arkansas, where precipitation that should be included in the climatology is excluded. However, this example does exhibit some strong points. First, all relevant precipitation to the east of the ECWS is correctly included in the climatology. Second, a broad area of lighter precipitation around the Great Lakes and into New England is correctly excluded from the climatology. This area of precipitation is likely the product of two frontal boundaries, one draped from southern New England back into the Ohio valley and the other stretching from Lake Superior into the Central Plains states, extending from a cyclone near Hudson Bay. 
Even though there was not an additional storm in the vicinity of the study domain to identify, the routine correctly positioned the PGL in this area to exclude the nonECWS precipitation. This example represents a strength of the automated procedure. Even when there is not an additional storm to be identified, and there is an area of non-ECWS precipitation, the PGL is capable of separating the ECWS precipitation from the non-ECWS precipitation when there is a sufficient gradient present.

A second example of scenario five, and one of the independent verification case studies, is from a 29 March 1992 ECWS, which lasted from 28 to 29 March. Figure 3.24 shows 29 March for this event. The synoptic set up for this day is a negatively tilted $500 \mathrm{hPa}$ trough with its axis through Maine. A $500 \mathrm{hPa}$ ridge is in place in the Ohio Valley, with surface high pressure anchored over Ohio and West Virginia. An unidentified additional storm with associated frontal boundaries along the Kansas/Oklahoma border is associated with a $500 \mathrm{hPa}$ trough in the center of the United States. This feature is responsible for all of the precipitation from Ohio westward. Even the precipitation across the Florida peninsula appears to be from an old stationary boundary, which extends to a warm front from the additional storm.

The decision for this day is to include only COOP stations to the east of the PGL in the climatology. This results in an excellent decision, since only precipitation in the northeast and New England associated with the ECWS is included in the climatology. Despite an additional storm not being identified, likely because the additional storm was too far west of the study domain, the correct decision is still made. While not used in the decision for this particular example, it is worth noting the pressure gradient line adequately signals the decreases in SLP associated with the approaching additional storm. 


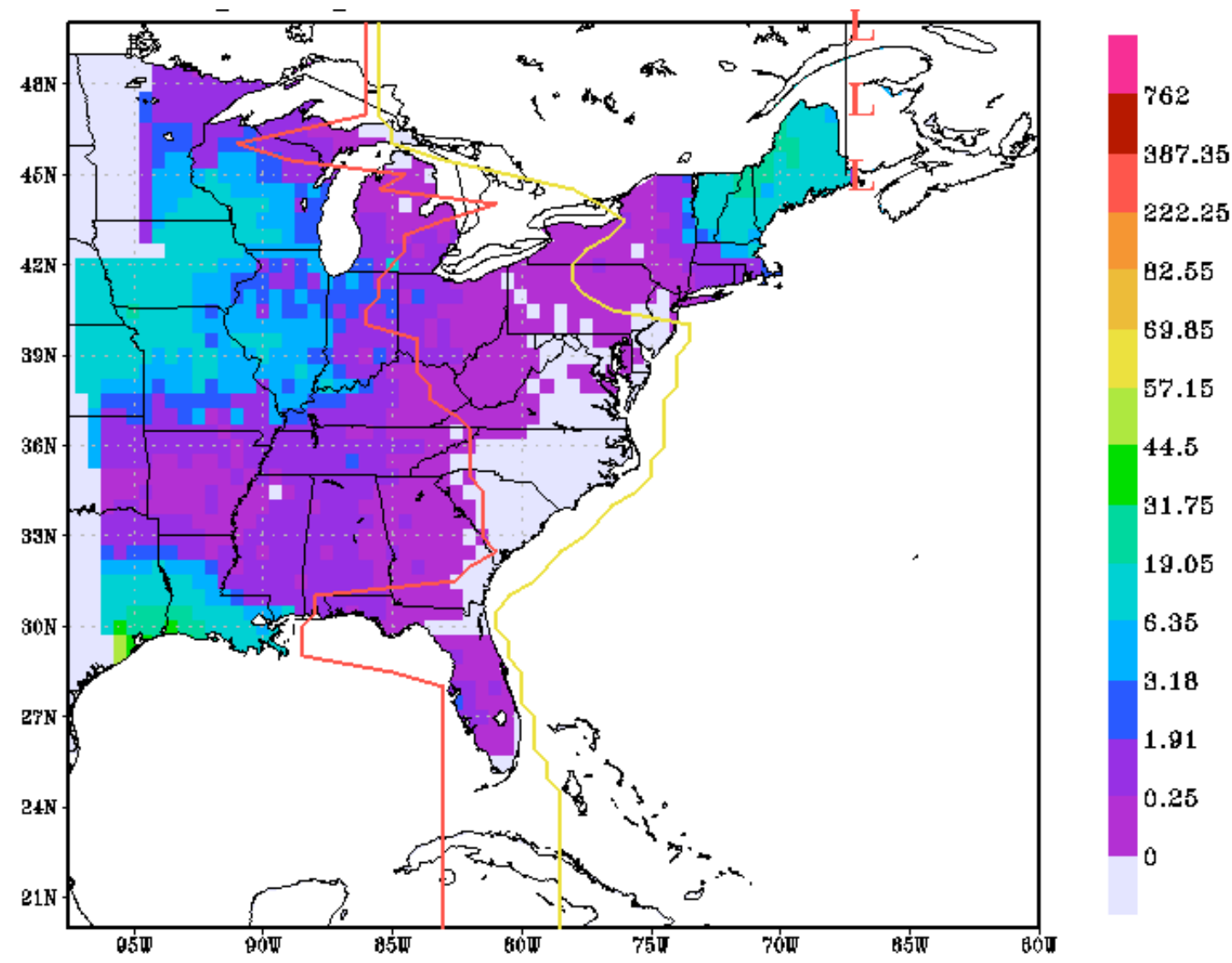

Figure 3.24: An ECWS from 29 March 1992 and an example of Scenario 5 in the ECWS precipitation decision process. Lines and shading information are the same as Figure 3.17.

Scenario 6: An additional storm is not identified to the west of the PGL, the precipitation maximum to the west of the PGL is lower than the maximum to the east of the line, and a large area of no precipitation is found (e.g. Zero Swath Found criteria are met). In this scenario, the decision is to include in the climatology only those COOP stations to the east of the PGL. An example of this condition is from a 2 November 1957 ECWS, which was long-lived lasting from 1 to 5 November. This storm was primarily a rain event and Figure 3.25 shows 2 November. 


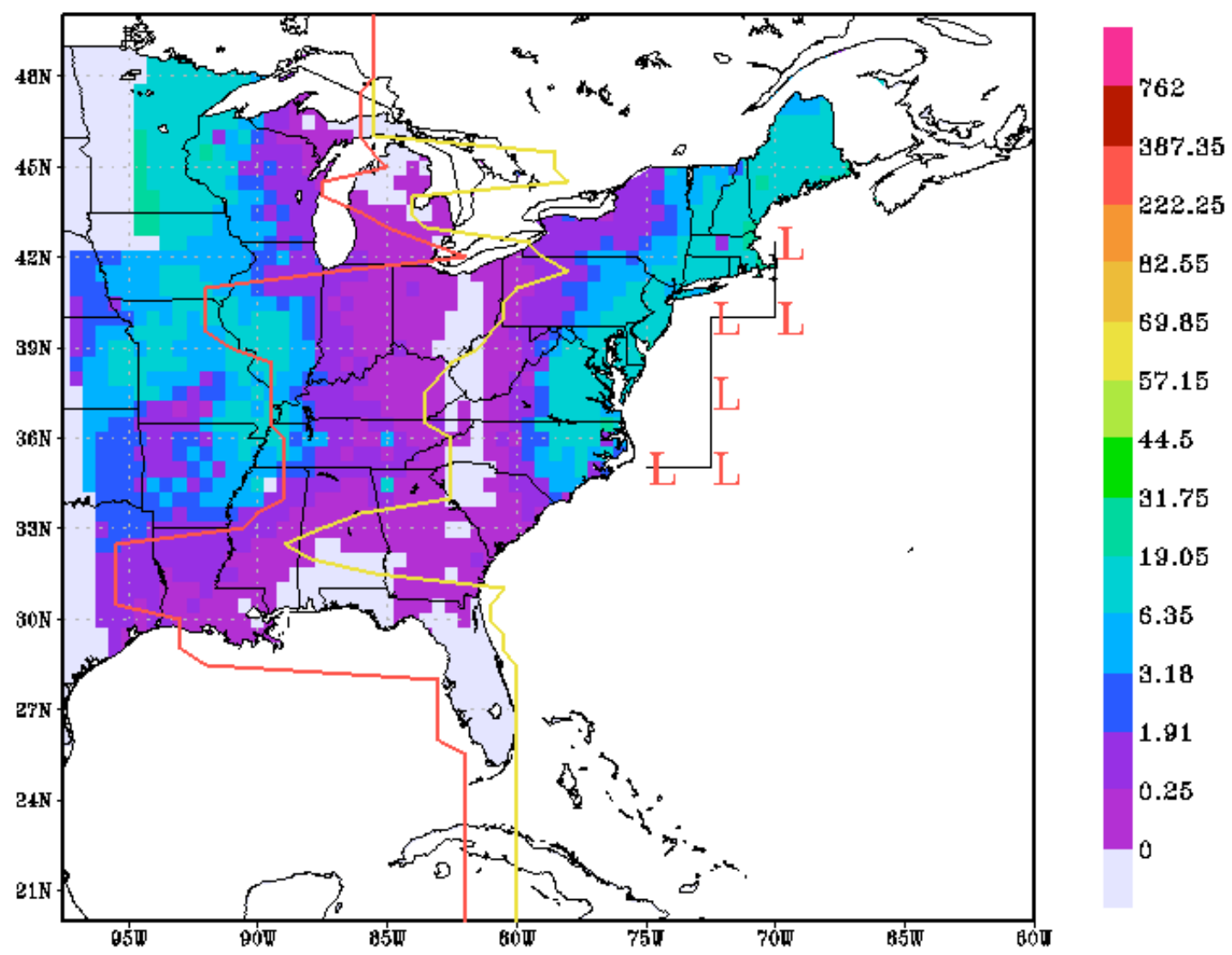

Figure 3.25: An ECWS from 2 November 1957 and an example of Scenario 6 in the ECWS precipitation decision process. Lines and shading information are the same as Figure 3.17.

This example shows the usefulness and the strength of incorporating the Zero Swath Evaluation. The two areas of precipitation in Figure 3.25 are clearly from two distinct synoptic systems. The area in the east and northeast is associated with the ECWS. The second area along the Mississippi River is associated with an unidentified additional storm in western Iowa with corresponding frontal boundaries. This additional storm is not identified because its location just outside of the study domain makes it difficult for the algorithm to identify and it appears to be filling.

Scenario 7: An additional storm is not identified to the west of the PGL, the precipitation maximum to the west of the PGL is lower than the maximum to the east of the line, and a large area of no precipitation is not found (e.g. Zero Swath Found criteria are not met). In this scenario, the decision is to include in the climatology only 
those COOP stations to the east of the pressure gradient line. An example of this scenario is from an ECWS on 7 February 1978. This storm lasted from 6 to 7 February, and is one of the storms Kocin and Uccellini (1990) included in their book on snowstorms along the east coast from 1955 to 1985 . Figure 3.26 depicts 7 February of this ECWS.

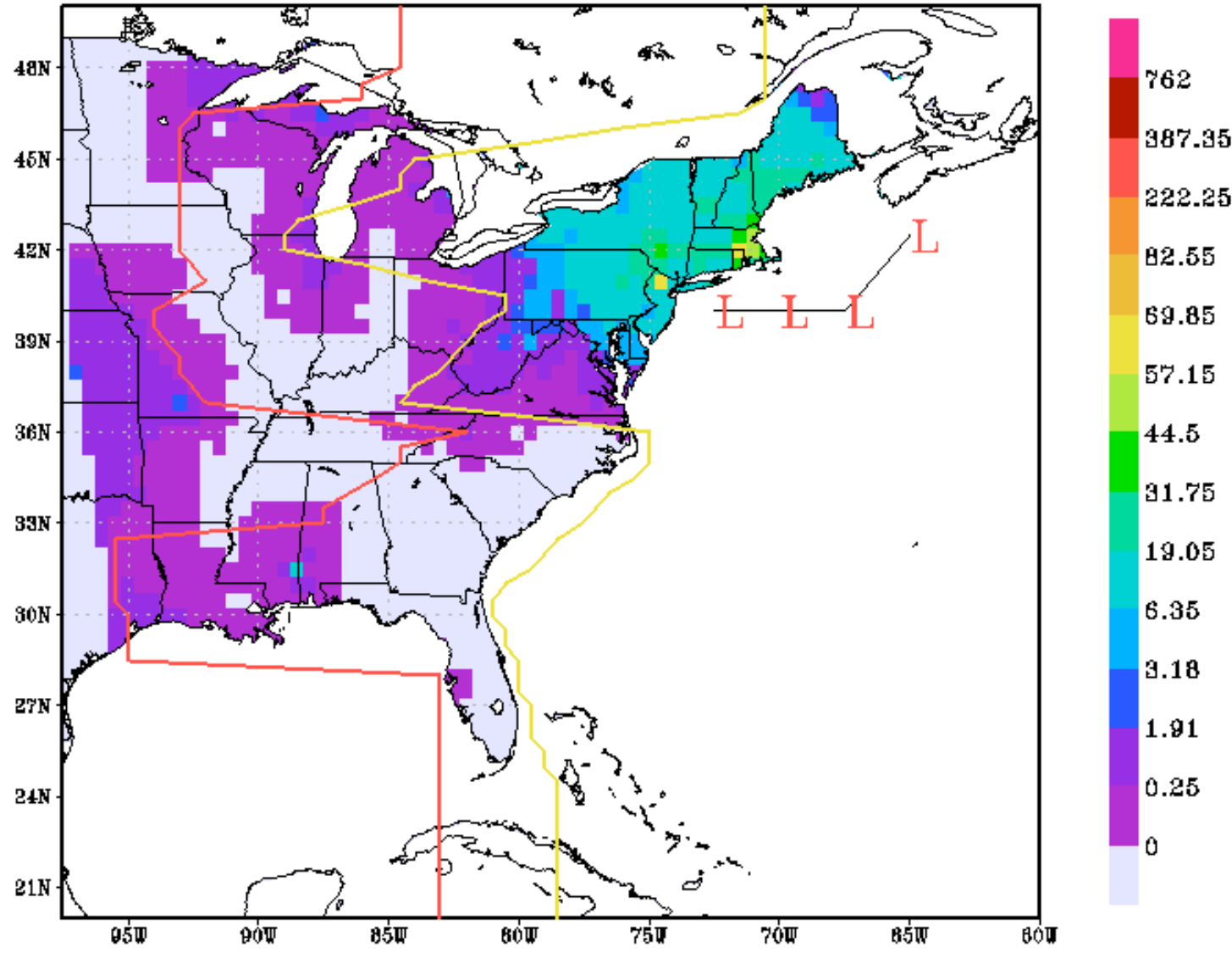

Figure 3.26: An ECWS from 7 February 1978 and an example of Scenario 7 in the ECWS precipitation decision process. Lines and shading information are the same as Figure 3.17.

This storm was a heavy snow producer, particularly along the Interstate 95 corridor from Washington D.C. to Boston, MA. On 7 February, the ECWS is exiting the study region, with high pressure anchored over Hudson Bay. The combined flow around this high and the ECWS is likely providing the moisture producing precipitation throughout the Great Lakes. Other relevant synoptic features on this day include an unidentified additional storm associated with a weak $500 \mathrm{hPa}$ shortwave in 
the Rocky Mountains in Wyoming and Colorado, positioned along a frontal boundary, as well as another unidentified additional storm in southwestern Texas and Mexico, associated with a broader $500 \mathrm{hPa}$ trough. These features appear responsible for the precipitation to the west of the Mississippi River, in Missouri, Arkansas and Louisiana. The only questionable areas of COOP stations included in this decision are in the Great Lakes region and in Louisiana, Mississippi and Alabama. Regarding the Great Lakes, there is no other identifiable synoptic feature, even on the daily surface map, which could be causing this precipitation. Therefore, inclusion of this precipitation in the climatology seems reasonable. The only potential very minor issue with the Great Lakes is the inclusion of this precipitation throughout the majority of the region, but the possible exclusion in extreme northern Wisconsin and the Upper Peninsula of Michigan. However, such exclusion would only impact a small number of COOP stations, if any. Regarding the Gulf Coast states, this is clearly an erroneous inclusion by the automated procedure. However, this still remains a relatively minor issue, since the precipitation amounts erroneously included are relatively small. Zero Swath Found criteria are not met in Figure 3.26 because the second area of precipitation (west of the Mississippi River) is primarily scattered and light in amount, and therefore not identified at enough latitudes (e.g. not enough Zero Swath Flags are identified).

A second example from scenario seven is from an ECWS on 25 January 1988. This storm was classified as a bomb lasting from 25 to 26 January. Heavy snow was produced, especially on 26 January in the interior sections of New England and the Northeast. Figure 3.27 depicts 25 January of this ECWS. 


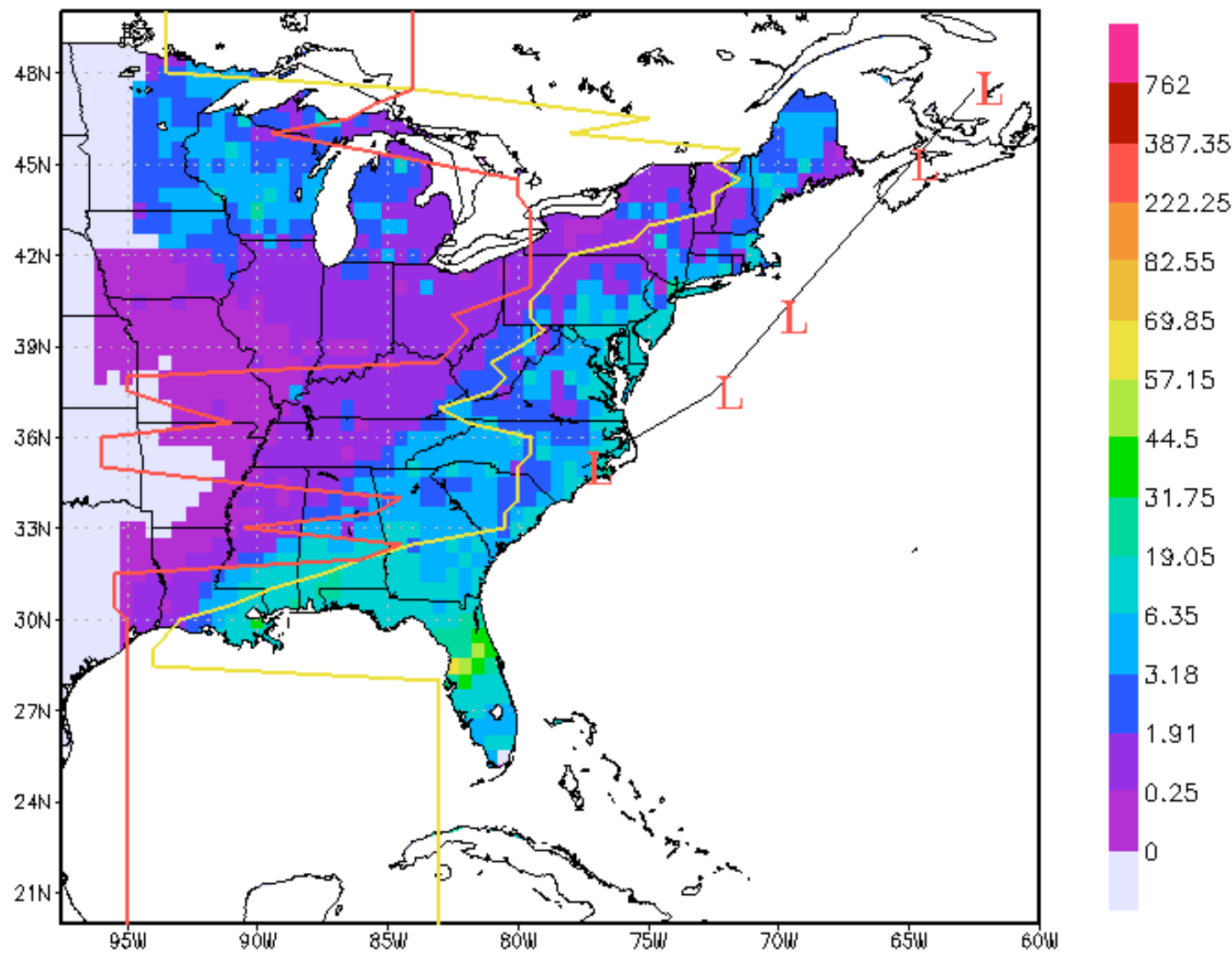

Figure 3.27: A bomb from 25 January 1988 and an example of Scenario 7 in the ECWS precipitation decision process. Lines and shading information are the same as Figure 3.17.

A fairly complex synoptic setup exists on the morning of 25 January, local time. At $500 \mathrm{hPa}$ a broad trough is dominating the eastern half of the United States, with its axis roughly along the Mississippi River. Around the base of this trough, the cyclone that will become the ECWS is making its way through the northern Gulf of Mexico, to northern Florida and then eventually up the east coast. Meanwhile, a Clipper system is ejecting from the high plains east to southeastward into the Great Lakes. This system either fills or transfers its energy to the ECWS by 26 January. Just downstream, and within the $500 \mathrm{hPa}$ trough, is an unidentified additional storm in central Ontario associated with a $500 \mathrm{hPa}$ shortwave, embedded in the large scale trough. The decision for 25 January is to include in the climatology those COOP stations to the east of the pressure gradient line. Given the complexity of the day, this 
results in a reasonable decision. Some precipitation in the southeastern states, such as Mississippi and Alabama is excluded, which should be included. However, much of the precipitation associated with the Clipper system in the Great Lakes is excluded, despite this additional storm not being identified.

\subsection{Generation of ECWS and Bombs Percentages Climatology}

Two methods of calculating the percentage of snowfall or precipitation from ECWS and bombs were used. The first method is a study period seasonal (in terms of snow years) average percentage, which represents for a given location the percentage of snowfall or precipitation from ECWS on average per snow year. For each snow year and for each COOP station, ECWS snowfall and ECWS precipitation was noted, as well as total snowfall and total precipitation. A percentage was computed for the snow year based on these totals. A study period average of these percentages for all snow years was then computed. In terms of seasonal percentages, a COOP station was required to have 25 or less snow years missing to be included in the results. These study period seasonal average percentages were then interpolated to the same $0.5^{\circ}$ grid, using the same interpolation methods described previously.

The second method is a study period overall percentage, which represents the percentage of snowfall or precipitation from ECWS for the entire study period. For each COOP station, ECWS snowfall and ECWS precipitation was summed for all of the study years. Similarly, total snowfall and total precipitation was summed. One percentage was computed for each COOP station, based on these study period sums. These percentages were again interpolated to the $0.5^{\circ}$ grid.

There are benefits to each method of computing percentages. The study period overall percentage gives higher weight to snow years in which high amounts of snowfall occurred. In contrast, the study period seasonal average percentage gives equal weight to each snow year. This is an important consideration, particularly for 
locations where snowfall has a high degree of interannual variability. For example, some locations where snowfall is rare, may receive as much snowfall in one snow year, as the previous five snow years combined. These two methods of computing percentages also lead to answering different questions. The study period overall percentage is a climatological feature, focusing on the importance of ECWS to overall snowfall. Whereas the study period seasonal average percentage is more of a seasonal forecasting feature, focusing on how much year to year variability in snowfall is related to year to year variability in ECWS. 


\section{CHAPTER 4}

\section{RESULTS AND STATISTICS}

\subsection{General Climatology}

There were 733 ECWS during the 55 snow years from 1951-1952 to 20052006, based on the improved ECWS climatology, for an average of 13.3 ECWS per snow year. This is slightly higher than the original climatology in Hirsch et al. (2001), which contained 562 ECWS during the 48 years including 1948 and 1951-97, for an average of 11.8 ECWS per snow year. For the improved climatology, the maximum number of ECWS in a snow year occurred three times, with 22 occurring in 19571958, 1982-1983, and 1997-1998. The minimum number of ECWS in a snow year was 6, occurring in 1967-1968. Figure 4.1 shows ECWS occurrences by snow year.

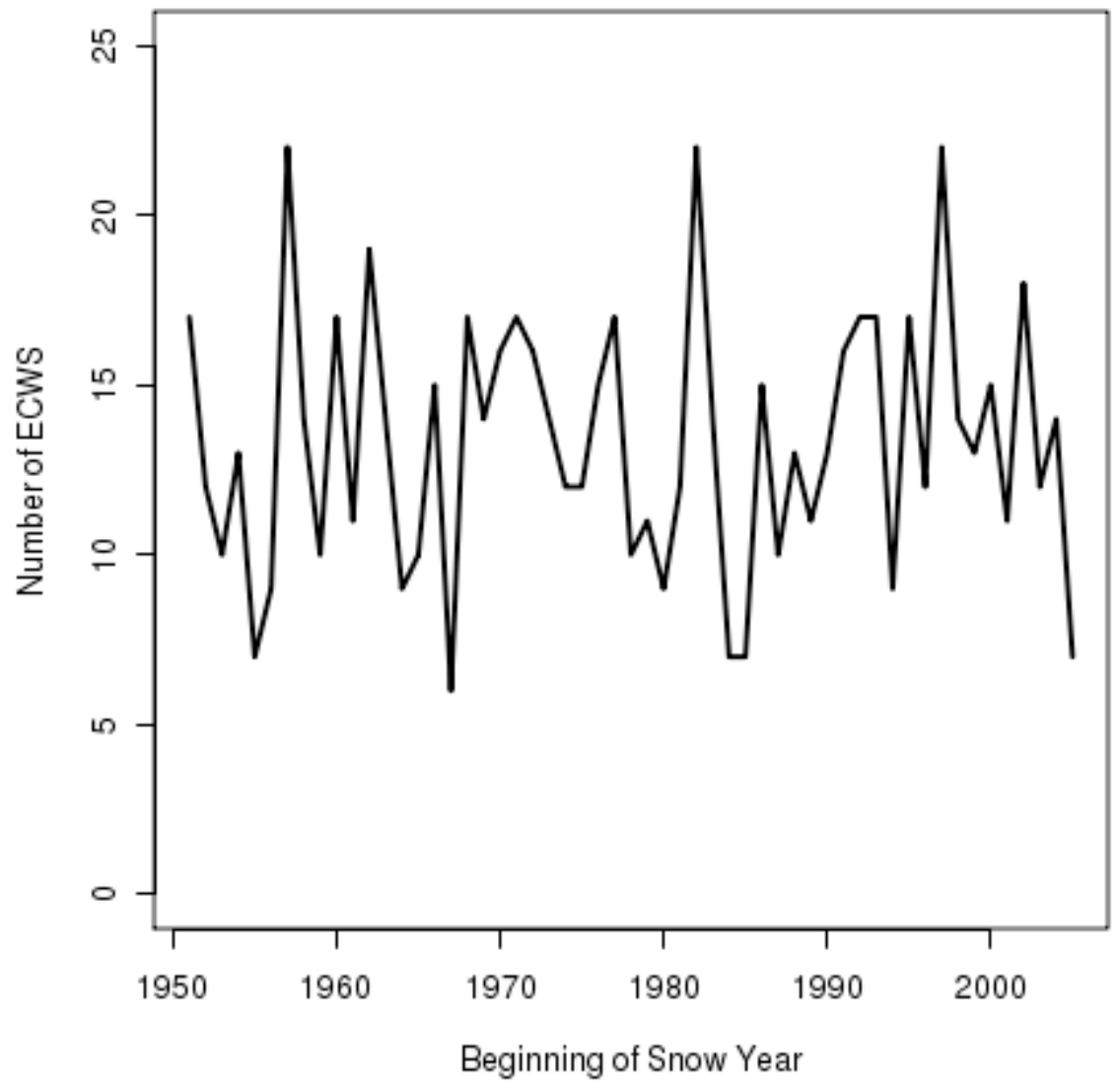

Figure 4.1: ECWS occurrences by snow year. 
There were a total of 62 bombs identified during the study period for an average of 1.1 bombs per snow year. The maximum number of bombs per snow year occurred in 1963-1964, with 6 bombs. The minimum number of bombs per snow year was zero, occurring in eighteen different snow years. Lim and Simmonds (2002) found that an average of 45 explosive cyclones occurred per year in the Northern Hemisphere (i.e. not just the Atlantic basin) during the period 1979 to 1999 . A confirmation can be inferred from these findings that bomb occurrences are underestimated in this study, and only the strongest bombs are represented. Figure 4.2 shows bomb occurrences by snow year.

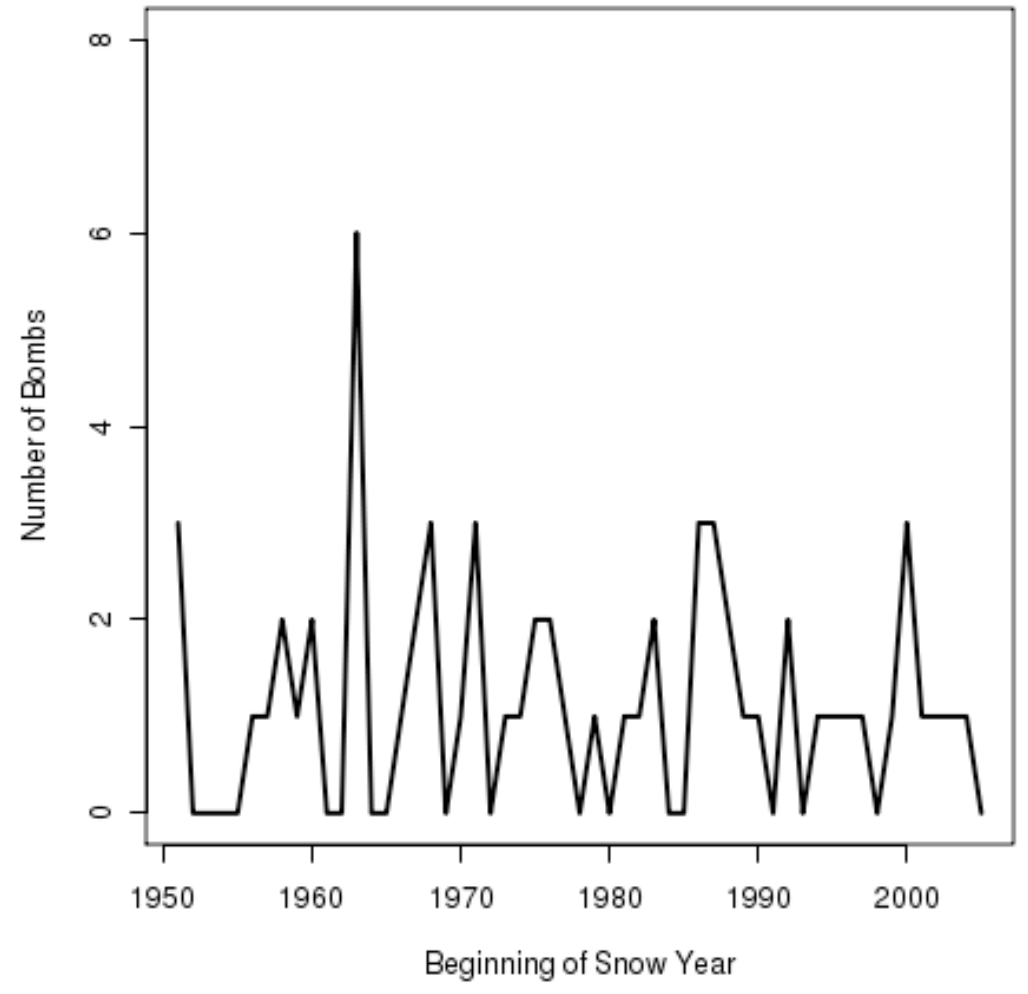

Figure 4.2: Bomb occurrences by snow year.

The highest average amount of snowfall per snow year from ECWS occurred at Mount Washington, NH, with an average of $221.9 \mathrm{~cm}(87.4 \mathrm{in})$. There were 18 stations, which had a study period seasonal average percentage of snowfall from ECWS of $100 \%$. These stations were all located in the south, either in Alabama, 
Florida, Georgia, Louisiana, or Mississippi. The highest average amount of precipitation per snow year from ECWS also occurred at Mount Washington, NH, with an average of $398.26 \mathrm{~mm}$ (15.68 in). The highest study period seasonal average percentage of precipitation from ECWS, occurred at Rockport, MA, with 26\%.

The highest average amount of snowfall per snow year from bombs occurred again at Mt Washington, $\mathrm{NH}$, with an average of $28.9 \mathrm{~cm}$ (11.4 in). There were 3 stations, which had a study period seasonal average percentage of snowfall from bombs of $100 \%$. These stations were located in Louisiana and Alabama. The highest average amount of precipitation per snow year from bombs also occurred at Mount Washington, NH, with an average of $42.85 \mathrm{~mm}$ (1.69 in). The highest study period seasonal average percentage of precipitation from bombs occurred at West Medway, MA, with 3\%.

In terms of study period overall percentages, similar percentages and geographic areas characterized the extremes. There were 22 stations where the study period overall percentage of snowfall from ECWS was 100\%. Again, these stations were all located in Alabama, Florida, Georgia, Louisiana or Mississippi. For the study period overall percentage of precipitation from ECWS, there were three stations with $26 \%$, and they were all located in Massachusetts. Regarding bombs, there were four stations with a study period overall percentage of snowfall from bombs of $100 \%$. These stations were in Alabama and Louisiana. Finally, the highest study period overall percentage of precipitation from bombs was $3 \%$, which occurred at 23 stations, located in Massachusetts, Maine, New Hampshire, New York and Rhode Island.

\subsection{Study Period Seasonal Average Percentages for ECWS and Bombs}

The percentages of snowfall and precipitation from ECWS and bombs in the following figures were all computed using the one period LES scenario. The percentage of total snowfall directly from ECWS, on average per snow year, varies 
greatly by location throughout the study area. Figure 4.3 shows these study period seasonal average percentages for snowfall from ECWS. The highest percentages occur in the south, in the states Georgia, Florida, Alabama and Mississippi, particularly in a swath from southeast Mississippi to northeast Georgia. Here the percentages are typically $50 \%$ to $80 \%$.

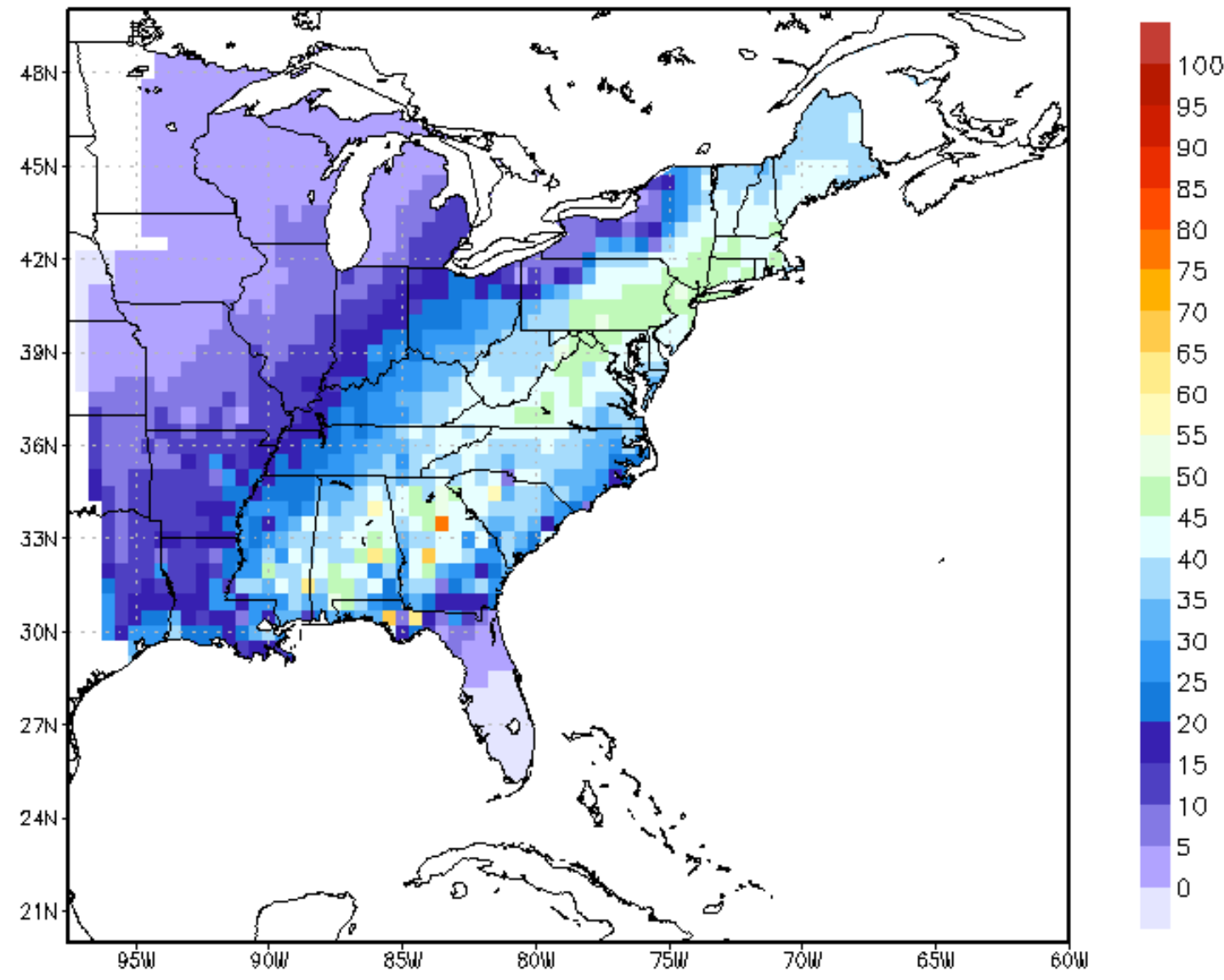

Figure 4.3: The percentage of snowfall from ECWS, on average per snow year (study period seasonal average percentages). LES based on one period criterion.

The heavily populated urban corridor of the Northeast, roughly from Richmond, VA to Boston, MA, shows on average per year $40 \%$ to $55 \%$ of total snowfall is directly from ECWS. The percentages taper off quickly moving west of the Appalachian Mountains, and especially west of the Mississippi River. Furthermore, the outline of the LES belts can be seen clearly, particularly downwind of Erie and Ontario, owing to the additional snowfall producing mechanisms in these 
areas. These percentages were also calculated on a monthly basis, with similar patterns to the annual percentages exhibited, but with different values. Months at the beginning and end of the season differed most in terms of values, and patterns to some extent. As an example, Figure 4.4 shows the average percentage of snowfall from ECWS for the month of November. The highest percentages are shifted slightly south and east, and are much higher than the annual percentages, typically 70 to $100 \%$ from the western Florida panhandle to southern South Carolina. The percentages for November along the urban corridor of the Northeast are slightly lower than annual values, typically from 25 to $55 \%$. However, the percentages around the Great Lakes, particularly downwind of Lakes Erie and Ontario, are consistent with annual values.

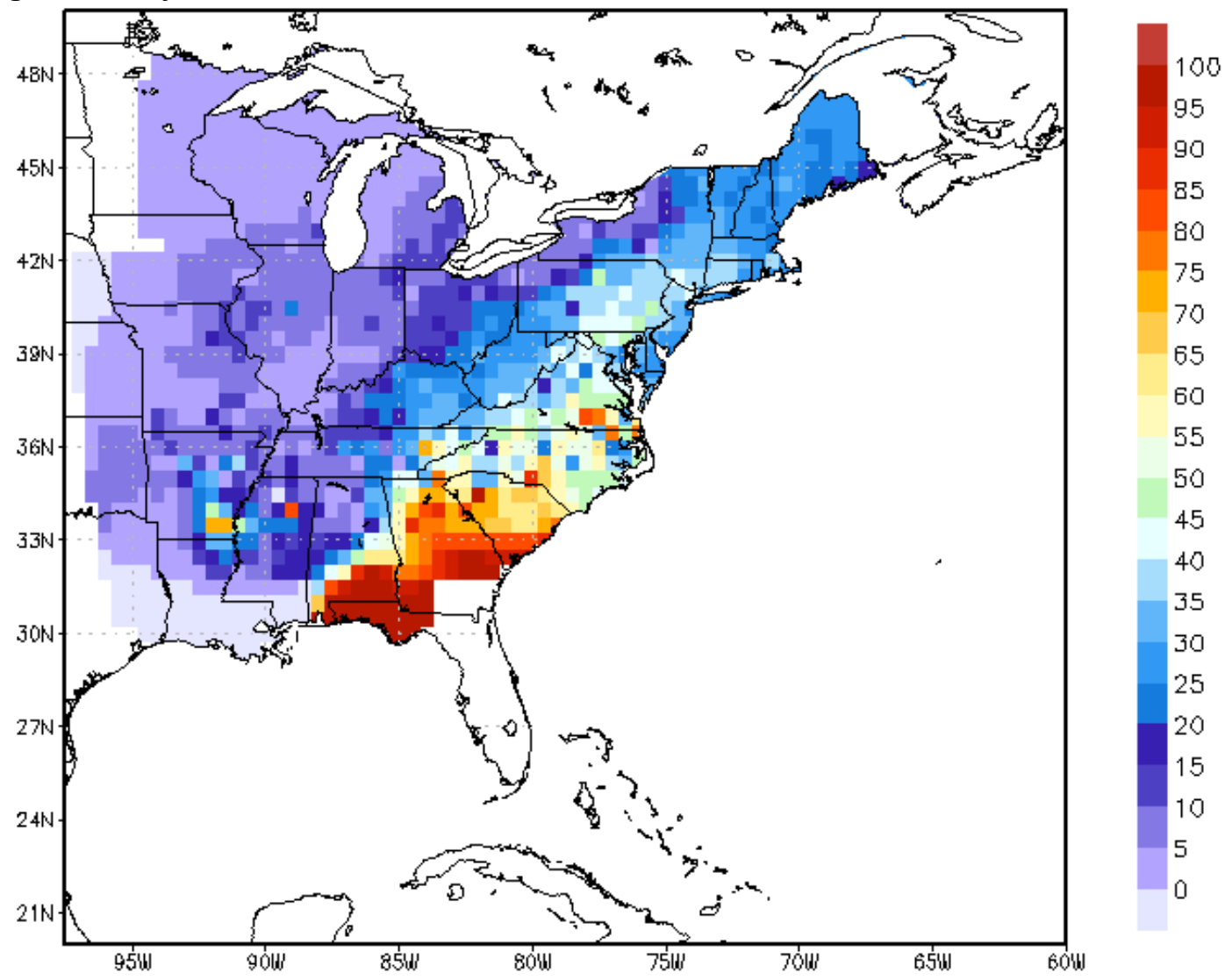

Figure 4.4: The percentage of snowfall from ECWS, on average for the month of November. LES based on one period criterion. 
Figure 4.5 shows the percentage of total annual precipitation from ECWS, on average per snow year. The highest percentages, around $25 \%$, are confined to small portions of the mid-Atlantic coast, specifically the Delmarva Peninsula, and northward along the New England coast. These percentages taper off uniformly, while moving both south and west from these coastal areas. Evidence of the LES belts can again be seen, particularly down wind of Lake Ontario and Lake Erie. While Lake Effect Rain was ignored in developing this climatology, the liquid equivalent precipitation associated with LES was excluded using the same previously discussed methods. As with snowfall, percentages were also calculated on average per month. These monthly averages are consistent with the annual averages.

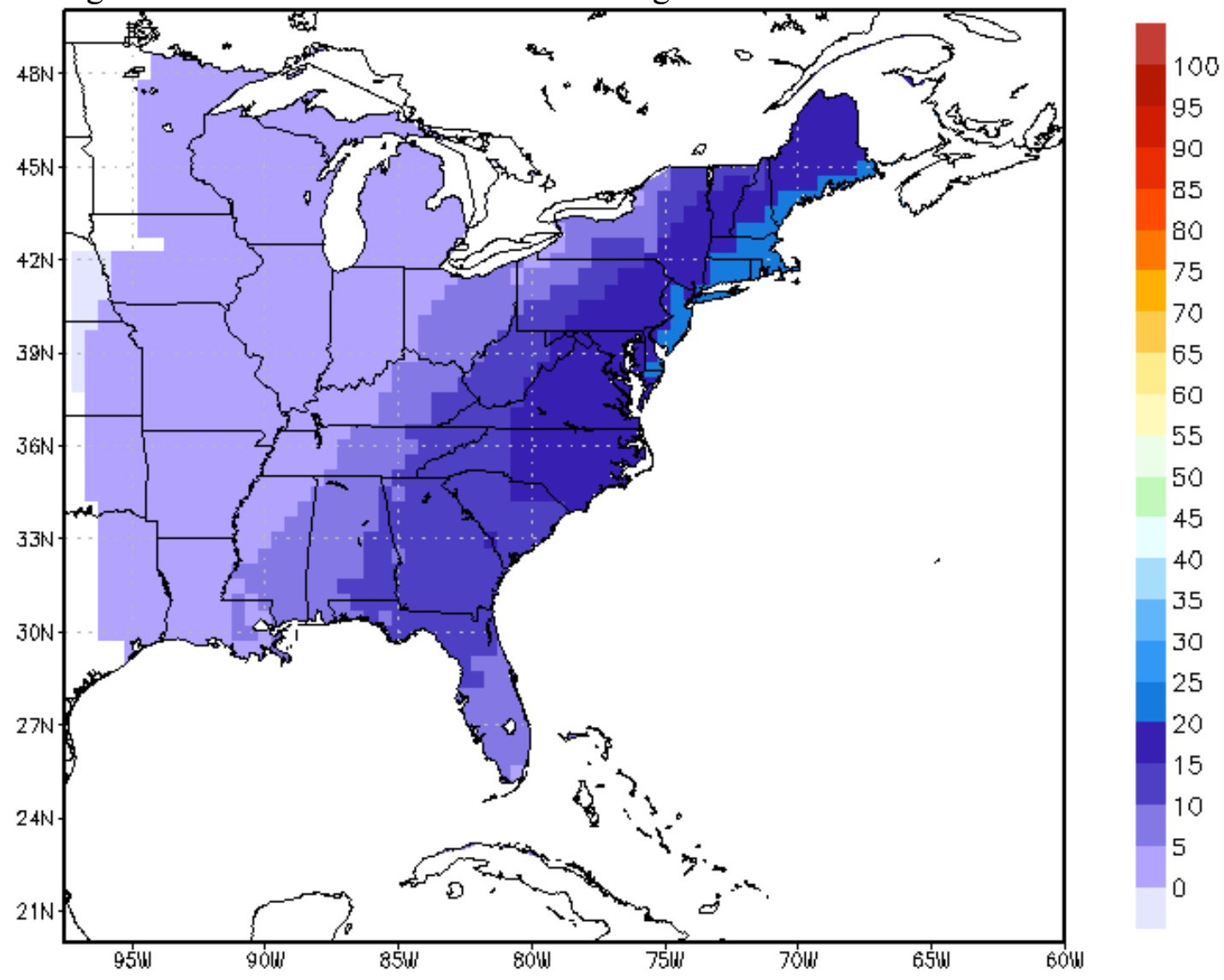

Figure 4.5: The percentage of precipitation from ECWS, on average per snow year (study period seasonal average percentages). LES based on one period criterion. 
Regarding these monthly average percentages, Figure 4.6 shows the percentage of precipitation from ECWS on average, for the month of November, as an example. In comparison to the annual percentages, the monthly values are in general higher since the annual percentages are computed by accounting for precipitation throughout the snow year, not just during the winter season. However, the overall pattern is similar to Figure 4.5. Although in the case of Figure 4.6, the maximum in percentages are shifted slightly south, more towards the mid-Atlantic coast and surrounding the Chesapeake Bay.

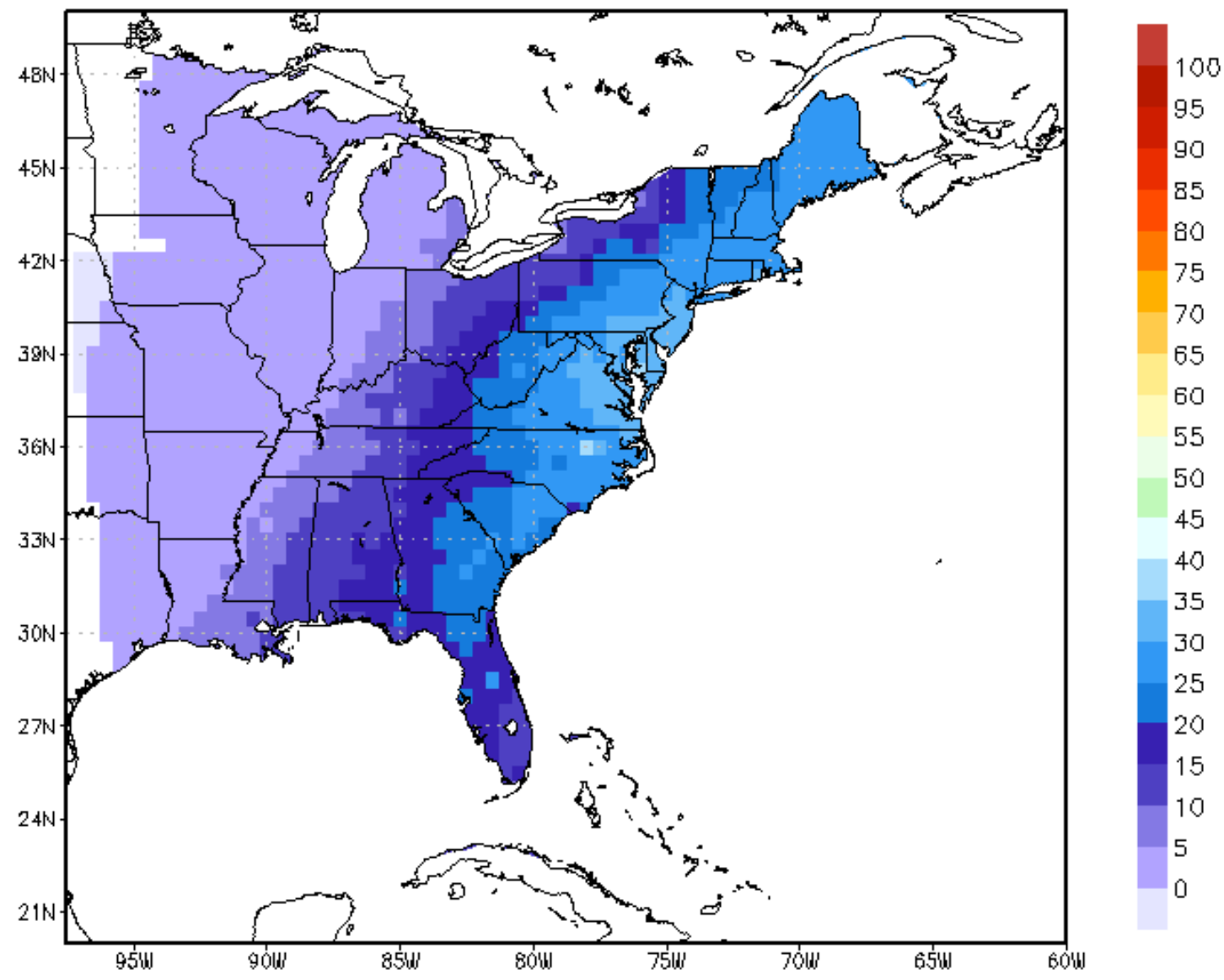

Figure 4.6: The percentage of precipitation from ECWS, on average for the month of November. LES based on one period criterion.

Figure 4.7 shows the percentage of snowfall, on average per snow year, from bombs. From Figure 4.7, there are two areas worth mentioning, the first in the New York City metropolitan area and the other stretching from western South Carolina to 
southern Mississippi. Interestingly, the metropolitan area of New York City, from central New Jersey, into southeastern Connecticut, sees as much as 10 to $15 \%$ of snowfall in a given snow year from bombs. The percentages from western South Carolina to southern Mississippi see quite a bit of spatial variability, but in general anywhere from 5 to $50 \%$ of snowfall in a snow year is the result of bombs.

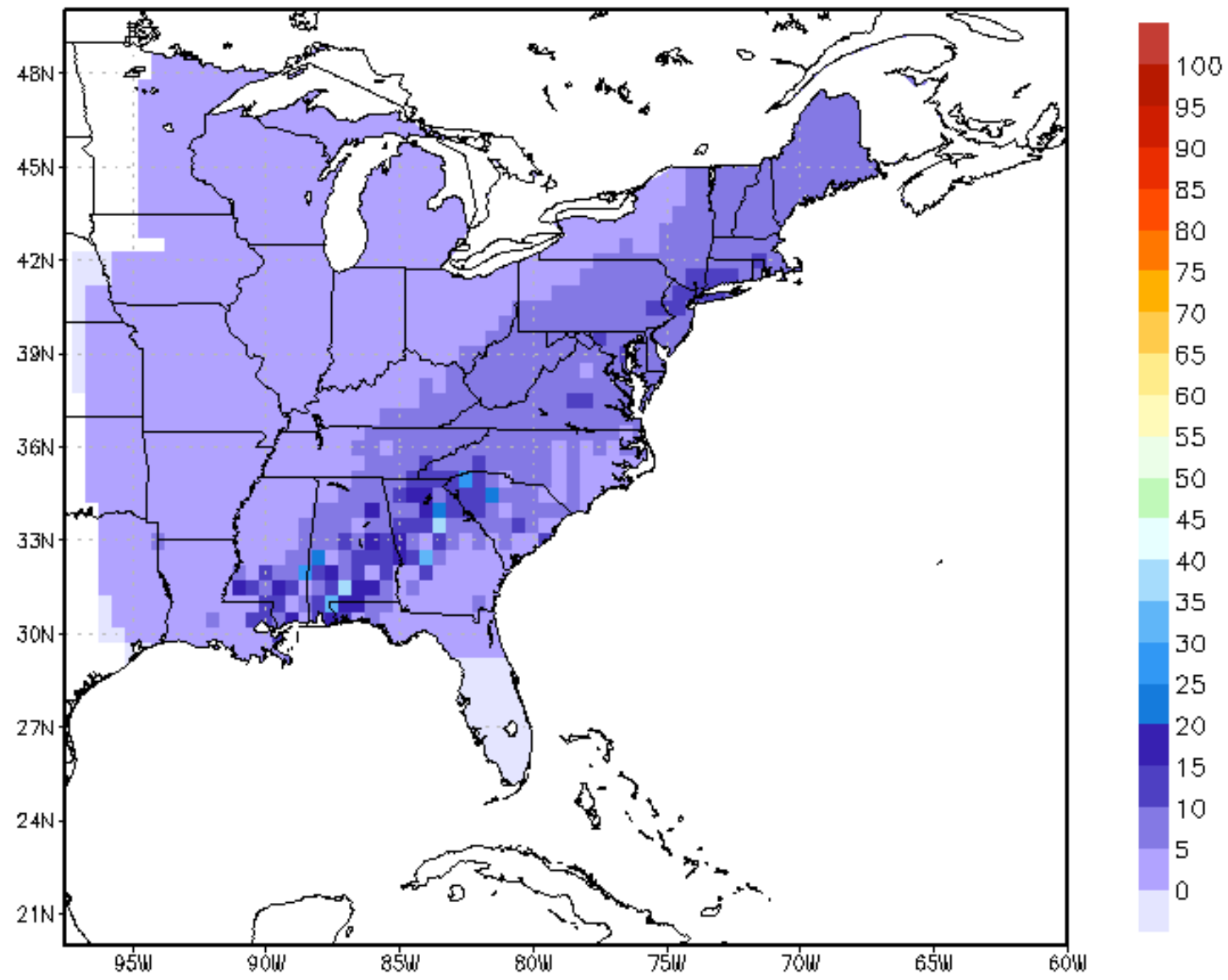

Figure 4.7: The percentage of snowfall on average per snow year from bombs. Based on one period LES criterion.

The percentage of precipitation from bombs, on average per snow year, was uniformly between 0 and 3\% throughout the entire study region (not pictured here). In contrast to comparing Figures 4.3 and 4.5, a typical rain snow line during bomb events is not evident by comparing Figure 4.7 and the percentage of precipitation from bombs results. These percentages were also looked at on a monthly basis for both snowfall and precipitation. The percentage of precipitation from bombs in terms of monthly 
averages was consistent with the annual findings. However, the monthly percentages of snowfall from bombs, did exhibit the following interesting patterns. In April, a small maximum exists in the mountains in western North Carolina into northeastern Georgia, with percentages as high as 30 to $35 \%$. In March, a large maximum area exists covering much of Georgia, Alabama and Mississippi as well as portions of eastern Louisiana, where percentages range from 5 to $95 \%$ throughout this region. Finally, in November a maximum exists along the costal plain of Virginia and North Carolina, with percentages as high as $70 \%$.

\subsection{Study Period Seasonal Average Totals for ECWS and Bombs}

The amount of snowfall and precipitation from ECWS and bombs, on average per snow year, was also computed using one period LES criterion. Figure 4.8 shows the average amount of snowfall $(\mathrm{cm})$ per snow year from ECWS. Areas of northern New England, from the Adirondack Mountains east and northward into Maine see the highest annual average ECWS snowfall (with greater than $50 \mathrm{~cm}$ typical). These amounts taper off moving towards the coast of New England, and moving southwest into the interior sections of the Northeast and mid-Atlantic.

Along the Appalachian Mountains, including parts of Virginia, West Virginia, Western Maryland and southwest Pennsylvania, a local maximum of ECWS snowfall can be noted, with totals as high as 50 to $60 \mathrm{~cm}$. The amounts here are consistent with that received in the Pocono and Catskill Mountains, in northeast Pennsylvania, and southeast New York, respectively. Moving west of Ohio, and south of North Carolina, amounts taper off quickly to $1 \mathrm{~cm}$ or less of snowfall per snow year from ECWS. 


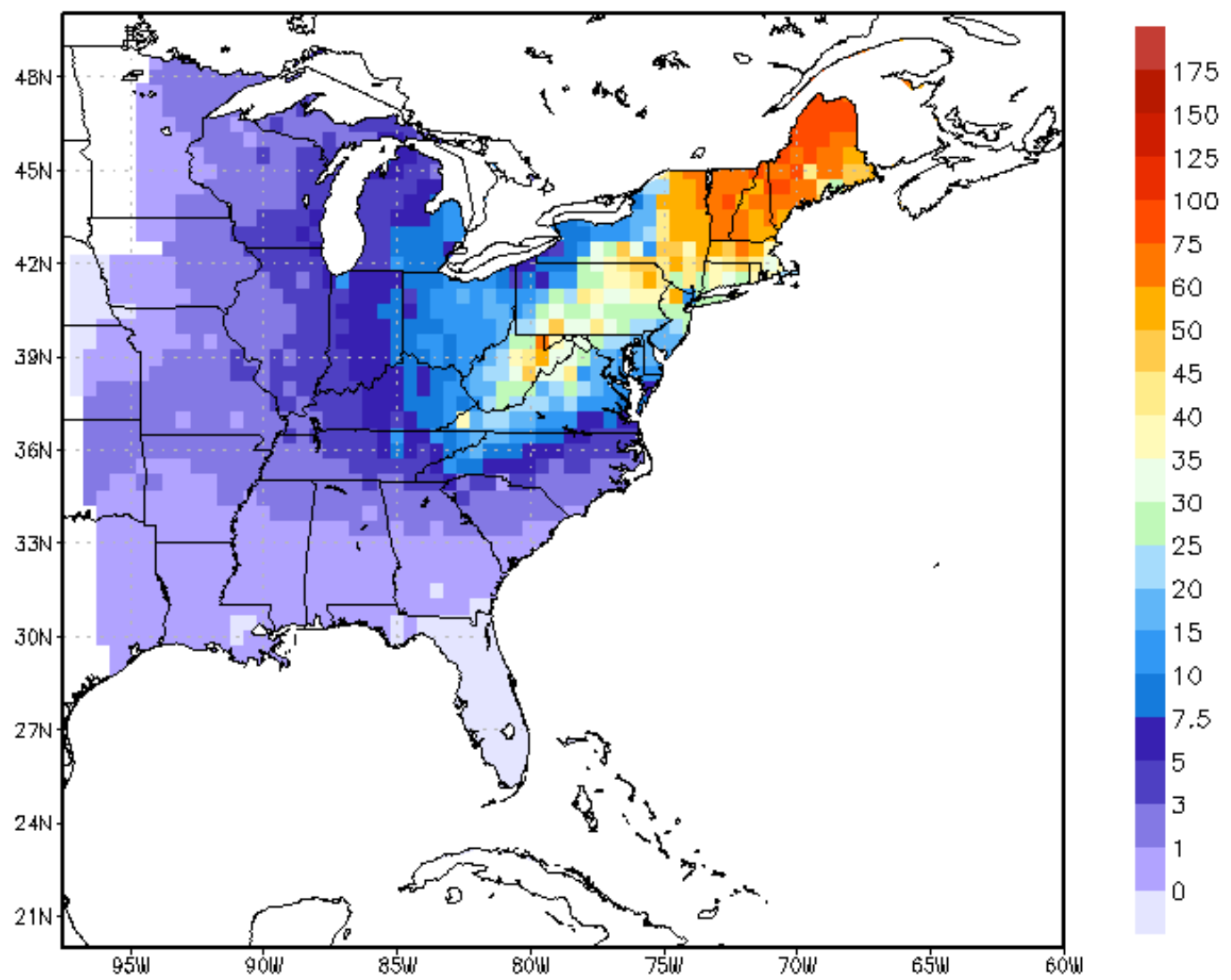

Figure 4.8: The amount of snowfall $(\mathrm{cm})$ from ECWS, on average per snow year. Based on one period LES criterion.

Similarly, Figure 4.9 shows the average amount of precipitation $(\mathrm{mm})$, per snow year, from ECWS. Two maxima occur, both in the Northeast, with one in northern New Jersey, and the other to the south of Boston, encompassing much of Rhode Island and southeastern Massachusetts. A broad local maximum occurs through Virginia, North Carolina and portions of South Carolina. This corresponds to a local minimum in ECWS snow percentages (Figure 4.3), suggesting a transition of the predominant precipitation type associated with ECWS across this region. The remainder of Figure 4.9 is consistent with earlier Figures, in that precipitation amounts from ECWS taper off rapidly moving west of the Appalachian Mountains and particularly west of the Mississippi River. For example, northern Missouri may only experience on average per snow year, 0 to $5 \mathrm{~mm}$ ( 0 to $0.20 \mathrm{in})$ of precipitation from 
ECWS. These average amounts for ECWS precipitation and snowfall were also considered on a monthly basis. As with the ECWS percentages, the patterns of monthly average amounts were consistent with the annual average amounts.

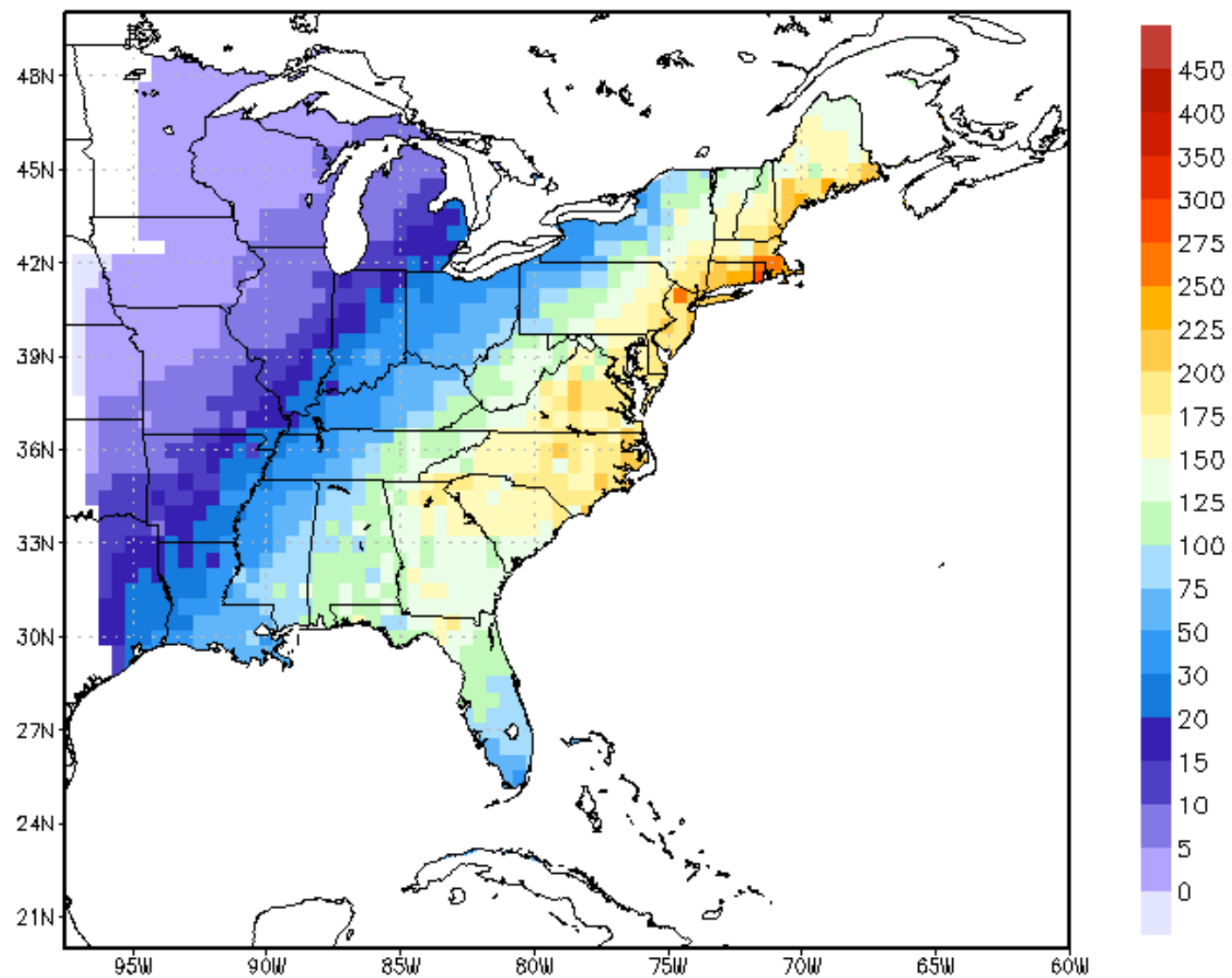

Figure 4.9: The amount of precipitation $(\mathrm{mm})$ from ECWS, on average per snow year. Based on one period LES criterion.

The spatial distribution of the average amount of bomb snowfall per snow year is consistent with the annual ECWS amounts in Figure 4.8. Figure 4.10 shows the amount of bomb snowfall on average per snow year. Two local maxima exist, similar to the ECWS snowfall amounts map in Figure 4.8. The first is in northern New England, roughly from the Adirondack Mountains, east and north, where amounts are typically 10 to $15 \mathrm{~cm}$ or greater. The second is in the mountains of West Virginia and western Maryland, where amounts are generally 7.5 to $15 \mathrm{~cm}$ and are in line with 
those found in the Pocono Mountains and Catskill Mountains of northeast

Pennsylvania and southeastern New York, respectively.

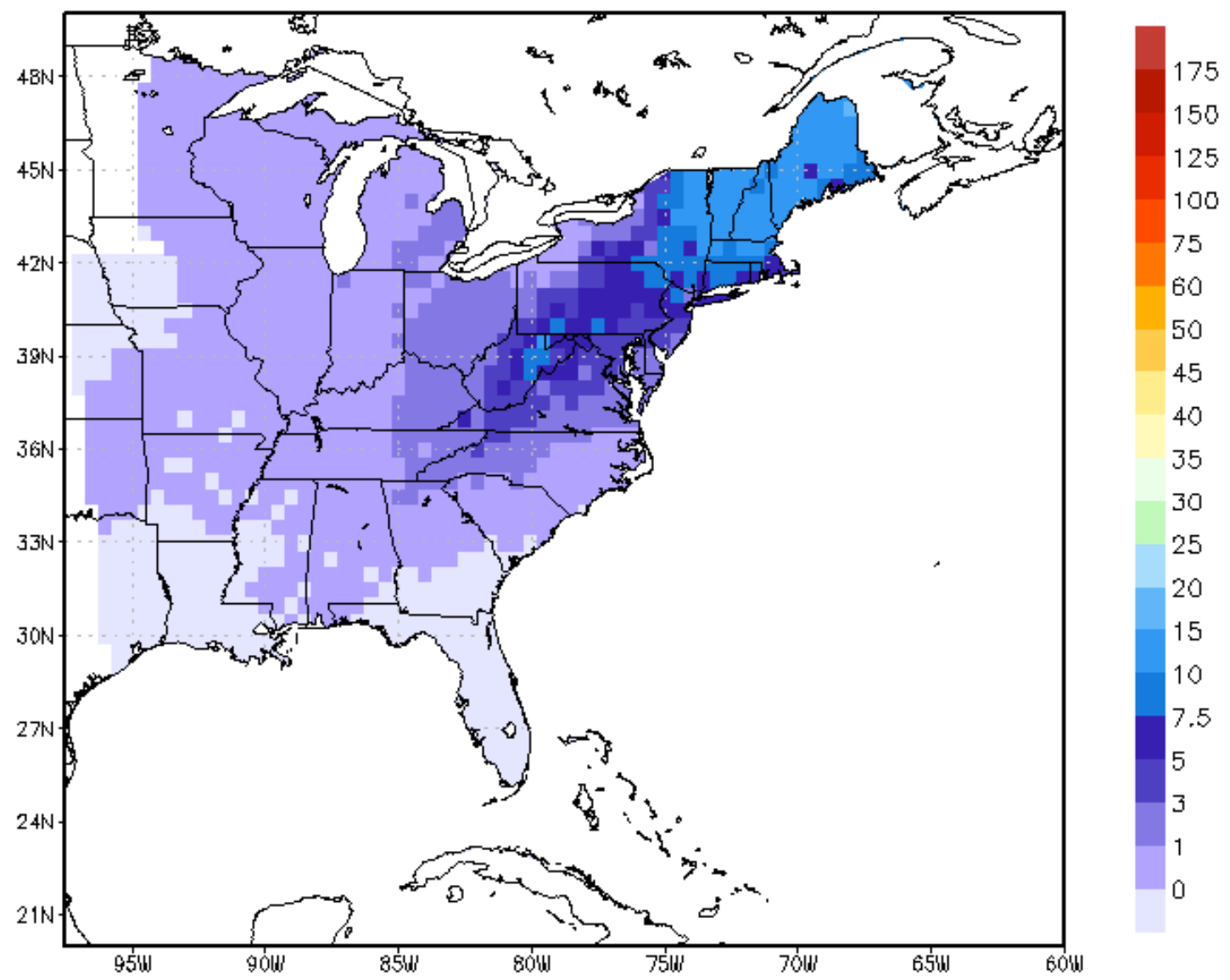

Figure 4.10: The amount of snowfall $(\mathrm{cm})$ from bombs, on average per snow year. Based on the one period LES criterion.

Figure 4.11 shows the amount of precipitation from bombs on average per snow year. These results are consistent with the findings of Figure 4.9. The highest amount of bomb precipitation is confined primarily to the New England coast from central Connecticut, north through Maine, with amounts typically between 20 and 30 $\mathrm{mm}$. The amounts taper off moving south down the coast, but a local maximum of 15 to $20 \mathrm{~mm}$ occurs along the coastal plain of North Carolina and parts of South Carolina. Also, the amounts taper off rapidly moving west of the Appalachian Mountains. Monthly bomb precipitation and snowfall amounts display a similar pattern. 


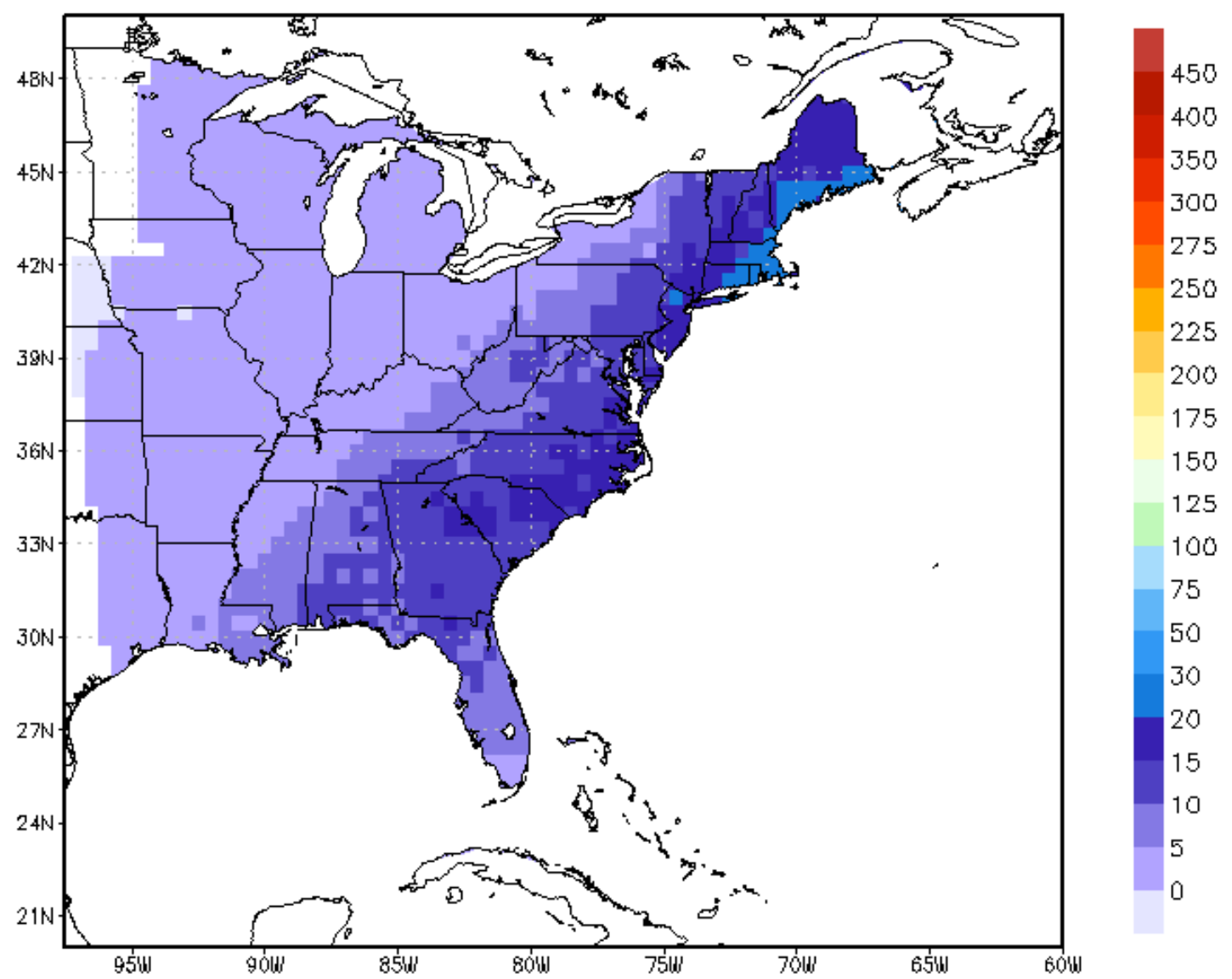

Figure 4.11: The amount of precipitation ( $\mathrm{mm}$ ) from bombs, on average per snow year. Based on the one period LES criterion.

\subsection{Study Period Overall Percentages for ECWS and Bombs}

The study period overall percentage calculations give more weight to snow years with higher ECWS snowfall, whereas the study period seasonal average percentage calculations give equal weight to each snow year. For the study period overall percentages in this sub-section, one period LES criterion was applied. Figure 4.12 shows the study period overall percentage of snowfall from ECWS. 


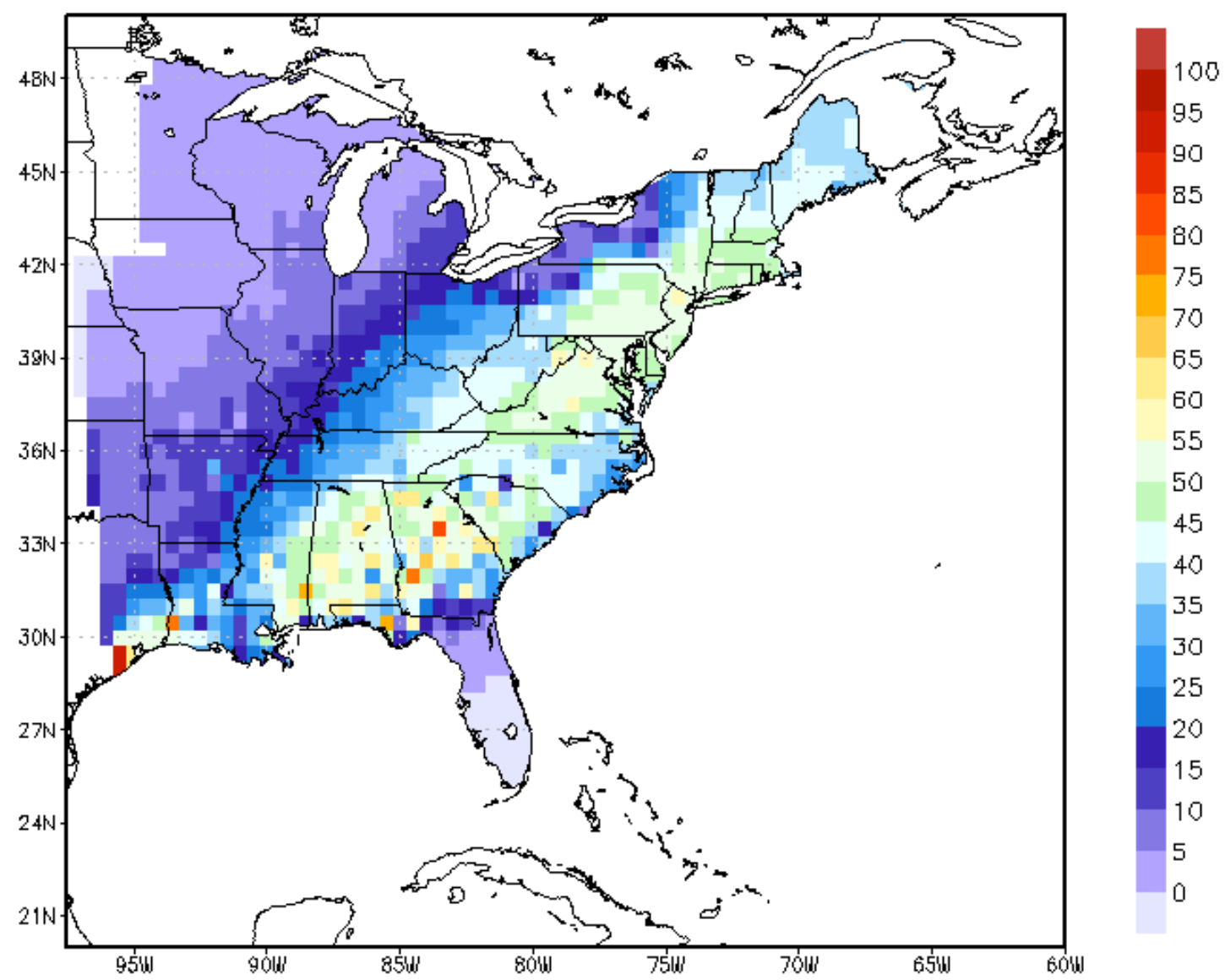

Figure 4.12: The study period overall percentage of snowfall from ECWS. Based on one period LES criterion.

Considering Figure 4.12 relative to Figure 4.3, the percentage of overall snowfall from ECWS is approximately 45 to $60 \%$ along the urban corridor of the midAtlantic and Northeast, in comparison to 40 to $55 \%$ calculated for the annual averages. This indicates that a few high ECWS snowfall years in this region, increase the percentages in the overall calculation. The overall snowfall percentages are also higher in the mountains in the southeast, as well as for Georgia and Alabama. Specifically in Figure 4.12, in parts of Georgia almost $100 \%$ of snowfall results from ECWS.

Figure 4.13 shows the percentage of overall precipitation from ECWS during the study period. These percentages in Figure 4.13 very closely resemble the 
percentages in Figure 4.5. One subtle difference is the percentages in the 20 to $25 \%$ range cover a larger portion of the Delmarva Peninsula in Figure 4.13.

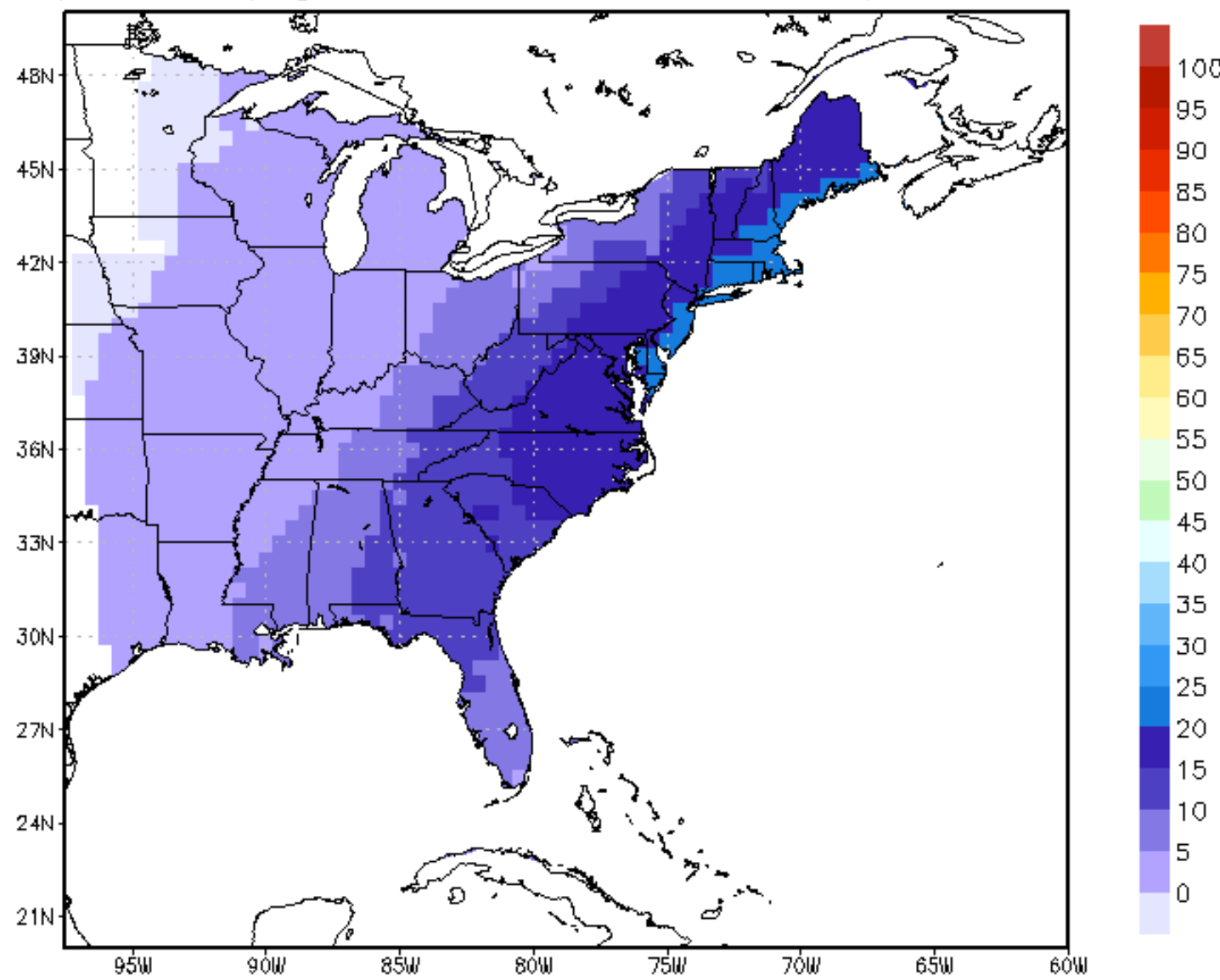

Figure 4.13: The study period overall percentage of precipitation from ECWS. Based on one period LES criterion.

This method for calculating study period overall percentages was also applied to bombs. Figure 4.14 shows the overall percentage of snowfall directly from bombs during the study period. The results of Figure 4.14 are similar to Figure 4.7. One notable difference with the overall percentages is a larger local maximum around the Washington DC area, of around 10 to $15 \%$ of snowfall from bombs. In addition, the overall percentages in Georgia and Alabama, in general, appear to be higher using the overall percentages. Regarding the study period overall percentage of precipitation from bombs, all of the percentages in the study region are between 0 and $3 \%$. 


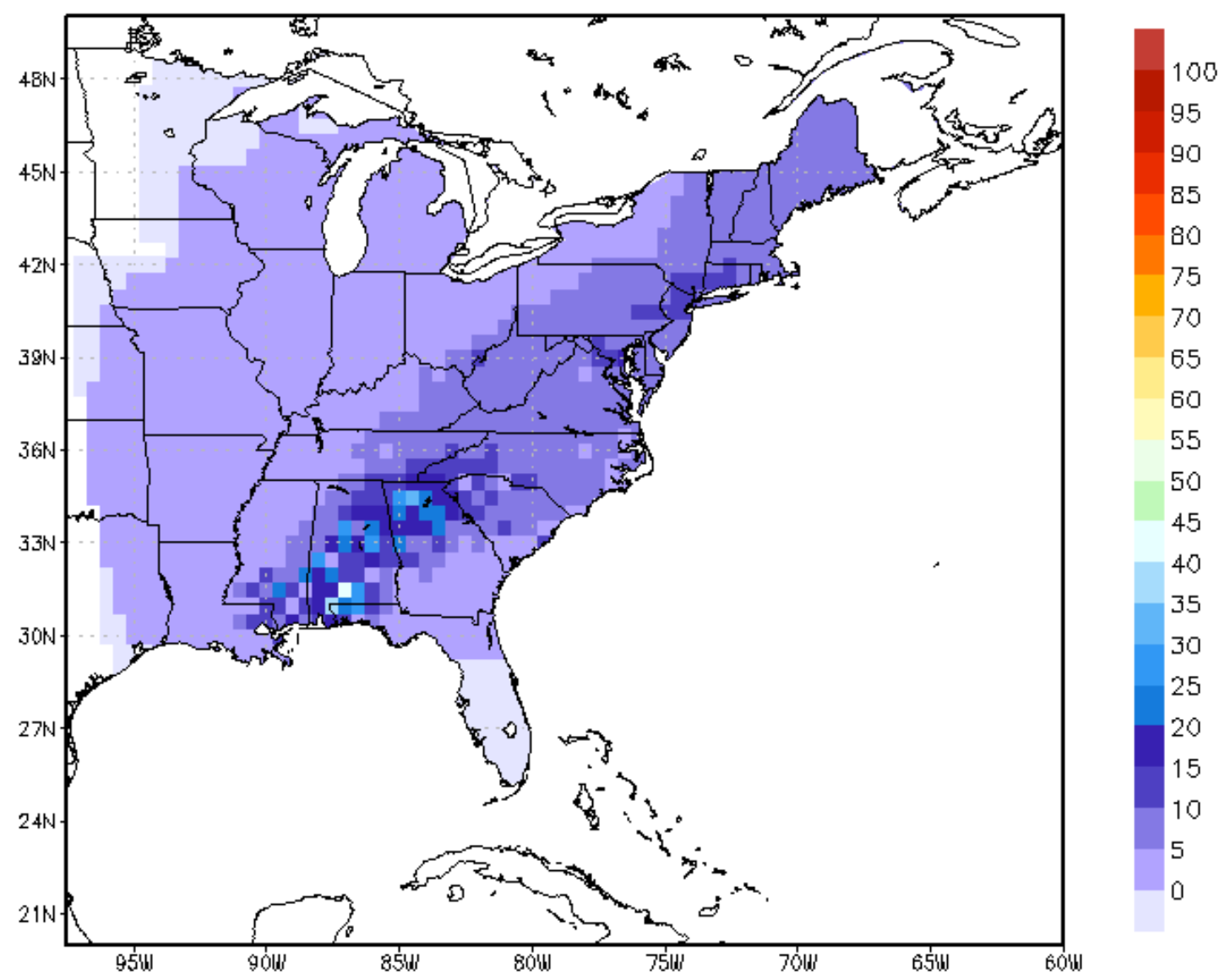

Figure 4.14: The study period overall percentage of snowfall from bombs. Based on one period LES criterion.

\subsection{Sensitivity Analysis for ECWS and Bombs}

Regarding the ECWS percentages, a sensitivity analysis was conducted to consider how the percentages would change if different methods were used to ascribe the cause of precipitation to ECWS or some other feature. There were three situations considered for this sensitivity analysis. First, how would the percentages change if no criteria were put in place to determine what COOP stations were receiving ECWS snowfall or precipitation and what stations were not. In this situation, for each day of an ECWS event, if the COOP station was anywhere in the study region, and it was receiving snow or precipitation on that day, it was assumed to be from the ECWS. This is termed the no criteria scenario. 
Second, how would the percentages change if no criteria were put in place to determine what COOP stations were receiving LES. This is termed the no LES scenario. In this case, all of the aforementioned criteria to determine ECWS snow or precipitation would still apply. The only exception is for COOP stations within LES belts. For these stations, the contribution of LES during an ECWS event is not directly excluded from the climatology. Third, how would the percentages change if the half period LES criterion described previously was used.

Figure 4.15 shows how the percentage of total snowfall directly from ECWS, on average per snow year, would have changed if there were no criteria in place to identify ECWS snowfall. These percentages in Figure 4.15 represent the percentage results if there were no criteria in place less the ECWS snowfall percentage results in Figure 4.3. The no criteria percentages are of course higher, and therefore this difference is positive. For areas in the western portion of the study domain, particularly along the middle and upper Mississippi River Valley, the percentage of snowfall on average per snow year from ECWS increases by as much as 15 to $25 \%$ if no criteria were in place. The percentages are also high in the LES belts. This will be further addressed in the no LES scenario. To the east of the Appalachians, the percentage difference is generally between 0 and $5 \%$. In these areas the procedure for identifying ECWS snowfall is of little consequence. This suggests that when an ECWS is present, it is not likely that additional snowfall from a non-ECWS feature affects the coastal region. 


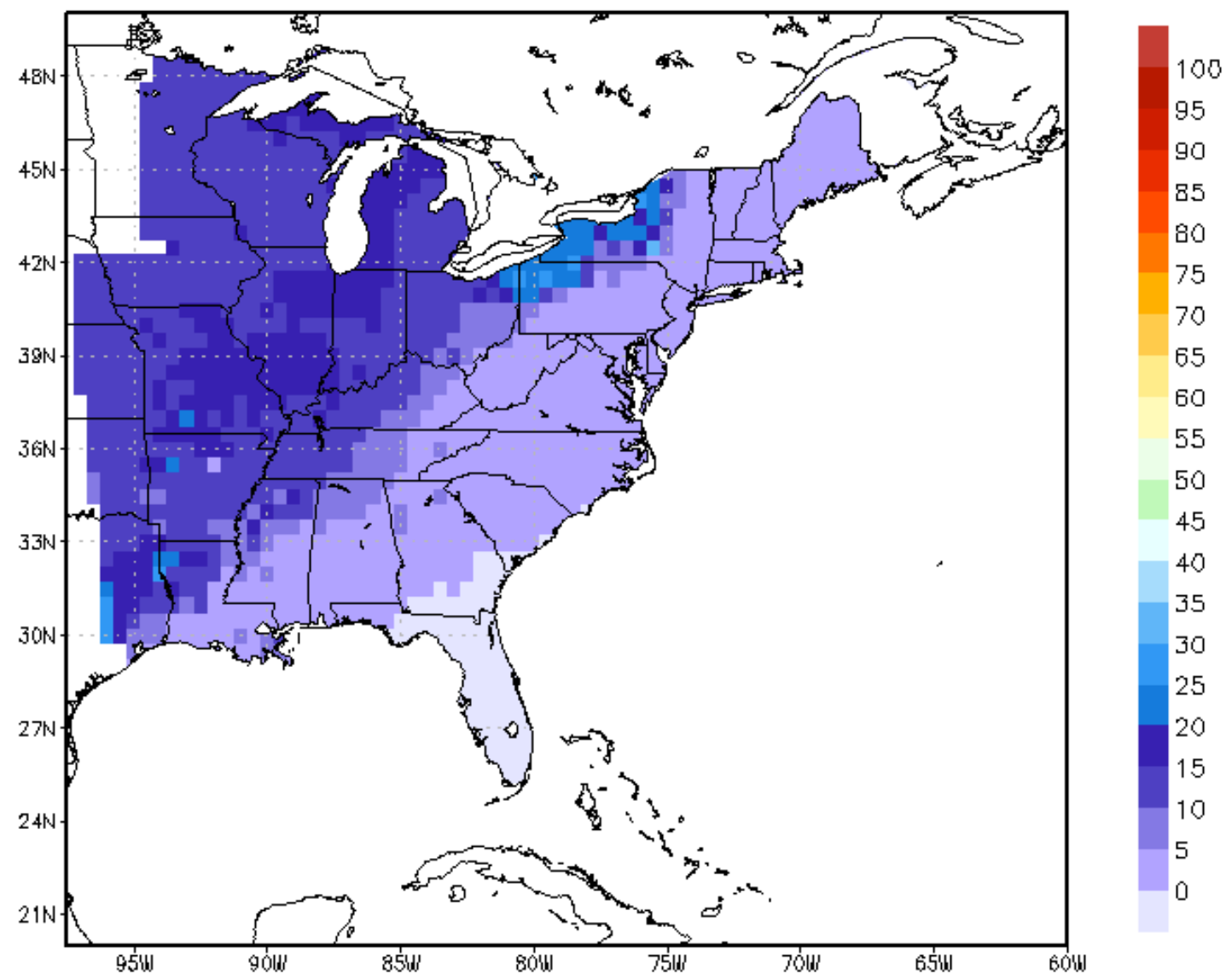

Figure 4.15: Sensitivity Analysis showing the percentage of snowfall from ECWS under the no criteria scenario less the percentage of snowfall from ECWS using the one period LES criterion, on average per snow year.

Figure 4.16 is similar, except for precipitation. In this case, the percentage differences are uniformly low throughout the study region, mainly because the percentages are calculated from total precipitation throughout the entire year. Therefore, less variability is expected in the percentages across the region, and between the two scenarios compared in Figure 4.16. Nonetheless, the highest percentage differences, around $10 \%$, occur in the vicinity of the Lake Erie and Lake Ontario LES belts, which will be addressed further in the sensitivity analysis for the no LES scenario. The remainder of the study region is primarily in the 0 to $5 \%$ range. The Outer Banks, and inland portions of North Carolina, as well as a few areas of the 
Northeast, show there is almost no difference between the percentages calculated using no criteria and the percentages calculated in this study.

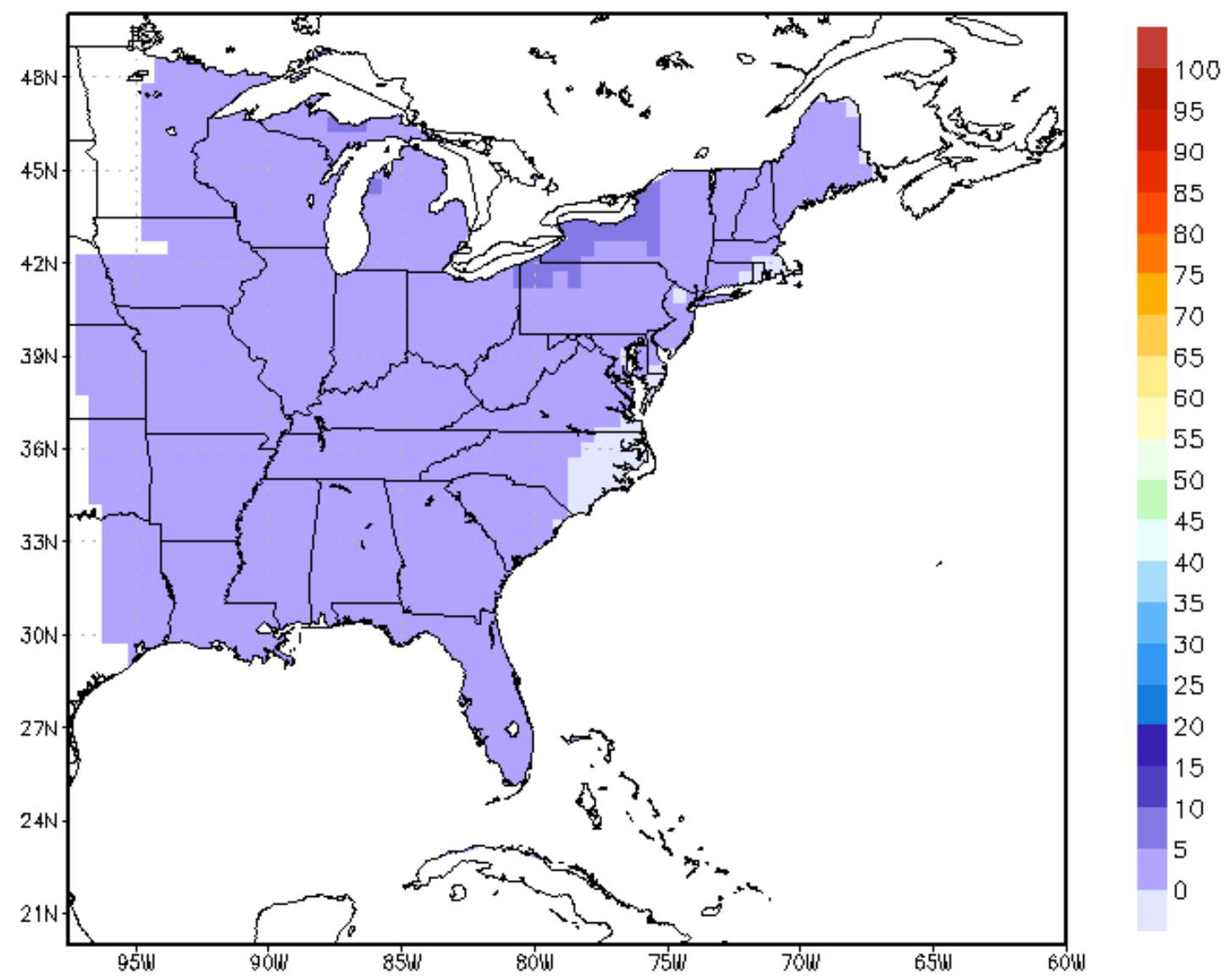

Figure 4.16: Sensitivity Analysis showing the percentage of precipitation from ECWS under the no criteria scenario less the percentage of precipitation from ECWS using the one period LES criterion, on average per snow year.

Overall, this sensitivity analysis for snowfall shows the methods in this study have minimal impact east of the Appalachians. West of the mountains snowfall is reduced by as much as $20-25 \%$. This is not unexpected given the distance of this region from the ECWS tracks and the intervention of the mountains. For precipitation, the impacts are small everywhere. This sensitivity analysis was also looked at on a monthly basis with consistent results.

The next sensitivity analysis to consider, deals with LES. Figure 4.17 shows the percentage of snowfall, directly from ECWS, if LES had not been directly 
excluded from the climatology, less the percentage of snowfall from ECWS using one period LES criterion, as depicted in Figure 4.3, on average per snow year. Due to interpolation, this Figure and the other Figures involving LES sensitivity analyses will have percentage differences greater than zero outside of the LES belts. As expected, the highest percentages occur in the Lake Erie and Lake Ontario belts. During a given snow year, on average, disregarding LES or assuming LES is a direct result of the ECWS, the percentage of snowfall directly from ECWS would increase by as much as 15 to $30 \%$ in the Lake Erie and Lake Ontario belts, and by as much as 5 to $10 \%$ in the Lake Michigan and Lake Superior belts.

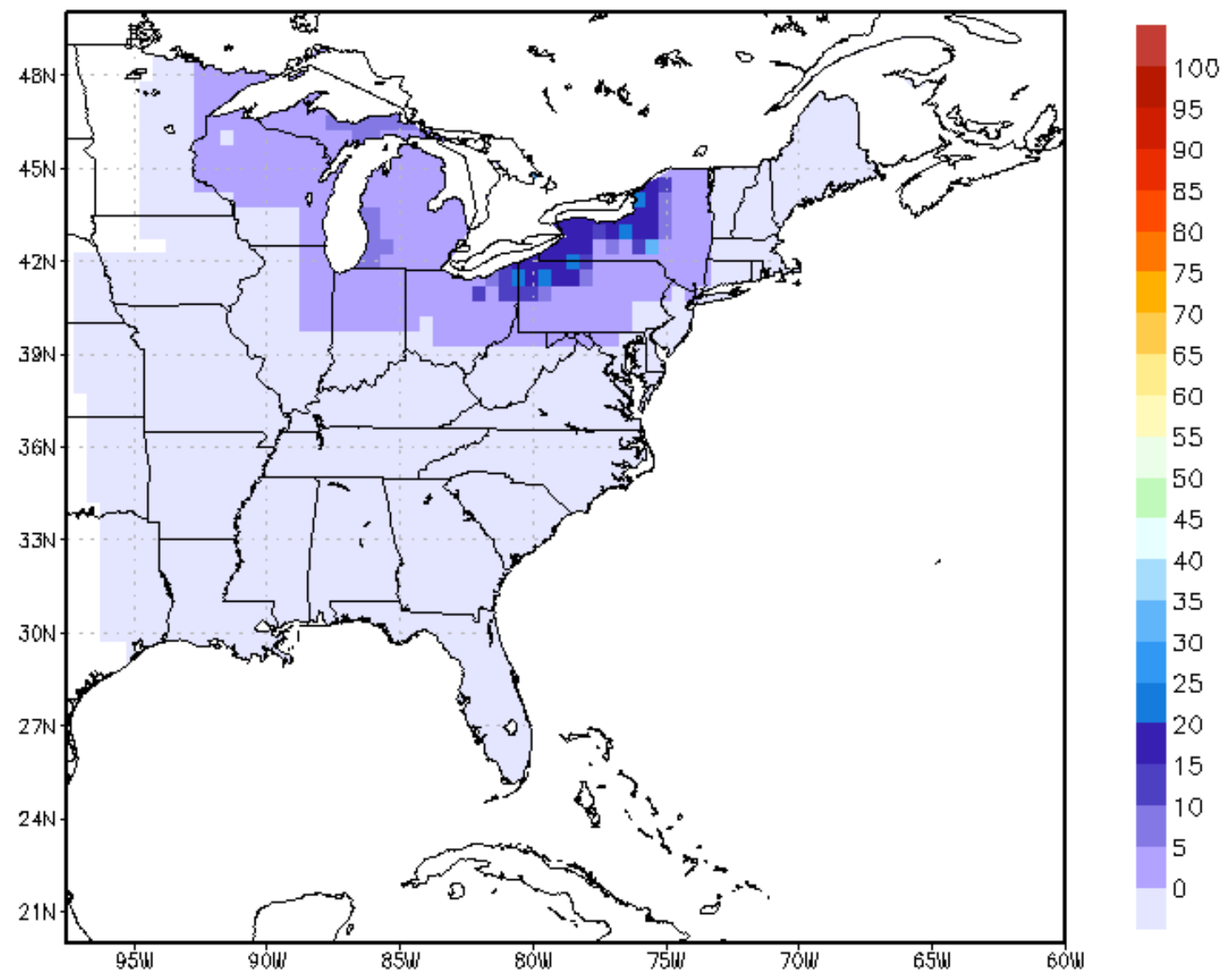

Figure 4.17: The sensitivity analysis showing the percentage of snowfall directly from ECWS assuming no LES, less the percentage of snowfall directly from ECWS using the one period LES criterion, on average per snow year. 
Figure 4.18 is similar to Figure 4.17, except for precipitation. Downwind of Lake Erie and Lake Ontario the percentage of precipitation from ECWS increases by 5 to $10 \%$, on average per snow year, if LES is included in the climatology. For the Lake Michigan and Lake Superior belts, these same percentages are from 0 to $5 \%$.

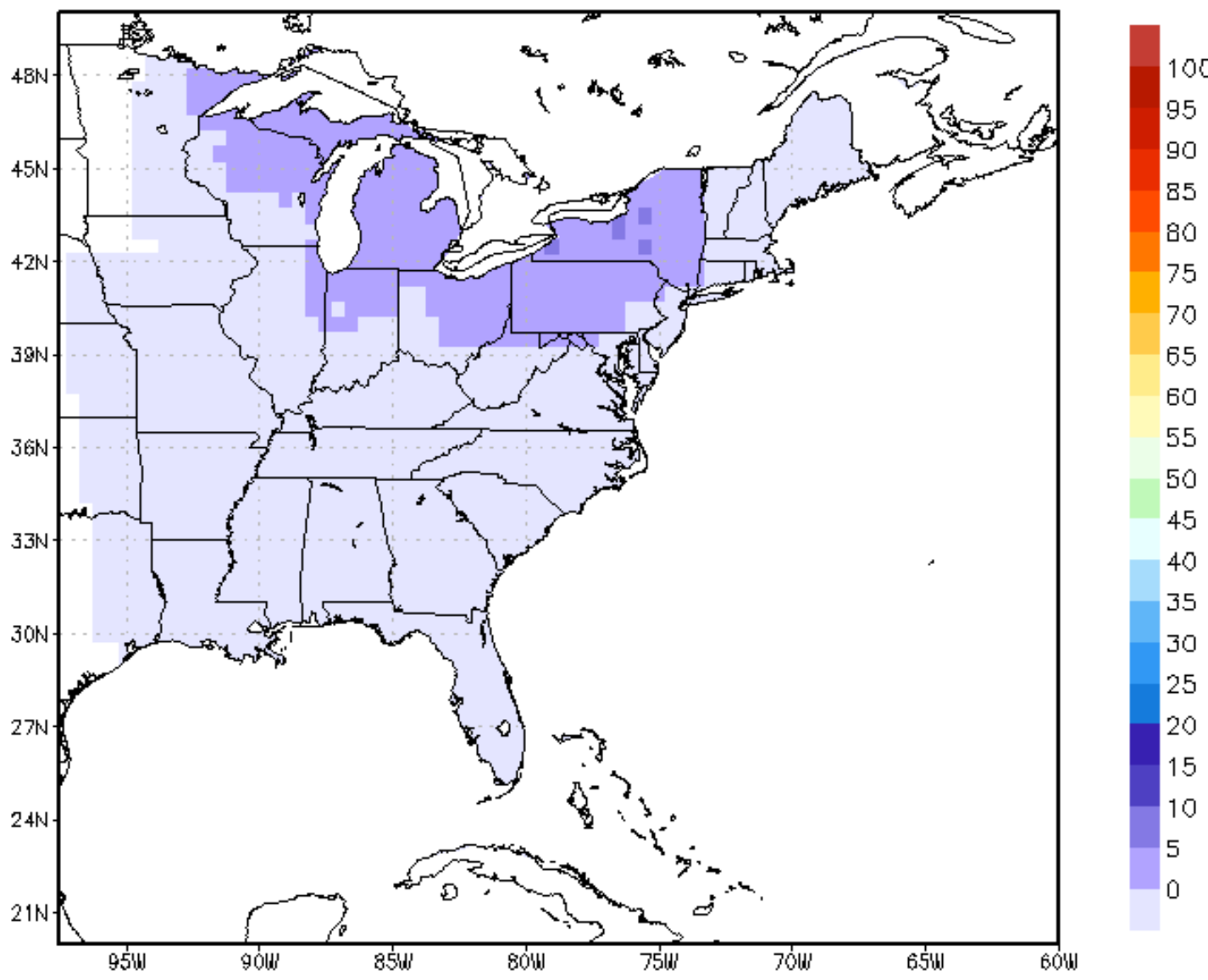

Figure 4.18: The sensitivity analysis showing the percentage of precipitation directly from ECWS assuming no LES, less the percentage of precipitation directly from ECWS using the one period LES criterion, on average per snow year.

The last portion of the sensitivity analysis was to compare the two methods for determining LES, one period and half period. The one period criterion is a stricter classification of ECWS snowfall, in that if one $6 \mathrm{~h}$ period of a storm day has LES favorable winds, then the snowfall for the entire day at that station is considered LES. In contrast, the half period scenario is more lenient, requiring more than half of the $6 \mathrm{~h}$ periods of a storm day to have LES favorable winds, to consider the snowfall for the 
entire day at that station LES. Figure 4.19 shows the percentage of snowfall, on average per snow year, from ECWS using the half period LES criterion, less the percentage using the one period LES criterion. Since the one period LES criterion is stricter, and by definition all those stations excluded in the half period scenario should also be excluded in the one period scenario, this difference will be positive.

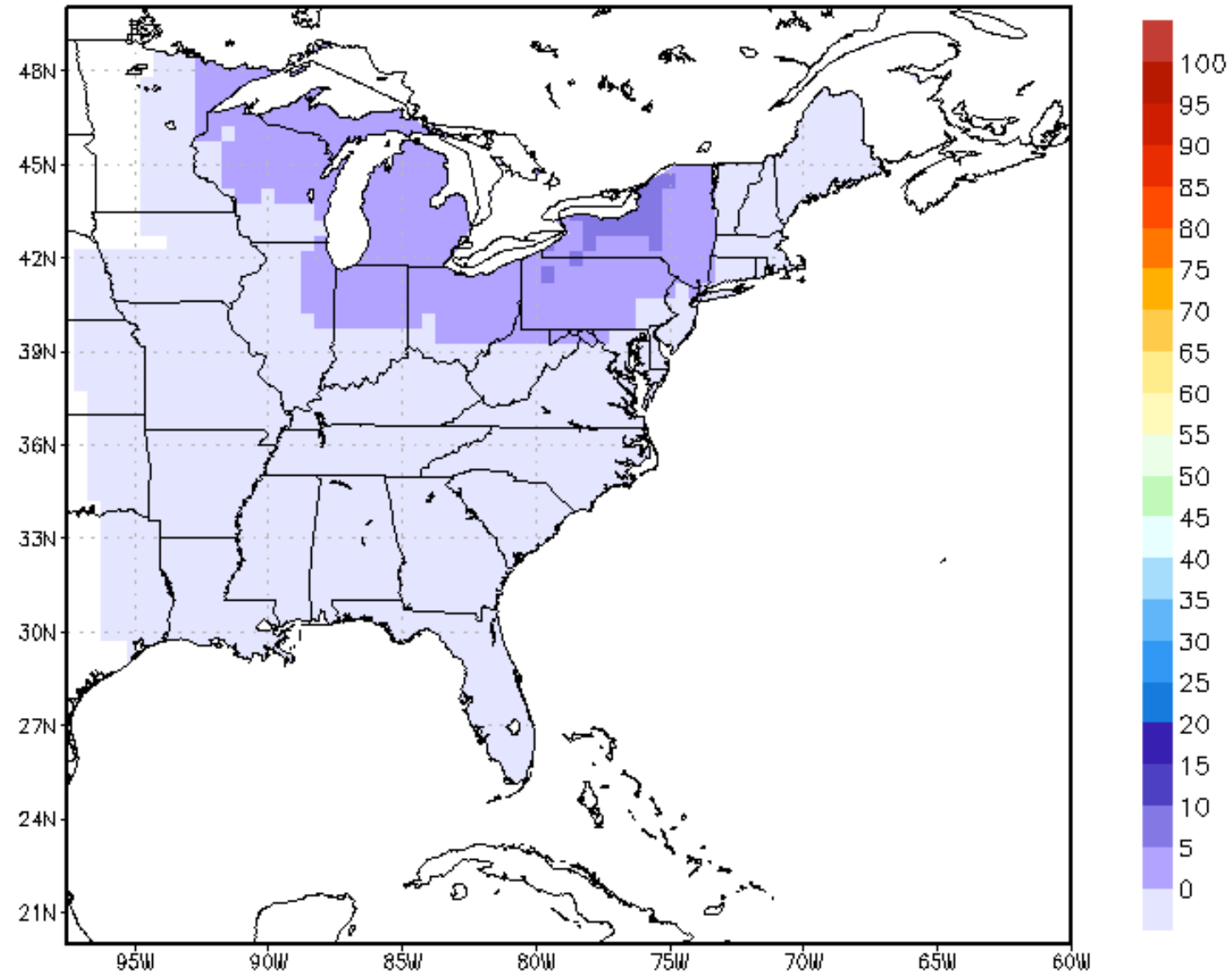

Figure 4.19: The percentage of snowfall from ECWS on average per snow year using the half period LES criterion, less the percentage of snowfall from ECWS on average per snow year using the one period LES criterion.

Figure 4.19 does show there is some difference between the two LES scenarios, particularly in the Lake Erie and Lake Ontario belts. Here, between 5 to $10 \%$ more of snowfall, on average per snow year, would be classified as ECWS snowfall if the more lenient half period LES criterion was adopted. Figure 4.20 is similar to Figure 4.19, except it is for precipitation. 


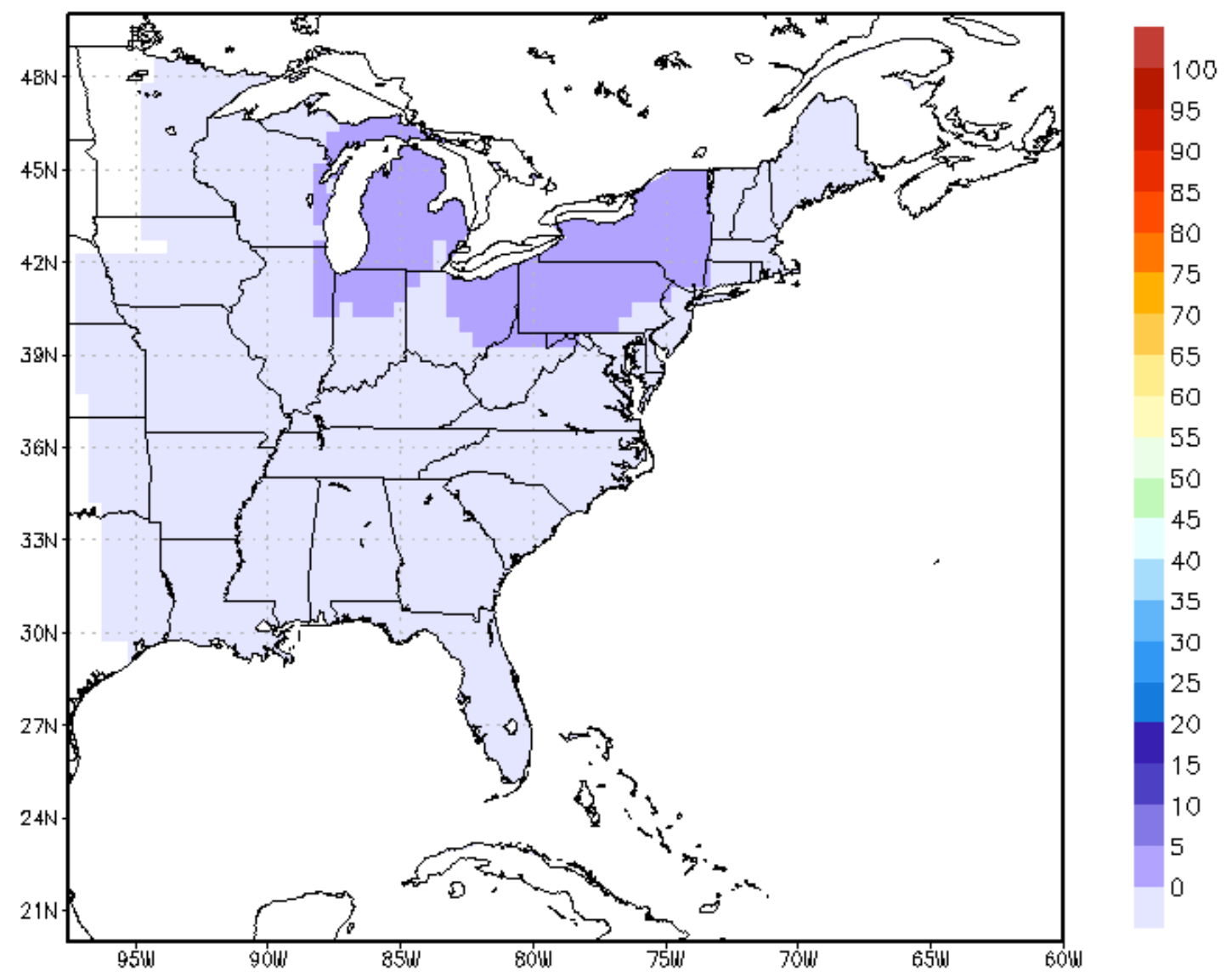

Figure 4.20: The percentage of precipitation from ECWS on average per snow year using the half period LES criterion, less the percentage of precipitation from ECWS on average per snow year using the one period LES criterion.

Figure 4.20 shows that between 0 and 5\% more precipitation, on average per snow year, is classified as ECWS precipitation if the more lenient LES criterion is applied. In parts of the Lake Superior belt, the difference is $0 \%$. Monthly percentage differences for both snow and precipitation were consistent with the annual values. While the choice of LES criterion does impact the results in the LES belts, the impact for snowfall is generally $10 \%$ or less, with the impact even smaller for precipitation. Since both of these LES scenarios are simplifications, the preference was to use the one period LES criterion. This decision was supported by the manual comparison of ECWS snowfall and LES discussed in the next section. 
The only sensitivity analysis investigated for bombs was to compare the percentage of snowfall or precipitation from bombs in an average snow year using the one period and half period LES scenarios. This analysis involves the percentage of precipitation or snowfall directly from bombs, on average per snow year, using the half period LES scenario, less the percentages using one period LES. The results (not pictured here) show that for snowfall the difference is between 0 and $5 \%$ across each of the snow belts. Regarding precipitation, the difference is $0 \%$ across the Lake Superior and Lake Michigan snow belts, and between 0 and 5\% across the Lake Ontario and Lake Erie belts.

\subsection{ECWS and LES Manual Analysis}

Three COOP stations across New York, within LES belts, were considered as part of a manual analysis of the LES identification procedure: Syracuse, Rochester, and Buffalo. Four snow years were considered: 2000-2001, 2002-2003, 2004-2005, and 2005-2006. Recent years were chosen, because archived radar images were used in this portion of the study. The archived radar images used were from the National Climatic Data Center (NCDC) and their Next Generation Weather Radar (NEXRAD) National Mosaic Reflectivity Images (NCDC, 2008). In the event the reflectivity images were missing for a particular day, NOAA archived weather maps (Daily Weather Maps, 2008), were looked at to assess an appropriate classification for the precipitation. An attempt was made at looking at a variety of snow years.

The snow year 2000-2001 was chosen because it was a particularly high total snowfall year for all three stations. Moreover, the occurrence of ECWS was slightly above average (15), with high LES activity based on the frequency and intensity of events reported on the NWS Buffalo Lake Effect Snow web page (NWS Buffalo Snow Season Archive, 2008). The snow year 2002-2003 was chosen to represent high ECWS activity (18 occurrences), as well as high LES activity. The snow year 2004- 
2005 was selected to represent a low LES activity year, but average ECWS activity (14 occurrences). Finally, the snow year 2005-2006 was chosen as a year with below average ECWS activity (7 occurrences) and high LES activity.

For each COOP station, and for each day that snowfall was recorded, archived radar images were subjectively examined to determine if the snowfall was in either of four categories. If the snowfall was directly the result of an ECWS based on the associated ECWS dates used in this study and based on the movement of the precipitation on the radar, it was classified as ECWS snowfall. If during an ECWS event, the snowfall appeared to be enhanced by the Great Lakes, the snowfall was classified as a combination. For example, a large area of precipitation moving southeast across Lake Ontario, during an ECWS event, would be classified as combination snowfall for COOP stations impacted by this area of precipitation with recorded snowfall that day. If the snowfall was directly the result of LES, based primarily on movement of the precipitation on the radar, and secondarily on archived LES events from NWS Buffalo (NWS Buffalo - Snow Season Archive, 2008), it was classified as LES snowfall. However, LES was occasionally identified at stations on days not included in NWS Buffalo's archived events (NWS Buffalo - Snow Season Archive, 2008), and in general these amounts were light. LES was manually identified in some instances during ECWS events, and a few NWS Buffalo archived events (NWS Buffalo - Snow Season Archive, 2008) corresponded with ECWS. In addition, it was not uncommon for NWS Buffalo archived events (NWS Buffalo Snow Season Archive, 2008) to precede or follow ECWS events. Finally, if snowfall occurred not falling into any of the previously mentioned categories it was classified as "neither". Each daily snowfall amount was assigned to a single category, despite the possibility that different mechanisms were responsible for generating snowfall throughout the day. 
Appendix A and Figures A.1 through A.3 contain results for Syracuse, Rochester and Buffalo, respectively, for the manual classification of snowfall types during the snow years 2000-2001, 2002-2003, 2004-2005, and 2005-2006. Table 4.1 contains a summary of snowfall amounts found at each of these stations, by snow year.

Table 4.1: Summary of manual classification for Syracuse (SYR), Rochester (ROC), and Buffalo (BUF), by snow year. Amounts $(\mathrm{cm})$ are listed for manually classified LES and ECWS snowfall, as well as snow year totals.

\begin{tabular}{|l|c|c|c|c|c|c|c|c|c|c|c|c|}
\hline & \multicolumn{9}{|c|}{ 2000-2001 } & \multicolumn{4}{c|}{ 2002-2003 } & \multicolumn{3}{c|}{ 2004-2005 } & \multicolumn{3}{|c|}{$\mathbf{2 0 0 5 - 2 0 0 6}$} \\
\hline & LES & ECWS & Total & LES & ECWS & Total & LES & ECWS & Total & LES & ECWS & Total \\
\hline SYR & 252.0 & 73.9 & $\mathbf{4 8 7 . 4}$ & 181.1 & 75.7 & $\mathbf{3 8 9 . 1}$ & 132.6 & 46.2 & $\mathbf{3 4 5 . 9}$ & 260.1 & 4.8 & $\mathbf{3 1 6 . 5}$ \\
\hline & & & & & & & & & & & & \\
ROC & 110.0 & 34.3 & $\mathbf{3 3 0 . 7}$ & 144.0 & 60.2 & $\mathbf{3 3 4 . 0}$ & 77.0 & 68.3 & $\mathbf{2 8 8 . 5}$ & 122.9 & 5.8 & $\mathbf{1 8 7 . 7}$ \\
\hline & & & & & & & & & & & & \\
BUF & 200.9 & 23.4 & $\mathbf{3 7 9 . 0}$ & 126.5 & 37.8 & $\mathbf{2 8 2 . 7}$ & 85.3 & 51.8 & $\mathbf{2 7 7 . 1}$ & 135.6 & 4.1 & $\mathbf{1 9 8 . 6}$ \\
\hline
\end{tabular}

Figure 4.21 is a summary, comparing the automated procedure results to the manually computed results. In general, the automated procedure, using one period LES criterion, most closely matches the manually calculated percentages of snowfall from ECWS for Rochester and Buffalo, where each station had two years where the difference was 6 percentage points or less. In contrast, Syracuse exhibited the greatest difference between the automated and manual procedures, with three years having greater than a 10 percentage point difference. A comparison was also made between the percentage of ECWS snowfall plus combination snowfall, both identified manually, and the automated procedure percentage of ECWS snowfall where LES is included in the climatology (no LES scenario). 


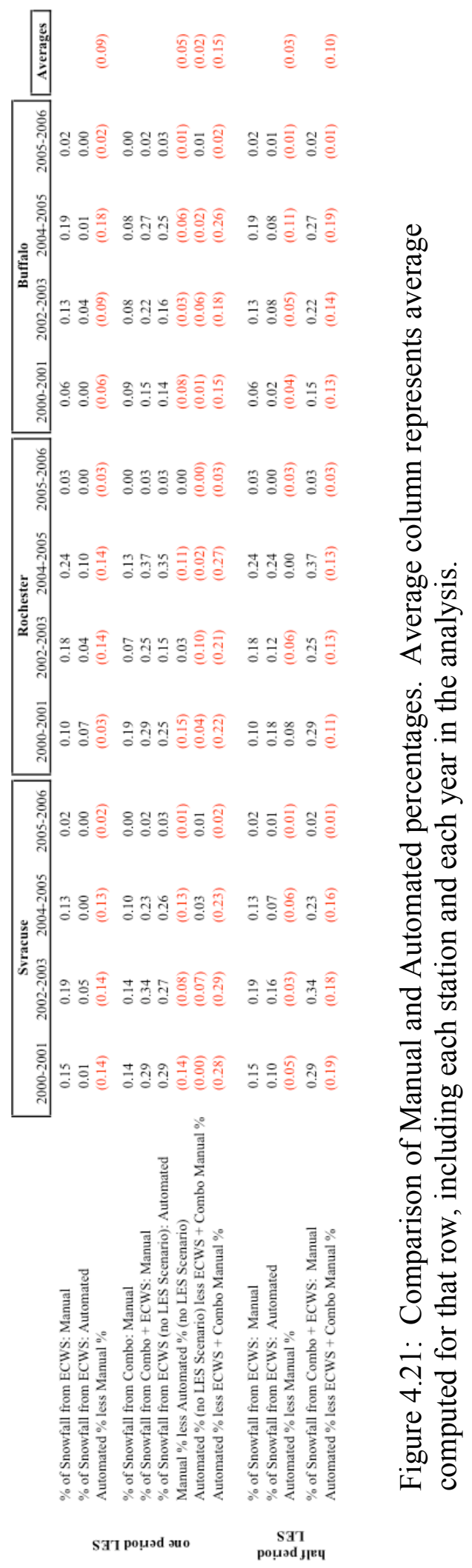


For Syracuse, Rochester and Buffalo, this comparison in Figure 4.21 suggests that combination snowfall or lake enhanced snowfall is a factor, and indicates a source of uncertainty during ECWS events. More specifically, for each of these stations, from Figure 4.17 , it can be inferred that approximately 15 to $20 \%$ of snowfall, on average per snow year, is related to LES during an ECWS event either as direct LES or as lake enhanced snow.

Considering Figure 4.21 further, in the absence of any criteria for directly identifying LES, the percentage of snowfall from ECWS (no LES scenario) on average per snow year is approximately $5 \%$ higher than the manually computed ECWS percentages, which exclude combination snowfall. This shows that some method for identifying and excluding LES from the climatology is necessary. However, the manually computed ECWS snowfall percentages and combination snowfall percentages closely sum to the automated percentages where LES is included in the climatology. Furthermore, the difference between the manually computed ECWS snowfall percentages, and the automated percentages using the half period LES criterion, is marginal in most cases. Finally, in comparing the difference between the manually calculated ECWS percentages, and the automated percentages, for both LES scenarios, the half period scenario attributes approximately $6 \%$ more snowfall per snow year to combination or lake enhancement. This analysis suggests that if lake enhanced or combination snowfall during an ECWS is to be included in the climatology, the half period LES criterion is more effective. However, if the objective is to exclude lake enhanced snowfall, the one period LES criterion is the better choice. Even though the one period automated procedure underestimates ECWS snowfall percentages by approximately $9 \%$, the scenario was still desirable. Since both scenarios are simplifications, and both contain imperfections, using the one period scenario was desirable to exclude from the climatology, as much as possible, LES, and 
lake enhanced events, since both are sources of uncertainty. This brief manual analysis provides reasoning for further research to improve the precipitation climatology presented in this paper. Both lake enhanced snowfall and the identification of LES during ECWS events are sources of uncertainty in the Great Lakes region, particularly downwind of Lakes Erie and Ontario.

\subsection{Analysis of Five Regions}

Based on Figure 4.3, five regions were chosen for further analysis. These five Regions can be seen in Figure 4.22. The first region, Region I, primarily including Mississippi, Alabama, and Georgia, coincides with the area of highest ECWS snow percentages. Region II, also in the southeast, but along the coast, represents a regional minimum in ECWS snow percentages. One possible explanation for this feature, which would require further research, is that this area is often in the warm sector of an ECWS, and likely receives mostly rain during an ECWS. Region III, which includes a large portion of the Appalachian Mountains or the central Appalachian Mountains, was selected as a transition zone from higher percentages to the east of and along the Mountains, to lower percentages to the west of the Mountains. Region IV was selected to include the large urban centers of the mid-Atlantic and Northeast. Finally, Region V was selected to represent the region where ECWS often reach their peak intensity (Glickman, 2000), but ECWS snowfall percentages are relatively low (Figure $4.3)$. 


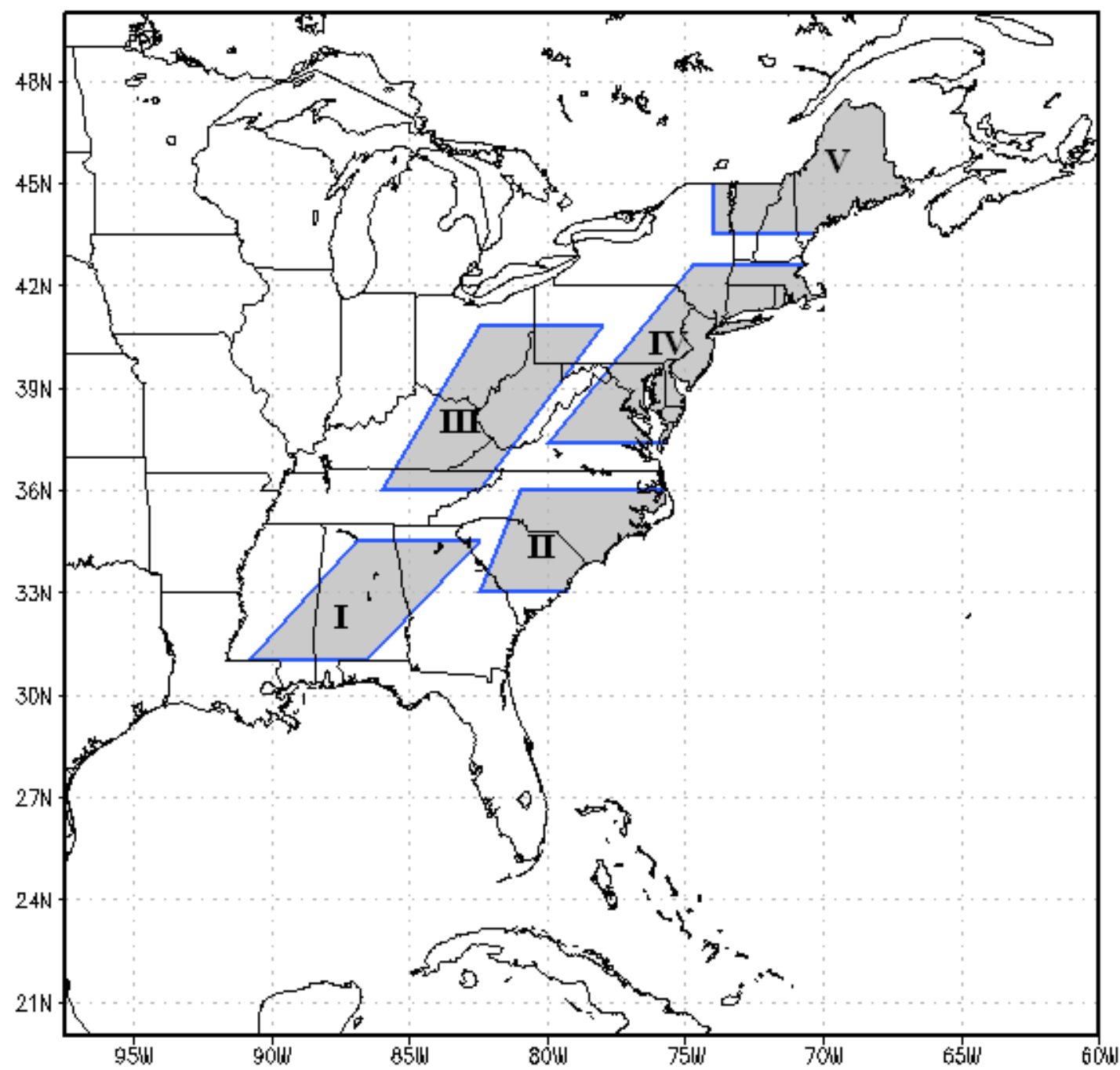

Figure 4.22: Boundaries of regions included in analysis of five regions.

These five regions depicted in Figure 4.22 were used for further evaluation by averaging the study period seasonal average percentages for all stations in each region, resulting in a single percentage for each snow year for each region. This procedure was applied to each region, for the following variables: percentage of snowfall from ECWS, amount of snowfall from ECWS, amount of total snowfall, percentage of precipitation from ECWS, amount of precipitation from ECWS, and amount of total precipitation. The analysis consists of four parts.

First was to visually inspect graphs for each region, showing by snow year, the percentage of snowfall or precipitation from ECWS and the amount of snowfall or 
precipitation from ECWS. These graphs can be seen in Appendix B as Figures B.1 through B.10. Qualitatively, no trends are evident, which is confirmed by statistics. In general, snow years with a high percentage of snowfall or precipitation from ECWS correspond with relatively high amounts of snowfall or precipitation from ECWS. The opposite holds true as well, and that in general, snow years with a low percentage of snowfall or precipitation from ECWS correspond with relatively low amounts of snowfall or precipitation from ECWS.

Since Hirsch et al. (2001) find relationships between ECWS frequency and El Niño months, the next portion of the analysis was to consider ECWS percentages and amounts during each ENSO phase. Each snow year was classified as either an El Niño, La Niña or Neutral year based on the methods from Eichler and Higgins (2006). Using this classification, the methods of Hirsch et al. (2001) were applied to the following variables to test each region for the presence of a significant relationship to El Niño, La Niña or Neutral years: percentage of snowfall from ECWS, amount of snowfall from ECWS, percentage of precipitation from ECWS, and amount of precipitation from ECWS. A test statistic (Hirsch et al., 2001) was calculated as:

$$
t=\frac{\left(\bar{X}_{\text {event }}-\bar{X}_{\text {non-event }}\right)}{\sqrt{\frac{s_{\text {event }}^{2}}{n_{\text {event }}}+\frac{s_{\text {non-event }}^{2}}{n_{\text {non-event }}}}}
$$

This test statistic in Eq. (3) was used to identify significant differences between event years and non-event years (Hirsch et al., 2001). In Eq. (3), $\bar{X}$ is an average of one of the variables, $n$ is the number of events (either El Niño, La Niña or Neutral snow years) and $s$ is the corresponding variable's standard deviation (Hirsch et al., 2001). Event years are associated with the ESNO phase being considered, and nonevent years are all remaining years. From here, consistent with Hirsch et al. (2001), a 
dataset of 10,000 test statistics was computed using a resampling technique. With this technique, the variable values were randomly assigned to different years resulting in different event and non-event classification (Hirsch et al., 2001). An advantage to this technique over traditional statistical procedures is that assumptions regarding the underlying distribution of the dataset are not necessary (Wilks, 1995 and Hirsch et al., 2001). Finally, a two-tailed $p$ value was computed by comparing the original test statistic to the artificial dataset of 10,000 test statistics (Hirsch et al., 2001). A twotailed test was desirable because no assumptions were made regarding the sign of the original test statistics (DeGaetano and Allen, 2002). Figures 4.23 through 4.27 show the results of this analysis, with each figure depicting a different region. A discussion of these figures follows.

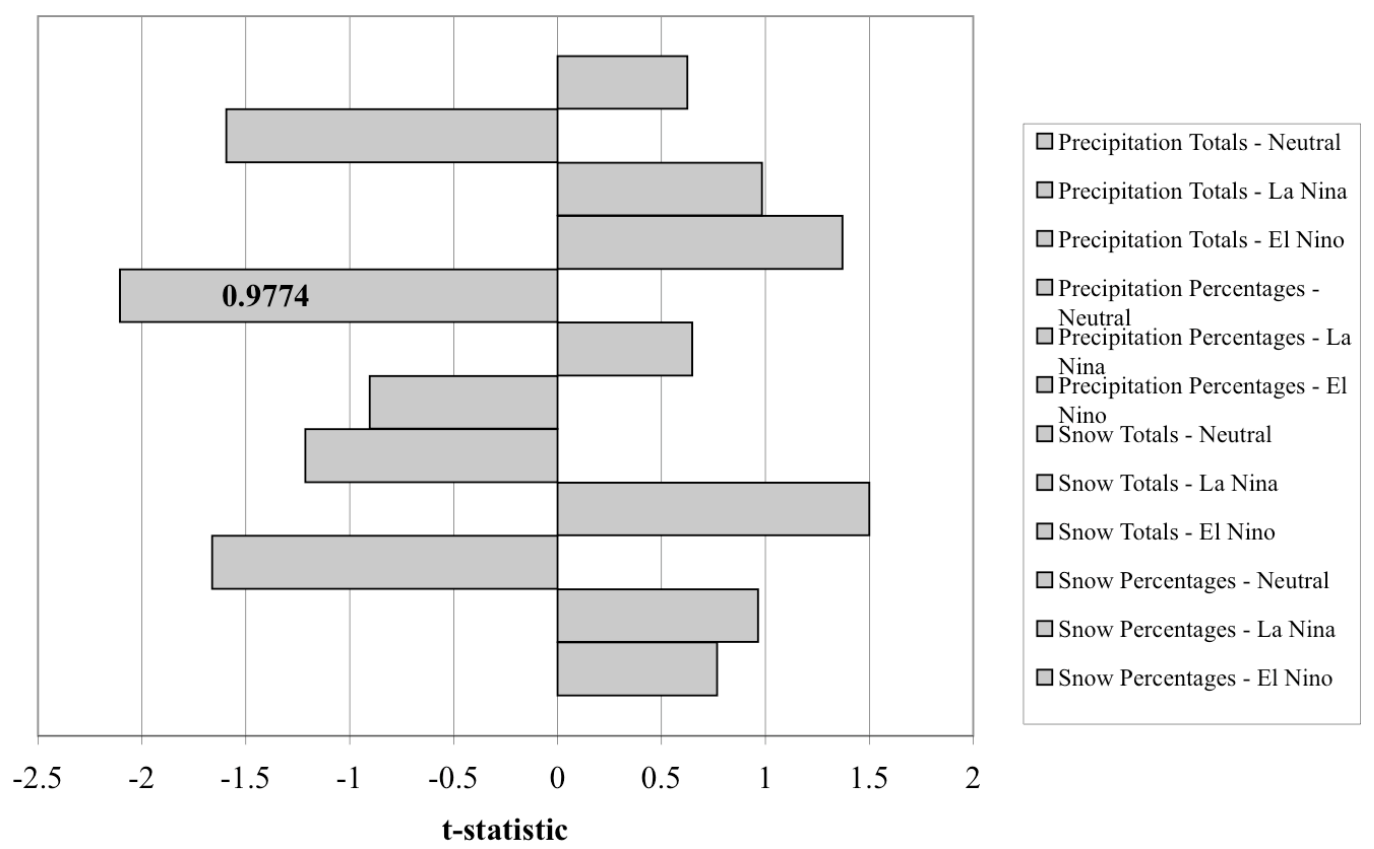

Figure 4.23: For Region I, a test (t) statistic, which compares event years (El Niño, La Niña or Neutral) to non-event years, for the following variables: amount of precipitation from ECWS, percentage of precipitation from ECWS, amount of snowfall from ECWS, and percentage of snowfall from ECWS. Positive (Negative) values for the t-statistic indicate an (a) increase (decrease) in that variable during event years. Any variables and associated bars with a $p$ value significant at the $5 \%$ level, using a two-tailed test, are noted. The order of the event type - variable combinations in the key (right) corresponds to the order of the variables in the bar graph (left). 


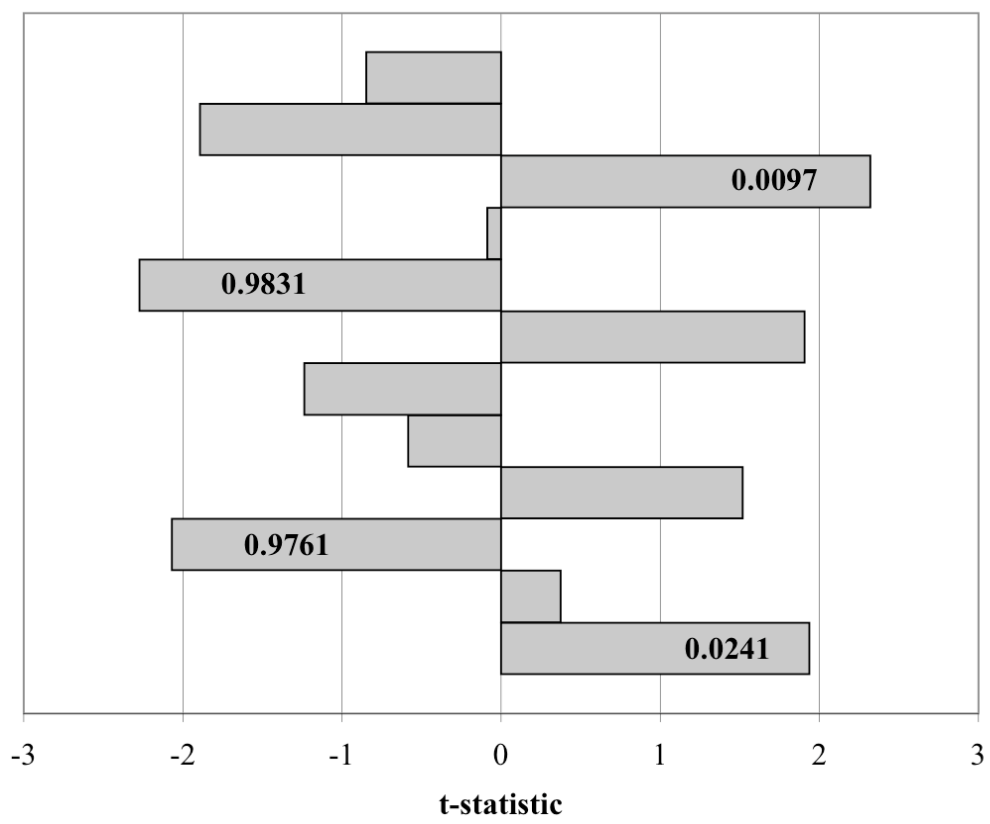

$\square$ Precipitation Totals - Neutral

$\square$ Precipitation Totals - La Nina

$\square$ Precipitation Totals - El Nino

$\square$ Precipitation Percentages -

Neutral

$\square$ Precipitation Percentages -

La Nina

$\square$ Precipitation Percentages - El

Nino

$\square$ Snow Totals - Neutral

$\square$ Snow Totals - La Nina

$\square$ Snow Totals - El Nino

$\square$ Snow Percentages - Neutral

$\square$ Snow Percentages - La Nina

$\square$ Snow Percentages - El Nino

Figure 4.24: Same as Figure 4.23, for Region II.

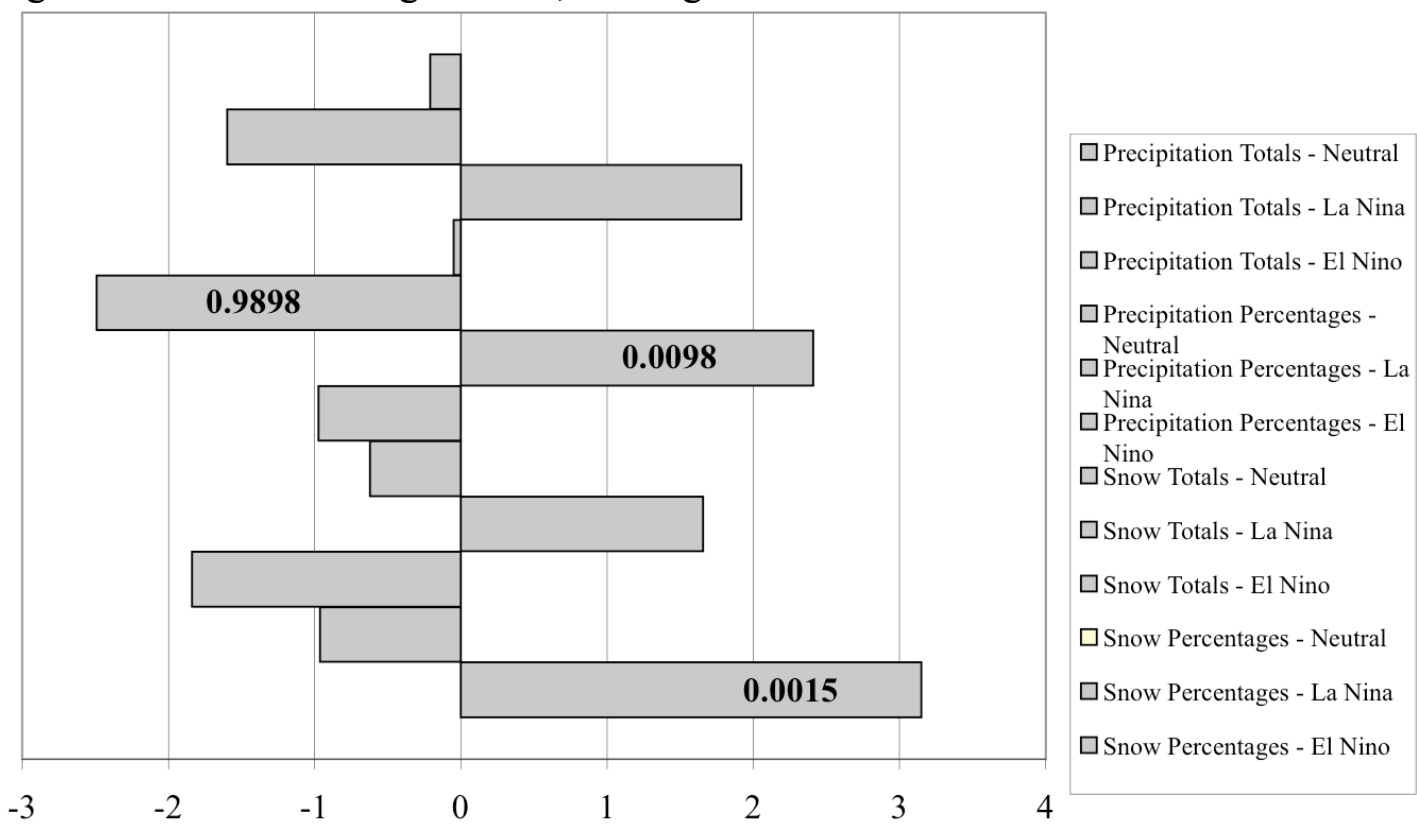

t-statistic

Figure 4.25: Same as Figure 4.23, for Region III. 


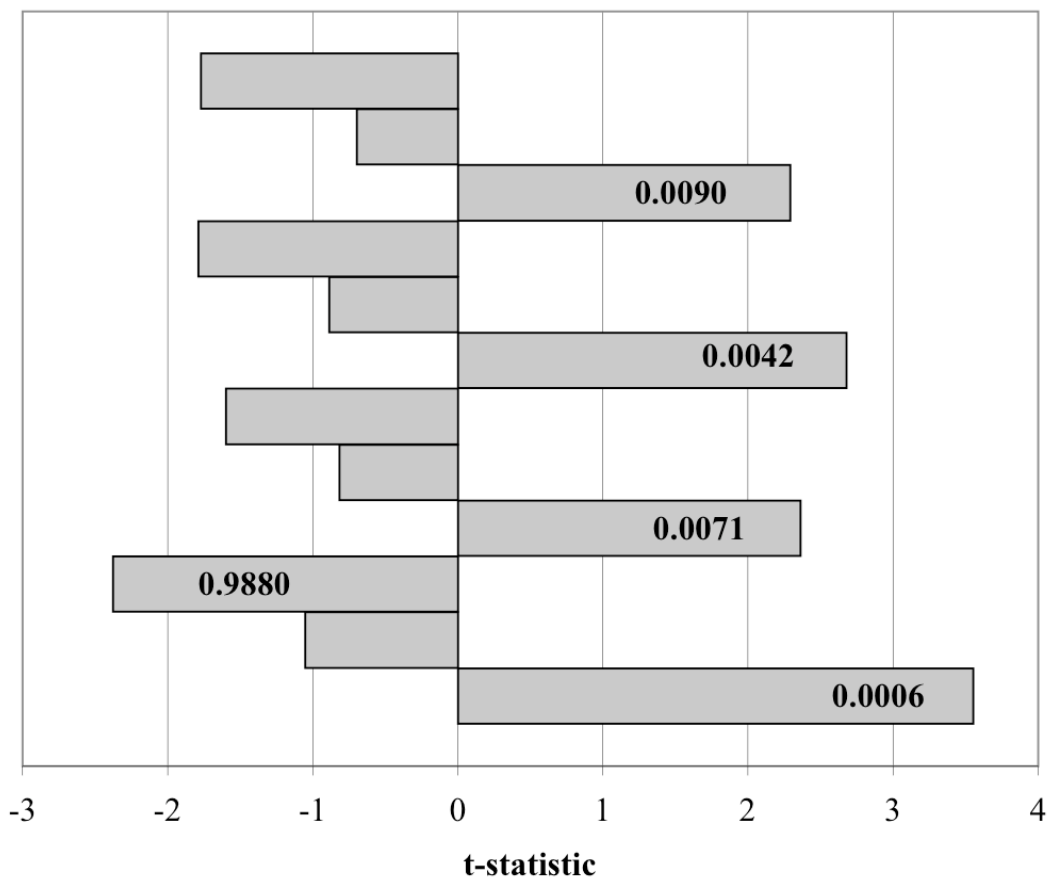

$\square$ Precipitation Totals - Neutral $\square$ Precipitation Totals - La Nina $\square$ Precipitation Totals - El Nino $\square$ Precipitation Percentages Neutral

$\square$ Precipitation Percentages - La Nina

$\square$ Precipitation Percentages - El Nino

$\square$ Snow Totals - Neutral

$\square$ Snow Totals - La Nina

$\square$ Snow Totals - El Nino

$\square$ Snow Percentages - Neutral

$\square$ Snow Percentages - La Nina

$\square$ Snow Percentages - El Nino

t-statistic

Figure 4.26: Same as Figure 4.23, for Region IV.

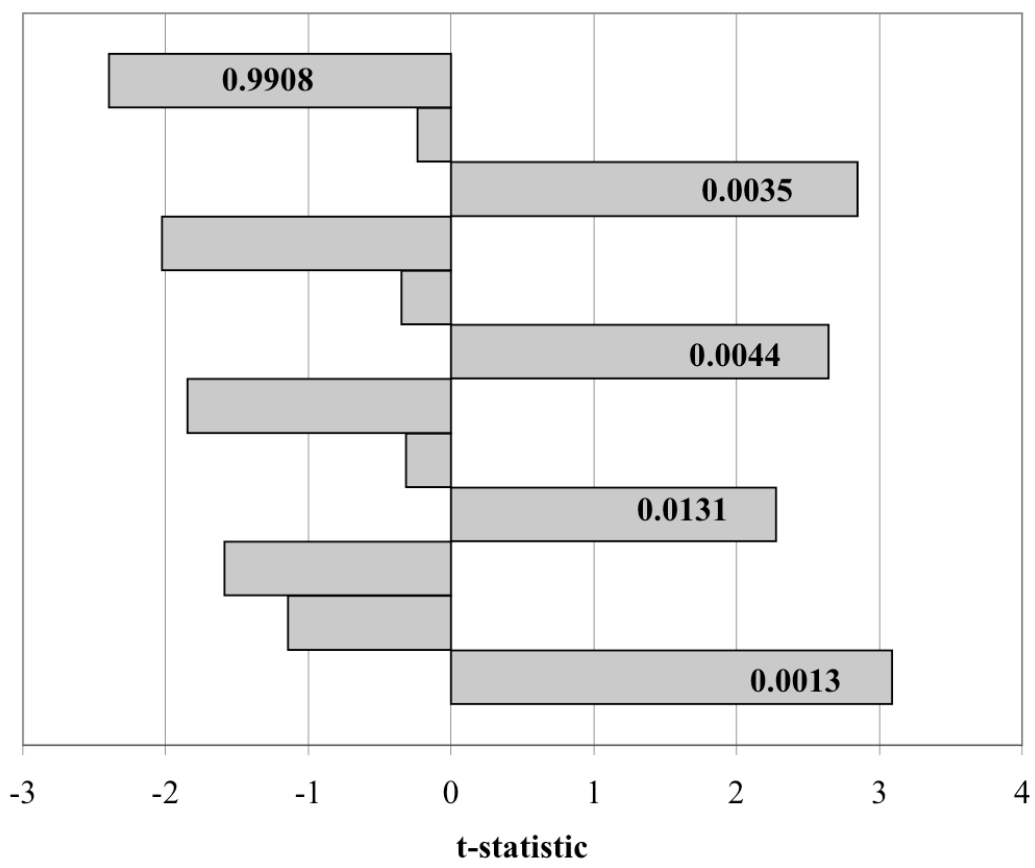

$\square$ Precipitation Totals - Neutral

$\square$ Precipitation Totals - La Nina

$\square$ Precipitation Totals - El Nino

$\square$ Precipitation Percentages -

Neutral

$\square$ Precipitation Percentages - La

Nina

$\square$ Precipitation Percentages - El

Nino

$\square$ Snow Totals - Neutral

$\square$ Snow Totals - La Nina

$\square$ Snow Totals - El Nino

$\square$ Snow Percentages - Neutral

$\square$ Snow Percentages - La Nina

$\square$ Snow Percentages - El Nino

Figure 4.27: Same as Figure 4.23, for Region V.

Beginning with Region I, Figure 4.23 shows the only significant relationship is during La Niña years for ECWS precipitation percentages. During La Niña years, a decrease is expected in the percentage of precipitation from ECWS. These findings are 
consistent with Ropelewski and Halpert's (1996) Figure 3, who find cold or La Niña (Philander, 1990) episodes are associated with less precipitation in the Gulf and Northern Mexico region. From Region II, there are four significant relationships in Figure 4.24. As in Region I, for Region II, during La Niña years, a decrease is expected in the percentage of precipitation from ECWS. During El Niño years for Region II, an increase is expected in the amount of precipitation from ECWS and the percentage of snowfall from ECWS. The percentage of precipitation from ECWS also shows the same relationship, although not significant. Finally, for Region II, Neutral years indicate a decrease in the percentage of snowfall from ECWS. The other variables show this relationship as well, but are not significant at the 5\% level. Region III exhibits significant relationships for both El Niño years and La Niña years for precipitation percentages. During La Niña years, a decrease is expected in the percentage of precipitation from ECWS. In contrast, El Niño years result in an increase in the percentage of precipitation and snowfall from ECWS.

Regions IV and V exhibit the highest number of significant relationships. Region IV, which includes the large metropolitan areas of Washington D.C., Baltimore, Philadelphia, New York and Boston, shows significant relationships during El Niño years. This same relationship is found in Region V as well. Figures 4.26 and 4.27 reveal that during El Niño years an increase is expected in the following variables: amount of precipitation and snowfall from ECWS, percentage of precipitation and snowfall from ECWS. These findings are consistent with results from Hirsch et al. (2001), where they find the frequency of ECWS increases during El Niño months. Interestingly, Region IV has negative relationships with all of these variables during both La Niña and Neutral years, with the only significant negative relationship being the percentage of snowfall from ECWS during Neutral years. Region $\mathrm{V}$ also has this same negative relationship with all of these variables during 
both La Niña and Neutral years. However, the only significant negative relationship is the amount of precipitation from ECWS during Neutral years.

To validate the visual inspection of the graphs for each region in Appendix B showing no evidence of any time dependent trends, a technique was adopted from DeGaetano and Allen (2002), which follows the methods of Karl and Williams (1987). The identification of any time dependent trends was considered for the following variables: percentage of snowfall from ECWS, amount of snowfall from ECWS, percentage of precipitation from ECWS, and amount of precipitation from ECWS. For each region and for each variable, a first-difference series was computed by taking the value of the 10-year running mean centered on year $i+1$ and subtracting from it the value centered on year $i$ (DeGaetano and Allen, 2002). DeGaetano and Allen (2002) note that by using this procedure, equal weight is given to all observations, which eliminates overemphasis on observations at the end and beginning of the time series. Using this first-difference series, a test statistic was computed based on a single mean student's t-test. Next, a dataset of 10,000 test statistics was computed using the same resampling technique as before. The variable values were randomly assigned to different snow years, first-difference series were computed based on these artificial datasets, and a set of test statistics was computed. A two-tailed $p$ value was computed by comparing the original test statistic to the artificial dataset of 10,000 test statistics (Hirsch et al., 2001). As with the ENSO phase analysis, a two-tailed test was desirable because no assumptions were made regarding the direction of any possible trends (DeGaetano and Allen, 2002). These $p$ values (not pictured) confirm the visual inspection that there are no significant time dependent trends evident with any of the variables during the study period. None of the variables exhibited significant trends at the $5 \%$ level, nor were any evident at the $10 \%$ level of significance. 
The final element of the statistical analysis of the five regions is to consider the relationship with the frequency of ECWS by snow year. The following variables were considered for each snow year: percentage of snowfall from ECWS, amount of snowfall from ECWS, amount of total snowfall, percentage of precipitation from ECWS, amount of precipitation from ECWS, and amount of total precipitation. Certainly, one would expect that years with higher occurrences of ECWS will likely result in higher amounts of ECWS snowfall or precipitation. That the opposite will hold true is also a reasonable expectation. However, neither of these expectations are certainties. Years with high occurrences of ECWS might be conducive to rain, lowering the amount of ECWS snow, or during such years storms may track far offshore, limiting precipitation in some regions. In addition, the impact on the percentage of ECWS snowfall or precipitation is even more uncertain. Therefore, the relationship between ECWS frequency and total snowfall or precipitation for a snow year, needs to be verified as well.

The method for conducting this analysis is similar to that used for the ENSO phases. However, instead of snow years being classified by ENSO phase, they were classified by occurrences of ECWS as either high, average or low activity. High years were considered to be those snow years in the top $25^{\text {th }}$ percentile (with rounding to the nearest whole occurrence) of ECWS occurrences by snow year, while low years were those in the bottom $25^{\text {th }}$ percentile. The remaining years were considered average. Table 4.2 provides detail of this classification.

Table 4.2: Number of snow years classified as high, average, and low occurrence years, with range of the number of storms per year included in each category.

\begin{tabular}{|c|c|c|}
\hline $\begin{array}{c}\text { Snow Year Classification } \\
\text { of ECWS Occurrences }\end{array}$ & $\begin{array}{c}\text { Number of Snow Years } \\
\text { in Category }\end{array}$ & $\begin{array}{c}\text { Range of Number of } \\
\text { ECWS per Snow Year }\end{array}$ \\
\hline High & 13 & 22 to 17 \\
\hline Average & 28 & 16 to 11 \\
\hline Low & 14 & 10 to 6 \\
\hline
\end{tabular}


Next, for each region, each variable, and each ECWS frequency classification, the test statistic in Eq. (3) was computed. The event years are those snow years associated with the ECWS frequency classification being considered, while non-event years are the remaining years. Again, a dataset of 10,000 test statistics was constructed using a resampling technique, whereby the variable values were randomly assigned to different years resulting in different event and non-event classification (Hirsch et al., 2001). Depending on the variable being considered, either a one-tailed or two-tailed test was conducted with a $p$ value computed by comparing the original test statistic to the artificial dataset of 10,000 test statistics (Hirsch et al., 2001). In cases where no assumptions were made regarding the sign of the original test statistic, a two-tailed test was desirable (DeGaetano and Allen, 2002). This two-tailed test applied to all variables and ECWS occurrence classification schemes except for the amount of snowfall and precipitation from ECWS in high and low occurrence years. For the variables where a two-tailed test is applicable, there is considerable uncertainty in determining their relationship to ECWS frequency. The uncertainty arises from having no knowledge of non-ECWS events in any given snow year. In contrast, a one-tailed test was applied to the amount of snowfall and precipitation from ECWS in high and low occurrence years. Even for ECWS snowfall or precipitation amounts, no assumptions were made regarding average ECWS occurrence years. Figures 4.28 through 4.32 show the results of this analysis, and a discussion follows. 


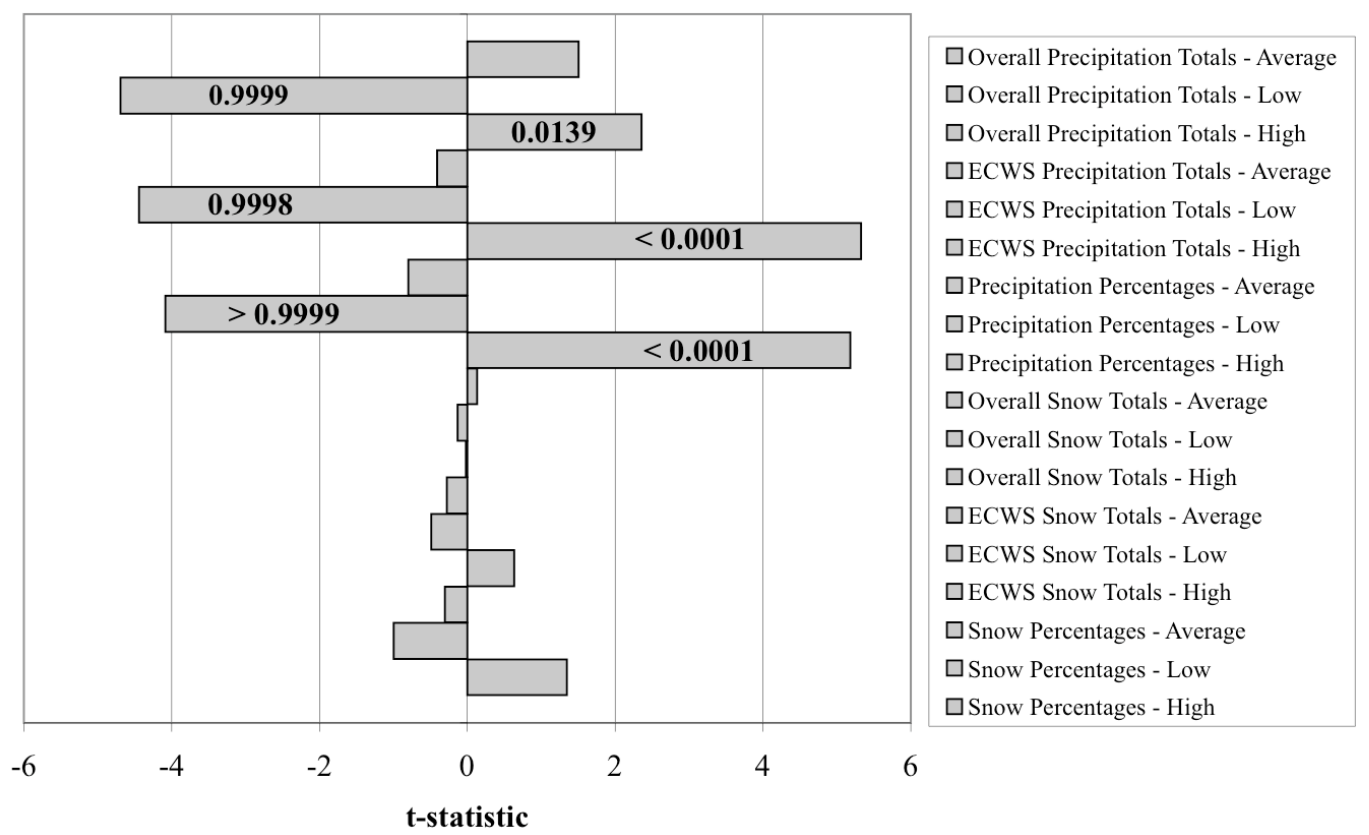

Figure 4.28: For Region I, a test (t) statistic, which compares event years (High, Average, or Low ECWS Occurrence) to non-event years, for the following variables: amount of total precipitation, amount of precipitation from ECWS, percentage of precipitation from ECWS, amount of total snowfall, amount of snowfall from ECWS, and percentage of snowfall from ECWS. Positive (Negative) values for the t-statistic indicate an (a) increase (decrease) in that variable during event years. Any variables and associated bars with a $p$ value significant at the 5\% level, using a two-tailed test or one-tailed test where applicable, are noted. The order of the variables in the key (right) corresponds to the order of the variables in the bar graph (left).

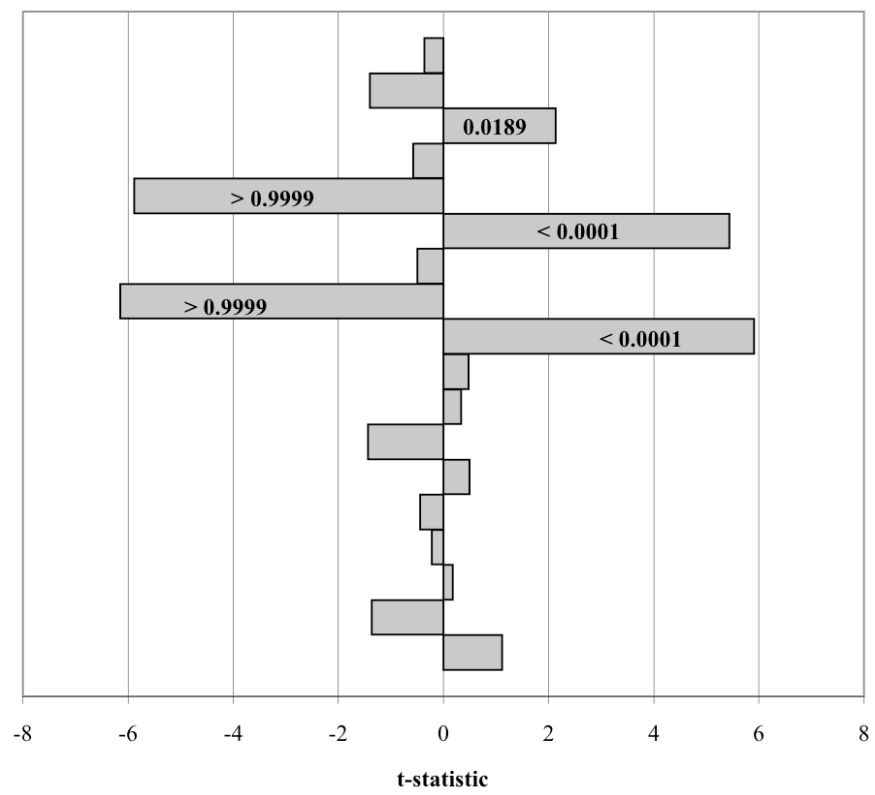

$\square$ Overall Precipitation Totals - Average $\square$ Overall Precipitation Totals - Low $\square$ Overall Precipitation Totals - High $\square$ ECWS Precipitation Totals - Average $\square$ ECWS Precipitation Totals - Low $\square$ ECWS Precipitation Totals - High $\square$ Precipitation Percentages - Average $\square$ Precipitation Percentages - Low $\square$ Precipitation Percentages - High $\square$ Overall Snow Totals - Average $\square$ Overall Snow Totals - Low $\square$ Overall Snow Totals - High $\square$ ECWS Snow Totals - Average $\square$ ECWS Snow Totals - Low $\square$ ECWS Snow Totals - High $\square$ Snow Percentages - Average $\square$ Snow Percentages - Low $\square$ Snow Percentages - High

Figure 4.29: Same as Figure 4.28, for Region II. 


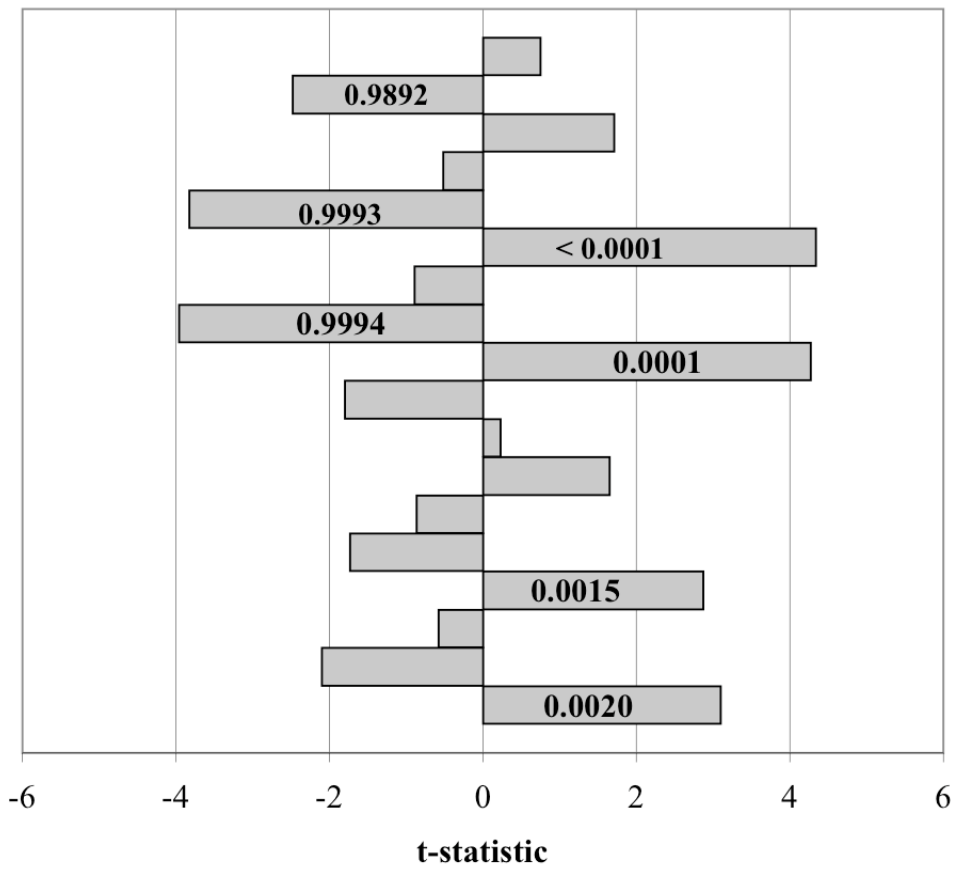

Figure 4.30: Same as Figure 4.28, for Region III.

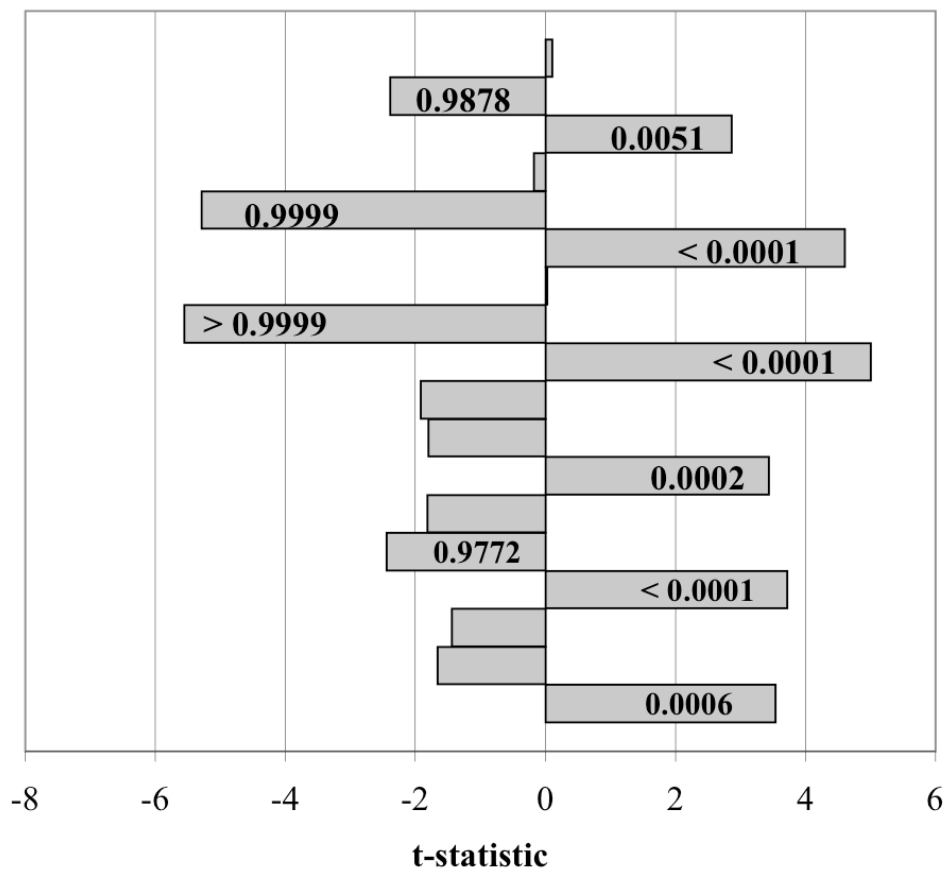

Figure 4.31: Same as Figure 4.28, for Region IV. $\square$ Overall Precipitation Totals - Average

$\square$ Overall Precipitation Totals - Low

$\square$ Overall Precipitation Totals - High

$\square$ ECWS Precipitation Totals - Average

口ECWS Precipitation Totals - Low

口ECWS Precipitation Totals - High

$\square$ Precipitation Percentages - Average

$\square$ Precipitation Percentages - Low

$\square$ Precipitation Percentages - High

$\square$ Overall Snow Totals - Average

$\square$ Overall Snow Totals - Low

$\square$ Overall Snow Totals - High

口ECWS Snow Totals - Average

$\square$ ECWS Snow Totals - Low

口ECWS Snow Totals - High

$\square$ Snow Percentages - Average

$\square$ Snow Percentages - Low

$\square$ Snow Percentages - High $\square$ Overall Precipitation Totals - Average $\square$ Overall Precipitation Totals - Low $\square$ Overall Precipitation Totals - High $\square$ ECWS Precipitation Totals - Average $\square E C W S$ Precipitation Totals - Low $\square$ ECWS Precipitation Totals - High $\square$ Precipitation Percentages - Average $\square$ Precipitation Percentages - Low $\square$ Precipitation Percentages - High $\square$ Overall Snow Totals - Average $\square$ Overall Snow Totals - Low $\square$ Overall Snow Totals - High 口ECWS Snow Totals - Average $\square E C W S$ Snow Totals - Low $\square E C W S$ Snow Totals - High $\square$ Snow Percentages - Average

$\square$ Snow Percentages - Low

$\square$ Snow Percentages - High 


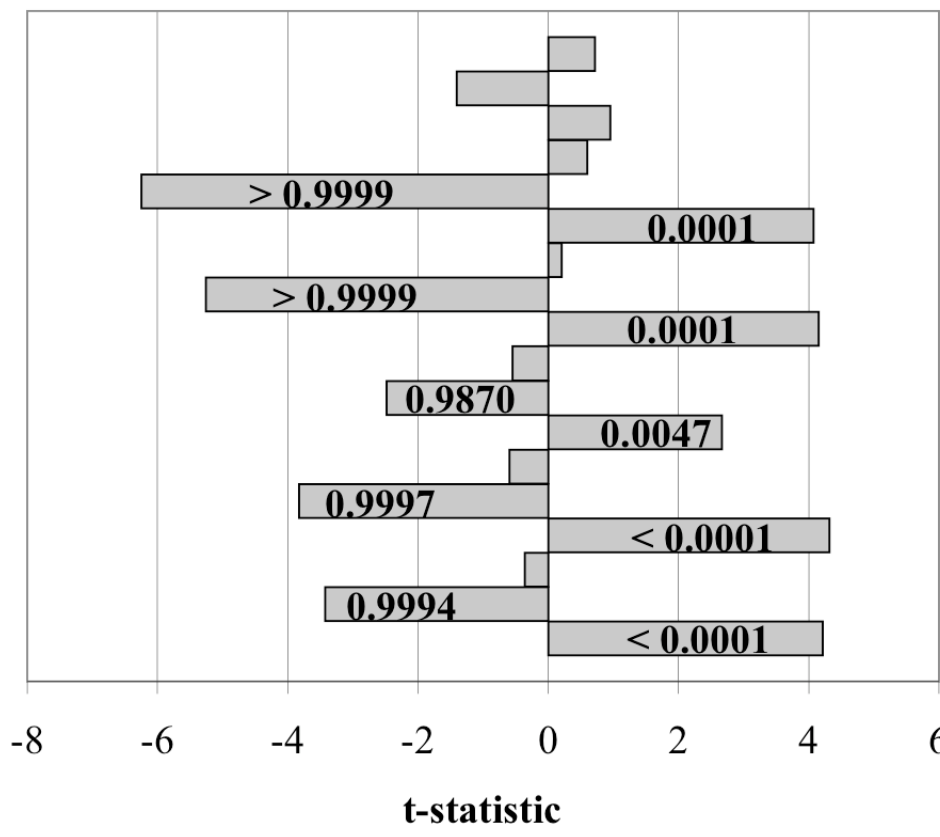

$\square$ Overall Precipitation Totals - Average
$\square$ Overall Precipitation Totals - Low
$\square$ Overall Precipitation Totals - High
$\square$ ECWS Precipitation Totals - Average
$\square$ ECWS Precipitation Totals - Low
$\square$ ECWS Precipitation Totals - High
$\square$ Precipitation Percentages - Average
$\square$ Precipitation Percentages - Low
$\square$ Precipitation Percentages - High
$\square$ Overall Snow Totals - Average
$\square$ Overall Snow Totals - Low
$\square$ Overall Snow Totals - High
$\square$ ECWS Snow Totals - Average
$\square$ ECWS Snow Totals - Low
$\square$ ECWS Snow Totals - High
$\square$ Snow Percentages - Average
$\square$ Snow Percentages - Low
$\square$ Snow Percentages - High

Figure 4.32: Same as Figure 4.28, for Region V.

In general, the results of Figures 4.28 through 4.32 are as expected. Beginning with Region I and Figure 4.28, significant relationships exist for many of the precipitation variables. However, no relationships of significance exist for any of the snowfall variables. This is likely the case due to the relatively infrequent nature of any type of appreciable snowfall event in this region of the south. In Region I, a high occurrence of ECWS leads to an increase in overall precipitation and a low occurrence of storms leads to a decrease in overall precipitation. Both of these relationships are significant at the 5\% level. The same findings exist for precipitation directly from ECWS. Finally, significant at even the $1 \%$ level, a high occurrence of ECWS in a snow year leads to an increase in the percentage of precipitation from ECWS, while a low occurrence of storms results in a decrease in the percentage of precipitation from ECWS. The results for Region II are quite similar. A high occurrence of ECWS in a snow year indicates an increase in overall precipitation amounts, ECWS precipitation amounts, and the percentage of precipitation from ECWS. These findings are significant at the 5\% level, with the latter two significant at the $1 \%$ level. Also in 
Region II, significant at the $1 \%$ level, a low number of ECWS in a snow year signals a decrease in ECWS precipitation amounts, and the percentage of precipitation from ECWS. What is curious is that high ECWS occurrence snow years actually signal a decrease in both ECWS snow amounts and overall snow amounts. However, these relationships are not significant at even the $10 \%$ level. Yet, this is still an interesting finding considering the lower than anticipated percentages of snowfall from ECWS found in this region, depicted in Figure 4.3. Again, a likely scenario is that this region of the east coast is primarily in the warm sector of an ECWS, receiving mostly rain. This would imply a large percentage of the snowfall in Region II occurs from some non-ECWS feature. For Region III, the results basically correspond with what is expected. Significant at the 5\% level, a snow year with a low occurrence of ECWS results in a decrease in overall precipitation amounts, ECWS precipitation amounts, and the percentage of precipitation from ECWS. Significant at the $1 \%$ level, a high occurrence of ECWS for a snow year indicates an increase in ECWS precipitation and snowfall amounts, and the percentage of precipitation and snowfall from ECWS.

As was the case with the analysis of ENSO phases, considering ECWS occurrences, Regions IV and V had the highest number of variables with significant relationships, in comparison to the other regions. For Region IV, and the large urban centers of the mid-Atlantic and Northeastern United States, significant at the 5\% level, for snow years with a high occurrence of ECWS, an increase in the following variables is signaled: overall precipitation and snowfall amounts, ECWS precipitation and snowfall amounts, and the percentage of precipitation and snowfall from ECWS. All of these, with the exception of overall precipitation amounts, are significant at the $1 \%$ level. Similarly, significant at the $5 \%$ level, a snow year with a low number of ECWS, results in decreases in the following: overall precipitation amounts, ECWS precipitation and snowfall amounts, and the percentage of precipitation from ECWS. 
Finally, for Region V the results are similar to Region IV, except no significant relationships exist for overall precipitation, regardless of the number of ECWS per snow year. Significant at the $1 \%$ level in Region V, a snow year with a high occurrence of ECWS indicates increases in the following: ECWS precipitation and snowfall amounts, the percentage of precipitation and snowfall from ECWS, and overall snowfall amounts. In contrast, significant at the $5 \%$ level, a decrease in these same variables is expected during snow years with a low occurrence of ECWS. 


\section{CHAPTER 5}

\section{CONCLUSIONS}

\subsection{General Summary}

This paper develops an automated procedure for building an ECWS precipitation climatology for the eastern region of the United States, which shows the percentage of snowfall and precipitation directly from ECWS, on average per snow year, during the period 1951-1952 to 2005-2006. This same climatology was also constructed for rapidly deepening ECWS, or bombs. The primary components utilized in determining whether precipitation or snowfall at a station was from an ECWS include a PGL, a pressure gradient line, and whether or not a non-ECWS was present. In addition, maximum amounts of precipitation to the west and east of a PGL, were useful in the decision process. Attempting to exclude LES was also addressed. Examples of this ECWS decision process, using storms included in the climatology, were also presented, depicting the seven scenarios encountered by the automated procedure. A sensitivity analysis for the climatology was also considered, and addressed three situations. First, how would the climatology change in the absence of the ECWS decision process. Second, how would the climatology change in the Great Lakes region if LES was not accounted for. Third, again in the Great Lakes region, how would the climatology change if a different method of identifying LES was considered. A manual analysis of three stations near Lake Erie and Lake Ontario, over four recent snow years, was considered using archived radar data, which helped to approximately quantify LES during ECWS events. Finally, an analysis of five regions was presented. This analysis focused on relationships of percentage of precipitation and snowfall from ECWS, as well as ECWS precipitation and snowfall amounts, to ENSO phases. Time dependent trends in these variables were also considered. 
Finally, the frequency of ECWS and the relationship to these variables, as well as to total snowfall and precipitation, was also investigated.

\subsection{Key Findings}

The results are presented in detail with discussion and Figures in Chapter 4. The key findings are summarized here as follows:

1. On average per snow year, the highest percentage of snowfall from ECWS is found in the Southeastern United States, particularly in a swath from southeastern Mississippi to northeastern Georgia. The percentages here are typically from 50 to $80 \%$. The lowest percentage of snowfall from ECWS is found from Lake Ontario and Lake Erie, west to Indiana, southwest to the Mississippi River, and all points west. Here percentages range primarily from 0 to $20 \%$. The urban corridor of the Northeastern United States, including the major metropolitan areas of Washington DC, Baltimore, Philadelphia, New York, and Boston, receive approximately 40 to 55\% of snowfall from ECWS, on average per snow year.

2. The highest percentage of precipitation from ECWS is found along the midAtlantic and New England coast or from the Maryland and Delaware border to coastal sections of Maine. Here percentages generally range from 20 to $25 \%$. The lowest percentage of precipitation from ECWS, on average, is found to the west of the Appalachian Mountains, ranging from 0 to $10 \%$.

3. Calculating the percentages using a study period overall percentage approach, shows the highest percentage of snowfall from ECWS still remains in the southeast, with percentages typically ranging from 65 to $90 \%$. Using this method, the urban corridor of the Northeastern United States received approximately 45 to $60 \%$ of snowfall from ECWS for the study period. For the percentage of precipitation from ECWS, for the entire study period, the 
percentages are roughly the same as those calculated using the study period seasonal average percentage approach.

4. A sensitivity analysis shows, in the absence of the ECWS decision process presented here, percentage of snowfall from ECWS on average per snow year would be 0 to $5 \%$ higher to the east of the Appalachian Mountains, and approximately 5 to $25 \%$ higher to the west of the Mountains. For precipitation, these percentages would be 0 to $5 \%$ higher across the study region, with the exception being downwind of Lakes Erie and Ontario, where they would be 5 to $10 \%$ higher. Overall the automated procedure for differentiating ECWS from non-ECWS precipitation and snow appears robust and effective.

5. Classification of LES is a challenge, particularly downwind of Lakes Erie and Ontario. If LES were included in this climatology, the percentage of snowfall from ECWS downwind of Lakes Erie and Ontario would be approximately 10 to $30 \%$ higher than using the one period LES scenario, on average per snow year. How LES is classified makes a marginal difference. Downwind of Lakes Erie and Ontario, the difference in the percentage of snowfall from ECWS using the half period versus one period LES classification scheme is approximately 5 to $10 \%$. Finally, a brief manual analysis of three stations near Lake Erie and Lake Ontario shows that lake enhanced snowfall, as well as the identification of what is strictly LES during an ECWS event, are sources of uncertainty in generating this climatology. Furthermore, while the one period method may underestimate ECWS snowfall in the LES belts by $9 \%$, on average per snow year, based on this brief manual analysis, the one period method is used in this climatology since both methods are simplifications, and the aim was to exclude, to the extent possible, the uncertainties associated with LES and lake enhanced snow during ECWS events. 
6. The climatology for bombs reveals that on average per snow year, the percentage of snowfall from bombs is highest in the southeast, in this same swath from southeastern Mississippi to northeastern Georgia. Here the percentages are typically from 5 to $50 \%$ of snowfall per snow year. The remainder of the study region sees generally from 0 to $10 \%$ of snowfall from bombs, on average per snow year. The exception is through parts of the urban corridor of the Northeast, which sees as much as 10 to $15 \%$. For the percentage of precipitation from bombs, on average per snow year, the study region was uniformly 0 to $3 \%$. Calculating these percentages applying the study period overall percentage approach, for both snowfall and precipitation from bombs, yielded similar results.

7. In northern New England and the urban corridor of the Northeast, El Niño years signal above average precipitation and snowfall amounts from ECWS, as well as an above average percentage of precipitation and snowfall from ECWS. In contrast for the regions covering the central Appalachian Mountains, the Carolinas and the Southeast, La Niña years signal a below average percentage of precipitation from ECWS.

8. No significant time dependent trends were identified for the amount of precipitation or snowfall from ECWS or for the percentage of precipitation or snowfall from ECWS.

9. The frequency of ECWS by snow year has a significant impact on the amount of ECWS precipitation and snowfall, the percentage of precipitation and snowfall from ECWS, as well as the total amount of precipitation and snowfall, for a given location. High (Low) ECWS occurrence snow years, or active (inactive) seasons, signal above (below) average ECWS precipitation amounts and percentage of precipitation from ECWS. Along the urban 
corridor of the Northeast or the metropolitan areas from Washington DC to Boston, high ECWS occurrence snow years, or active seasons, signal above average ECWS precipitation and snowfall amounts, above average overall precipitation and snowfall amounts, and an above average percentage of precipitation and snowfall from ECWS. While low ECWS occurrence snow years, or inactive seasons, signal below average ECWS precipitation and snowfall amounts, below average overall precipitation amounts, and below average percentage of precipitation from ECWS. For northern New England, high (low) ECWS occurrence snow years, or active (inactive) seasons, signal above (below) average ECWS precipitation and snowfall amounts, overall snow amounts, and percentage of precipitation and snowfall from ECWS.

10. The relationships between ECWS frequency by snow year and the amount of ECWS precipitation and snowfall, the percentage of precipitation and snowfall from ECWS, as well as the total amount of precipitation and snowfall, have important implications for applying seasonal forecasting techniques (e.g. DeGaetano et al., 2002). These relationships will help assess potential impacts of seasonally forecasted ECWS activity.

\subsection{Potential Further Research}

Certainly there are areas for further research, including methods to improve the climatology developed in this paper. Areas for potential further research include the following:

1. An investigation of non-ECWS features and their contribution to snowfall and precipitation throughout the region included in this study. These non-ECWS features may include mid-latitude cyclones, including Alberta Clippers or LES and other mesoscale processes. This investigation would include both nonECWS features occurring in conjunction with ECWS, and also at other times 
during the snow year. Ultimately a climatology may be developed for the entire eastern region of the United States depicting percentages of snowfall and precipitation from various sources.

2. Due to the complexity and uncertainty surrounding the identification of LES during an ECWS event, more rigorous procedures to classify LES may be investigated to improve this climatology in the Great Lakes region. In addition, considering how LES is influenced by active or inactive ECWS seasons may be useful. Moreover, a synoptic and mesoscale modeling study may provide insight as to the mechanisms producing LES during an ECWS event. For example, are direct LES processes the dominant influence or does the ECWS matter, even if indirectly. Also, what impact does the ECWS position with respect to the Lakes have on LES.

3. Future forecasting applications to be used in combination with DeGaetano et al. (2002) forecast and prediction techniques. The findings of DeGaetano et al. (2002) have important implications for the findings in this paper, in terms of what impact active or inactive seasons will have on, for example, snowfall amounts or percentage of snowfall from ECWS. Verification and more detailed research for specific stations or cities are needed.

In general, the complexity surrounding ECWS and the size of the geographic location and population impacted by these storms provide reasoning for continued research. In addition, how climate change may result in changes in ECWS frequency, has important repercussions. This paper develops a climatology showing the percentage of snowfall and precipitation from ECWS and how these percentages are influenced by ENSO phases and ECWS frequency. Forecasting seasonal impacts from ECWS in a given location is an extremely difficult process, and this paper aims to contribute to this task. 
APPENDIX A: Results of Manual ECWS and LES Analysis

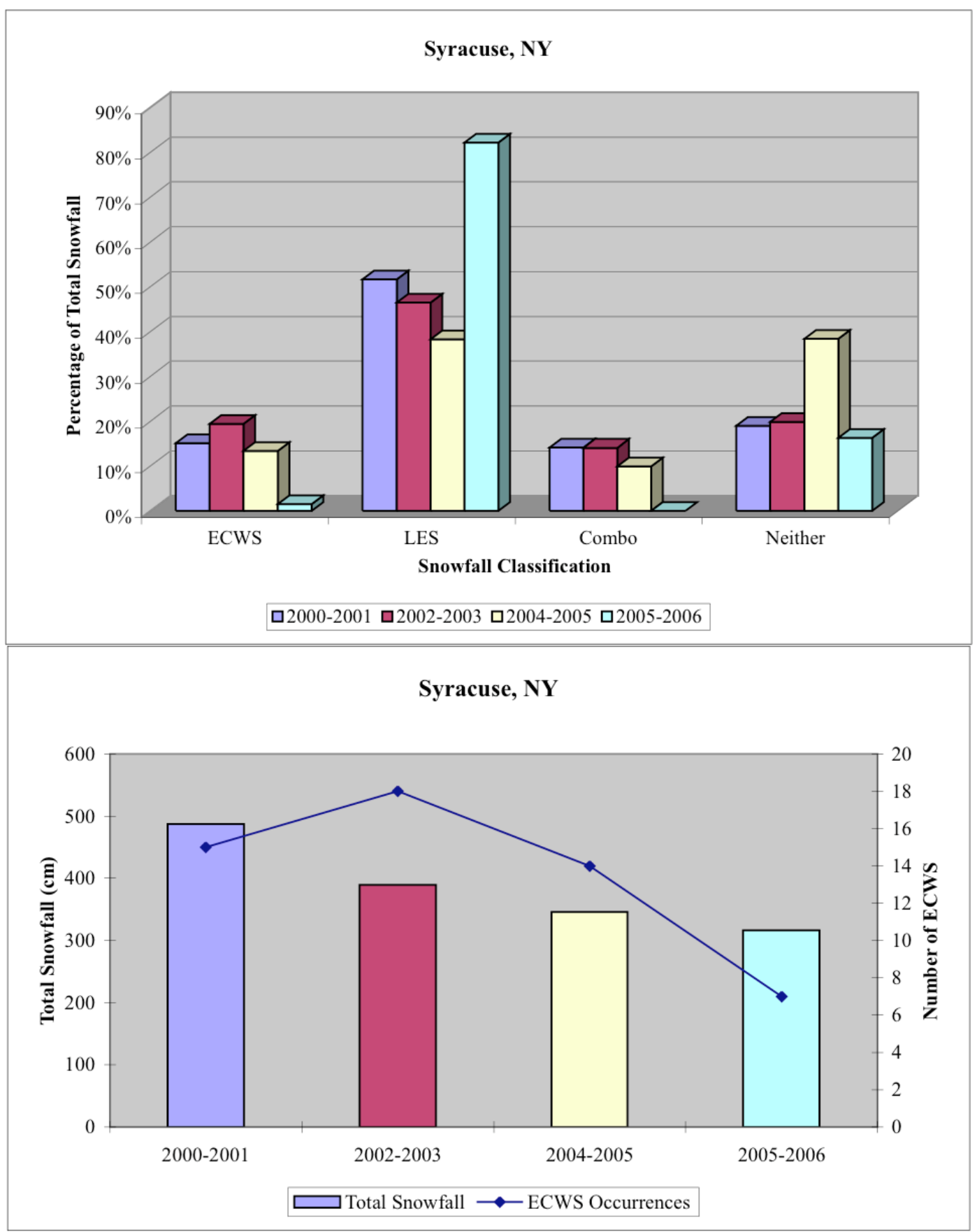

Figure A.1: For Syracuse, NY, percentage of total snowfall from each category by snow year (top), amount of total snowfall and number of ECWS by snow year (bottom). 


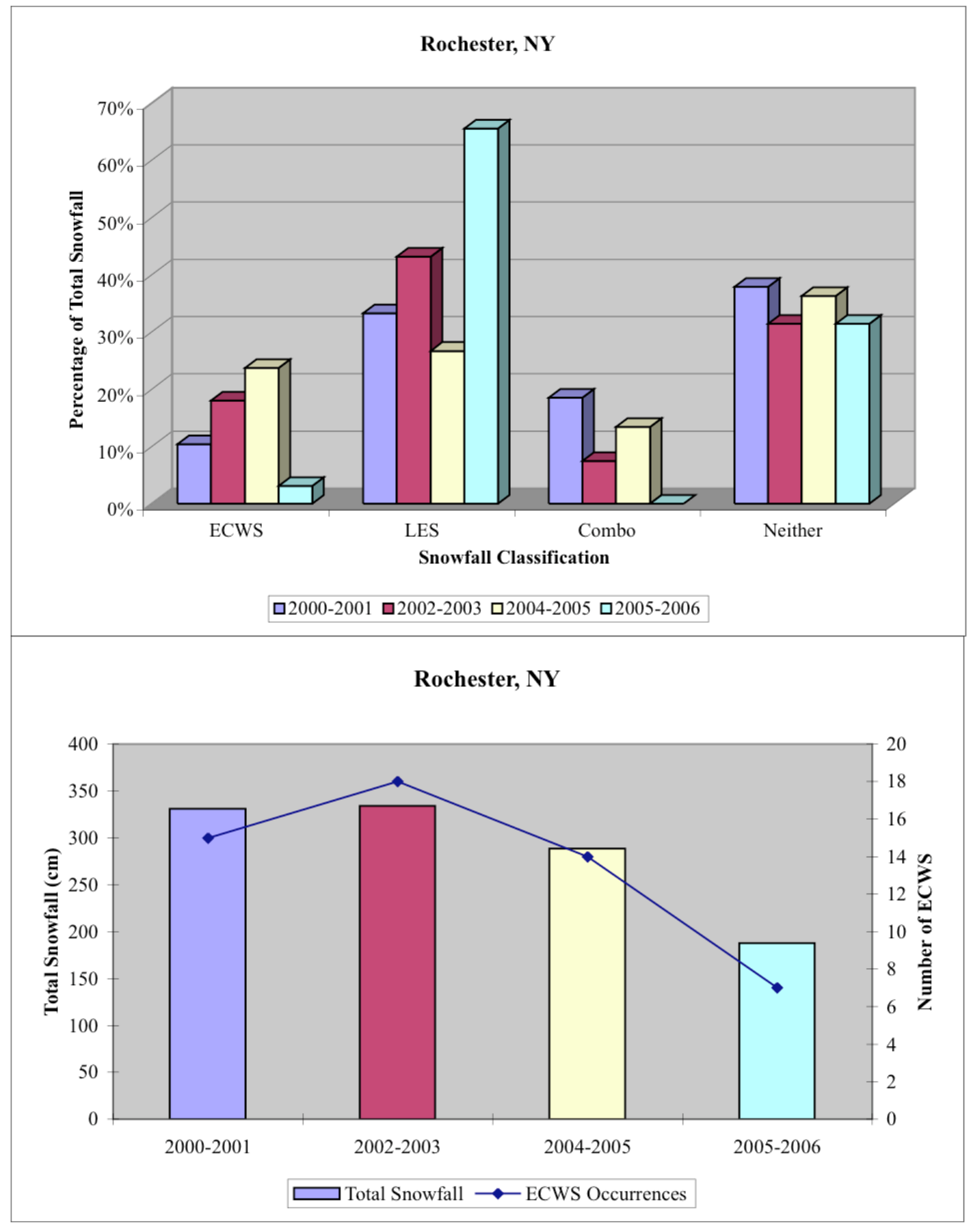

Figure A.2: Same as Figure A.1, for Rochester, NY. 


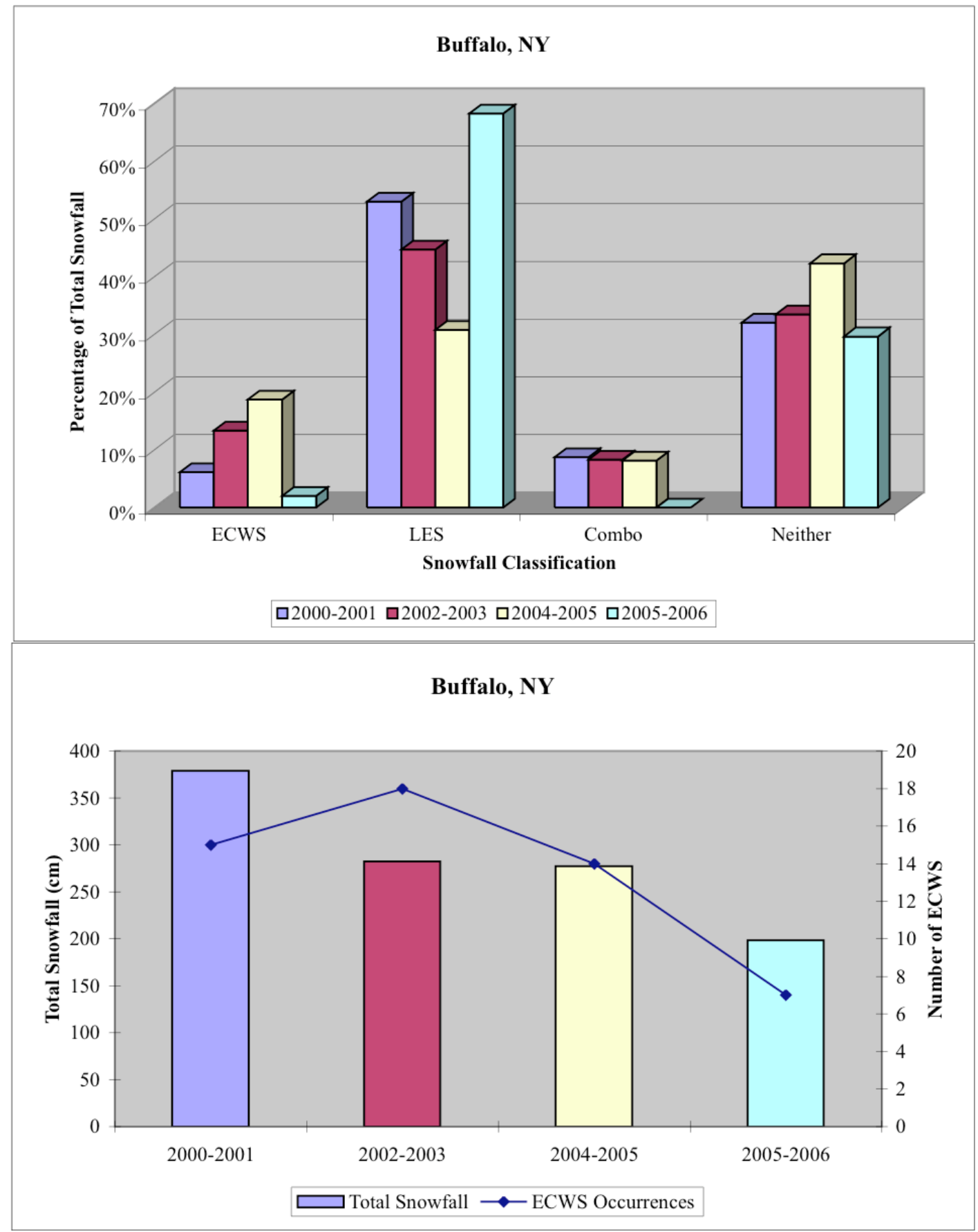

Figure A.3: Same as Figure A.1, for Buffalo, NY. 
APPENDIX B: Regions Analysis Snowfall and Precipitation Summaries

\section{Region I}

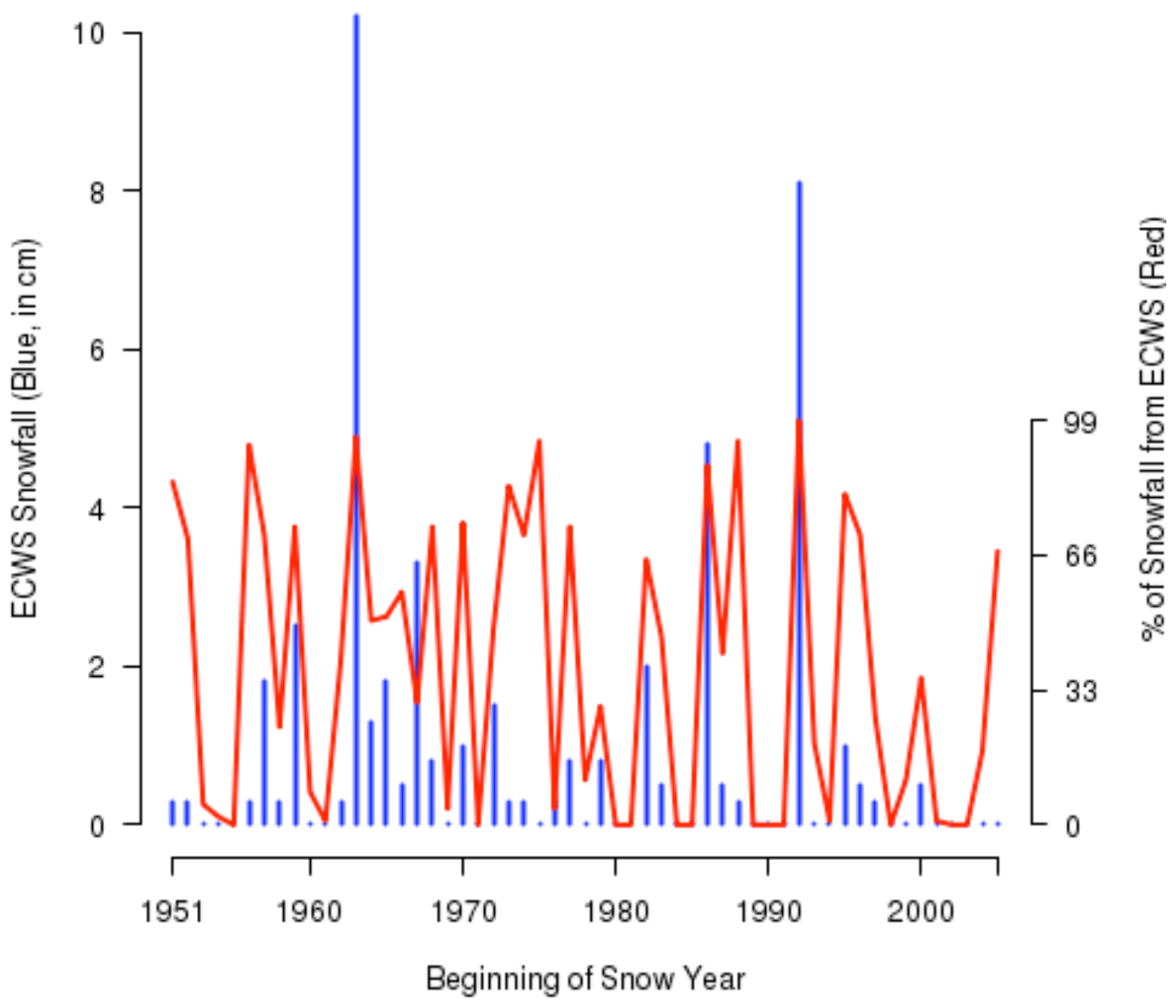

Figure B.1: By snow year, the amount of snowfall from ECWS (blue, in $\mathrm{cm}$ ), and the percentage of snowfall from ECWS (red), for Region I. 


\section{Region II}

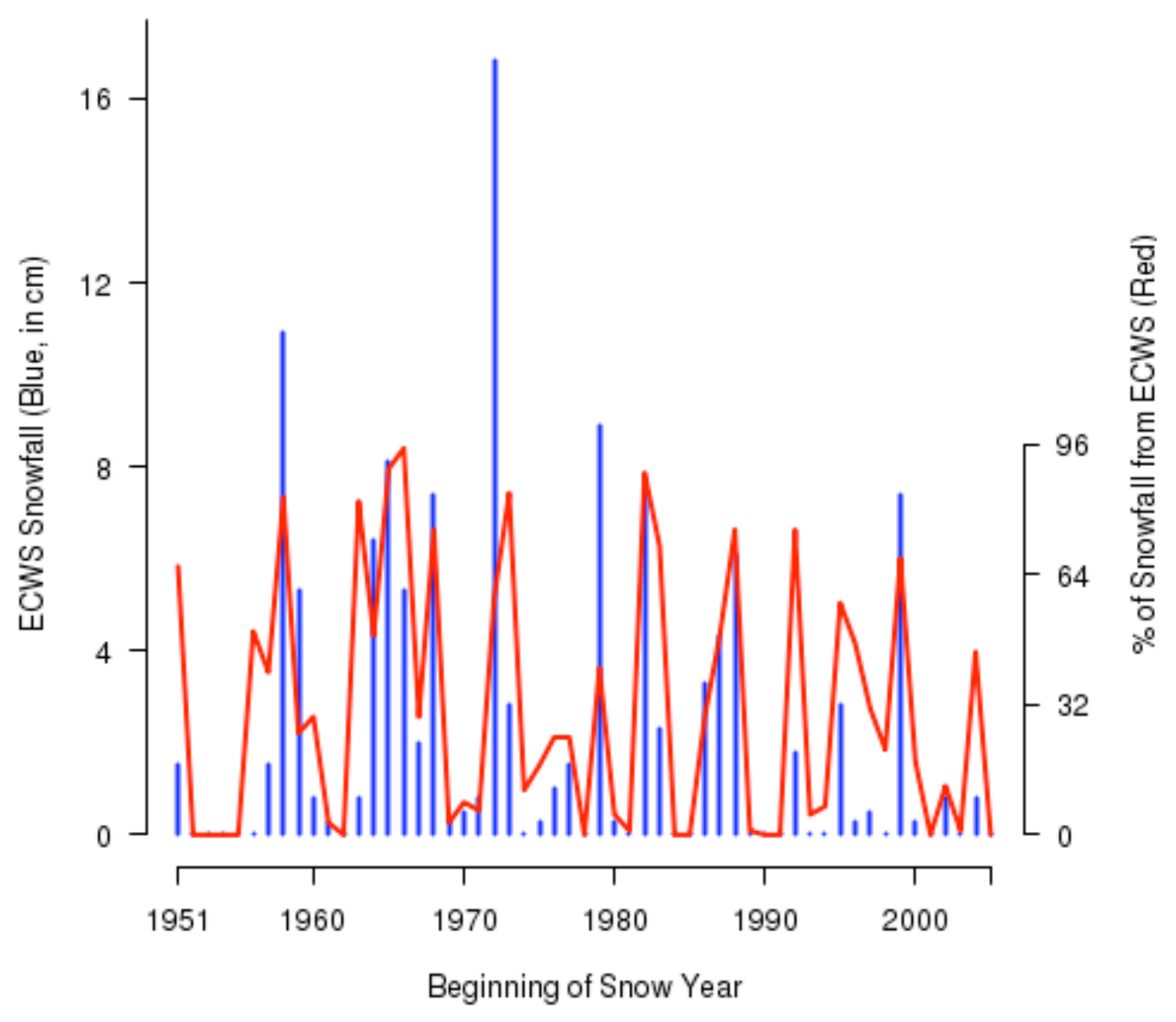

Figure B.2: Same as Figure B.1, for Region II. 


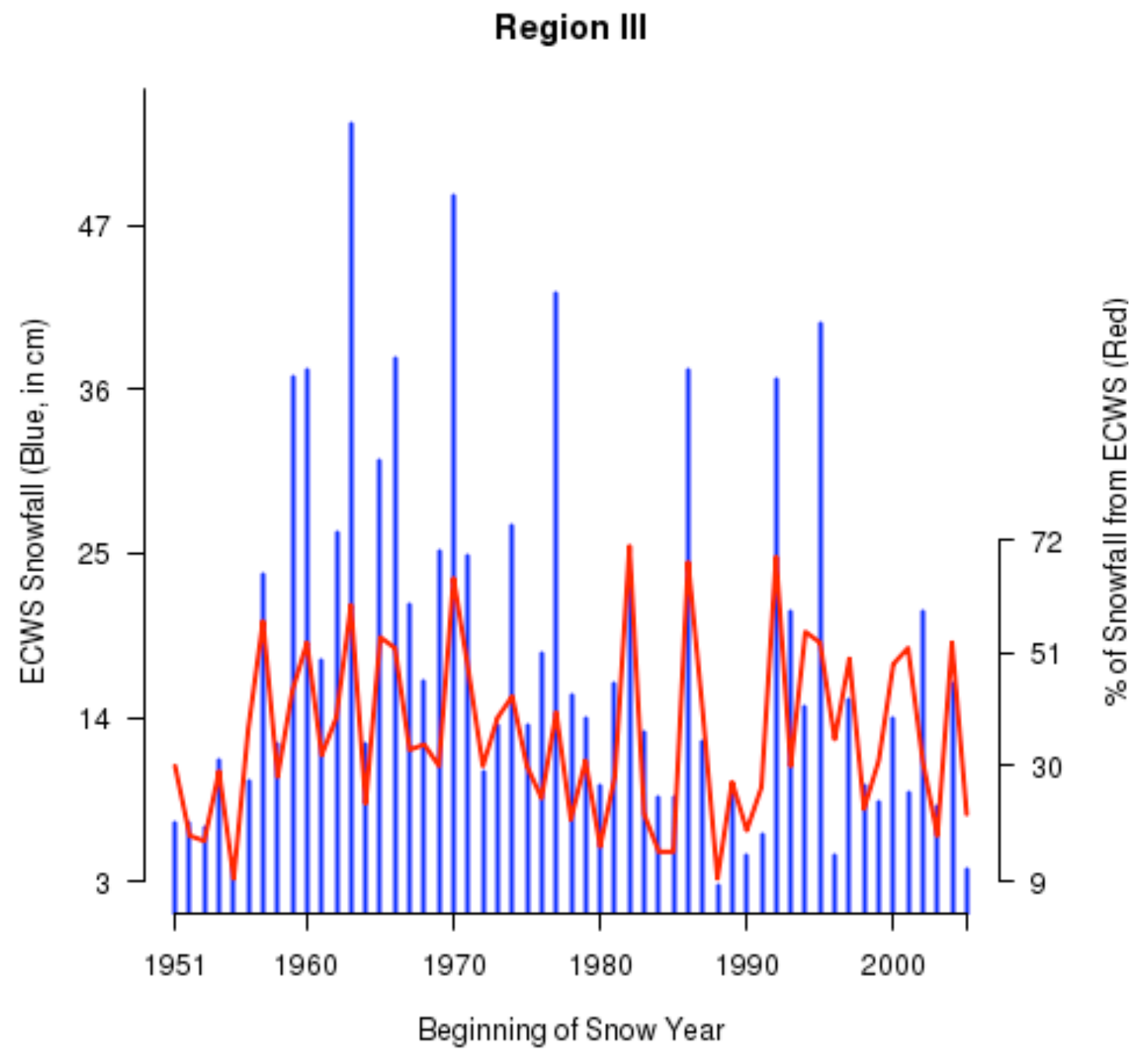

Figure B.3: Same as Figure B.1, for Region III. 


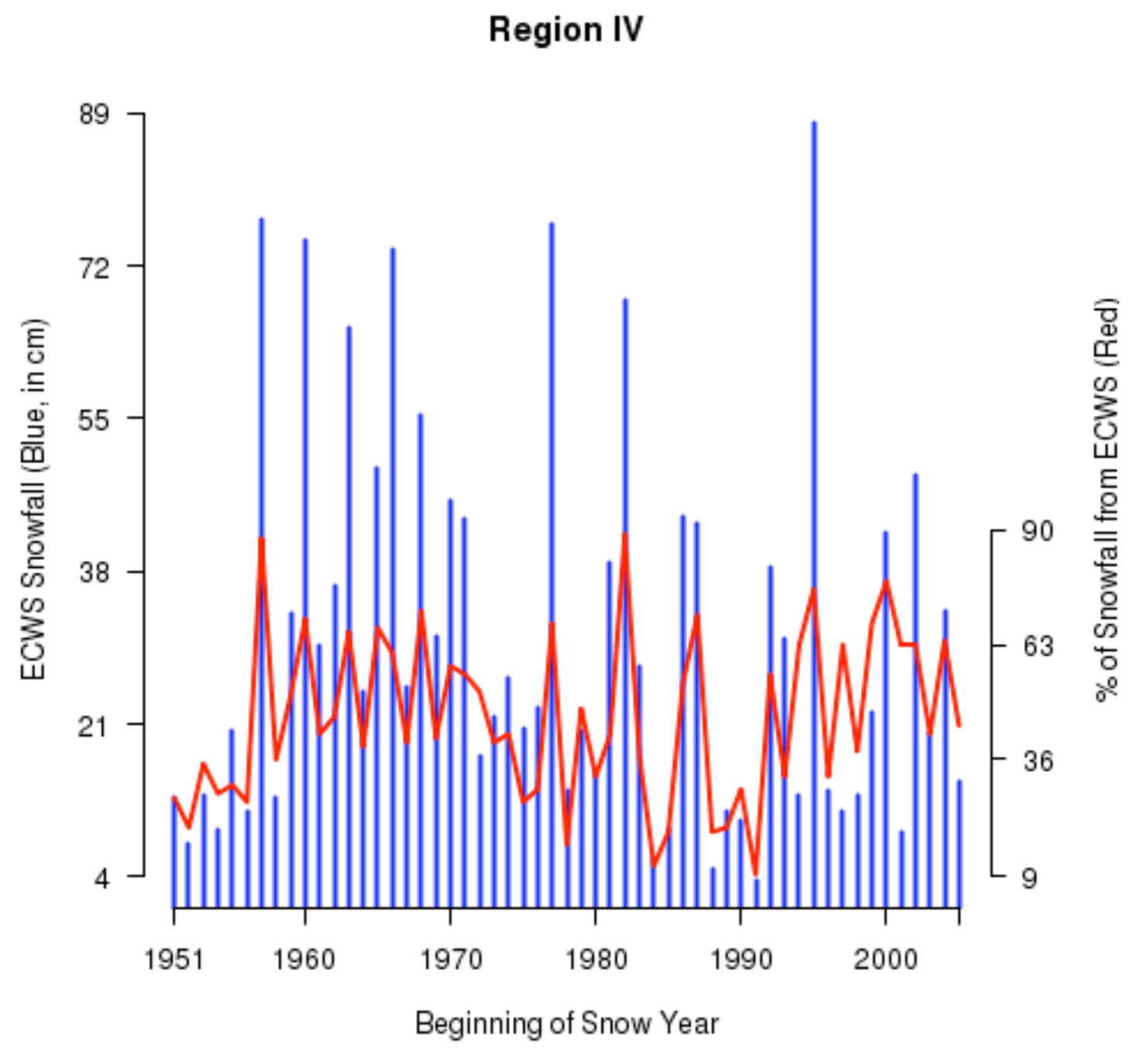

Figure B.4: Same as Figure B.1, for Region IV. 


\section{Region V}

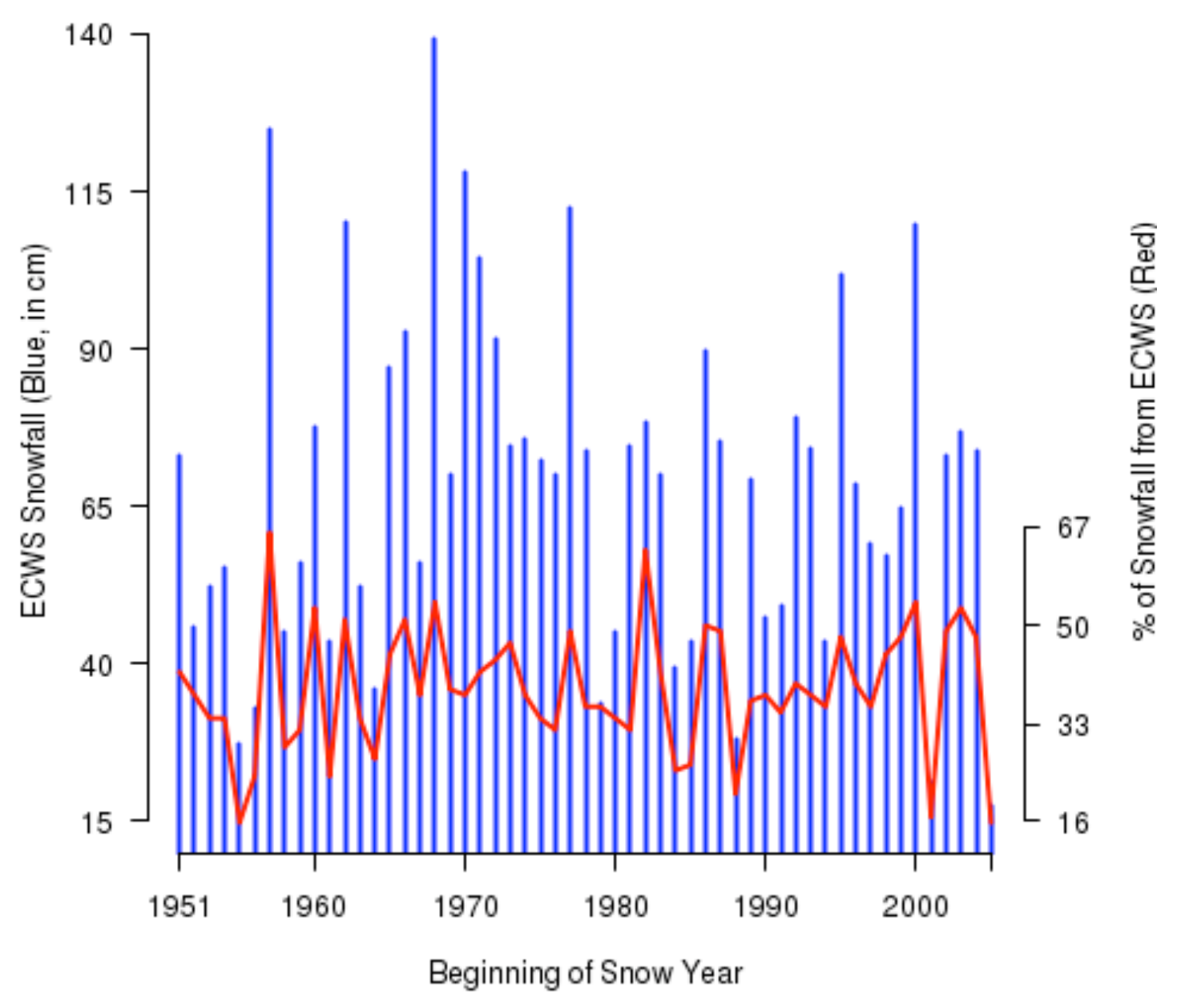

Figure B.5: Same as Figure B.1, for Region V. 


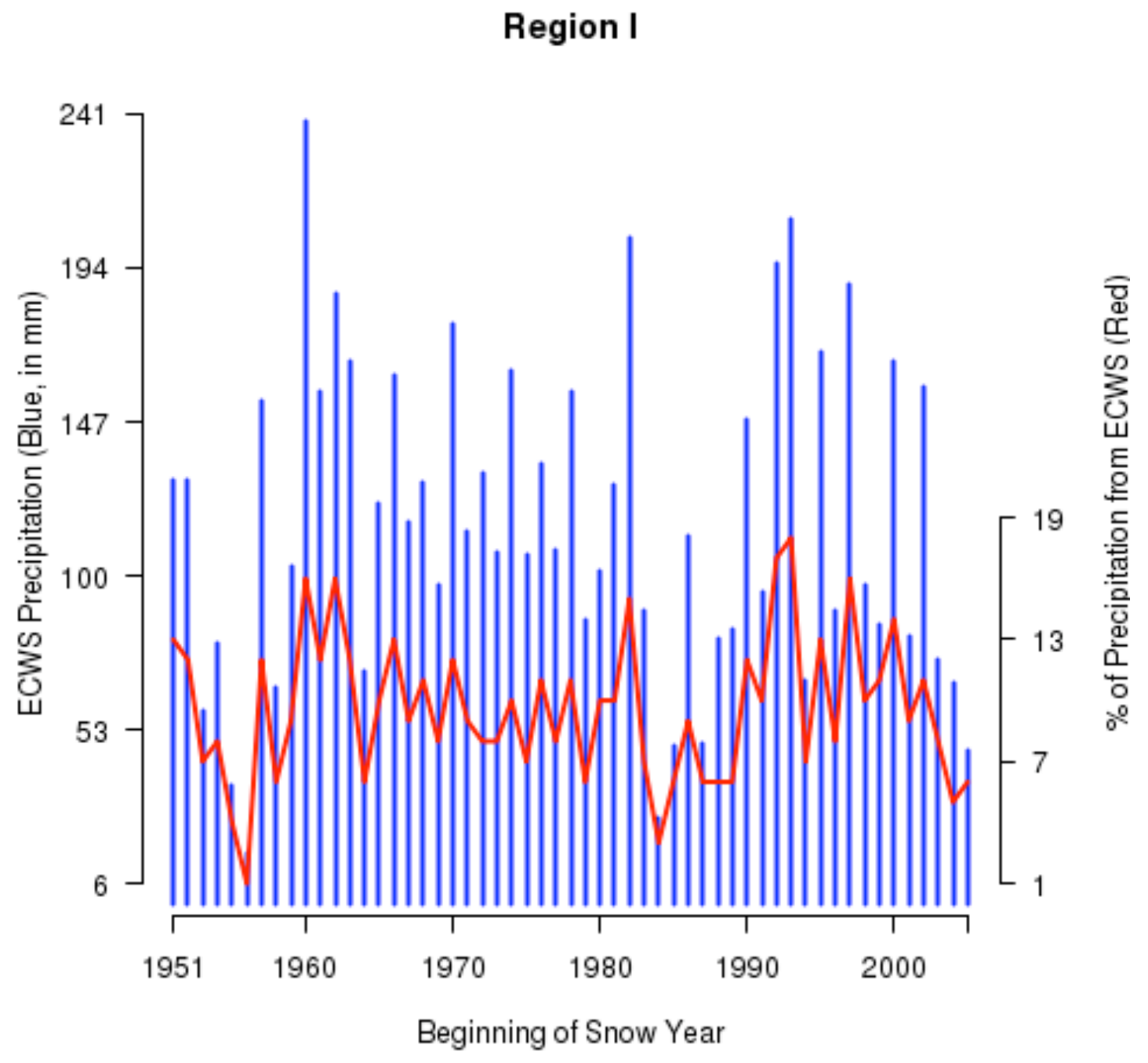

Figure B.6: By snow year, the amount of precipitation from ECWS (blue, in $\mathrm{mm}$ ), and the percentage of precipitation from ECWS (red), for Region I. 


\section{Region II}

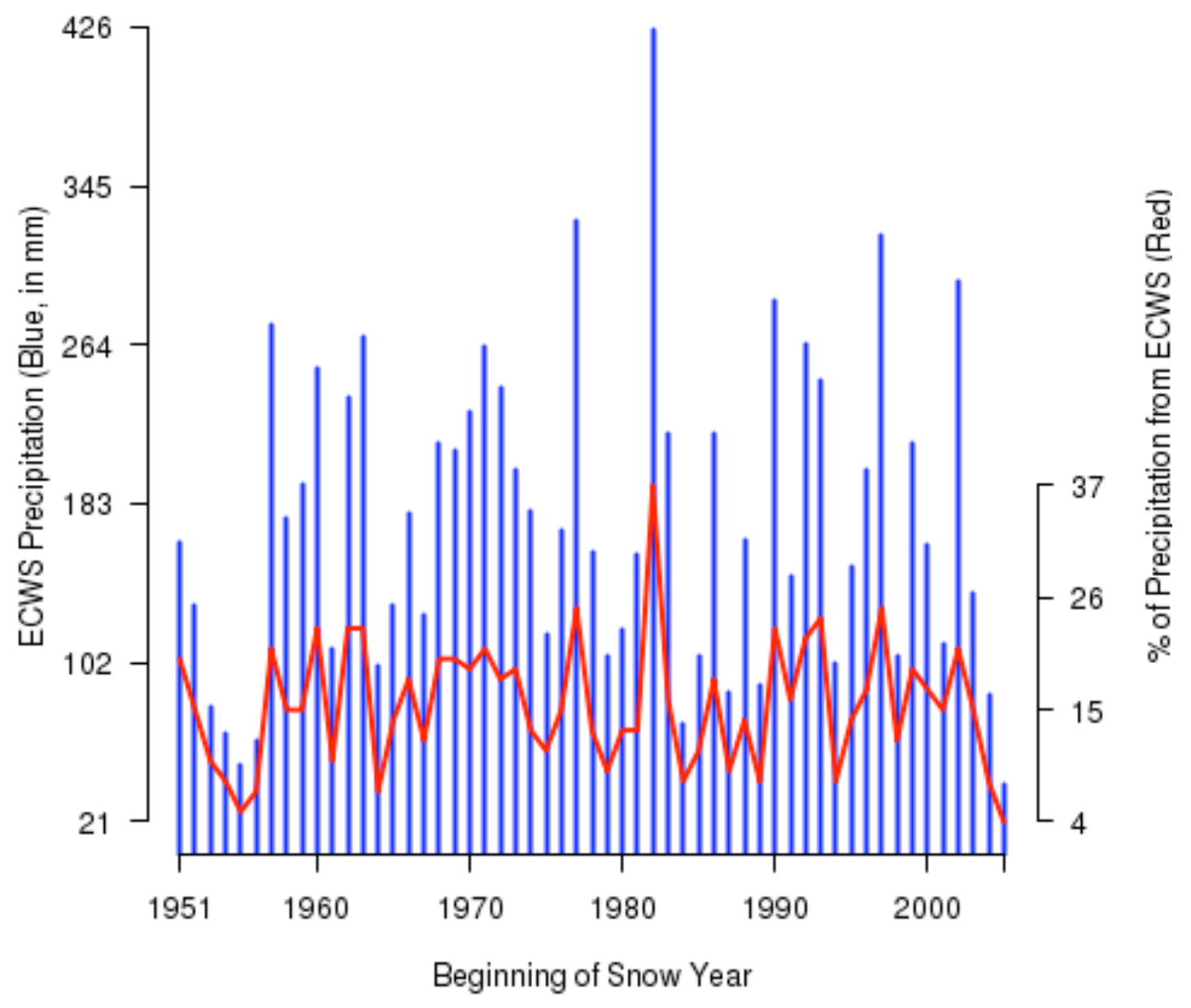

Figure B.7: Same as Figure B.6, for Region II. 


\section{Region III}

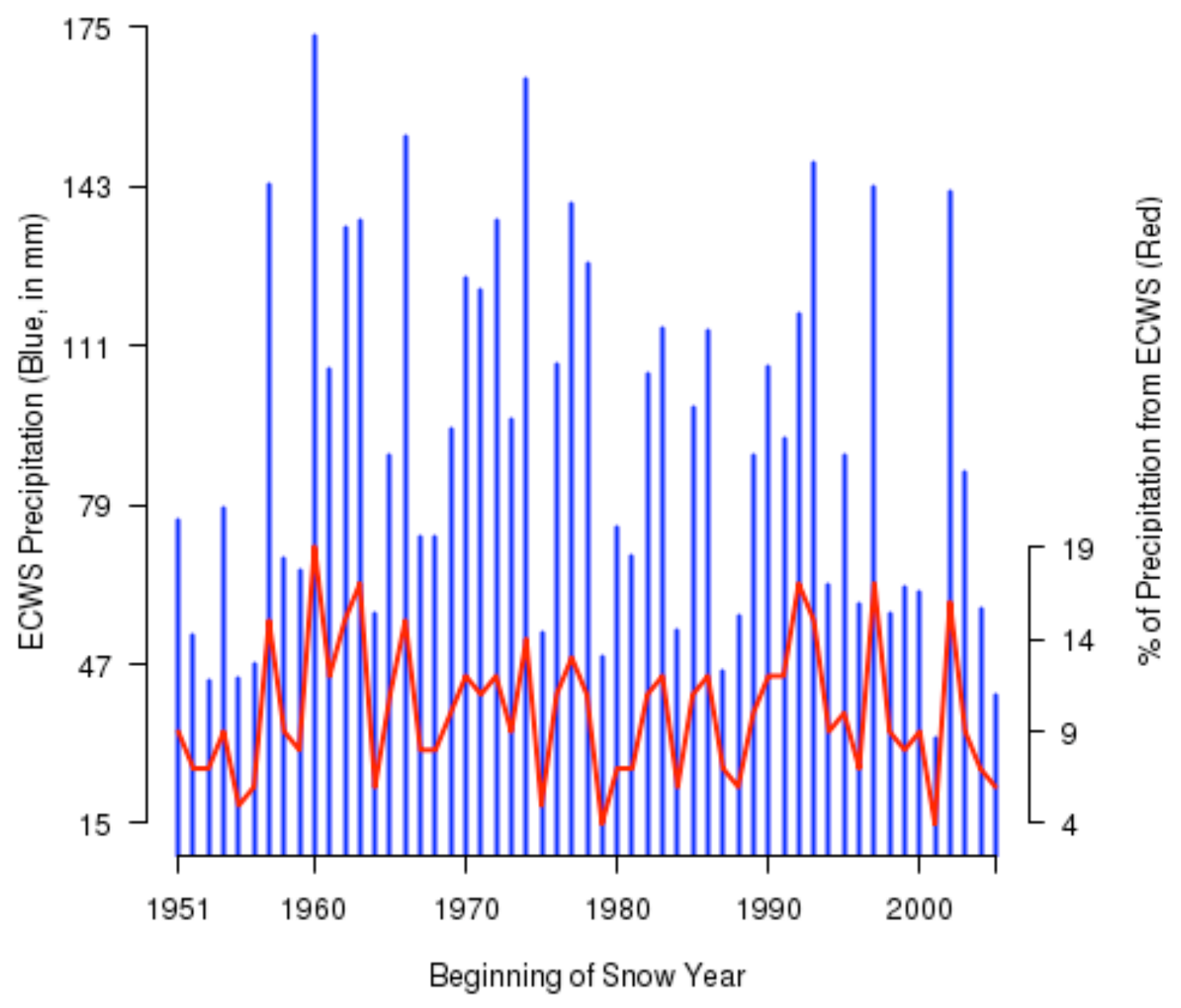

Figure B.8: Same as Figure B.6, for Region III. 


\section{Region IV}

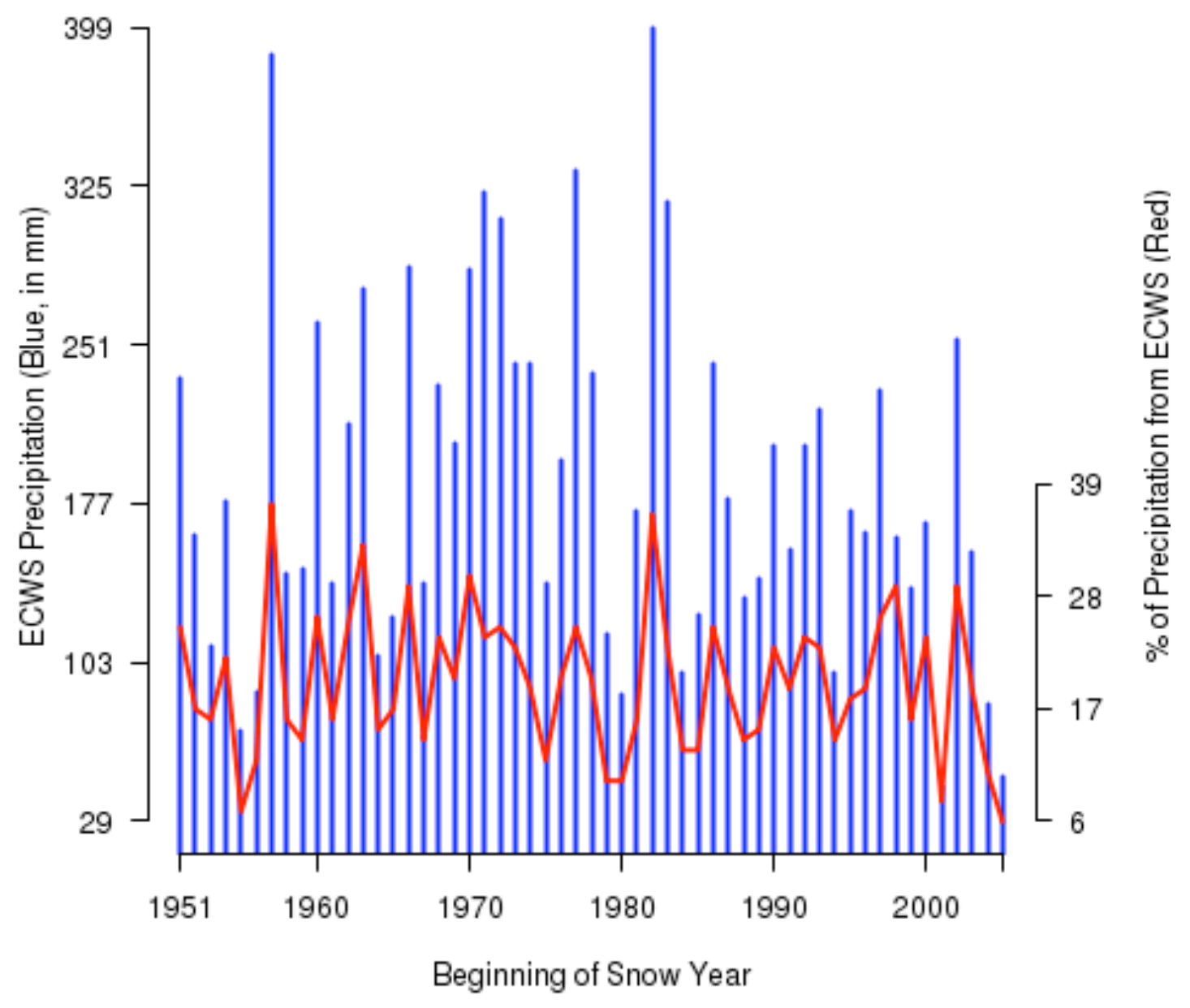

Figure B.9: Same as Figure B.6, for Region IV. 


\section{Region V}

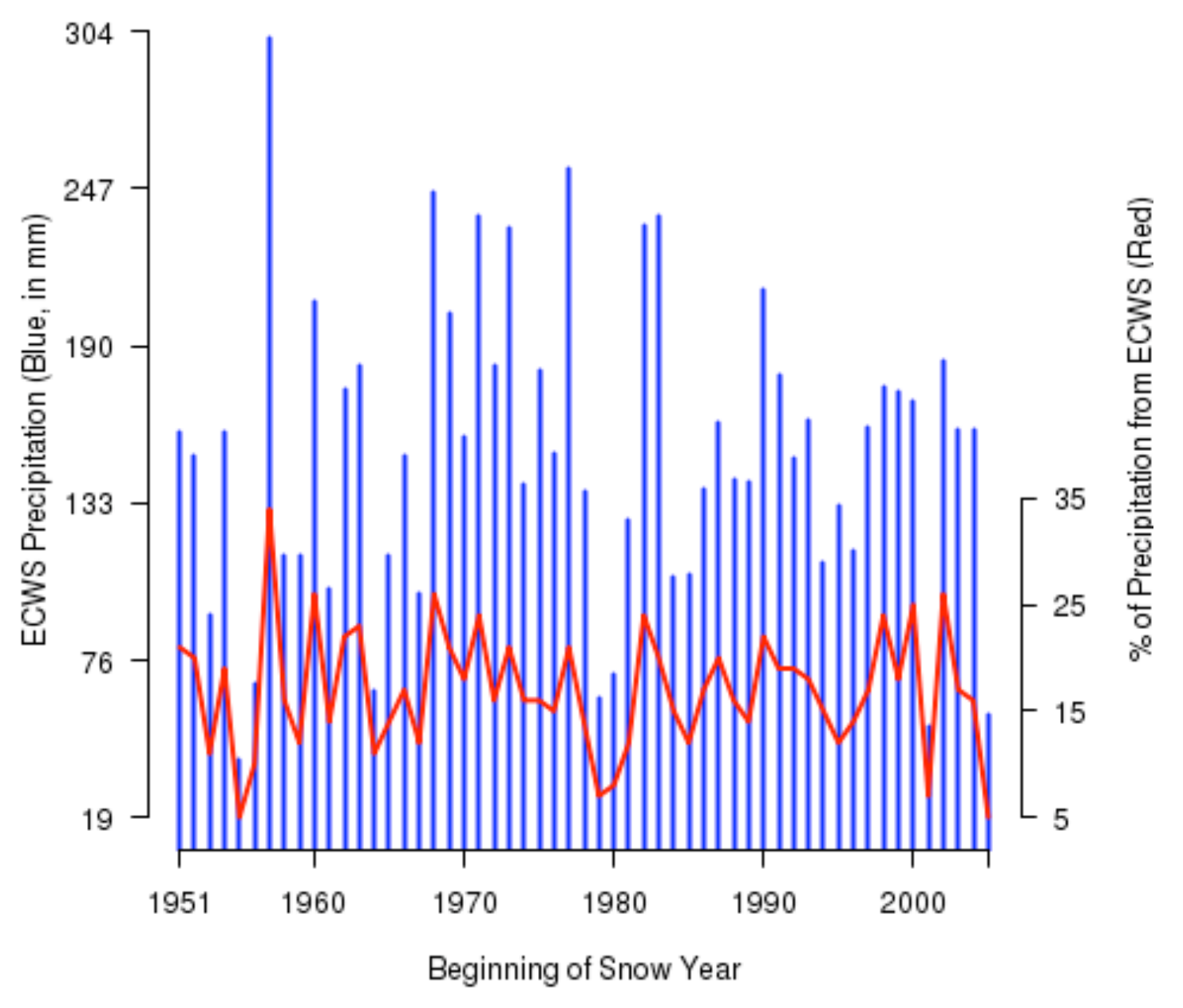

Figure B.10: Same as Figure B.6, for Region V. 


\section{REFERENCES}

Colucci, S. J., 1976: Winter Cyclone Frequencies Over the Eastern United States and Adjacent Western Atlantic, 1964-1973. Bull. Amer. Meteor. Soc., 57, 548-553.

Davis, R. E., R. Dolan, and G. Demme, 1993: Synoptic Climatology of Atlantic Coast North-Easters. Int. J. Climatol., 13, 171-189.

DeGaetano, A.T., R.J. Allen, 2002: Trends in Twentieth-Century Temperature Extremes Across the United States. J. Climate, 15, 3188-3205.

DeGaetano, A.T., B.N. Belcher, 2007: Spatial Interpolation of Daily Maximum and Minimum Air Temperature Based on Meteorological Model Analyses and Independent Observations. J. App. Meteor. and Climatol., 46, 1981-1992.

DeGaetano, A.T., M.E. Hirsch, and S.J. Colucci, 2002: Statistical Prediction of Seasonal East Coast Winter Storm Frequency. J. Climate, 15, 1101-1117.

Dirks, R. A., J. P. Kuettner, and J. A. Moore, 1988: Genesis of Atlantic Lows Experiment (GALE): An overview. Bull. Amer. Meteor. Soc., 69, 148-160.

Eichler, T., and W. Higgins, 2006: Climatology and ENSO-Related Variability of North American Extratropical Cyclone Activity. J. Climate, 19, 2076-2093.

ESRL, 2008: Earth System Research Laboratory, 6-Hourly NCEP/NCAR Reanalysis Data Composites. National Oceanic \& Atmospheric Administration, U.S. Department of Commerce, http://www.cdc.noaa.gov/data/composites/hour/ (Accessed 2008).

Glickman, T.S., Second Ed., 2000: Glossary of Meteorology. Amer. Meteor. Soc., $855 \mathrm{pp}$. 
Gurka, J. J., E. P. Auciello, A. F. Gigi, J. S. Waldstreicher, K. K. Keeter, S. Businger, and L. G. Lee, 1995: Winter Weather Forecasting throughout the Eastern United States. Part II: An Operational Perspective of Cyclogenesis. Wea. Forecasting, 10, 21-41.

Hadlock, R., and C.W. Kreitzberg, 1988: The Experiment on Rapidly Intensifying Cyclones over the Atlantic (ERICA) field study: Objectives and plans. Bull. Amer. Meteor. Soc., 69, 1309-1320.

Hirsch, M.E., A.T. DeGaetano, and S.J. Colucci, 2001: An East Coast Winter Storm Climatology. J. Climate, 14, 882-899.

Holroyd, E.W., III, 1971: Lake Effect Cloud Bands as Seen from Weather Satellites. J. Atmos. Sci., 28, 1165-1170.

Hosler, C. L., and L.A. Gamage, 1956: Cyclone Frequencies in the United States for the Period 1905 to 1954. Mon. Wea. Rev. 84, 388-390.

Janowiak, J.E. and G.D. Bell, 1999: Interannual Differences in the Distribution of Daily Wintertime Temperature, Precipitation and Snowfall in the U.S. preprints, $17^{\text {th }}$ Conf. on Weather Analysis and Forecasting, Denver, CO, Amer. Meteor. Soc., 1-5.

Kalnay, E., and Coauthors, 1996: The NCEP/NCAR 40-Year Reanalysis Project. Bull. Amer. Meteor. Soc., 77, 437-471.

Karl, T.R., and C.N. Williams Jr., 1987: An Approach to Adjusting Climatological Time Series for Discontinuous Inhomogeneities. J. Climate Appl. Meteor., 26, 1744-1763.

Klein, W. H., 1957: Principal Tracks and Mean Frequencies of Cyclones and Anticyclones in the Northern Hemisphere. US Department of Commerce Research Paper No. 40, Washington, DC, 60 pp. 
Klein, W. H., 1958: The Frequency of Cyclones and Anticyclones in Relation to the Mean Circulation. J. Meteor., 15, 98-102.

Kocin, P. J., and L.W. Uccellini, 2004: A Snowfall Impact Scale Derived from Northeast Storm Snowfall Distributions. Bull. Amer. Meteor. Soc., 85, 177194.

Kocin, P. J., and L.W. Uccellini, 1990: Snowstorms along the Northeastern Coast of the United States: 1955-1985. Meteor. Monogr., No. 44, Amer. Meteor. Soc., $280 \mathrm{pp}$.

Lim, E.P., and I. Simmonds, 2002: Explosive Cyclone Development in the Southern Hemisphere and a Comparison with Northern Hemisphere Events. Mon. Wea. Rev., 130, 2188-2209.

Maglaras, G.J., J.S. Waldstreicher, P.J. Kocin, A.F. Gigi, and R.A. Marine, 1995: Winter Weather Forecasting throughout the Eastern United States. Part I: An Overview. Wea. Forecasting, 10, 5-20.

Mather, J. R., H. Adams III, and G.A. Yoshioka, 1964: Coastal Storms of the Eastern United States. J. App. Meteor., 3, 693-706.

Mather, J. R., R.T. Field, G.A. Yoshioka, 1967: Storm Damage Hazard Along the East Coast of the United States. J. Appl. Meteorol., 6, 20-30.

Miller, J.E., 1946: Cyclogenesis in the Atlantic Coastal Region of the United States. J. Meteor., 3, 31-44.

National Climatic Data Center, 2008: NEXRAD National Mosaic Reflectivity Images. http://www4.ncdc.noaa.gov/cgi-win/wwcgi.dll?wwNexrad Images2 (Accessed 2008). 
NOAA Central Library U.S. Daily Weather Maps Project, 2008: Daily Weather Maps. http://docs.lib.noaa.gov/rescue/dwm/data_rescue_daily_weather_maps.html and http://www.hpc.ncep.noaa.gov/dailywxmap/index.html (Accessed 2008).

National Weather Service Buffalo Lake Effect Page (NWS Buffalo - Lake Effect Seasons), 2008: Lake Effect Seasons off Lake Erie. http://www.erh/noaa/gov/er/buf/lakeffect/lakeclimate.html (Accessed 2008).

National Weather Service Buffalo Lake Effect Page (NWS Buffalo - Snow Season Archive), 2008: Snow Season Archive. http://www.wbuf.noaa.gov/lakeffect/indexlk.html (Accessed 2008).

Noel, J., and D. Changnon, 1998: A Pilot Study Examining U.S. Winter Cyclone Frequency Patterns Associated with Three ENSO Parameters. J. Climate, 11, 2152-2159.

Niziol, T.A., 1987: Operational Forecasting of Lake Effect Snowfall in Western and Central New York. Wea. Forecasting, 2, 310-321.

Norton, D. C., and S. J. Bolsenga, 1993: Spatiotemporal Trends in Lake Effect and Continental Snowfall in the Laurentian Great Lakes, 1951-1980. J. Climate, 6, 1943-1956.

Nuss, W. A., and D.W. Titley, 1994: Use of Multiquadric Interpolation for Meteorological Objective Analysis. Mon. Wea. Rev., 122, 1611-1631.

Philander, G. S., 1990: El Niño, La Niña, and the Southern Oscillation. Academic Press, 289 pp.

Reitan, C. H., 1974: Frequencies of Cyclones and Cyclognesis for North America, 1951-1970. Mon. Wea. Rev., 102, 861-868.

Reitan, C. H., 1979: Trends in the Frequencies of Cyclone Activity over North America. Mon. Wea. Rev., 107, 1684-1688. 
Roebber, P. J., 1984: Statistical Analysis and Updated Climatology of Explosive Cyclones. Mon. Wea. Rev., 112, 1577-1589.

Ropelewski, C. F., and M. S. Halpert, 1996: Quantifying Southern OscillationPrecipitation Relationships. J. Climate, 9, 1043-1059.

Sanders, F., and J.R. Gyakum, 1980: Synoptic-Dynamic Climatology of the "Bomb". Mon. Wea. Rev., 108, 1589-1606.

Schmidlin, T.W., 1993: Impacts of Severe Winter Weather during December 1989 in the Lake Erie Snowbelt. J. Climate, 6, 759-767.

Wilks, D.S., 1995: Statistical Methods in the Atmospheric Sciences. Academic, 467 pp.

Zielinski, G.A., 2002: A Classification Scheme for Winter Storms in the Eastern and Central United States with an Emphasis on Nor'easters. Bull. Amer. Meteor. Soc., 83, 37-51.

Zishka, K. M., and P. J. Smith, 1980: The Climatology of Cyclones and Anticyclones Over North America and Surrounding Ocean Environs for January and July, 1950-77. Mon. Wea. Rev., 108, 387-401. 